\title{
Produktion und Destruktion in der trophogenen Schicht
}

\author{
Untersuchungen ökologischer Parameter im polytrophen Rotsee \\ und in der mesotrophen Horwer Bucht (Vierwaldstättersee) ${ }^{1}$ )
}

Von Ernst Schegg, EAWAG, Dübendorf

\section{INHAITSVERZEICHNIS}

1. Einleitung und Problemstellung . . . . . . . . . . . . . . . . . . 427

2. Die untersuchten Seen ................... 427

3. Methodik

3.1 Physikalische Bestimmungsmethoden . . . . . . . . . . . . . . 429

3.2 Chemische Analysenmethoden. . . . . . . . . . . . . . . . . . . . . . . . 429

3.3 Biologische Untersuchungsmethoden . . . . . . . . . . . . . . . 430

3.31 Qualitative und quantitative Untersuchungen des Phytoplanktons . . . . 430

3.32 Messung der Primärproduktion . . . . . . . . . . . . . 430

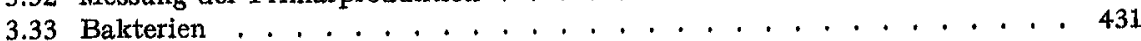

3.331 Plattenmethode. . . . . . . . . . . . . . . . 431

3.332 Membranfiltermethode . . . . . . . . . . . . . . . . 432

3.333 Auszählung spezieller Arten . . . . . . . . . . . . . . . . . . 432

3.4 Datenanalyse . . . . . . . . . . . . . . . . . . . . . 432

3.41 Berechnung der Korrelationskoeffizienten . . . . . . . . . . . . 433

3.42 Berechnung des Quadratmeterwertes . . . . . . . . . . . 433

4. Die Produktion

4.1 Begriffsbestimmung und Abgrenzung der trophogenen Schicht . . . . . . . . . . 434

4.2 Produktionsbestimmende Faktoren . . . . . . . . . . . . . . . . . . . . . 434

4.21 Physikalische Grundlagen . . . . . . . . . . . . . . . . . . . . . 434

4.211 Meteorologische Daten. . . . . . . . . . . . . . . . . . . . 434

4.212 Temperatur . . . . . . . . . . . . . . . . . . . . . . . . 436

4.213 Lichtverhältnisse . . . . . . . . . . . . . . . . . . . . . 440

4.22 Nährstoffe . . . . . . . . . . . . . . . . . . . . . . . . . 442

4.221 Phosphat . . . . . . . . . . . . . . . . . . . . . 442

4.222 Stickstoffkomponenten . . . . . . . . . . . . . . . . . . . . 444

4.223 Eisen . . . . . . . . . . . . . . . . . . . . . . . . . . 448

4.224 Gesamtsalzgehalt . . . . . . . . . . . . . . . . . . 449

1) Key words: freshwater bacteria, primary productivity, bacterial mineralisation, trophogenic and tropholytic layer, intrabiocoenotic turnover. 
4.3 Produktionsmessungen .. . . . . . . . . . . . . . . . . . . . . . 449

4.31 Phytoplankton im Rotsee . . . . . . . . . . . . . . . . . . . . 449

4.311 Cyanophyta . . . . . . . . . . . . . . . . . . . . . . . . . 450

4.312 Chlorophyceae . . . . . . . . . . . . . . . . . . . . . 450

4.313 Konjugatae . . . . . . . . . . . . . . . . . . . . . 454

4.314 Chrysophyceae . . . . . . . . . . . . . . . . . . 456

4.315 Diatomeae . . . . . . . . . . . . . . . . . . . . . . . . 456

4.316 Cryptophyceae . . . . . . . . . . . . . . . . . . 457

4.317 Peridineae . . . . . . . . . . . . . . . . . . . . . 459

4.318 Die Phytoplanktonbiomasse . . . . . . . . . . . . . . . . . . 460

4.319 Die Populationssequenz des Phytoplanktons . . . . . . . . . . . 460

$4.3110 \mathrm{~K}$-Analyse bezüglich Biomasse . . . . . . . . . . . . . . . . . 462

4.3111 Partikuläre Komponenten . . . . . . . . . . . . . . . . . . . 464

4.32 Phytoplankton im Vierwaldstättersee . . . . . . . . . . . . . . . . . 467

4.33 Primärproduktionsmessung . . . . . . . . . . . . . . . . . . . . . . 468

4.331 Tagesrhythmik . . . . . . . . . . . . . . . . . . . . . . . 468

4.332 Die Primärproduktion im Rotsee . . . . . . . . . . . . . . . . 472

4.333 Die Primärproduktion im Vierwaldstättersee . . . . . . . . . . . 474

5. Produktion in Beziehung zur Destruktion

5.1 Exkyetion und Autolyse des Phytoplanktons . . . . . . . . . . . . . . . . . 475

5.2 Morphologie der Bakterien des freien Wassers. . . . . . . . . . . . . . . . . . . . 478

5.21 Planktische Bakterien . . . . . . . . . . . . . . . . . . . . . . . . 478

5.22 Aufwuchsformen . . . . . . . . . . . . . . . . . . . . 482

5.23 Zoogloen ... . . . . . . . . . . . . . . . . . . . . 482

5.24 Spezielle Formen aus dem Rotsee . . . . . . . . . . . . . . . . . . . 483

5.3 Vertikale und jahreszeitliche Verteilung der Bakterien . . . . . . . . . . . . . 490

5.31 Rotsee. . . . . . . . . . . . . . . . . . . . . . . . 491

5.32 Vierwaldstättersee . . . . . . . . . . . . . . . . . . . . . . . . . 494

5.4 Bakterienzahlen und Primärproduktion . . . . . . . . . . . . . . . . . . . 497

5.5 Bakterienzahlen und Trophiegrad . . . . . . . . . . . . . . . . . . . . . . 499

5.6 Der khurzgeschlossene Kreislauf» . . . . . . . . . . . . . . . . . . . . . . 501

5.61 Sauerstoff . . . . . . . . . . . . . . . . . . . . . 501

5.62 Stickstoff and Phosphor . . . . . . . . . . . . . . . . . . . . . . . 504

5.7 Sedimentation, Destruktion und Primärproduktion. . . . . . . . . . . . . . . 507

6. Experimentelle Untersuchungen

6.1 Experiment I . . . . . . . . . . . . . . . . . . . . . . . . . . . . . . 507

6.11 Methodik . . . . . . . . . . . . . . . . . . . . 508

6.12 Resultate und Interpretation . . . . . . . . . . . . . . . . . . . 509

6.13 Schlussfolgerungen . . . . . . . . . . . . . . . . . . . . 511

6.2 Experiment II. . . . . . . . . . . . . . . . . . . . . . . . . 511

6.21 Methodik .. . . . . . . . . . . . . . . . . . . . 511

6.22 Resultate und Interpretationen . . . . . . . . . . . . . . . . . . . . 513

6.23 Schlussfolgerungen . . . . . . . . . . . . . . . . . . 515

7. Zusammenfassende Diskussion

7.1 Die trophogene Schicht . . . . . . . . . . . . . . . . . . . . . . . . . . 516

7.2 Modell kausaler Verknüpfungen im «kurggeschlossenen Kreislauf» . . . . . . . . 517

Literaturverzeichnis . . . . . . . . . . . . . . . . . . . . . . 522

Appendix

1. In der Arbeit verwendete Abkürzungen . . . . . . . . . . . . . . . . . . . . . 526

2. Programme . . . . . . . . . . . . . . . . . . . . . . . . . . . 527

3. Eingabedaten . . . . . . . . . . . . . . . . . . . . . . . 528

Verdankungen . . . . . . . . . . . . . . . . . . . 532 


\section{Einleitung und Problemstellung}

Ein Organismus wird sich dann in einem Habitat (Lebensraum) entwickeln, wenn dieses seinen Bedürfnissen entspricht, d.h. wenn eine verwertbare Energiequelle und Nährstoffe vorhanden sind.

Allein der Mensch gehorcht diesem Gesetz nicht. Er verfügt über rasch anwachsende Möglichkeiten, Energie nach seinen Bedürfnissen und an beliebigen Orten einzusetzen.

Weil die nichtmenschliche Lebewelt diese Möglichkeit nicht besitzt, wird sie infolge ihrer Passivität durch alle Änderungen des Energieflusses betroffen. Damit man Veränderungen, die ungewollt oder fahrlässig gesetzt wurden, wieder rückgängig machen kann, muss das Ökosystem analysiert werden. Voraussetzung für ein gezieltes Einwirken ist die Kenntnis der qualitativen und quantitativen Wechselwirkungen. Kenntnisse kann man aber nicht nur aus praktischen Sanierungsmassnahmen erhalten, sondern die Voraussetzung dafür ist eine umfassende ökologisch-physiologische und experimentell ausgerichtete Forschung. Nur auf diese Weise lassen sich Maßstäbe finden und setzen.

Beim Vorhandensein einer verwertbaren Energiequelle beginnt der Energietluss, der den ganzen Stoffhaushalt bestimmt. Ein Teil des Energieflusses passiert Organismen; dieser in Organismen fixierte und umgesetzte Energieanteil kann, wie OHLE [46] dies vorgeschlagen hat, als Bioaktivität des Gewässers bezeichnet werden. In diesem komplexen System treten mannigfaltige Wechselwirkungen auf. Es stehen sich dabei einerseits lebende Organismen, andererseits das Milieu gegenüber.

Die Beurteilung dieser Zusammenhänge soll durch eine grosse Zahl verschiedener Parameter, die in die Untersuchungen einbezogen werden, abgesichert sein.

Die vorliegende Arbeit will einen Beitrag zur Kenntnis dieser Wechselwirkung bieten und im speziellen die kausalen Verknüpfungen zwischen der Produktion und Destruktion aufzeigen. Sie trägt der Forderung einer Vielzahl festgestellter Parameter in weitgehendem Masse Rechnung.

Das gesteckte Ziel wurde von zwei Seiten her angegangen, nämlich

erstens von der ökologischen Seite, durch Untersuchungen im natürlichen Biotop, insbesondere die Bestimmung des Jahresverlaufes der Planktonbiozönose in ihren Wechselwirkungen zum umgebenden Wasser in zwei Seen verschiedenen Trophiegrades, und

zweitens von der experimentellen Seite durch Beantwortung von Fragen der Beziehungen zwischen Bakterien und Phytoplankton, die nur unter standardisierten Bedingungen untersucht werden konnten.

\section{Die untersuchten Seen}

Tab. 1. Orographie:

\begin{tabular}{llllll}
\hline See & Länge & Breite & Fläche & Max. Tiefe Mittı. Tiefe \\
\hline Rotsee & $2,4 \mathrm{~km}$ & $0,4 \mathrm{~km}$ & $0,48 \mathrm{~km}^{2}$ & $16 \mathrm{~m}$ & $9 \mathrm{~m}$ \\
Vierwaldstättersee, & $1,5 \mathrm{~km}$ & $1 \mathrm{~km}$ & $1,69 \mathrm{~km}^{2}$ & $72 \mathrm{~m}$ & $42,6 \mathrm{~m}$ \\
Seeteil Horwer Bucht & & & & & \\
\hline
\end{tabular}


Tab. 2. Typisierung.

\begin{tabular}{llll}
\hline See & Gewässerzustand & Abwasserbelastung & Literatur \\
\hline Rotsee & stark eutrophiert & bis 1933 von Stadtteil & DüGGELI [14] \\
& & von Luzern ungereinigt, & STADELMANN [73] \\
& & seither mechanisch & \\
& & gereinigt. Seit Mitte 1969 & \\
& & keine Belastung mehr & \\
Horwer Bucht & mesotroph & etwa 9000 Einwohner, & AMBÜHL [4] \\
(Vierwaldstättersee) & & ungereinigt & GäCHTER [19] \\
\hline
\end{tabular}

Die geographische Lage der beiden Seen ist aus der Kartenskizze Abb. 1 ersichtlich.

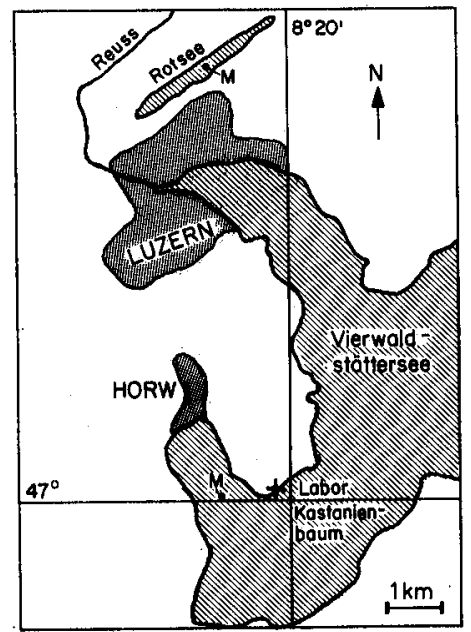

Abb. 1. Geographische Lage der Meßstellen (=M).

\section{Methodik}

Die beiden Seen wurden in den Jahren 1969/70 monatlich einmal in folgenden Tiefenstufen untersucht:

Tab. 3. Untersuchungsdaten und Tiefenstufen.

\begin{tabular}{|c|c|c|}
\hline & Untersuchungsdaten & Tiefenstufen \\
\hline Rotsee & $\begin{aligned} 1969: & \text { 20. 3., 17. 4., 22. 5., } \\
& \text { 10. 6., 10. 7., 14. 8., } \\
& \text { 11. 9., 10. 10., 6. 11., } \\
& \text { 3. } 12 . \\
1970: & 15.1 ., 18.2 ., 23.3 .\end{aligned}$ & $0,1,2,5,5,7,5$ und $14 \mathrm{~m}$ \\
\hline Vierwaldstättersee & $\begin{aligned} 1969: & \text { 23. 1., 19. 2., 18. 3., } \\
& \text { 17. 4., 20. 5., 17. 6., } \\
& \text { 8. 7., 6. 8., 9. 9., } \\
& \text { 7. 10., 4.11., 2. } 12 . \\
1970: & 6.1 ., 24.2 .\end{aligned}$ & $\begin{array}{l}0,2,5,5,7,5,10,12,5,15,25 \\
45,60 \mathrm{~m}\end{array}$ \\
\hline
\end{tabular}


Die obigen Untersuchungsdaten werden im folgenden mit der Monatsbezeichnung abgekürzt. Die Angaben zur Tiefenstufe $0 \mathrm{~m}$ beziehen sich auf Messungen in 0,2-0,3 m unter der Oberfläche.

Für den Vierwaldstättersee wurden in dieser Arbeit hauptsächlich die Werte von 0 bis $15 \mathrm{~m}$ (trophogene Schicht) verwendet.

Die Meßstellen (M) sind aus Abb. 1 ersichtlich; im Rotsee liegt sie in der Mitte der Fährspur, in der Horwer Bucht ungefähr in der Mitte des Seeteils. Die letztere wurde mittels eines Pentaprismas auf Grund von Hilfspunkten an Land eingemessen.

Die Proben für die chemische Analyse wurden mit einer Friedinger-Schöpfflasche erhoben. Bakteriologische Proben und Wasser für die Produktionsmessung wurden mit einer Sterilschöpfflasche nach ScHEGG [64] gewonnen.

Durch Bildung eines Teams von Untersuchern mit zwar verschiedener Zielsetzung, aber demselben Untersuchungsobjekt konnte der manuelle Aufwand beschränkt werden, während ein Maximum an Informationen gewonnen werden konnte. Unter Anwendung einer einfachen Netzplantechnik (CPM) können solche Teamworks weiter rationalisiert werden.

\subsection{Physikalische Bestimmungsmethoden}

1. Temperatur: Die Temperatur wurde mit dem Oxytester nach AмвёHL [3] bestimmt.

2. Leitfähigkeit: Die Leitfähigkeit wurde mit demselben Gerät wie die Temperatur gemessen.

3. Messung der Lichtverhältnisse: Nach den Empfehlungen von SAUBERER [61] wurde die Lichtintensität verschiedener Spektralbereiche mit einem Sperrschichtphotometer mit vorgeschalteten Filtern (Fa. Schott und Gen., Mainz, VG 9, BG 12 und RG 2) gemessen.

4. Die Sichttiefe wurde mittels der Secchischeibe ausgelotet.

\subsection{Chemische Analysenmethoden}

1. Sauerstoffgehalt: Der Sauerstoffgehalt wurde nach Winkler, modifiziert nach AlsterberG [2] bestimmt.

2. Schwefelwasserstoff: Die quantitative Bestimmung von Schwefelwasserstoff wurde kolorimetrisch mit NN-Dimethyl-p-phenylendiammoniumdichlorid und Eisen(III)-ammoniumsulfat durchgeführt (STRICKLAND-PARSons [76]).

3. Karbonathärte (SBV): Die Karbonathärte wurde nach der Vorschrift des Schweizerischen Lebensmittelbuches (3. Auflage) bestimmt.

4. Gesamtkohlenstoff (anorganisch): Aus pH-Wert und SBV wurde der Gesamtkohlenstoff nach HARveY und RODHE [24] berechnet.

5. Stickstoffkomponenten: Nitrat wurde mit der Natriumsalicylat-Methode nach Müller und Widemann [42], Nitrit mit Sulfanilamid und N-(1-Naphtyl)-äthylendiamin nach STRIckLand et al. [76] und Ammonium nach ScHmID [68] bestimmt. Der organisch gelöste Kjeldahl-Stickstoff und der partikuläre organische Kjeldahl-Stickstoff wurden nach STADELManN [73] bestimmt.

6. Phosphorkomponenten: Ortho-Phosphat: Ammoniummolybdat-Zinnchloridmethode nach Ohle, modifiziert nach Schmid und AmbüHL [69]. Aus der Differenz 
der Gesamt-P-Konzentration im Rohwasser und derjenigen des Filtrates wurde der partikuläre Phosphor berechnet.

7. Kieselsäure: Kolorimetrische Bestimmung mit Ammoniummolybdat (Deutsche Einheitsverfahren [15]).

8. Bestimmung von Eisen: Die Bestimmung von partikulärem und gelöstem Eisen wurde kolorimetrisch mit der Orthophenanthrolin-Methode durchgeführt (BLOESCH [8]).

Sämtliche gelösten Komponenten wurden im Filtrat, das mittels Filtration bei einer Porenweite von $0,45 \mu$ (Millipore HA) gewonnen wurde, gemessen.

\subsection{Biologische Untersuchungsmethoden}

3.31 Qualitative und quantitative Untersuchung des Phytoplanktons

Die Planktonproben des Vierwaldstättersees wurden mit Lugol fixiert, in Rundröhren-Verbundkammern $(50 \mathrm{ml})$ eingefüllt und nach 48 Stunden Absetzzeit im Umkehrmikroskop nach UTERMöHL [79] ausgezählt. Die Proben aus dem Rotsee wurden infolge der hohen Planktonzelldichten in fünffacher Verdünnung angesetzt. Die Biomasse wurde durch Summierung der Einzelzellvolumina berechnet. Diese wurden purch Ausmessen und mit Hilfe von Literaturangaben (PAvONI [53] und NAUWERck [44]) ermittelt.

\subsection{Messung der Primärproduktion}

Zur Produktionsmessung wurde die von SteEmann-NieLson [75] begründete ${ }^{14} \mathrm{C}$-Methode angewandt. Die ${ }^{14} \mathrm{C}$-Ampullen wurden aus einer Natriumbikarbonatlösung hergestellt (bezogen bei Radiochemical Centre, Amersham, England, Code Nr. CFA. 3). Die Herstellungsweise aus der Lösung gewährt mehr Sicherheit, da das ${ }^{14} \mathrm{C}$ nie als ${ }^{14} \mathrm{C} \mathrm{O}_{2}$ vorliegt. Die Ampullenaktivität wurde nach der Bariumbikarbonatmethode (VOLLENWEIDER [81]) bestimmt.

Das mit der Sterilschöpfflasche gewonnene Wasser wurde in sterile Expositionsflaschen (Jena G 20,125 ml) abgefüllt und mit Hilfe einer sterilen Spritze $5 \mu \mathrm{C}-\mathrm{Bi}$ karbonatlösung dazugegeben. Die Proben wurden während 4 Stunden, zwischen 10 und $14 \mathrm{Uhr}$, «in situ et loco» exponiert. Dabei hat sich das in Abb. 2 dargestellte Expositionsgestell bewährt. Die Flaschen sind in horizontaler Lage der vollen Belichtung ausgesetzt. Sie werden nach dem Knopflochprinzip in eine Halterung eingeschoben (Abb. 3). Die Montage verlangt daher sehr wenig Zeit, so dass ein «Lichtschock" der Algen (Gadman et al. [22]) vermieden werden kann. Nach der Expositionszeit wurden die Proben sofort aufgearbeitet. Je $25 \mathrm{ml}$ Probewasser wurden durch einen Filter mit Porenweite 0,22 $\mu$ (Göttinger Membranfiltergesellschaft SM 113 07) mit einem Mikrofiltrationsgerät der Fa. Millipore (Code XX1002500) filtriert. Die Filter wurden mit Rubber Cement in ein Aluminiumschälchen geklebt und während 20 Minuten rauchender Salzsäure ausgesetzt, um das anorganische, adsorbierte ${ }^{14} \mathrm{C}$ auszutreiben.

Die Messung erfolgte mit einem Methandurchflusszähler (Fa. Frieseke und Höpfner FH 407). Bei der Berechnung der Produktionsrate wurde der Korrekturfaktor von 1,06 für den Isotopeneffekt verwendet. Der Ausnützungskoeffizient des Zählers war mit etwa $1 \%$ klein, wurde aber bei der Berechnung kompensiert, da auch die Ampullenaktivität mit demselben Zähler und derselben Methodik festgestellt wurde. 


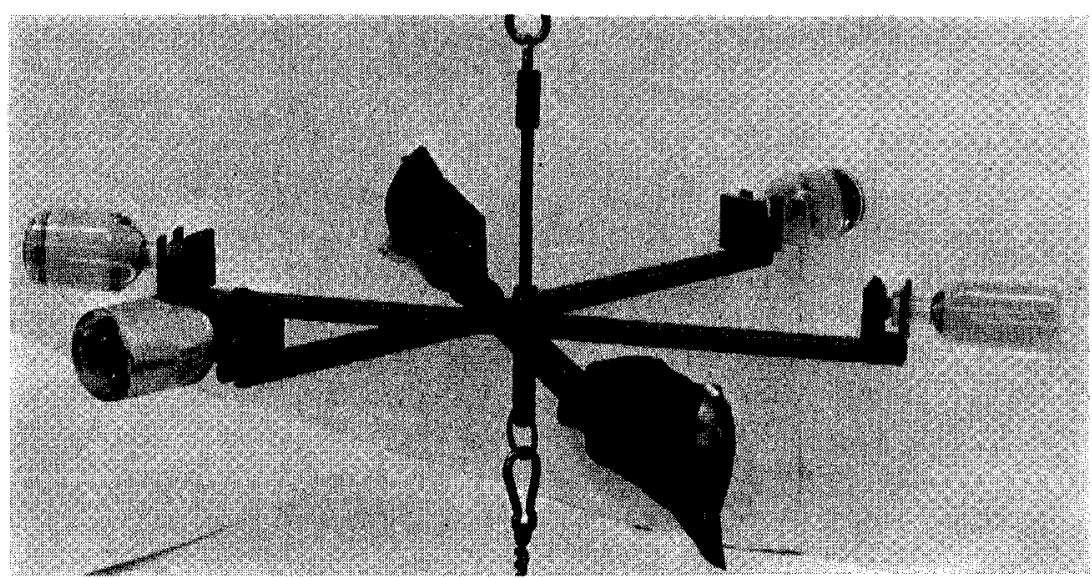

Abb. 2. Flaschenexpositionsgestell.

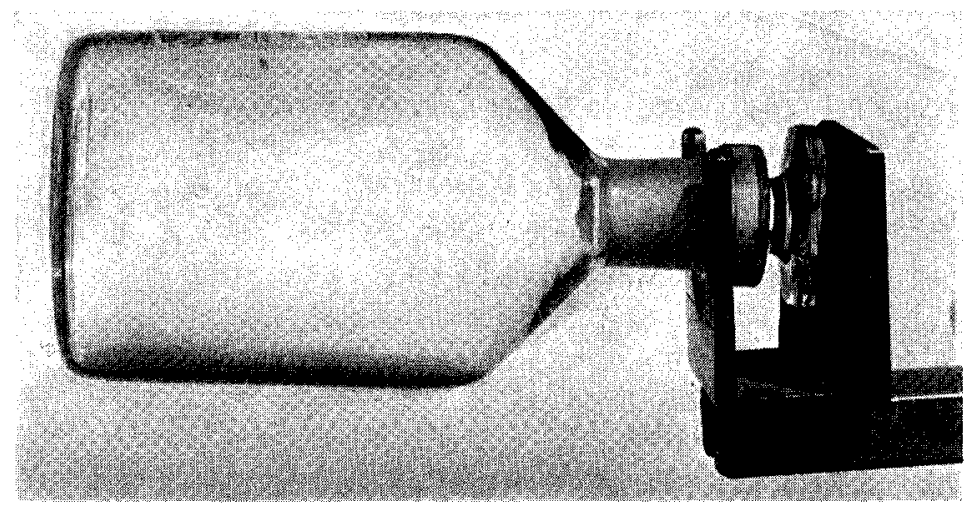

Abb. 3. Halterung: Die Flasche wird durch eine Schwammgummiplatte ins "Knopfloch" gedrückt.

\subsection{Bakterien}

Die Proben für die bakteriologische Analyse wurden innerhalb 1-2 Stunden verarbeitet. Bei längerer Aufbewahrung der Proben in Flaschen können nach PotTER [56] grosse Verschiebungen in der Keimzahl und in der Artenzusammensetzung auftreten. Die Artenzahl nimmt dabei ab, während die Gesamtzahl stark zunimmt.

\subsection{Plattenmethode}

Als Medium der Keimzahlbestimmung nach der Kochschen Plattenmethode wurde Trypton-Glukose-Extraktagar (Difco Nr. 521983) verwendet (Beef Extrakt $3 \mathrm{~g}$, Trypton $5 \mathrm{~g}$, Dextrose $1 \mathrm{~g}$, Agar $15 \mathrm{~g}$ auf $1000 \mathrm{ml}$ dest. Wasser). Die Proben wurden in sterile Plastik-Petrischalen ausgeplattet. Dabei wurde das Medium in flüssiger Form gegossen und darauf geachtet, dass die Probe erst kurz vor dem Erstarren des Agars mit diesem vermischt wurde. Bei den Proben aus dem Vierwaldstättersee wurden 0,1 $\mathrm{ml}$ der Originalprobe ausgeplattet. Die Proben aus dem Rotsee wurden 1:10 verdünnt und ebenfalls $0,1 \mathrm{ml}$ ausgeplattet. Pro Probe wurden fünf Parallelen er- 
stellt. Nach einer Bebrütungszeit von 5 Tagen bei $20^{\circ} \mathrm{C}$ wurden die Kolonien unter der Binokularlupe bei 60 facher Vergrösserung ausgezählt.

\subsection{Membranfiltermethode}

Den Auszählresultaten auf Membranfiltern liegt die Direktzählmethode nach Razumov (aus Kuznezov [36]) zugrunde. Die genaue Methodik findet sich bei SCHEGG und RUSChke [65]. In einigen Fällen wurde die Methode nach Razumov und Iwanov (aus KuzNEzov [36]) zur Bestimmung der Generationszeit verwendet.

Vorteile der Membranfiltermethode:

Die direkte mikroskopische Beobachtung und Auszählung ergibt die beste Aussage über die Zahl und die Morphologie des bakteriellen Planktons. Die tatsächlich vorhandene Keimzahl wird damit zweifellos richtiger erfasst als mit dem Plattenverfahren, da dort ein selektiv wirkendes Substrat die Keimzahl bestimmt.

Nachteile der Direktzählmethode:

Es ist oft schwierig, die Keime auf den Filtern von Detrituspartikeln zu unterscheiden, namentlich wenn sie in Kümmerformen vorliegen.

In stark belasteten Gewässern kommen Aufwuchspartikel und Zoogloen vor (JANNASCH [32]), d.h. Bakterienzellanhäufungen, deren Zahl nur geschätzt werden kann.

Nach JANNASCH [31] lassen sich durch Spezialfärbungen mit Acridinorange und fluoreszenzmikroskopischen Untersuchungen tote und lebende Bakterienzellen unterscheiden, indem tote Bakterienzellen rot, lebende Zellen grün erscheinen. DeufEL [10] kommt aber zum Schluss, dass alle rot fluoreszierenden Bakterien sicher tot sind, aber nicht alle toten Bakterien rot fluoreszieren. Daher wurde auf die Anwendung dieser Methode verzichtet. Nach KuzNEzov [36] ist der Anteil der toten Bakterien nicht mehr als 10\% der vorhandenen. Er konnte diese Grössenordnung auch mittels Messung der Atmungsintensität in durch teilweise Filtration angereicherten Zellsuspensionen von Seewasser nachweisen.

Es ist anzunehmen, dass tote Bakterien sehr rasch autolysieren und dass damit der Anteil lebender Bakterien, die auf den Membranfiltern gezählt werden, die Hauptmasse ausmachen. Trotzdem bleibt der genaue Anteil der toten Bakterien unbekannt.

\subsection{Auszählung spezieller Arten}

Einzelne Arten aus dem Rotsee, die morphologisch leicht zu erkennen waren, wurden gesondert betrachtet. Insbesondere Thiopedia rosea, Leptothrix pseudovacuolata und Chromatium densegranulatum wurden im Umkehrmikroskop nach Utermöhl ausgezählt.

\subsection{Datenanalyse $e^{2}$ )}

Das Registrieren der Resultate und das empirische Aufsuchen der Zusammenhänge wurde erweitert durch eine Auswertung und Interpretation der Resultate mittels Datenverarbeitung. Goldmann et al. [23] haben einen Weg gewiesen, wie eine Seeuntersuchung konsequent mit Datenverarbeitung ausgewertet werden kann.

In der vorliegenden Arbeit wurden die linearen Korrelationen zwischen den Parametern berechnet (Programm «Korrela»). Ein weiteres Programm (Programm «Pro-

2) Die Berechnungen wurden an einer IBM CPC 6500 des Rechenzentrums der ETH Zürich durchgeführt. 
fil») diente zur Berechnung der Quadratmeterzahlen (= über die Tiefe integrierte Werte unter $1 \mathrm{~m}^{2}$ Seeoberfläche).

Im Rotsee und im Vierwaldstättersee wurden in je 5 Tiefenstufen ca. 30 Parameter pro Untersuchung bestimmt. In diesen 5 Tiefenstufen lag eine lückenlose Datenfolge über die beiden Untersuchungsjahre vor. Damit war eine wesentliche Voraussetzung zur Anwendung der Datenverarbeitung erfüllt.

\subsection{Berechnung der Korrelationskoeffizienten}

Die jeweils verglichenen Wertpaare gelten als zufällige, normal verteilte Veränderliche. Der zugehörige Korrelationskoeffizient wurde nach der Formel

$$
r=\frac{S_{x y}}{\sqrt{S_{x} \cdot S_{y}}} \quad \begin{aligned}
& r=\text { Korrelationskoeffizient } \\
& S_{x y}=\text { Summe }(x-\bar{x})(y-\bar{y}) \\
& S_{x}=\text { Summe }(x-\bar{x})^{2} \\
& S_{y}=\text { Summe }(y-\bar{y})^{2}
\end{aligned}
$$

bestimmt.

Der Korrelationskoeffizient sagt aus, ob ein linearer, mathematischer Zusammenhang zwischen den eingegebenen verglichenen Grössen besteht. Goldman et al. [23] geben einzelne Parameter, namentlich wachstumsbedingte Grössen in logarithmischer Form ein. Darauf wurde bewusst verzichtet, da bei einem See nicht die Kriterien einer Reinkultur angewendet werden können.

Die Signifikanzschranken wurden bei $2 \alpha=p \leqq 0,1$ gesetzt (Dokumenta Geigy [12]). Der Korrelationskoeffizient $r$ wurde pro See zwischen allen Daten bestimmt, ebenso wurden immer alle Gleichungen der Regressionsgeraden berechnet.

Das im Appendix angeführte Programm «Korrela» leistet folgendes:

1. Herausschreiben sämtlicher eingegebener Daten im Block pro See und Datum.

2. Berechnung aller linearen Korrelationskoeffizienten zwischen den eingegebenen Variabeln in je einer Tiefenstufe über die Untersuchungszeit.

3. Angabe, ob der Korrelationskoeffizient signifikant ist, mit einer 10prozentigen Irrtumswahrscheinlichkeit $(p \leqq 0,1)$.

4. Herausschreiben aller signifikanten Korrelationskoeffizienten im «Kreuzungsdiagramm".

5. Berechnung beider Regressionsgeraden zwischen den jeweiligen beiden Variabeln. (Diese wurden in der vorliegenden Arbeit nicht ausgewertet.)

\subsection{Berechnung des "Quadratmeterwertes"}

Bei verschiedenen Parametern wird der Wert pro $\mathrm{m}^{2}$ Seeoberfläche benötigt, wie z.B. für die Primärproduktion. Mit dem Programm "Profil» (Appendix) kann die Fläche unter der Kurve Parameter gegen Tiefe ausgerechnet werden, indem die jeweiligen Trapezinhalte, begrenzt durch die Einzelmessungen des Parameters, summiert wurden.

Das im Anhang angeführte Programm «Profil» leistet folgendes:

Berechnung des Wertes eines Parameters pro $\mathrm{m}^{2}$ Seefläche, des Mittelwertes und des Quotienten Mittelwert zum Maximalwert. Dieser Quotient dient der Charakterisierung der Kurvenform; sofern die Kurven nur ein Maximum aufweisen, ist der Quotient direkt eine Aussage über die Schichtungsverhältnisse. 


\section{Die Produktion}

Eine autotrophe und heterotrophe Organismenproduktion kann nur dann stattfinden, wenn die entsprechende Energiequelle und Nährstoffe vorhanden sind. Die Verschlechterung des Gewässerzustandes manifestiert sich vor allem in einem erhöhten Wachstum der planktischen Algen; dies ist aber oft direkt von der Nährstoffkonzentration abhängig. GächTER [19] zeigte experimentell «in situ» für Phosphat, dass nicht nur ein einmaliger Schub von Nährstoffen eine grosse Produktion auslöst, sondern dass der ausschlaggebende Faktor die dauernde Nachlieferung von Nährstoffen ist.

Zur Organismenpopulation gehören nicht nur Produzenten sondern auch Destruenten. Daher ist dieser dauernde Nachschub von Nährstoffen nicht nur externer, sondern zu einem wesentlichen Teil interner Natur. Es ist nun von produktionsbiologischer Seite äusserst wichtig, die Quantität und Qualität dieser internen Belastung, Rezirkulation oder nach OHLE [48] des "kurzgeschlossenen Kreislaufs" zu kennen. Das Verständnis der Gesetzmässigkeiten und Leistungsfähigkeit des «kurzgeschlossenen Kreislaufs» in einem See ist Voraussetzung zur Beurteilung der Produktion.

Bei allen Interpretationen und Wertungen der Ergebnisse steht der Gesichtspunkt der Dynamik im Gewässer im Vordergrund. Der Erweiterung dieser Kenntnisse sollen die nachfolgend beschriebenen Seeuntersuchungen dienen.

\subsection{Begriffsbestimmung und Abgrenzung der trophogenen Schicht}

"Trophogene Schicht» ist ein produktionsbiologischer Begriff. Nach Ruttner [60] gliedert sich ein See während der Sommerstagnation in zwei grundverschiedene Räume, in eine trophogene und eine tropholytische Schicht. Der Titel der vorliegenden Arbeit beinhaltet zu dieser strengen Trennung einen gewissen Widerspruch, der aber durch die Befunde dieser Arbeit gerechtfertigt werden wird.

Es ist wohl richtig, von einer trophogenen Schicht zu sprechen, man sollte aber diese vom energetischen Standpunkt aus definieren, zum Beispiel als Schicht, in der die Energiebilanz für die lebenden Zellen positiv ist.

\subsection{Produktionsbestimmende Faktoren}

\subsection{Physikalische Grundlagen}

\subsection{Meteorologische Daten ${ }^{3}$ )}

In Abb. 4 und 5 sind die meteorologischen Daten für sämtliche Probenahmetage im Rotsee und im Vierwaldstättersee zusammengestellt. Die Monatsmitteltemperaturen der Luft sind als Stufendiagramme gezeichnet. Integriert man die Wassertemperatur $(0-5 \mathrm{~m})$ nach Programm «Profil», erhält man den Wärmeenergieinhalt des Wassers unter $1 \mathrm{~m}^{2}$ für die trophogene Schicht. Im Gegensatz zur Monatsmitteltemperatur erhielten wir nie einen negativen Wert, d.h. der Wärmeenergieinhalt der trophogenen Schicht blieb das ganze Jahr positiv.

Vergleicht man die beiden Kurven miteinander, so kann man direkt den Wärmeenergierückhalt des Sees erkennen, indem die Kurven zeitlich gegeneinander verschoben sind.

3) Ein Teil der Daten wurden mir freundlicherweise von der meteorologischen Zentralanstalt in Zürich zur Verfügung gestellt. 


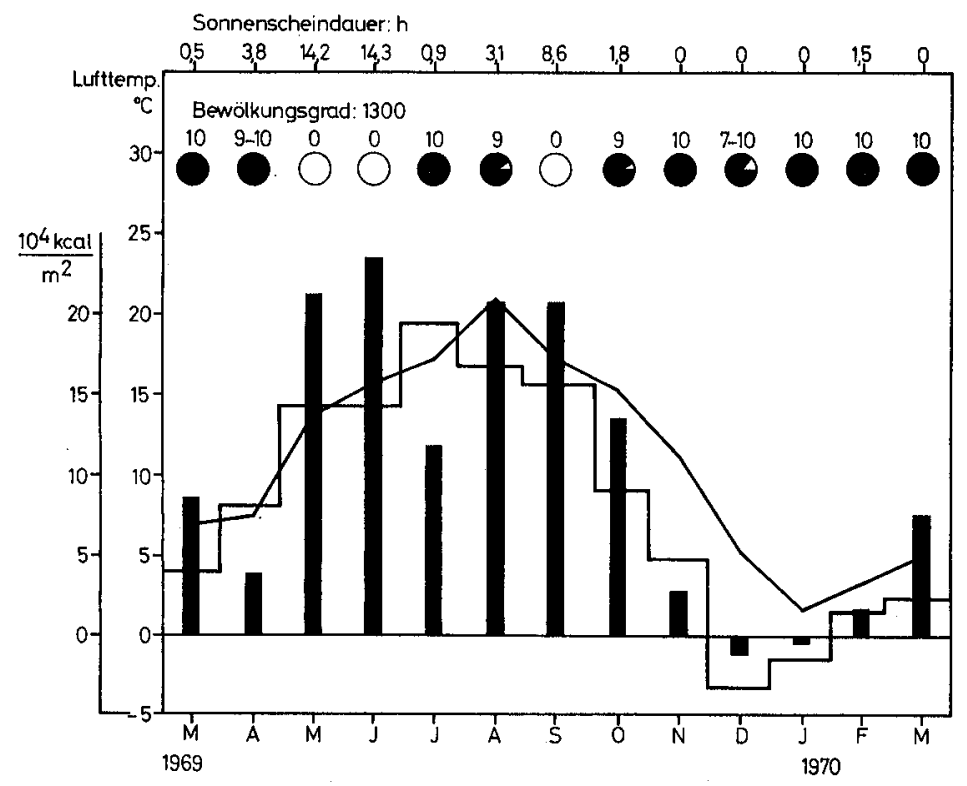

Abb. 4. Meteorologische Angaben, Rotsee:

Kreise: Bewölkungsgrad (schwarz = bewölkt, weiss = sonnig), Einzelsäulen: aktuelle Lufttemperatur in ${ }^{\circ} \mathrm{C}$, Stufendiagramm: mittlere Monatstemperaturen in ${ }^{\circ} \mathrm{C},(-)$ : Energieinhalt in $\mathrm{kcal} / \mathrm{m}^{2}(0-5 \mathrm{~m})$.

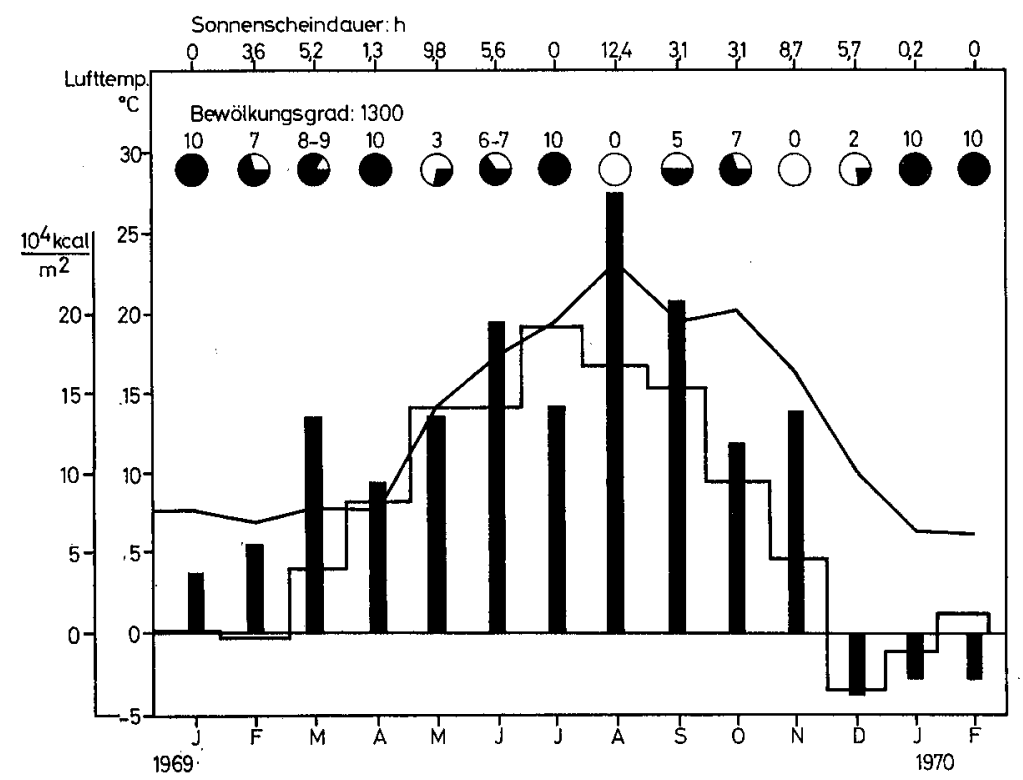

Abb. 5. Meteorologische Angaben, Vierwaldstättersee (Erklärungen siehe Abb. 4). 
In beiden Seen wurde bis zum August Wärme gespeichert und anschliessend wieder abgegeben. Für den See war die Wärmebilanz nach dem August wieder negativ. Aus den entsprechenden Kurven $\left(\mathrm{kcal} / \mathrm{m}^{2}\right)$ kann direkt die Anzahl der kcal abgelesen werden, die an der Oberfläche pro $\mathrm{m}^{2}$ ausgetauscht wurden. Multipliziert man den Energieaustausch durch $1 \mathrm{~m}^{2}$ mit der Seeoberfläche, erhält man den Energiefluss zwischen Luft und Wasser. Da dies für die aufgezeichnete Kurve nun eine Parallelverschiebung bedeutet, wurde darauf verzichtet. Der maximale Wert des Energieinhaltes betrug im August 1969 im Rotsee unter der gesamten Seeoberfläche etwa $5 \cdot 10^{10} \mathrm{kcal}$, bei Berücksichtigung der Schicht $0-5 \mathrm{~m}$ und der Basis $0^{\circ} \mathrm{C}$.

\subsection{Temperatur}

Rotsee: Abb. 6.

Der Rotsee wurde erstmals im März 1969 zu Beginn der Ausbildung der Sommerstagnation untersucht. Eine ausgesprochene Thermokline fand sich im August 1969 von oberflächlich maximal $23,5^{\circ} \mathrm{C}$ und einem Temperatursprung bei $5 \mathrm{~m}$. Ende November begann die Herbstzirkulation. Dass diese Zirkulation nur einen Teil des Hypolimnions erfasste, ging daraus hervor, dass die Temperatur im Dezember in den tieferen Schichten mit 6 Grad gegenüber 5 Grad höher lag als im Epilimnion. Es handelte sich dabei um eine inverse Schichtung. Dass die Zirkulation die untersten Schichten nicht erreichte, liess sich auch aus den nachfolgend beschriebenen chemischen Analysenwerten und den Werten der Leitorganismen erkennen (siehe Thiopedia rosea). Es ist möglich, dass der Salzgehalt des Tiefenwassers diese inverse Schichtung bewirkte. Im Januar kam es zur Ausbildung einer Winterstagnation, die bis Ende Februar andauerte.

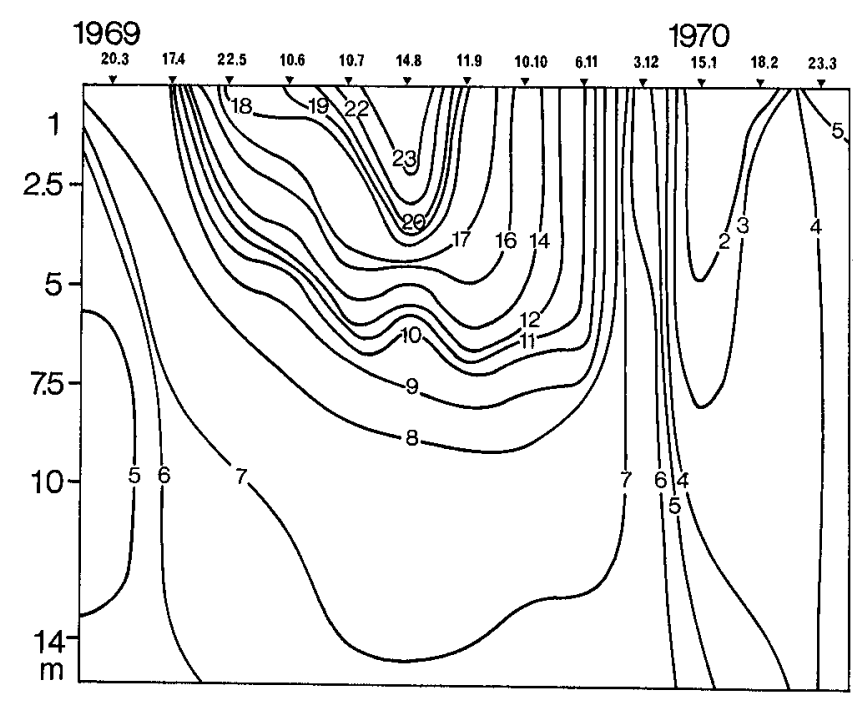

Abb. 6. Isothermen des Rotsees $\left({ }^{\circ} \mathrm{C}\right)$ (nach Stadelmann 1971). 


\section{Horwer Bucht}

Aus der Isopletendarstellung (Abb. 7) ist der Temperaturverlauf in der Horwer Bucht ersichtlich. Im Januar und Februar herrschte Vollzirkulation bei einer Temperatur von $4,5^{\circ} \mathrm{C}$. Im April begann die Ausbildung einer stabilen epilimnischen Schichtung, die im August ihr Maximum erreichte (maximale Oberflächentemperatur $22,7^{\circ} \mathrm{C}$ ). Die Temperaturbeeinflussung umfasste die Schichten bis $50 \mathrm{~m}$, darunter war die Temperatur über das ganze Jahr mit etwa $5^{\circ} \mathrm{C}$ konstant. In unseren Betrachtungen wurden nur die Werte bis $15 \mathrm{~m}$ berücksichtigt, da vereinfachend in dieser Tiefe die untere Grenze der trophogenen Schicht angenommen wurde.

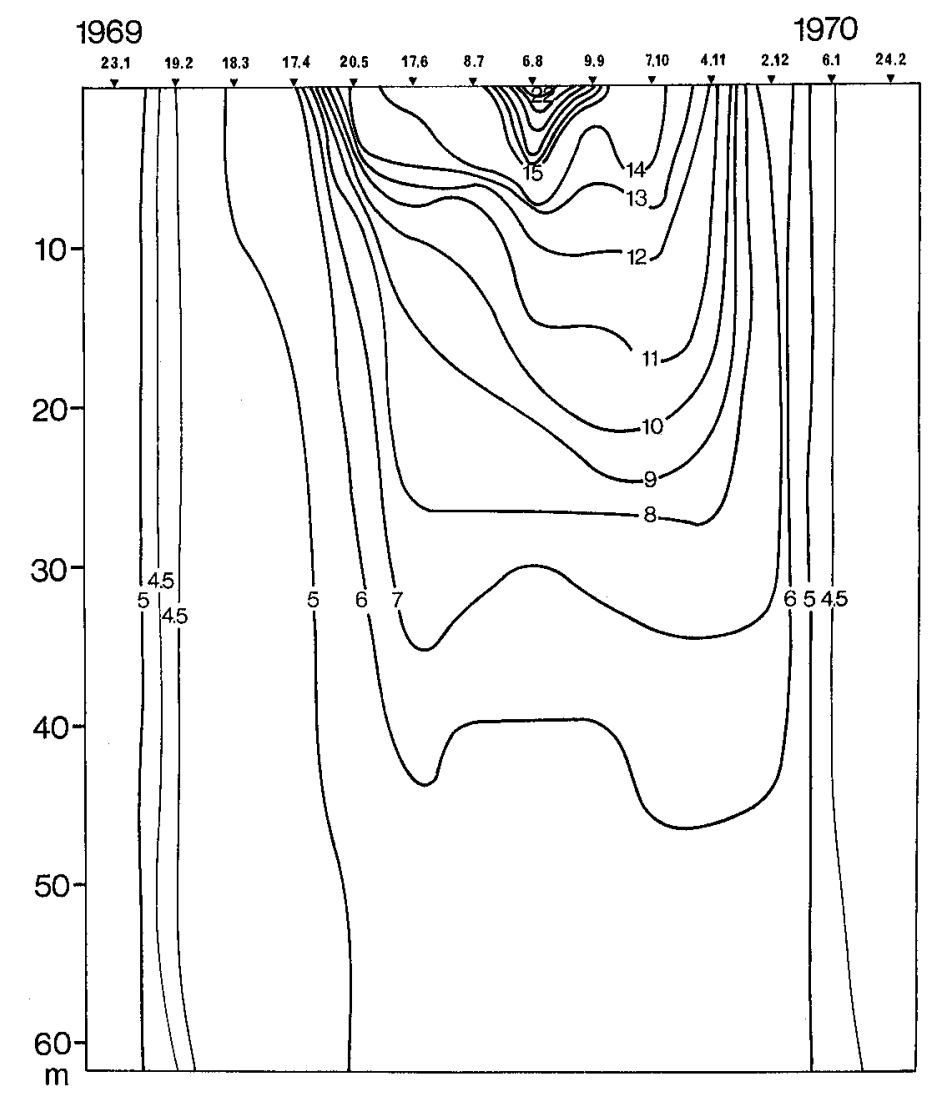

Abb. 7. Isothermen der Horwer Bucht $\left({ }^{\circ} \mathrm{C}\right.$ ) (nach Stadelmann 1971).

\section{Stabilität der Schichtung}

Es ist von Interesse, ein Mass zu finden, das für die momentane Stabilität der thermischen Schichtung repräsentativ ist. Für eingipflige Kurven bietet sich die Möglichkeit der Bildung eines Quotienten zwischen dem Maximalwert und dem Mittelwert über die Wassersäule an. Ein Quotient von 1,0 bedeutet, dass wir uns in einer Homothermie befinden, ein hoher Quotient bedeutet eine hohe Spitze bezüglich dem Mittelwert und ist das direkte Mass für die Stabilität der vorliegenden Schichtung. 
Beim Vergleich zweier verschiedener Seen untereinander ist aber darauf zu achten, dass dieselbe Mächtigkeit der Wassersäule ausgewertet wird, sonst sind die Quotienten nicht vergleichbar.

Diese Quotienten wurden mit dem Programm «Profil» für sämtliche Komponenten durchgerechnet. Für die Temperatur wurden sie in Abb. 8 aufgezeichnet. Es zeigt sich, dass der Quotient, ermittelt aus den Rotseewerten über das ganze Jahr, einen höheren Wert aufweist als derjenige des Vierwaldstättersees. Der Verlauf beider Kurven ist eine Folge der meteorologischen Verhältnisse. Weil die beiden Seen räumlich nahe beieinanderliegen, laufen die Kurven weitgehend parallel.

Im Frühling $1969 \mathrm{kam}$ es nach anfänglichem Anstieg der Schichtungsstabilität zu einem wetterbedingten Zusammenbruch im April. Dies zeigte sich bei beiden Seen, indem der Temperaturstabilitätsquotient stark abfiel. Innerhalb eines Monates baute sich dann eine stabile Schichtung auf, die bis zum September anhielt, und erst im Oktober bis Dezember kam es zur Herbstzirkulation mit Zusammenbruch der Schichtungsstabilität. Deutlich zeigte sich wieder die Winterstagnation, insbesondere die Ausbildung einer starken inversen Schichtung im Rotsee.

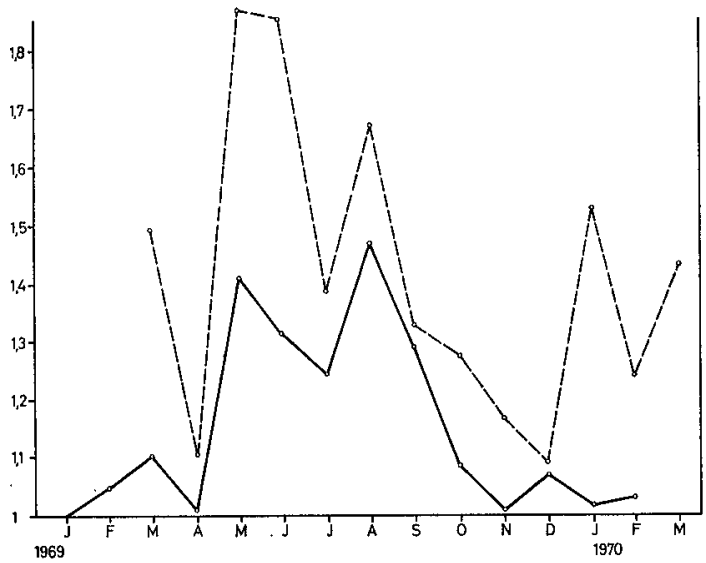

Abb. 8. Schichtungsstabilitätskurven, Vierwaldstättersee (- - ) und Rotsee (----).

\section{Korrelationsanalyse}

Die folgende Darstellungsweise (Tab. 4) wird im Verlauf dieser Arbeit immer wieder als Grundschema verwendet werden. Sie soll daher kurz erklärt werden:

In der Mitte der Tabelle befindet sich derjenige Parameter, gegen den die Korrelation aufgestellt wird, und zwar für jede Tiefenstufe gesondert. Nach rechts und links sind die Intervalle der Korrelationskoeffizienten aufgetragen, nach rechts im positiven und nach links im negativen Sinn. Steht z.B. Ammonium im Rechteck $0 \mathrm{~m}$ zwischen $-0,7$ und $-0,8$, so heisst das, der Korrelationskoeffizient zwischen Temperatur und Ammonium ist signifikant und hat den Wert -0,7 usw. Aus der Anordnung innerhalb der Rechtecke von unten nach oben kann man die zweite Kommastelle in aufsteigendem Sinne abschätzen. 
Tab. 4. K-Analyse zum Bezugsparameter Temperatur, Rotsee.

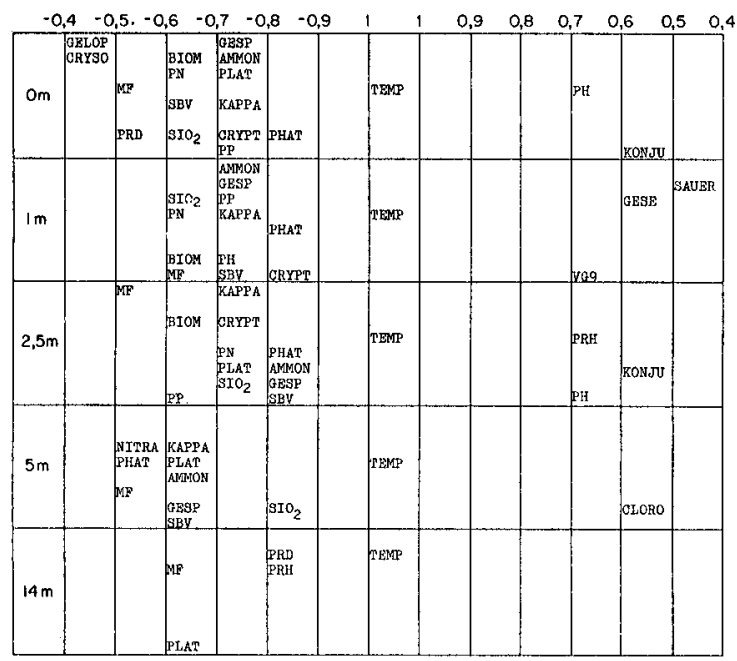

Prinzipiell wurden sämtliche in der Korrelationsanalyse benützten Parameter eingetragen, obwohl man sich bewusst ist, dass ein Teil der Korrelationen sekundär oder vom ökologischen Standpunkt wenig sinnvoll ist. Eine Besprechung jedes einzelnen Parameters ist in diesem Zusammenhang unmöglich, hingegen wird auf wesentliche Korrelationen im einzelnen hingewiesen.

Sämtliche Daten, die zur Korrelationsanalyse verwendet wurden, sind im Appendix zusammengestellt.

Im folgenden Text werden folgende Abkürzungen verwendet:

$\mathrm{K}=$ Korrelation

$\mathrm{KK}=$ Korrelationskoeffizient.

Rotsee (Tab. 4)

Die KK liegen im wesentlichen im negativen Bereich. Es handelt sich dabei um die produktionsbestimmenden und produktionsrepräsentativen Parameter. Einen besonderen Hinweis verdient das mit 0,83-0,84 negativ korrelierte Phosphat. Aus der Gesamtheit dieser Korrelationen kann geschlossen werden, dass die Temperatur, d.h. der Energieinhalt des Sees, in produktionsbiologischer Hinsicht von untergeordneter Bedeutung ist, dass insbesondere Nährstoffe, wie Phosphat und Ammonium, produktionsbestimmend sind. Diese Aussage gilt nicht nur für die Algenpopulation, sondern, wie die verschiedenen negativ korrelierten Bakterienzahlen zeigen, auch für die Bakterienpopulation.

\section{Vierwaldstättersee (Tab. 5)}

Im Vierwaldstättersee zeigt das K-Diagramm ein ganz anderes Bild. Wir finden einen sehr hohen KK von über 0,9 zur Primärproduktion in der Schicht maximaler Produktion $(2,5 \mathrm{~m})$. Ebenso finden wir positive $\mathrm{KK}$ für die den «standing crop» charakterisierenden Koeffizienten wie PP und PN. Die Bakterienzahlen, sowohl Plat- 
Tab. 5. K-Analyse zum Bezugsparameter Temperatur, Vierwaldstättersee.

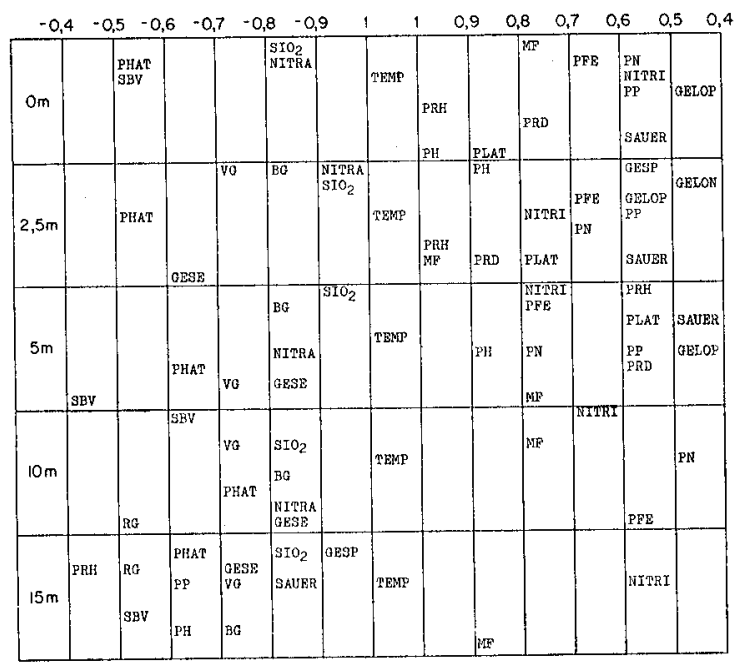

ten- als auch Membranfilterzahlen, sind mit der Temperatur positiv korreliert. Interessant ist, dass die Nährstoffe Phosphat und Nitrat negativ mit der Temperatur korrelieren. Dies ist ein Ausdruck dafür, dass bei steigendem "standing crop" und Produktion die Nährstoffe Phosphat und Nitrat gezehrt werden.

Weitere Beziehungen werden bei anderen Bezugsparametern klarer hervortreten.

\section{Schlussfolgerungen aus der $K$-Analyse}

Beim Rotsee handelt es sich um ein hochproduktives Gewässer, dessen Produktivität nicht in erster Linie temperaturabhängig ist. Wir finden diese Aussage bestätigt in den entsprechenden nachfolgend beschriebenen Produktionszahlen.

Die maximale Produktion des Vierwaldstättersees fällt mit der sommerlichen Erwärmung zusammen; sie ist in grossem Masse temperaturabhängig.

\subsection{Lichtverhältnisse}

Bei der Beurteilung der Produktion müssen die Lichtverhältnisse als energetische Grundlage der photoautotrophen Produktion berücksichtigt werden.

Messungen mit einer Selen-Photozelle ergeben nur relative Werte bezüglich der als $100 \%$ angenommenen Oberflächenintensität.

In den beiden untersuchten Seen dringt die grüne Komponente (VG 9) am tiefsten ein. Abb. 9 und 10 illustrieren die Eindringungstiefen des grünen Lichtes für 1\% und $20 \%$ der Oberflächenintensität. RODHE [59] definiert die Mächtigkeit der produktiven Schicht mit der 1\%-Eindringungstiefe des grünen Lichtes. Von dieser sehr variablen Abgrenzung der trophogenen Schicht wurde aus Gründen der Datenverarbeitung Abstand genommen und die Grenze für den Vierwaldstättersee auf $15 \mathrm{~m}$ und diejenige im Rotsee auf $5 \mathrm{~m}$ festgelegt.

Die Sichttiefen fallen im grossen und ganzen mit VG $920 \%$ zusammen. Für die Praxis lässt sich daraus für die betreffenden Seen mit ziemlicher Genauigkeit aus der Sichttiefe die $1 \%$-Grenze des grünen Lichtes (VG 9) berechnen. 


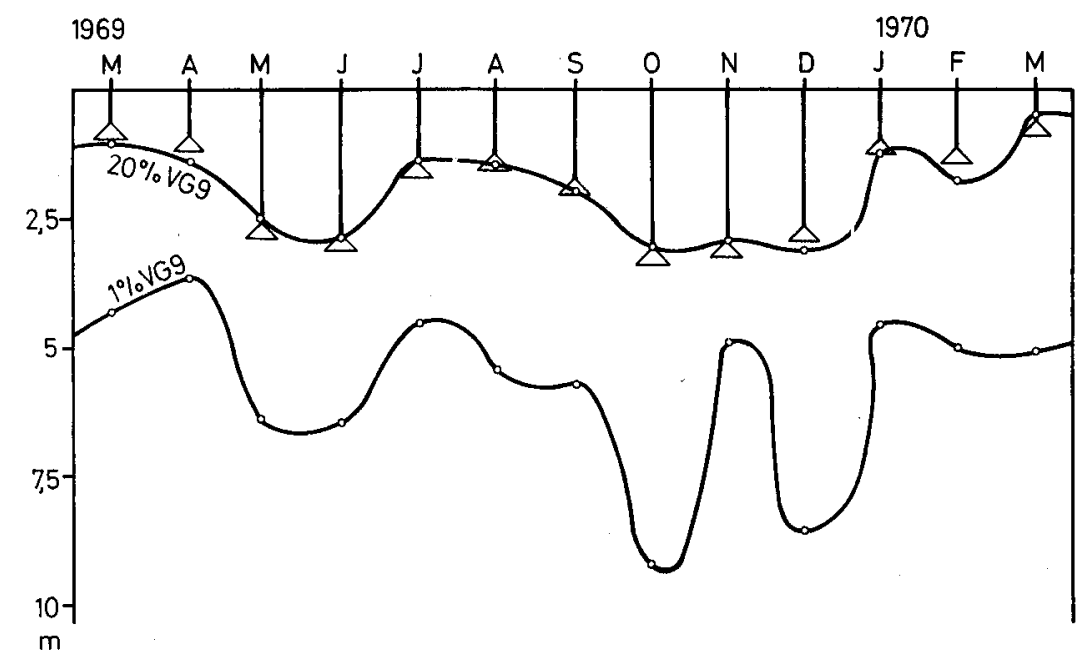

Abb. 9. Eindringungstiefe des grünen Lichtes (VG9) in Prozenten der Oberflächenintensität und Sichttiefen, Rotsee.

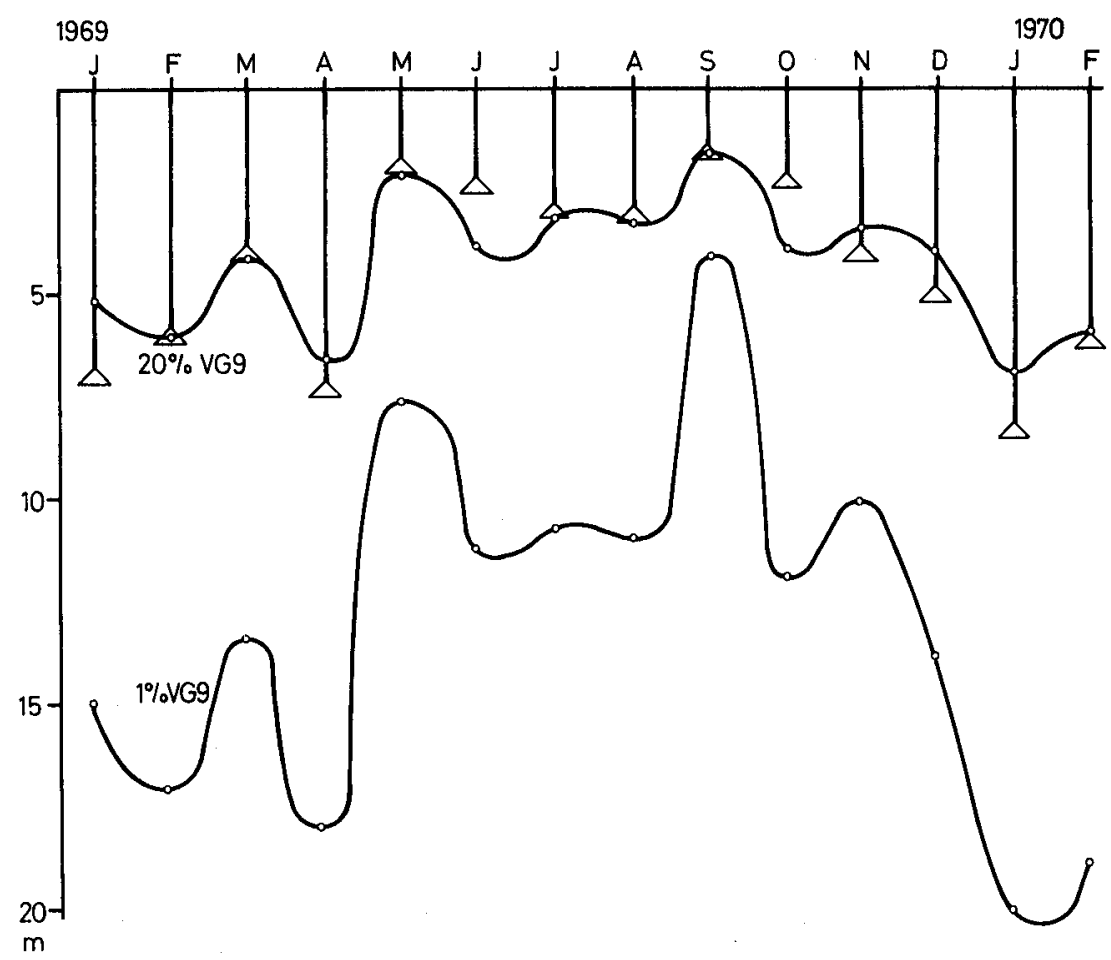

Abb. 10. Eindringungstiefe des grünen Lichtes (VG9) in Prozenten der Oberflächenintensität und Sichttiefen, Vierwaldstättersee. 
Bemerkenswert ist, dass die Sichttiefe im Rotsee in den Sommermonaten teilweise grössere Werte annimmt als im Vierwaldstättersee. Weitere Daten der Lichtintensitäten finden sich im Appendix.

\subsection{Nährstoffe}

Zur Charakterisierung der Nährstofflage der untersuchten Gewässer werden im folgenden die beiden wichtigsten Nährstoffe Phosphat und Nitrat in ihrem Jahresverlauf dargestellt. Eine eingehendere Wertung der Rolle des Stickstoffs im Nährstoffkreislauf findet sich bei Stadelmann [73]. Auf die Bedeutung des Phosphors wird im Zusammenhang mit Sedimentationsmessungen BLOESCH [8] Eingehenderes berichten. Von den Mikronährstoffen sei als einziger das Eisen angeführt.

Die Werte wurden pro $\mathrm{m}^{2}$ Seeoberfläche ausgerechnet, indem die Gehalte der trophogenen Schicht (im Vierwaldstättersee von 0 bis $15 \mathrm{~m}$ und im Rotsee von 0 bis $5 \mathrm{~m}$ ) mit dem im Appendix angeführten Programm "Profil» bestimmt wurden. Zu jeder Nährstoffkomponente wurden die $\mathrm{K}$ zu allen anderen Parametern mit dem Programm "Korrela» berechnet und nach demselben Schema wie die Temperatur dargestellt.

\subsection{Phosphat}

\section{Rotsee}

In Abb. 11 ist der Phosphatgehalt pro $\mathrm{m}^{2}$ Seeoberfläche der trophogenen Schicht im Rotsee dargestellt. In den Monaten August bis Oktober 1969 fand eine fast vollständige Zehrung des Phosphates in der trophogenen Schicht statt, während im Winter (Dezember), bedingt durch die Vollzirkulation des Sees, der Phosphatgehalt unter $1 \mathrm{~m}^{2}$ bis $\mathrm{zu} 1 \mathrm{~g}$ anstieg. Schon im Mai (1969) begann von der Oberfläche aus wieder die Aufzehrung des vorhandenen Phosphates bei abnehmender Algenpopulation.

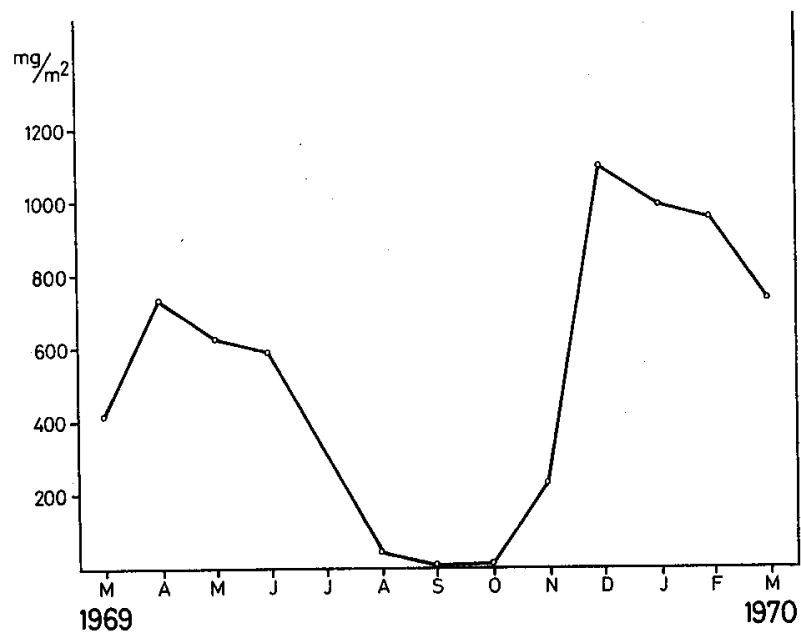

Abb. 11. Phosphatgehalt der trophogenen Schicht $(0-5 \mathrm{~m})$ in $\mathrm{mg} \mathrm{PO}_{4}-\mathrm{P} / \mathrm{m}^{2}$, Rotsee. 
Tab. 6. K-Analyse zum Bezugsparameter Phosphat, Rotsee.

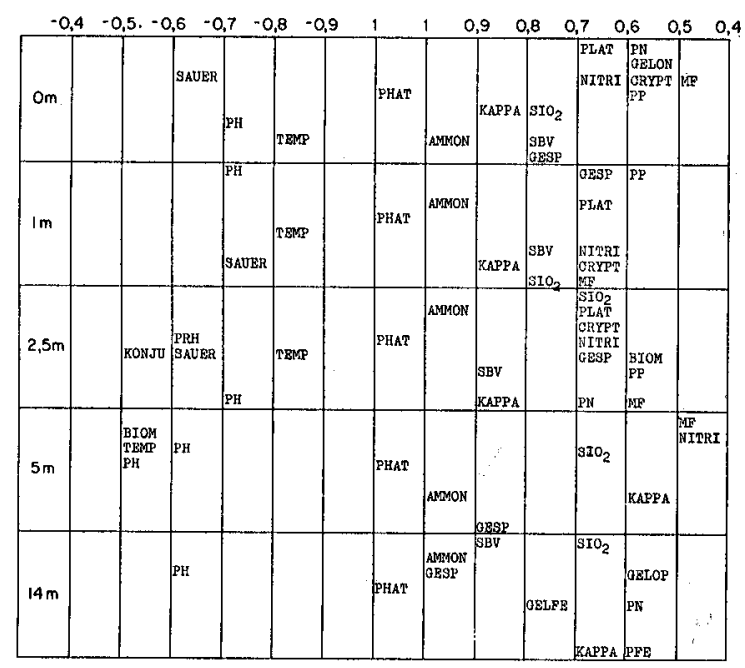

Die $K$-Analyse (Tab. 6) zeigt, dass die Phosphatkonzentrationen im Winter hoch sind, indem ein hoher negativer KK zur Temperatur vorliegt. Im weiteren zeigt sich eine $\mathrm{K}$ zwischen Phosphat und Leitfähigkeit in den Schichten bis 2,5 m Tiefe.

Eine $\mathrm{K}$ zu den Produktionsparametern ist nur im weitesten Sinne festzustellen (CRYPT, PN und PP 0,55-0,6). Die K zu den anderen Phosphorkomponenten sind auch nur sekundärer Natur. Hingegen besteht ein sehr enger Zusammenhang zwischen Phosphat und Ammoniumkonzentration. Dies hat seinen Ursprung darin, dass bei Vollzirkulation die beiden Komponenten aus dem Hypolimnion eingetragen werden. Diese Annahme wird dadurch bestätigt, dass auch im Hypolimnion zwischen Phosphatkonzentration und Ammoniumkonzentration ein $\mathrm{K}$ von 0,98 besteht.

\section{Vierwaldstättersee (Abb. 12)}

Die Phosphatkonzentration unter $1 \mathrm{~m}^{2}(0-15 \mathrm{~m})$ ist im Vierwaldstättersee um eine Zehnerpotenz kleiner als im Rotsee. Sie liegt im Durchschnitt bei $40 \mathrm{mg} / \mathrm{m}^{2}$.

In den Sommermonaten bis Ende des Jahres zeigte sich ein starker Phosphatschwund. $\mathrm{Zu}$ einer fast vollständigen Phosphatzehrung kam es im September, als zwischen 2,5 und $15 \mathrm{~m}$ Tiefe kein Phosphat mehr nachgewiesen werden konnte.

Offenbar wurde durch eine ausgeprägtere Vollzirkulation im Januar 1970 eine grössere Menge von Phosphat in die trophogene Schicht zurückgeführt und die allochthon eingeflossenen Mengen über das Profil verteilt, so dass der Gehalt im Februar 1970 viel höher ausfiel als im Jahr zuvor.

Die $K$-Analyse (Tab. 7) zeigt negative Korrelationen zwischen Phosphat und den Produktionsfaktoren wie Primärproduktion, PN, Temperatur und positive Korrelationen zwischen Phosphat und Nitratgehalt in allen Tiefenstufen von 0 bis $10 \mathrm{~m}$ von 0,6 bis 0,64, d.h..es besteht eine Konstanz der Abhängigkeit der beiden Nährstoffe voneinander. 


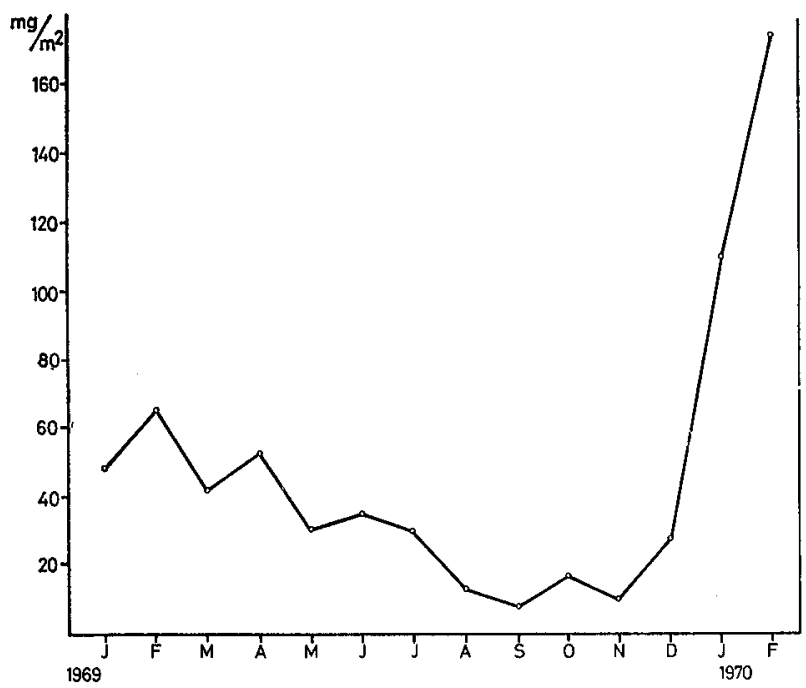

Abb. 12. Phosphatgehalt der trophogenen Schicht $(0-15 \mathrm{~m})$ in $\mathrm{mg} \mathrm{PO}_{4}-\mathrm{P} / \mathrm{m}^{2}$, Vierwaldstättersee.

Tab. 7. K-Analyse zum Bezugsparameter Phosphat, Vierwaldstättersee.

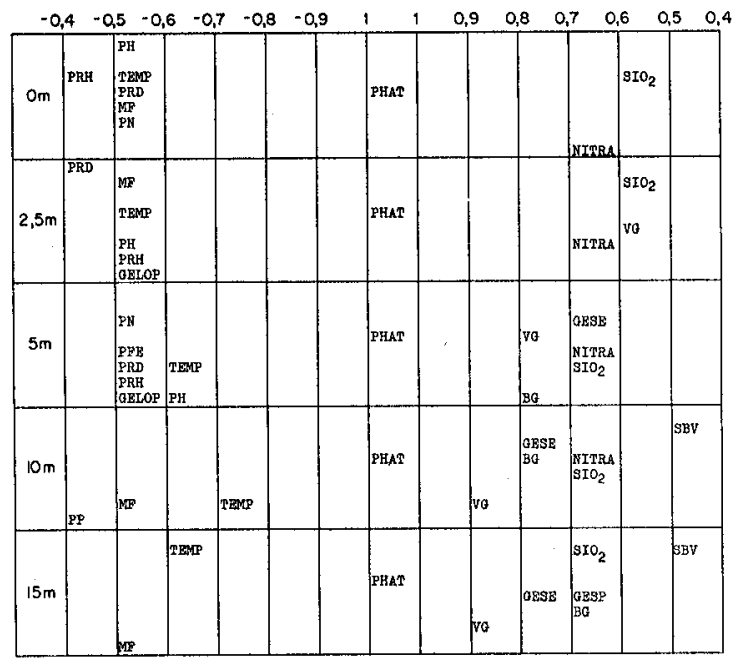

\subsection{Stickstoffkomponenten}

Der Stickstoffkreislauf wurde von Stadelmann [73] im Detail untersucht. In Abb. 13 sind die Stickstoffkomponenten Nitrat, Ammonium und Nitrit im Rotsee in Form von Quadratmeterwerten zusammengestellt.

Alle drei Stickstoffkomponenten zeigen, dass die N-Zehrung im Rotsee sehr gross ist, indem vom August bis im November die Werte fast auf Null absinken. Die Nitratkonzentration erhöht sich erst nach der Herbstzirkulation, im Januar bis Mai. Es ist 


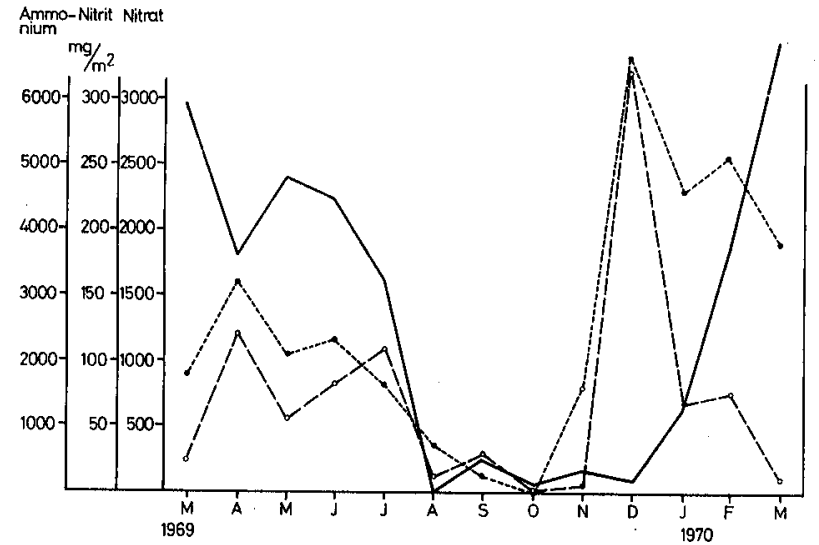

Abb. 13. Quadratmeterwerte $(0-5 \mathrm{~m})$ von Ammonium (----), Nitrit (- - ), Nitrat (- - in $\mathrm{mg} / \mathrm{m}^{2}$, Rotsee.

anzunehmen, dass die Anreicherung aus der Nitrifikation stammt, die wegen der ansteigenden Sauerstoffkonzentration in Gang kommt.

Aus der $K$-Analyse des Nitrates (Tab. 8) ist zu ersehen, dass im Rotsee das Nitrat als Stickstoffkomponente im Jahresregime eine bedeutend kleinere Rolle spielt als das Ammonium.

Tab. 8. K-Analyse zum Bezugsparameter Nitrat, Rotsee.

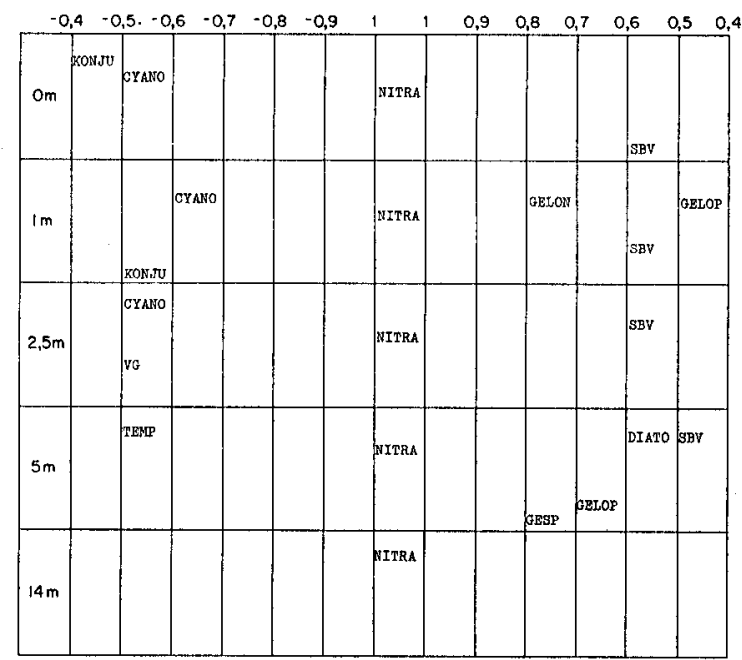

Das bestätigt sich in der $K$-Analyse des Ammoniums (Tab. 9). Ammonium korreliert sehr eng mit Phosphat und ist im K-Muster ein produktionsbeteiligter Nährstoff. Der negative KK zu Sauerstoff in $0 \mathrm{~m}, 1 \mathrm{~m}$ und $2,5 \mathrm{~m}$ ist ein weiterer Hinweis dafür. 
Tab. 9. K-Analyse zum Bezugsparameter Ammonium, Rotsee.

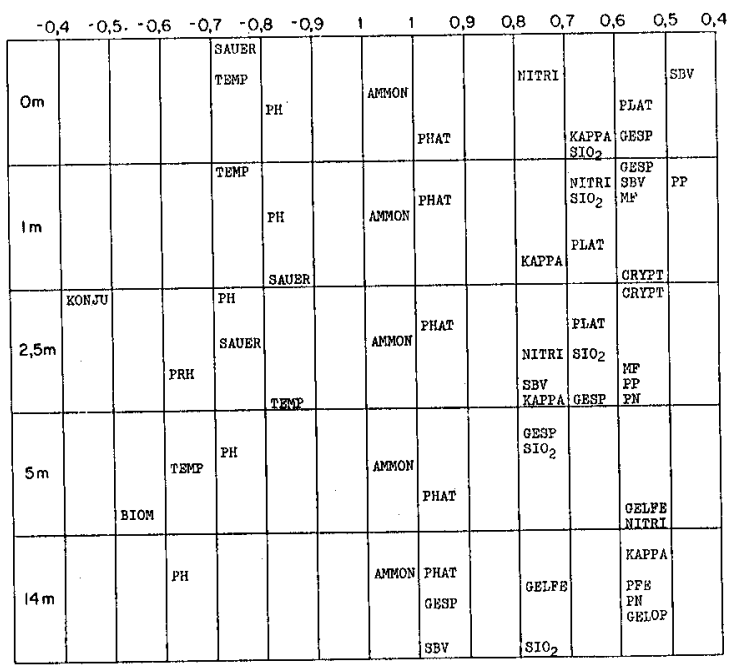

Vierwaldstättersee (Abb. 14)

Im Vierwaldstättersee wird Nitrat im Jahresverlauf in der trophogenen Schicht als Ganzes nie vollständig aufgezehrt. Es gibt zwar im Oktober 1969 in der hauptproduktiven Schicht von 0 bis 2,5 m eine fast vollständige Nitratzehrung. Der Nitratgehalt der trophogenen Schicht bleibt hingegen immer über $2 \mathrm{~g} / \mathrm{m}^{2}$.

Nitrit ist im Vierwaldstättersee von untergeordneter Bedeutung. Es treten 2 Maxima, und zwar im Juli und im September 1969, an der unteren Grenze der trophogenen Schicht bei etwa $12 \mathrm{~m}$ auf.

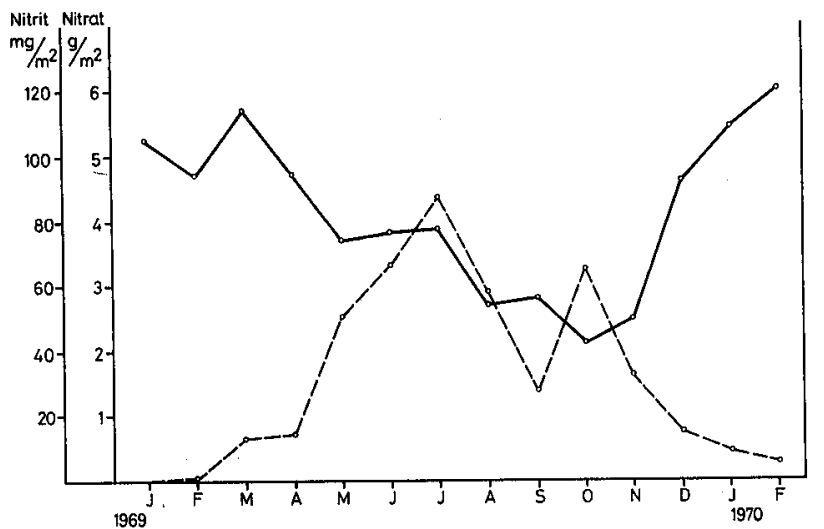

Abb. 14. Quadratmeterwerte $(0-15 \mathrm{~m})$ von Nitrit $(--\rightarrow)$ und Nitrat $(-)$ in $\mathrm{mg}-\mathrm{N} / \mathrm{m}^{2}$, Vierwaldstättersee.

K-Analyse des Nitrates im Vierwaldstättersee (Tab. 10)

Im Gegensatz zum Nitrat im Rotsee (siehe K-Analyse Tab. 8) tritt Nitrat im Vierwaldstättersee antagonistisch $\mathrm{zu}$ den meisten Produktionsparametern auf. Speziell 
Tab. 10. K-Analyse zum Bezugsparameter Nitrat, Vierwaldstättersee.

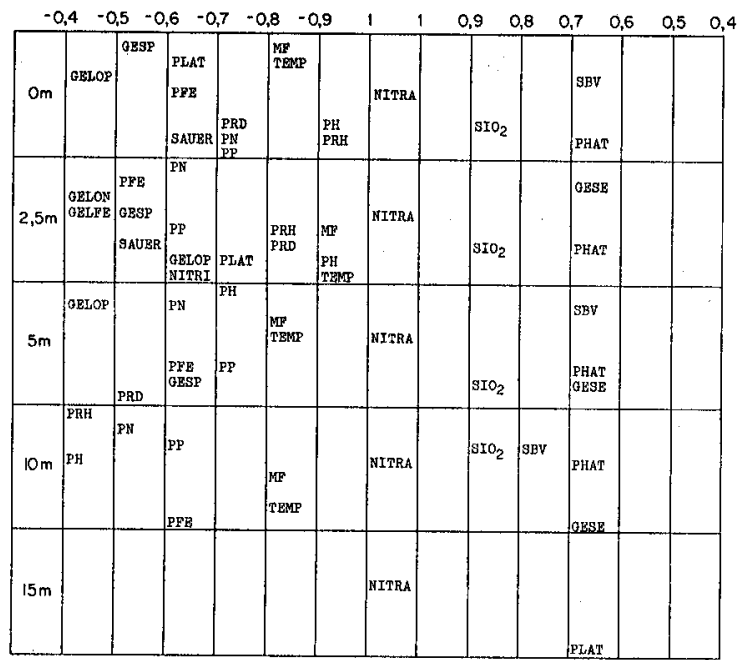

Tab. 11. K-Analyse zum Bezugsparameter Nitrit, Vierwaldstättersee.

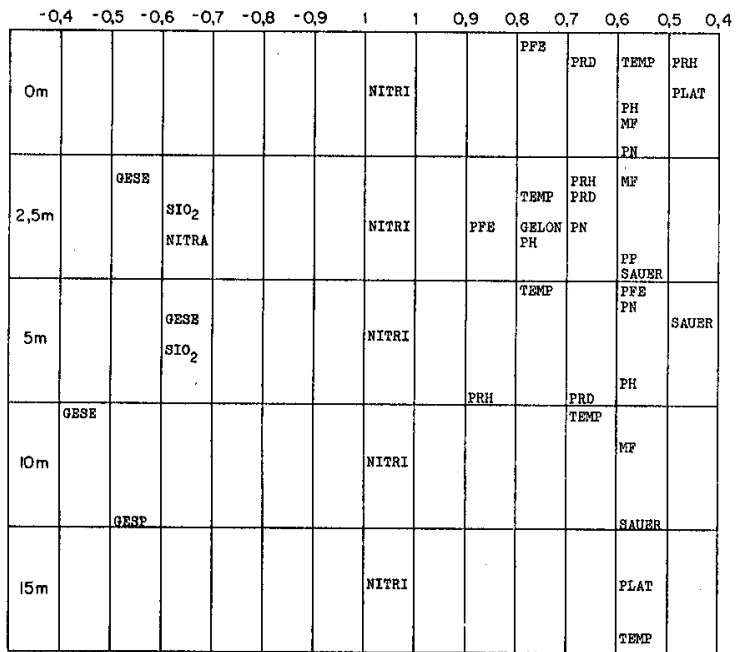

besteht ein hoher negativer KK zwischen Primärproduktion und Nitrat $(0,92)$. Es treten daneben negative $\mathrm{K}$ zu den für den «standing crop» repräsentativen PN- und PP-Werten von 0,7 bis 0,6 auf. Wie eng diese Verknüpfung ist, zeigt sich auch darin, dass in $15 \mathrm{~m}$ Tiefe keine signifikante $\mathrm{K}$ zwischen Nitrat und den Produktionsparametern festgestellt werden kann. Positive $K$ bestehen $z u$ Kieselsäure mit 0,82 und Phosphat mit 0,63. Diese K-Werte sind bis zu $10 \mathrm{~m}$ Tiefe erstaunlich konstant.

Die $K$-A nalyse des Nitrits (Tab. 11) zeigt, dass die Denitrifikationsvorgänge in der Tiefe von $10 \mathrm{~m}$ im Zusammenhang zur Bakterienpopulation stehen. In der hauptproduktiven Schicht bestehen positive KK zu den Produktionsparametern und ein 
negativer KK zu Nitrat. Es lässt sich daraus schliessen, dass bei hoher Nitratassimilation, d.h. hoher Photosynthese, Nitrit entsteht. Dies ist verständlich, da Nitrit als erstes $Z$ wischenprodukt der Nitratassimilation entsteht (STADELMANN [73]).

\subsection{Eisen}

Wie aus Abb. 15 und 16 ersichtlich ist, liegen die Konzentrationen des gelösten Eisens sowohl im Rotsee als auch im Vierwaldstättersee auf die trophogene Schicht berechnet in derselben Grössenordnung. In keinem der beiden Beispiele fällt die gelöste Eisenkonzentration auf $0 \mathrm{ab}$.

Die $K$-Analysen (Tab. 12: K-Analyse im Rotsee) ergeben nur im Rotsee eine negative $\mathrm{K}$ zwischen der vorhandenen Biomasse und dem gelösten Eisen in der trophogenen Schicht. Im Vierwaldstättersee ergaben die K-Analysenwerte keine $\mathrm{Zu}$ -

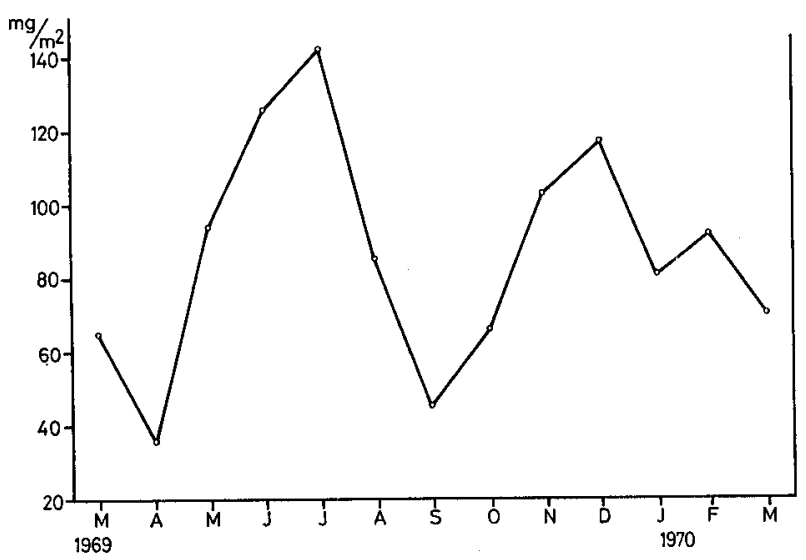

Abb. 15. Quadratmeterwerte $(0-5 \mathrm{~m})$ des gelösten Eisens in $\mathrm{mg}-\mathrm{Fe} / \mathrm{m}^{2}$, Rotsee.

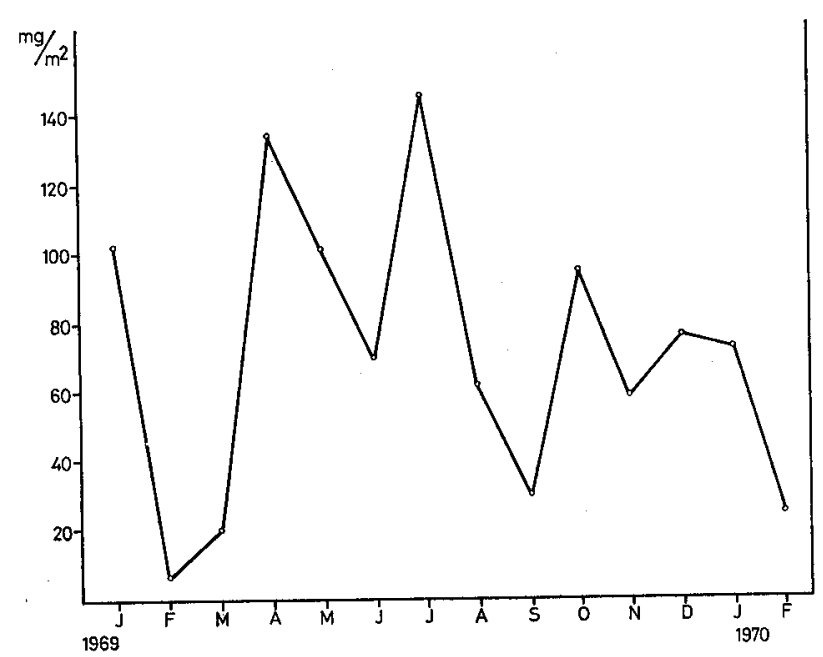

Abb. 16. Quadratmeterwerte (0-15 m) des gelösten Eisens in mg-Fe/m², Vierwaldstättersee. 
Tab. 12. K-Analyse zum Bezugsparameter gelöstes Eisen, Rotsee.

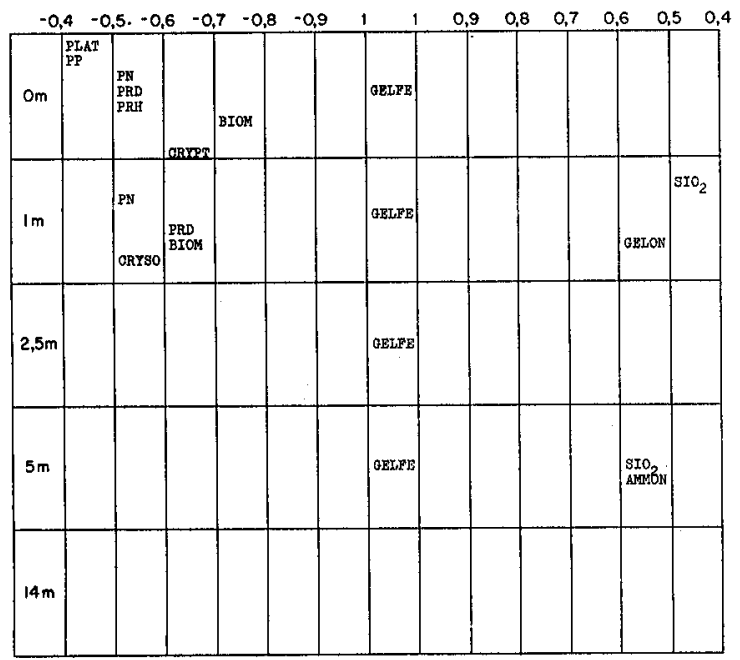

sammenhänge mit den Produktionsparametern. Auf eine Darstellung wurde daher verzichtet.

\subsection{Gesamtsalzgehalt}

Die $K$-Analyse zwischen der Leitfähigkeit und den Produktionsparametern wurde in beiden Seen durchgeführt. Für den Vierwaldstättersee fällt auf, dass die Leitfähigkeit allein von der Alkalinität (SBV) abhängt. In der trophogenen Schicht fallen die $\mathrm{KK}$ von 0,8 in $0 \mathrm{~m}$ bis 0,62 in $15 \mathrm{~m}$ ab, d. h. dass unterhalb der trophogenen Schicht die Leitfähigkeit auch durch angereicherte Nährstoffe beeinflusst werden kann. Es findet sich keine Korrelation mit einem der Produktionsparameter. Auf eine Darstellung wurde daher verzichtet.

Diese Situation stellt sich im Rotsee (Tab. 13) völlig anders dar; die Leitfähigkeit korreliert mit Phosphat in den Tiefen $0 \mathrm{~m}, 1 \mathrm{~m}$ und 2,5 $\mathrm{m}$ mit 0,82. Ebenso bestehen signifikante KK zwischen Kieselsäure, Ammonium und der Wasserhärte (SBV).

\subsection{Produktionsmessungen}

Grundlage der Produktion ist eine entsprechende Phytoplanktonpopulation. Die Grösse der Produktion ist abhängig von der Zusammensetzung der Population und der aktuellen Umsatzgeschwindigkeit. Die Umsatzgeschwindigkeit kann, wie schon früher gezeigt wurde (SCHEGG [63]), je nach Artzusammensetzung des Planktons stark variieren. Phytoplanktonuntersuchungen dienen daher auch dem Verständnis dynamischer Zusammenhänge. In diesem Sinne ist die nachfolgend beschriebene detaillierte Untersuchung des Phytoplanktons im Rotsee zu verstehen.

\subsection{Phytoplankton im Rotsee}

Die Beschreibung des Auftretens des Phytoplanktons erfolgt einerseits gruppenweise, andererseits unter Darstellung der hauptsächlichsten Formen im Raum-ZeitDiagramm. 
Tab. 13. K-Analyse zum Bezugsparameter Leitfähigkeit, Rotsee.

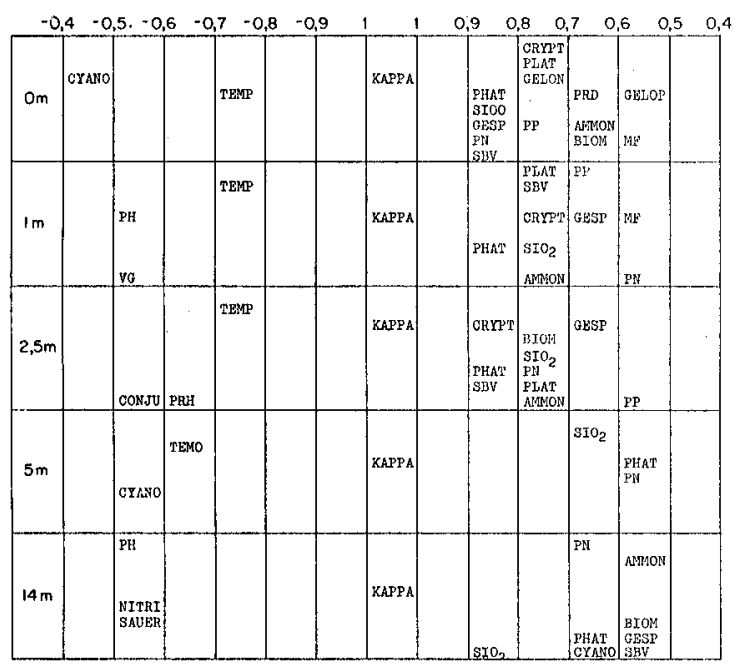

Die Algengruppen werden in Biomasse als Frischgewicht (= Zellvolumen · spezifisches Gewicht) angegeben, die Einzelformen in Zellzahlen, Kolonien oder Anzahl Fäden pro ml. In den Raum-Zeit-Diagrammen sind zur Verdeutlichung der Hauptvegetationszeiten Raster eingezeichnet. Diese sind aber nicht als Isopleten zu verstehen, d.h. die Begrenzungen wurden fallweise zweckmässig gewählt, aber nicht berechnet. Eine Isopletendarstellung würde ein grösseres Grundlagenmaterial erfordern. Die entsprechende Darstellung wird auch noch bei anderen Parametern verwendet.

\subsection{Cyanophyta (Abb. 17)}

Die Blaualgen hatten eine ziemlich scharf abgegrenzte Wachstumsperiode zwischen dem September und dem Dezember 1969. Im Vergleich zum Gesamtphytoplankton sind ihre Werte in der trophogenen Schicht relativ klein, sie spielen im Rotsee eine untergeordnete Rolle.

Einzig Coelosphaerium Naegelianum erreichte im November 1969 in 5 m Tiefe einen sehr hohen Wert. Während des ganzen Jahres waren immer einige Filamente von Oscillatoria rubescens und Oscillatoria redeckii anzutreffen.

\section{Coelosphaerium Naegelianum (Abb. 18)}

Das Auftreten von Coelosphaerium Naegelianum war begrenzt auf die Monate Oktober 1969 bis Januar 1970 mit einem Maximum im November 1969. Die grösste Anzahl Kolonien (850 Kolonien/ml) fand sich an der Grenze zwischen Schwefelwasserstoff und Sauerstoff bei 7,5 m Tiefe. In $14 \mathrm{~m}$ Tiefe, bei einem Schwefelwasserstoffgehalt von $6,8 \mathrm{mg} \mathrm{S} \mathrm{S}^{2-} / 1$, waren immer noch $467 \mathrm{Kolonien} / \mathrm{ml}$ vorhanden. $\mathrm{Ob}$ es sich dabei um abgesunkene Kolonien handelte oder ob diese Form im anaeroben Bereich bei extrem schwachen Lichtintensitäten wuchs, konnte nicht festgestellt werden.

\subsection{Chlorophyceae (Abb. 19)}

Die Chlorophyceen waren nach der Artenzahl eine relativ bedeutende Gruppe, nahmen aber bezüglich der Biomasse keine führende Stellung ein. Einzig im April 


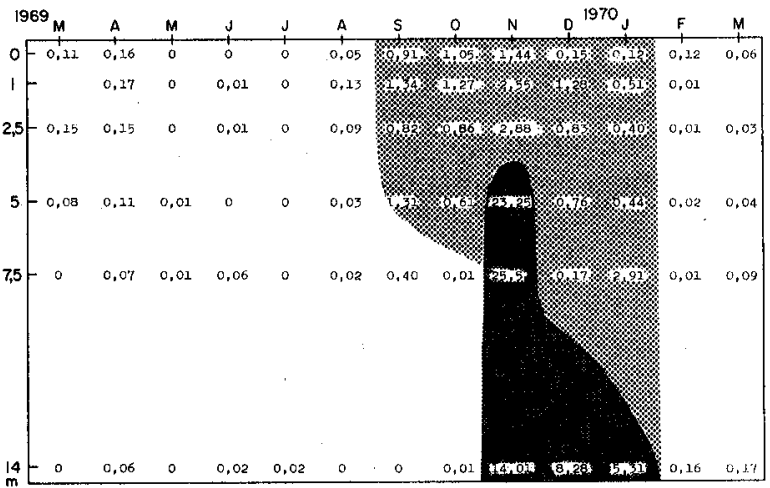

Abb. 17. Cyanophyceae, $\mu \mathrm{g} / \mathrm{ml}$, Rotsee.

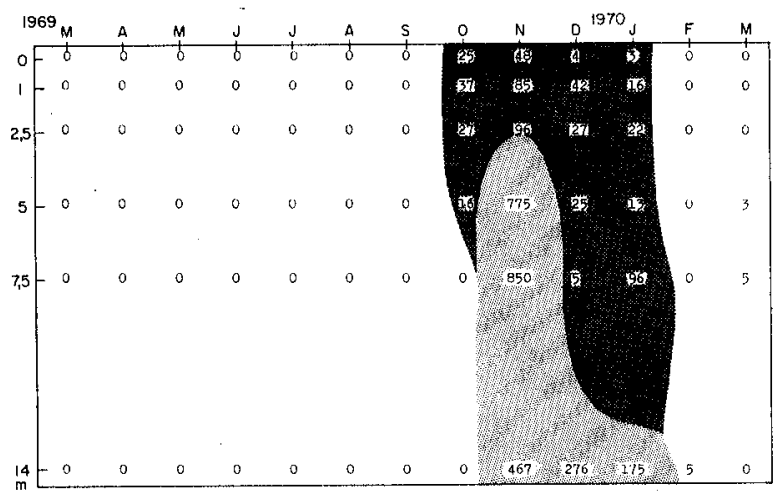

Abb. 18. Coelosphaevium Naegelianum, Kolonien zu 30-50 Zellen, Kolonien/ml, Rotsee.

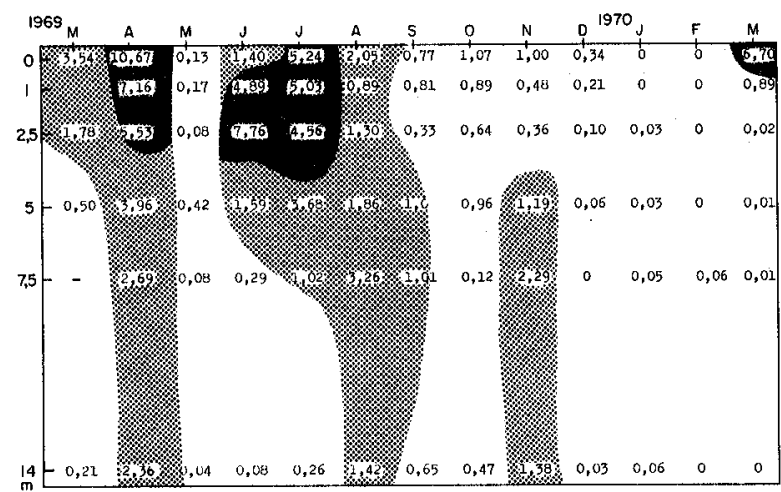

Abb. 19. Chlorophyceae, $\mu \mathrm{g} / \mathrm{ml}$, Rotsee. 
1969 waren sie an der Biomasse bis zu 30\% beteiligt. Ihr Auftreten war im wesentlichen auf die erste Jahreshälfte beschränkt, wobei ein Maximum der Entwicklung im April und ein zweites im Juli und August 1969 beobachtet wurde. Das Maximum im April wurde durch Chlamydomonas sp. (Abb. 20) ausgelöst, dessen Auftreten sich analog dem der später zu besprechenden Flagellaten (Abb. 29) im wesentlichen auf die Monate März und April beschränkte.

Oocystis lacustris (Abb. 21)

Oocystis lacustris wurde in den Monaten Juni bis September beobachtet, wobei auffällt, dass am 10. Juli 1969 eine Massenentwicklung in $5 \mathrm{~m}$ Tiefe an der Schwefelwasserstoff-Sauerstoff-Grenze auftrat. Ein Monat später wurde in $14 \mathrm{~m}$ Tiefe eine grosse Anzahl festgestellt. Offensichtlich war diese Population, ohne dass sie sich wesentlich aufgelöst hatte, über die anaerobe Schicht abgesunken.

Es ist möglich, dass Oocystis lacustris wie das unter den Cyanophyceen beschriebene Coelosphaerium Naegelianum zu Formen gehört, die auch unter anaeroben Verhältnissen leben können oder dank ihren Gallerthüllen zellulär im aeroben Milieu verbleiben.

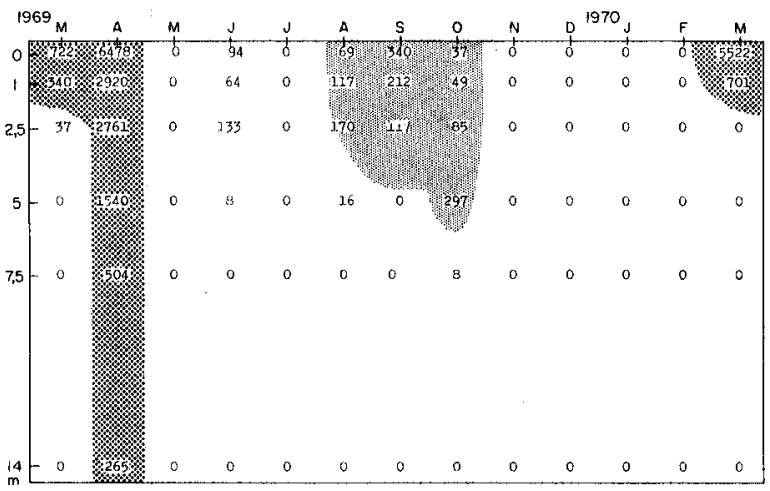

Abb. 20. Chlamydomonas sp., Zellen/ml, Rotsee.

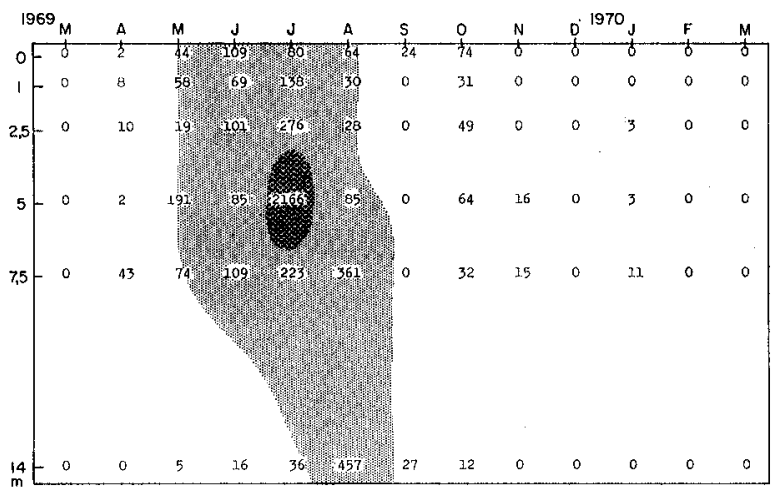

Abb. 21. Oocystis lacustris, Zellen/ml, Rotsee. 
Sphaerocystis Schroeteri (Abb. 22)

Diese Kolonien wurden im Juni und im November besonders im Epilimnion beobachtet.

\section{Characium gracilipes (Abb. 23)}

Diese Form trat in relativ grosser Zahl im Mai in $1 \mathrm{~m}$ Tiefe auf und in kleineren Mengen im November und Dezember 1969.

\section{Coelastrum microporum (Abb. 24)}

Coelastrum microporum wies eine Massenentfaltung (2549 Kolonien $/ \mathrm{ml}$ ) am 10. Juli 1969 auf. Eine kleinere Anzahl von Kolonien blieben bis in den November erhalten. Auch bei dieser Form liessen sich noch sehr grosse Kolonienzahlen in der anaeroben Schicht beobachten, z. B. wurden am 14. August 1969 in 7,5 m Tiefe 1444 Kolonien/ml

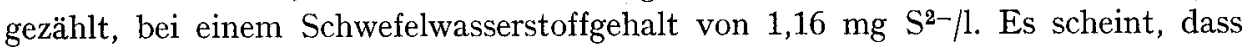
wieder die Kolonieform mit festen Membranen der Zellen das Leben in anaeroben Verhältnissen gestattet hatte.

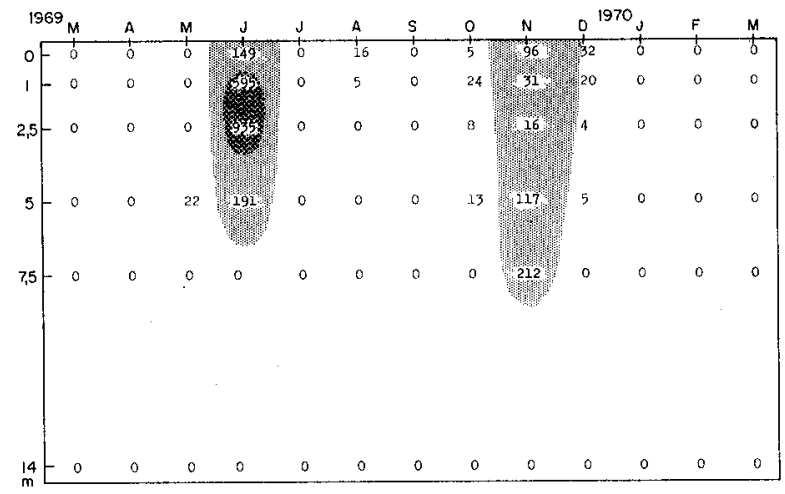

Abb. 22. Sphaerocystis Schroeteri, Kolonie zu 10-20 Zellen, Kolonien/ml, Rotsee.

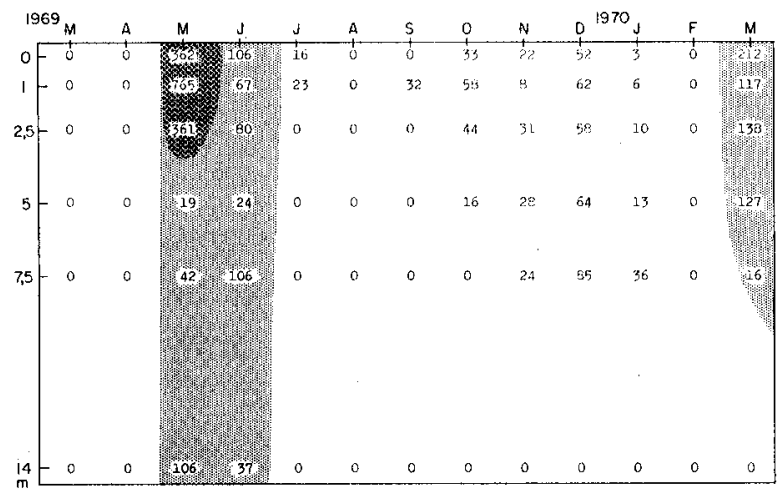

Abb. 23. Characium gracilipes, Zellen/mI, Rotsee. 


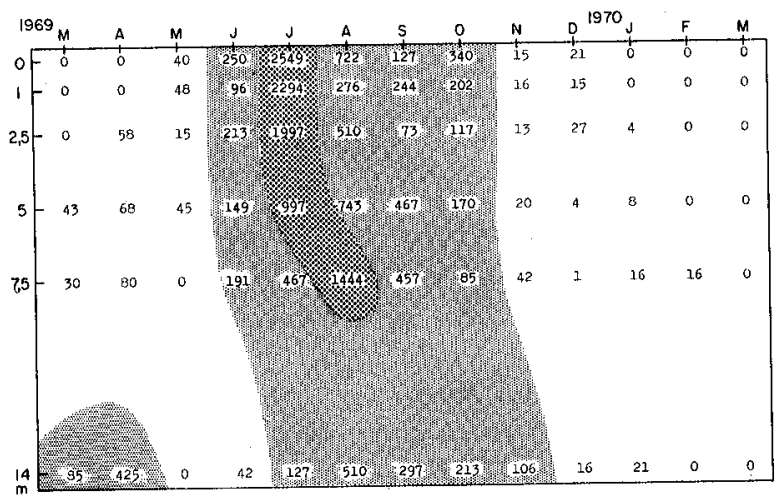

Abb. 24. Coelastrum microporum, Kolonien zu etwa 20 Zellen, Kolonien/ml, Rotsee.

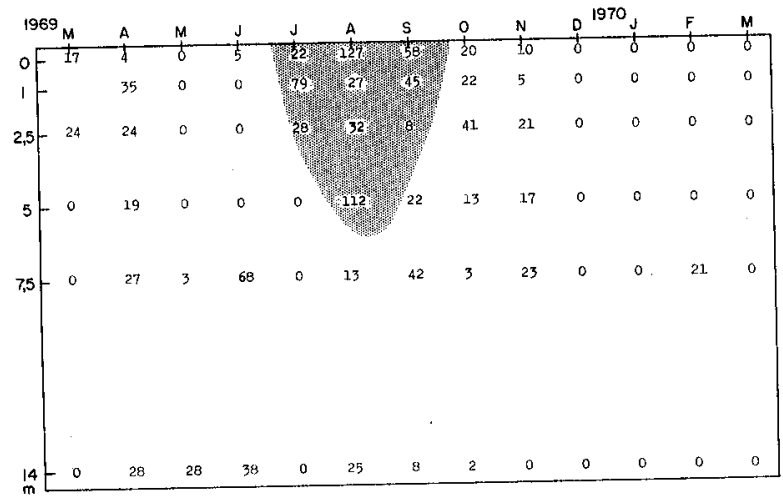

Abb. 25. Scenedesmus quadricauda, Kolonien/ml, Rotsee.

\section{Scenedesmus quadricauda (Abb. 25)}

Diese Kolonien traten sporadisch auf, hauptsächlich aber in den Sommermonaten im Epilimnion.

Ankistrodesmus convolutus (Abb. 26)

war hauptsächlich in den Wintermonaten Dezember 1969 bis April 1970 entwickelt, wobei eine Massenentfaltung im April festgestellt wurde (4737 Zellen/ml in $0 \mathrm{~m}$ Tiefe). Für die Biomasse ist diese Form wegen des kleineren Zellinhaltes unbedeutend.

\subsection{Konjugatae (Abb. 27)}

Das Auftreten dieser Gruppe war auf die Monate August bis Oktober beschränkt. Die hauptsächlichste Form, die auftrat, war Closterium sp. Für die Gesamtbiomasse ist auch diese Gruppe unbedeutend. 


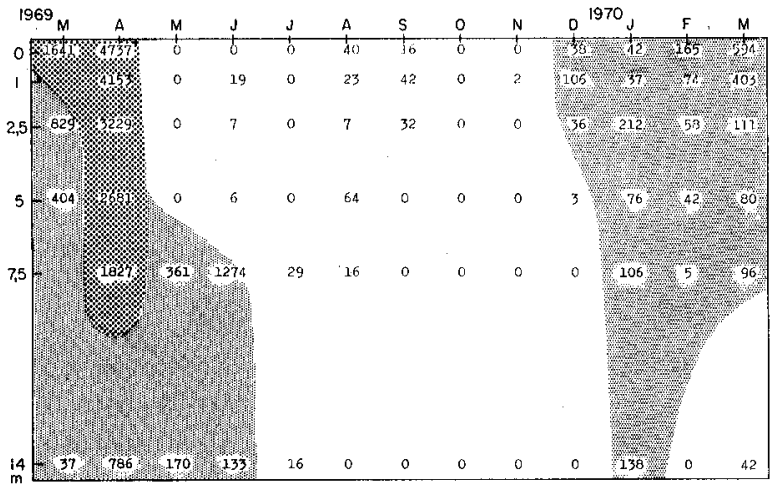

Abb. 26. Ankistrodesmus convolutus, Zellen/ml, Rotsee.

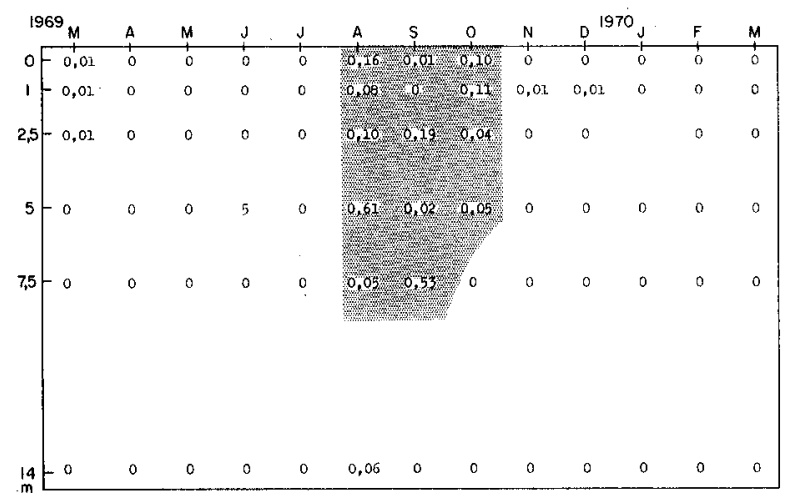

Abb. 27. Konjugatae, $\mu \mathrm{g} / \mathrm{ml}$, Rotsee.

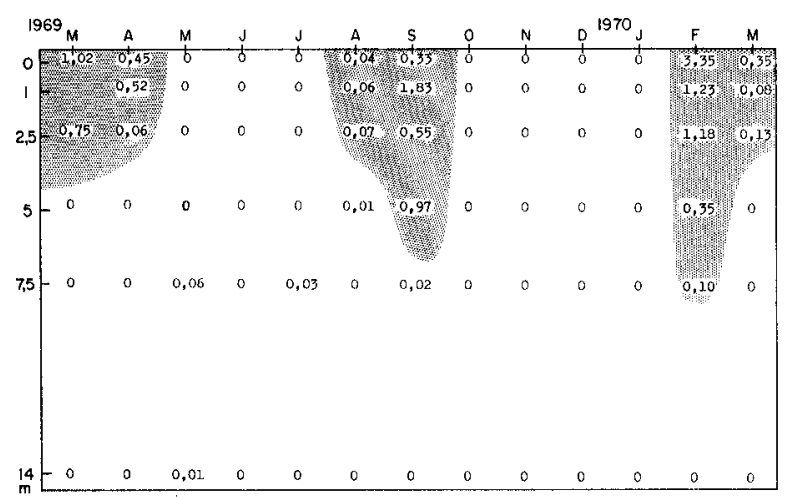

Abb. 28. Chrysophyceae, $\mu \mathrm{g} / \mathrm{ml}$, Rotsee. 
4.314 Chrysophyceae (Abb. 28)

Von den Chrysophyceen waren hauptsächlich zwei Formen vertreten, und zwar im März und April 1969 Erkenia subaequiciliata und im September 1969, Februar und März 1970 Uroglena americana. Einzig am 18. Februar 1970 in $0 \mathrm{~m}$. Tiefe betrug der Biomassenanteil $14 \%$. Im weiteren wurden schwerer differenzierbare Flagellaten ausgezählt, die in Abb. 29 zusammengestellt sind.

\subsection{Diatomeae (Abb. 30)}

Die Kieselalgen entfalteten sich in Vegetationsschüben, und zwar in den Frühlingsmonaten März und April 1969 und im Februar und März 1970 sowie im August, September und Oktober 1969.

Synedra acus (Abb. 31)

Diese Form bestimmte die Diatomeenbiomasse im August, während sie in den übrigen Monaten kaum vertreten war.

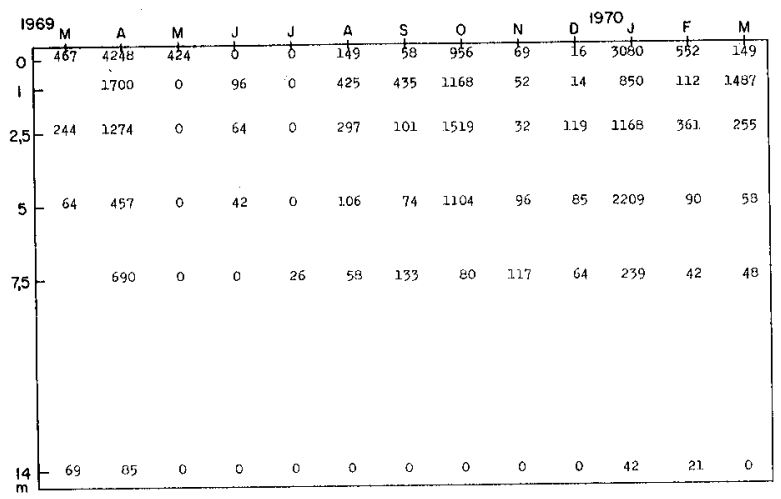

Abb. 29. Diverse Flagellaten, Zellen/ml, Rotsee.

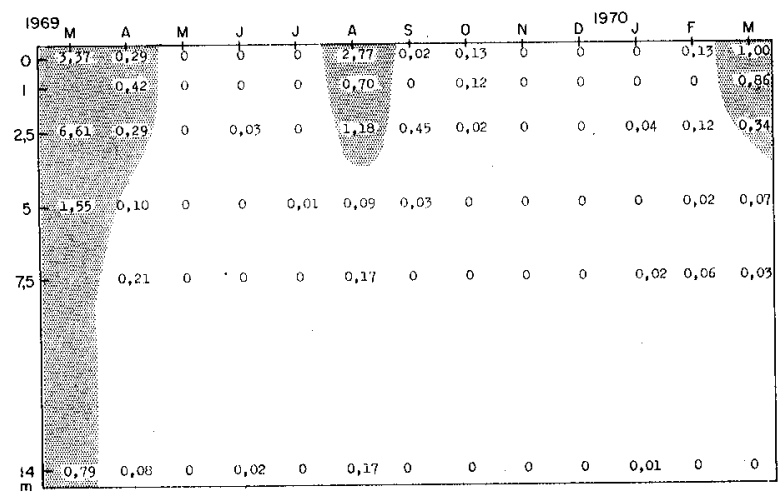

Abb. 30. Diatomae, $\mu \mathrm{g} / \mathrm{ml}$, Rotsee. 
Stephanodiscus hantzschii (Abb. 32)

Der wichtigste Vertreter der Kieselalgen war Stephanodiscus hantzschii mit zwei Wintermaxima. Diese Form erreichte im März 1969 in 2,5 m Tiefe Zellzahlen von 44000 Zellen/ml. Wegen der kleinen Zellvolumina war jedoch der Biomassenanteil auch während dieser Massenentwicklung nur 38\%. Interessant war ein sporadisches Auftreten dieser Form am 11. September 1969 in 2,5 m Tiefe. Diese bekannte Winternannoplanktonform (NAUWERCK [44]) kam im Rotsee bei einer Temperatur von $18^{\circ} \mathrm{C}$ vor.

\subsection{Cryptophyceae (Abb. 33)}

Die Cryptophyceen waren die dominierende Algengruppe im Rotsee. Ihre Vegetationsschwerpunkte lagen in den Wintermonaten und im August und September ( $5 \mathrm{~m}$ Tiefe). So wurde zum Beispiel die maximale Biomasse von $34 \mu \mathrm{g} / \mathrm{ml}$ unmittelbar unter der Eisschicht (1.5. Januar 1970) beobachtet. Über das ganze Jahr liess sich kein Aussedimentieren dieser Formen feststellen, indem schon bei 7,5 $\mathrm{m}$ Tiefe die Zellkonzentrationen im Vergleich zu den epilimnischen Zahlen verschwindend klein waren und in $14 \mathrm{~m}$ Tiefe nur noch vereinzelte Formen anzutreffen waren.

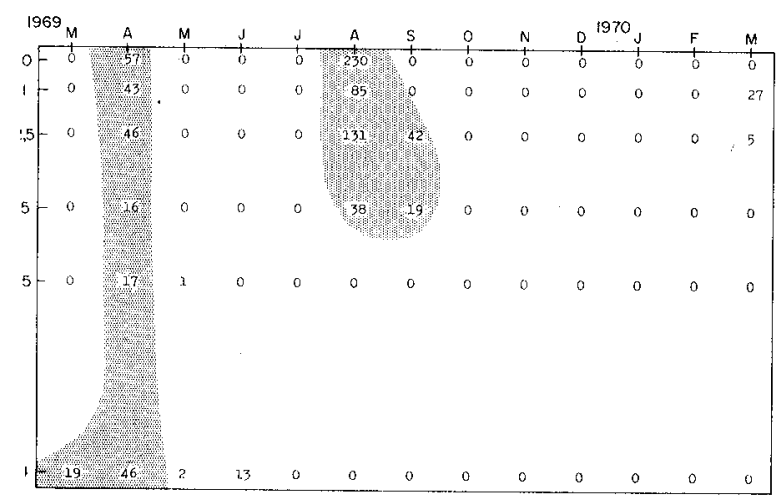

Abb. 31. Synedra acus, Zellen/ml, Rotsee.

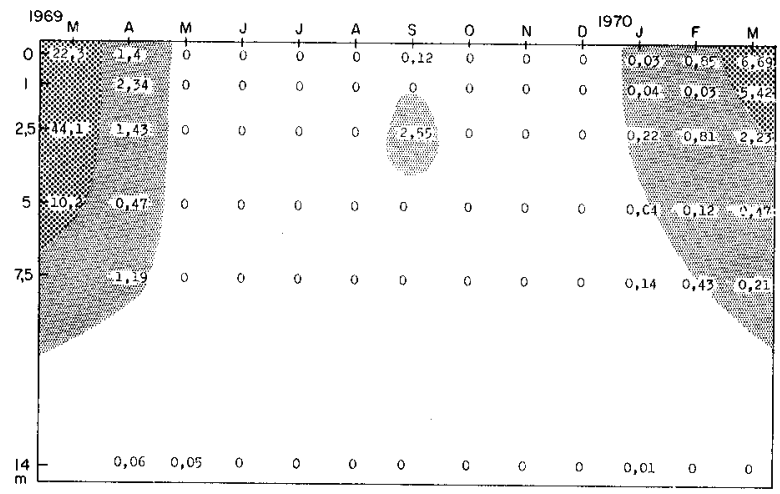

Abb. 32. Stephanodiscus hantzschii, $10^{3}$ Zellen/ml, Rotsee. 


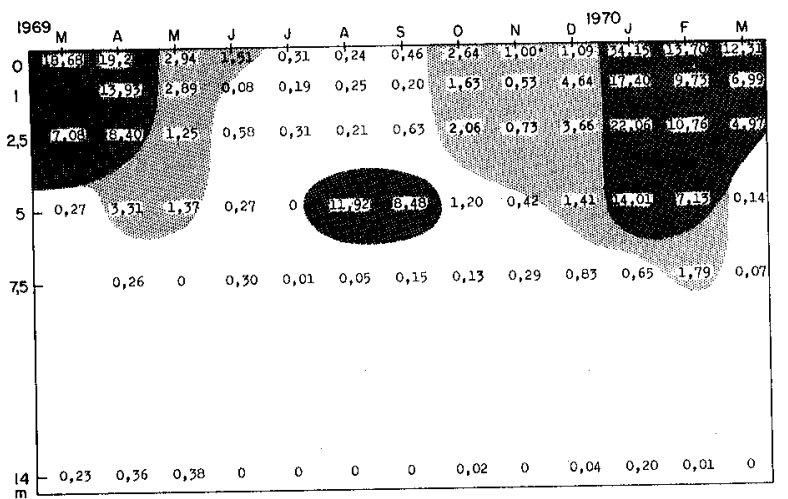

Abb. 33. Cryptophyceae, $\mu \mathrm{g} / \mathrm{ml}$, Rotsee.

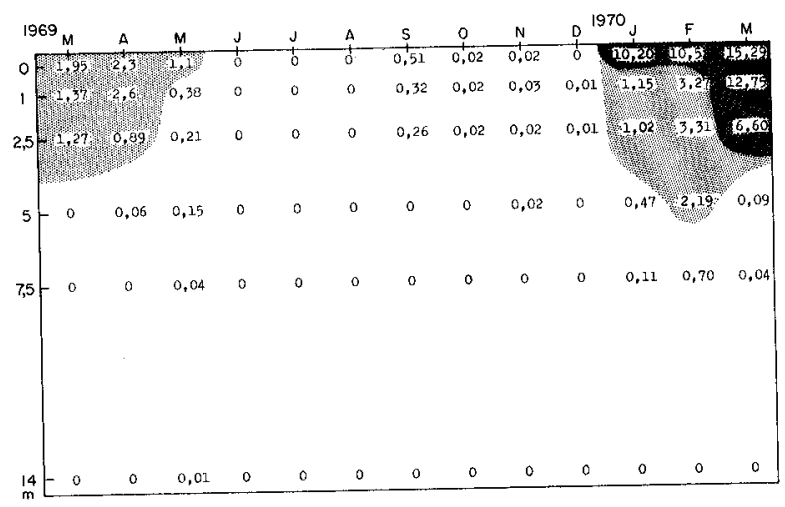

Abb. 34. Rhodomonas lacustris und lens, $10^{3}$ Zellen/ml, Rotsee.

Rhodomonas lacustris und lens (Abb. 34)

Die Massenentfaltungen von Rhodomonas waren auf die oberste Wasserschicht von 0 bis 2,5 $\mathrm{m}$ beschränkt. Die absoluten Maxima waren in $0 \mathrm{~m}$ Tiefe vom Januar bis März 1970 anzutreffen (März 1970: 15000 Zellen/ml).

Cryptomonas spp. (Abb. 35)

Cryptomonas spp. wurden während des ganzen Jahres vorgefunden, die Maximalentwicklungen lagen aber ebenfalls in den Wintermonaten. Im Januar 1970 wurden unter dem Eis 15290 Zellen/ml festgestellt. Eine interessante Erscheinung war das Auftreten von Cryptomonas in $5 \mathrm{~m}$ Tiefe an der Schwefelwasserstoff-SauerstoffGrenze im August und im September 1969.

Es ist möglich, dass die Cryptomonasblïte an dieser Grenze durch das Heraufdiffundieren des Ammonium-Stickstoffs ausgelöst wurde. Dies zeigt sich in der Ammoniumverteilung, indem wir beim Auftreten der Cryptomonasblüte ein sehr rasches Abnehmen von $1000 \mu \mathrm{g} / 1 \mathrm{im}$ Juni auf $520 \mu \mathrm{g} / \mathrm{l}$ im August, $200 \mu \mathrm{g} / 1 \mathrm{im}$ September und $0 \mu \mathrm{g} / \mathrm{lim}$ Oktober feststellen konnten. 


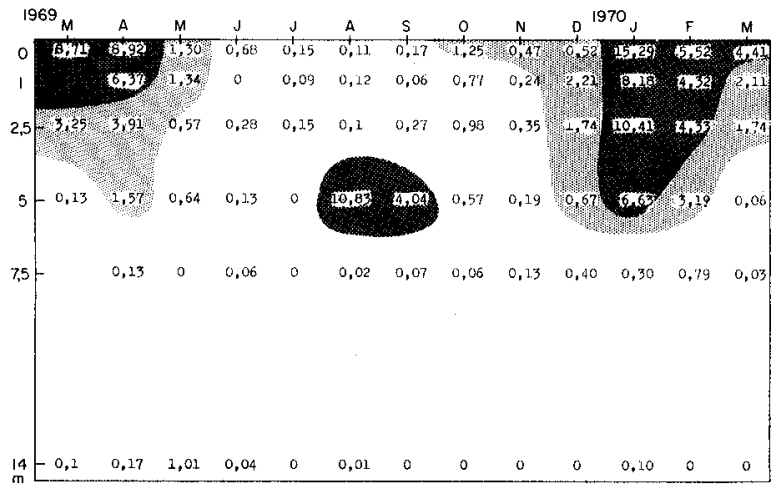

Abb. 35. Cryptomonas spp., $10^{3}$ Zellen/ml, Rotsee.

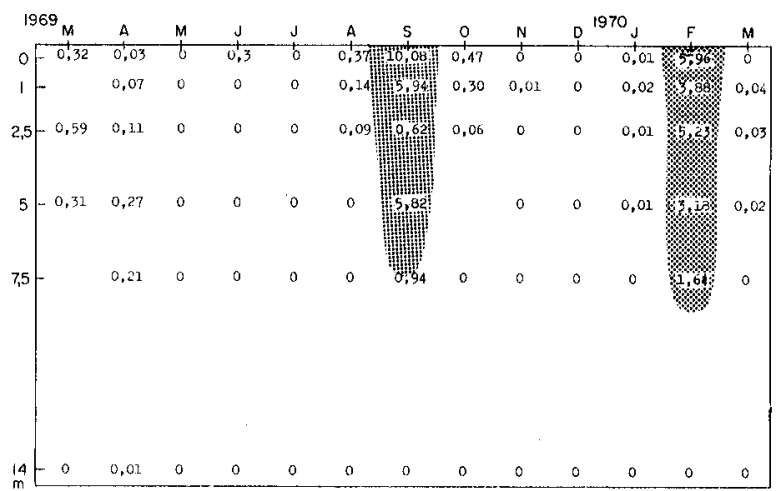

Abb. 36. Peridineae, $\mu \mathrm{g} / \mathrm{ml}$, Rotsee.

Diese metalimnische Cryptomonasblüte bewirkte auch einen plötzlichen Phosphatschwund, indem die Phosphatkonzentration in $5 \mathrm{~m}$ Tiefe von $244 \mu \mathrm{g} / \mathrm{l} \mathrm{im}$ Juli auf $3 \mu \mathrm{g} / \mathrm{l}$ im August sank.

Es ist möglich, dass neben den Nährstoffverhältnissen auch die Temperatur einen Einfluss auf dieses Einschichtungsverhalten hat. Diese lag bei $13-14^{\circ} \mathrm{C}$. FINDENEGG [17] stellte im Piburgersee fest, dass in $15 \mathrm{~m}$ Tiefe, im Metalimnion, eine Cryptomonasblüte bei $5^{\circ} \mathrm{C}$ auftrat.

\subsection{Peridineae (Abb. 36)}

Diese Gruppe trat nur im September 1969 und im Februar 1970 in Erscheinung. Im September handelte es sich um eine starke Entwicklung von Peridinium cinctum, das wegen seines grossen Volumens in $0 \mathrm{~m} 80 \%$ der gesamten Phytoplanktonbiomasse ausmachte.

Im Februar 1970 wurde eine Massenentfaltung von Gymnodinium hantzschii mit über $5000 \mathrm{Zellen} / \mathrm{ml}$ angetroffen.

In allen anderen Monaten waren die Peridinieen kaum vertreten. 


\subsection{Die Phytoplanktonbiomasse}

In Abb. 37 ist das Raum-Zeit-Diagramm des Frischgewichtes des Phytoplanktons aufgetragen. Im Jahresverlauf zeigten sich zwei Schwerpunkte, je zu Beginn des Jahres 1969 und 1970. In der Sommerstagnationsperiode waren maximale Biomassen im Metalimnion an der Grenze von Schwefelwasserstoff und Sauerstoff anzutreffen.

Die absoluten Zahlen von über $30 \mathrm{mg} / \mathrm{l}$ Frischgewicht (April 1969, Januar 1970) lagen ausserordentlich hoch. So wird von PAvoni [53] für den Hallwilersee ein beobachtetes maximales Phytoplanktonfrischgewicht von $26 \mathrm{mg} / \mathrm{l}$ angegeben. VolLENWEIDER [80] gibt in seinem OECD-Bericht Phytoplanktonfrischgewichte an, die durchwegs kleiner sind als die im Rotsee festgestellten.

Auf die erstaunliche Tatsache, dass auch in den Sommermonaten vergleichsweise hohe Planktondichten bei fast vollständiger Zehrung des Phosphates und anderer Nährstoffe auftraten, soll später eingegangen werden (siehe Seite 506).

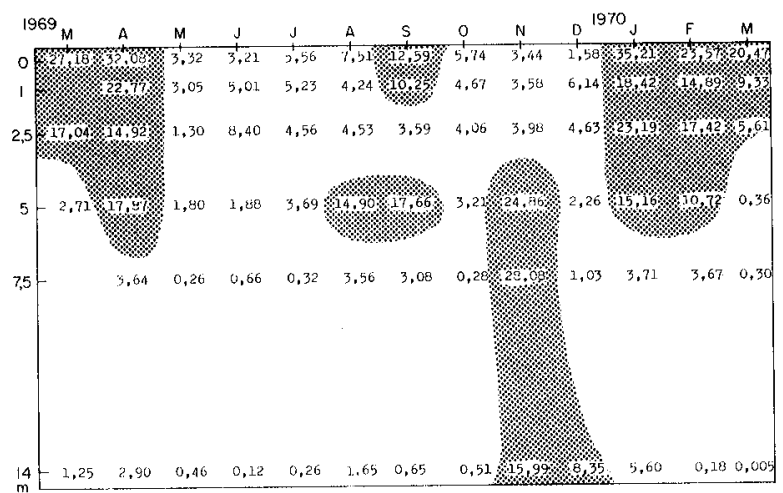

Abb. 37. Phytoplanktonbiomasse (Frischgewicht), $\mu \mathrm{g} / \mathrm{ml}$, Rotsee.

4.319 Die Populationssequenz des Phytoplanktons

Die Phytoplanktonpopulationen im Rotsee entwickelten sich in rascher Sequenz. In $\mathrm{Abb} .38$ sind diese Populationen auf Grund der Biomasse pro $\mathrm{m}^{2}$ Seeoberfläche (Tiefe 0-5 m) dargestellt. Im März 1969 bestand ein Diatomeen- (Stephanodiscus hantzschii) und ein Cryptomonadenmaximum. Einen Monat später waren die Diatomeen fast vollständig verschwunden, während die Zahl der Cryptomonaden weiter anstieg. Gleichzeitig traten grosse Mengen von Chlorophyceen aut. Im Mai brach die Gesamtpopulation zusammen, ausser kleinen Resten von Cryptophyceen. Sämtliche anderen Gruppen blieben unbedeutend, während im Juni und Juli Chlorophyceen im Planktonbild vorherrschten. Im August traten vermehrt Cryptophyceen auf; es handelte sich dabei im wesentlichen um das diskutierte Cryptomonasmaximum (siehe Seite 458) in $5 \mathrm{~m}$ Tiefe. Im September traten schlagartig Peridineen auf, die Cryptonomadenentwicklung in $5 \mathrm{~m}$ Tiefe ging stark zurück. Der Oktober brachte einen vollständigen Zusammenbruch der Populationen, allerdings mit einem Beginn der Entwicklung von Cyanophyceen, die im November eine ausgeprägte Spitze zeigten. Aufgelöst wurde diese Cyanophyceenspitze zu Beginn der Vollzirkulation im Dezember mit einer gleichzeitigen Verfrachtung der später noch zu beschreibenden 


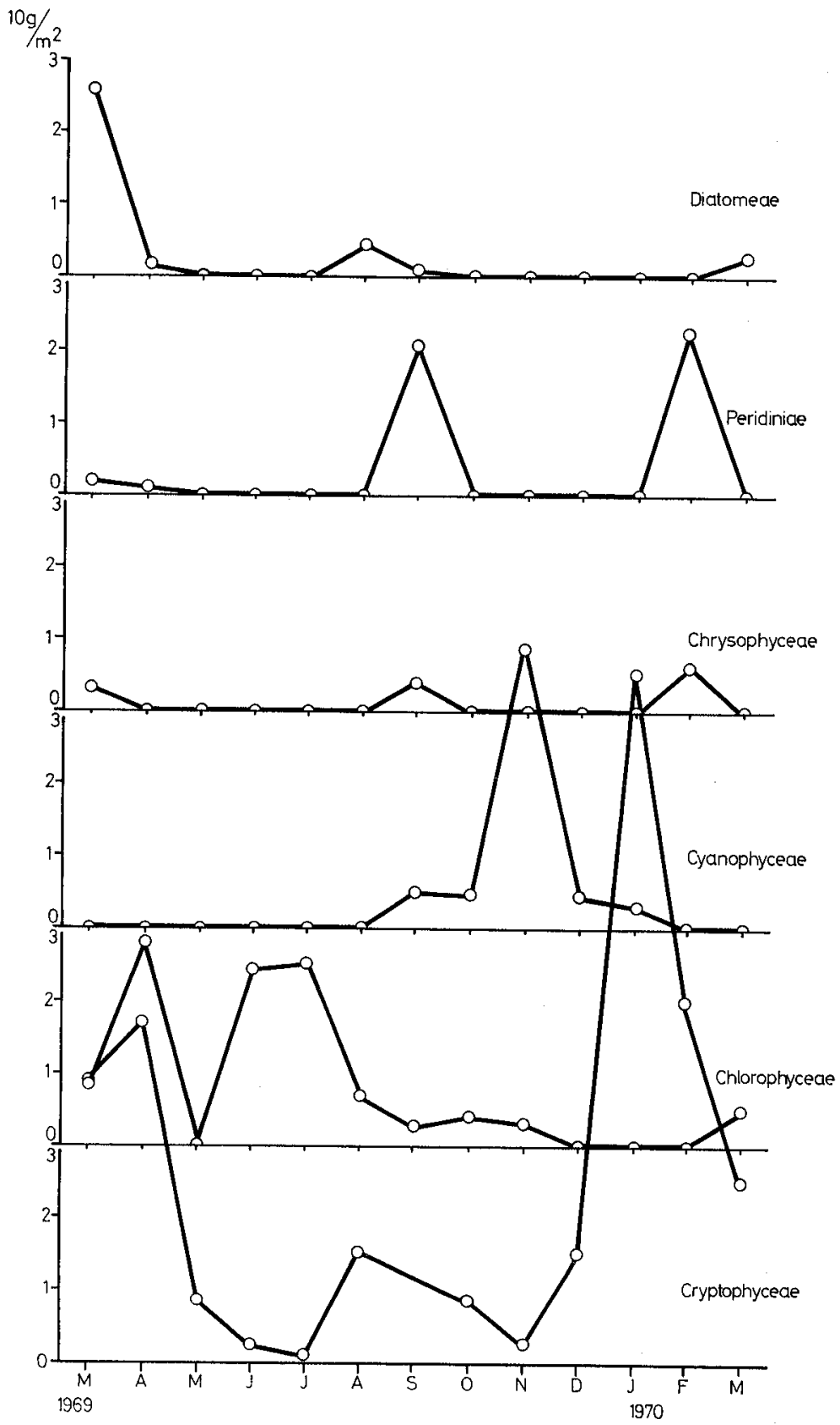

Abb. 38. Populationssequenz des Phytoplanktons, Quadratmeterwerte $(0-5 \mathrm{~m}), \mathrm{g}$ Frischgewicht $/ \mathrm{m}^{2}$, Rotsee. 
hypolimnischen Formen (siehe Seite 484) an die Oberfläche. Im Januar 1970 zeigte sich das absolute Cryptomonasmaximum unter Eis, das das Planktonbild vollständig beherrschte. Im Februar erkennt man ein paralleles Auftreten von Chrysophyceen und Peridineen bei immer noch bestehender Cryptomonadendominanz.

\section{Diskussion}

Die sehr gedrängte Sequenz verschiedener Planktongruppen (einzelner Arten) zeigt, dass das System der Phytoplanktonpopulation an sich schon über eine grosse Valenz der Anpassung verfügt, indem die Population, die die besten Bedingungen vorfindet, zur Entwicklung zu gelangen scheint. Die Phytoplanktonbiozönose ist offenbar sehr labil und von vielen rasch wechselnden Faktoren begrenzt. Im Jahresregime kann daher nicht mit den Gesetzmässigkeiten einer Fliesskultur gerechnet werden. Stark vereinfachend kann das Modell einer Batch-Kultur für kurze Zeitabschnitte herangezogen werden.

\subsection{K-Analyse zum Bezugsparameter Biomasse}

Im Rotsee ist das Frischgewicht des Phytoplanktons (= Biomasse) (Tab. 14) in der Schicht von 0 bis 2,5 $\mathrm{m}$ in hohem Masse korreliert mit dem partikulären Stickstoff und in $1 \mathrm{~m}$ und $2,5 \mathrm{~m}$ auch mit dem partikulären Phosphor. Für den partikulären Stickstoff wurde dieser Zusammenhang von Pavoni [54] für Einzelprofile beschrieben. Eine $\mathrm{K}$ zwischen dem "standing crop» und der Primärproduktion besteht nur in $0 \mathrm{~m}$ und $1 \mathrm{~m}$, wobei der $\mathrm{KK}$ in $1 \mathrm{~m}$ nur noch $+0,48$ beträgt.

Tab. 14. K-Analyse zum Bezugsparameter Biomasse, Rotsee.

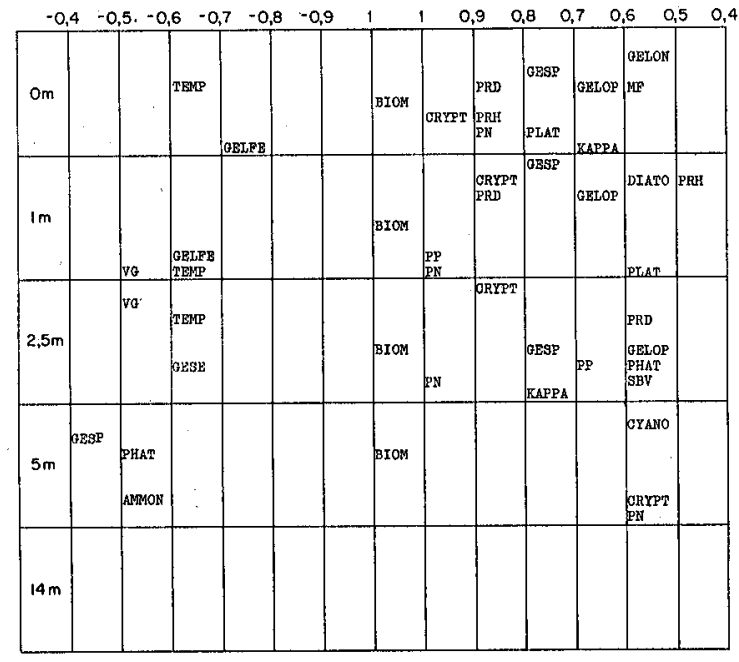

In der 0-m-Schicht besteht ein KK zu den Membranfilterbakterienzahlen, der aber kleiner ist als derjenige zur Primärproduktion. Der höchste KK findet sich mit 0,93 in $0 \mathrm{~m}$ zu den Cryptophyceen, eine Aussage dafür, dass das Phytoplankton in dieser Schicht über das Jahr wesentlich von den Cryptophyceen gestellt wird. Auf die 
Zusammenhänge zwischen Biomasse und gelösten organischen Stickstoff- und Phosphorkomponenten soll später eingegangen werden (siehe Seite 476). Interessant ist im Rotsee, dass keine negativen KK zu Phosphat und Nitrat vorliegen, hingegen ein negativer KK zu gelöstem Eisen besteht.

Die $K$-Analyse in Bezug auf Cryptophyceen (Tab. 15) ergibt ein ähnliches Bild wie für die Biomasse. Mit den Parametern partikulärer Phosphor und partikulärer Stickstoff besteht in $0 \mathrm{~m}$ ein sehr hoher KK von 0,95 bis 0,96 . Es bestätigt sich dabei für den See die von PAvoni [54] beschriebene Tatsache, dass die Wechselbeziehungen zwischen den partikulären Komponenten und der Biomasse um so klarer hervortreten, je mehr man sich einer Reinkultur nähert.

Tab. 15. K-Analyse zum Bezugsparameter Cryptophyceae, Rotsee.

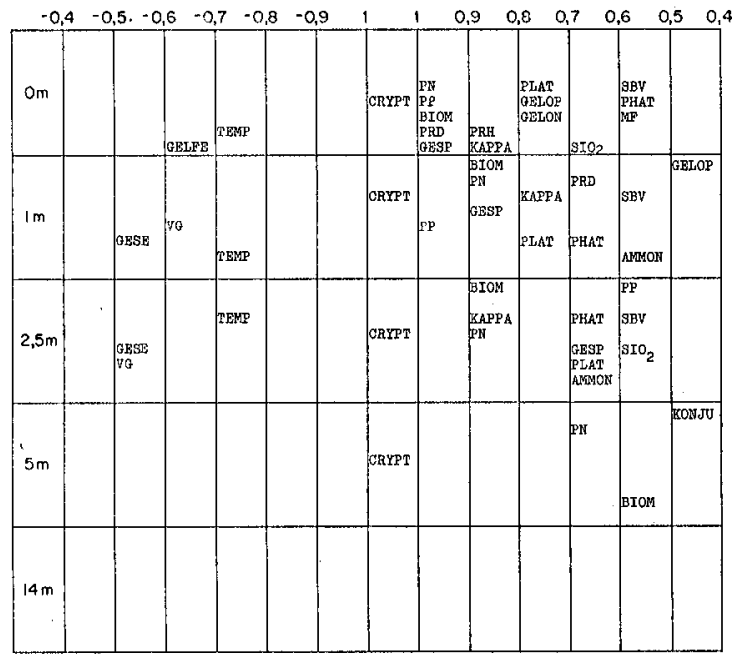

\section{Schlussfolgerungen}

Bildet man in $0 \mathrm{~m}$ eine Reihenfolge der Korrelationen (K-Wert!) bezüglich Biomasse, stellt sie sich folgendermassen dar:

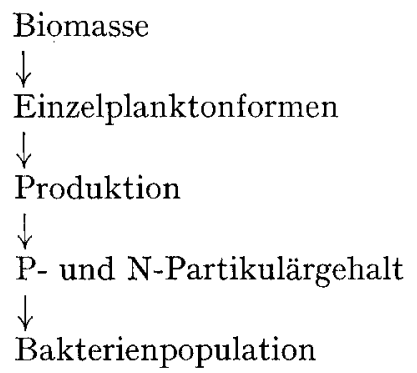

Diese mathematische Aneinanderreihung widerspiegelt direkt die oekologischen kausalen Verknüpfungen der Parameter im See. 


\subsection{Partikuläre Komponenten}

In Abb. 39 sind die Quadratmeterwerte des Phytoplanktonfrischgewichtes für die trophogene Schicht von 0 bis $5 \mathrm{~m}$ aufgezeichnet. Der maximale Wert liegt über $100 \mathrm{~g} / \mathrm{m}^{2}$.

STADELmanN [73] hat aus den partikulären Stickstoffwerten (nach Stumm [77]) den Kohlenstoffgehalt des partikulären Materials berechnet. Diese Kurve ist in die Biomasse $/ \mathrm{m}^{2}$-Kurve eingezeichnet. Es zeigt sich, dass die beiden Kurven nicht identisch sind, aber im gegenseitigen Verlauf und für einzelne spezielle Werte vergleichbar sind.

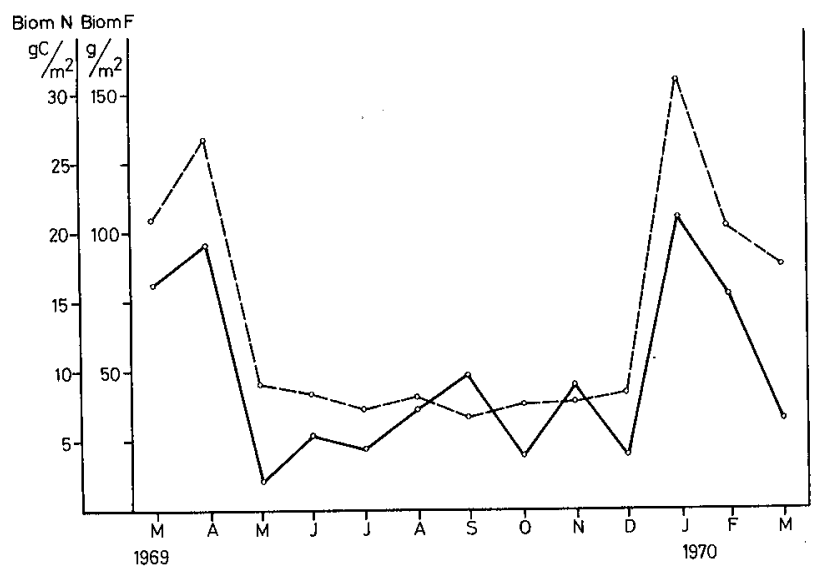

Abb. 39. Quadratmeterwerte des Phytoplanktons $(0-5 \mathrm{~m})$, Frischgewicht Phytoplankton, g/ $\mathrm{m}^{2}$ $(=$ Biom F) ( $(\longrightarrow)$; Biomasse nach STADELMANN (1971) (Berechnung aus PN), g C/m² (= Biom N) $(---)$; Rotsee.

Berechnet man aus dem Verhältnis zwischen Frischgewicht und dem Kohlenstoff (aus den PN-Werten) den prozentualen Anteil, so erhält man Prozentwerte Kohlenstoff vom Frischgewicht, die zwischen 25 und $28 \%$ liegen. Allerdings wurden nur die Cryptophyceenmaxima ausgewertet, weil für diese Gruppe auf Grund der hohen KK zwischen Biomasse und partikulärem Stickstoff Gewähr besteht, einen relativ kleinen Anteil an Detritus fehlerhaft verwendet zu haben. Nach VolLENweIDER [80] besteht eine grosse Diskrepanz in den Angaben über den Kohlenstoffgehalt des Phytoplanktons; er kann zwischen 3 und $25 \%$ schwanken. Der hohe Wert für den C-Gehalt im Phytoplanktonfrischgewicht im Rotsee kann nach Mullin et al. (aus VolLenweider [80]) mit den relativ kleinen Zellvolumina der Plankter erklärt werden.

In Abb. 40 sind die Quadratmeterwerte des partikulären Phosphors aufgetragen. Diese Kurve folgt im Prinzip derjenigen des partikulären Stickstoffs bzw. der Umrechnung auf Kohlenstoff, mit Ausnahme des Wertes im Juli, wo ein erhöhter partikulärer Phosphor in der trophogenen Schicht festgestellt wurde. Dieser dürfte einerseits auf die Anwesenheit einer grösseren Anzahl von Oocystis lacustris und die Anwesenheit des noch zu beschreibenden Chromatium densegranulatum (siehe Seite 486) in $5 \mathrm{~m}$ Tiefe zurückzuführen sein. 
Der Vollständigkeit halber wird die $K$-Analyse des partikulären Stickstoffs (Tab. 16) angeführt. In der Anordnung der Produktionsparameter zeigt sie keine wesentlichen Unterschiede zu derjenigen der Biomasse. Ein sehr hoher KK besteht zwischen partikulärem Stickstoff und partikulärem Phosphor (über 0,9 in den Tiefen von 0 bis $1 \mathrm{~m})$.

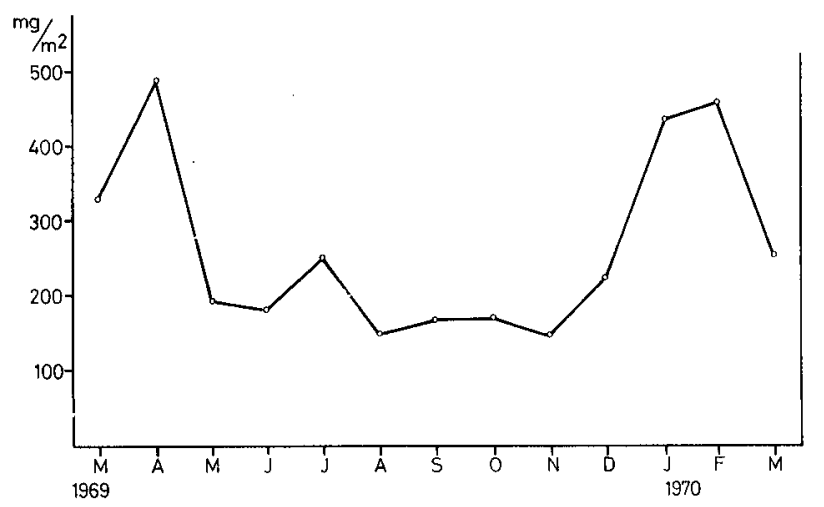

Abb. 40. Quadratmeterwerte $(0-5 \mathrm{~m})$ des partikulären Phosphors $\left(\mathrm{mg}-\mathrm{P} / \mathrm{m}^{2}\right)$, Rotsee.

Tab. 16. K-Analyse zum Bezugsparameter partikulärer Stickstoff, Rotsee.

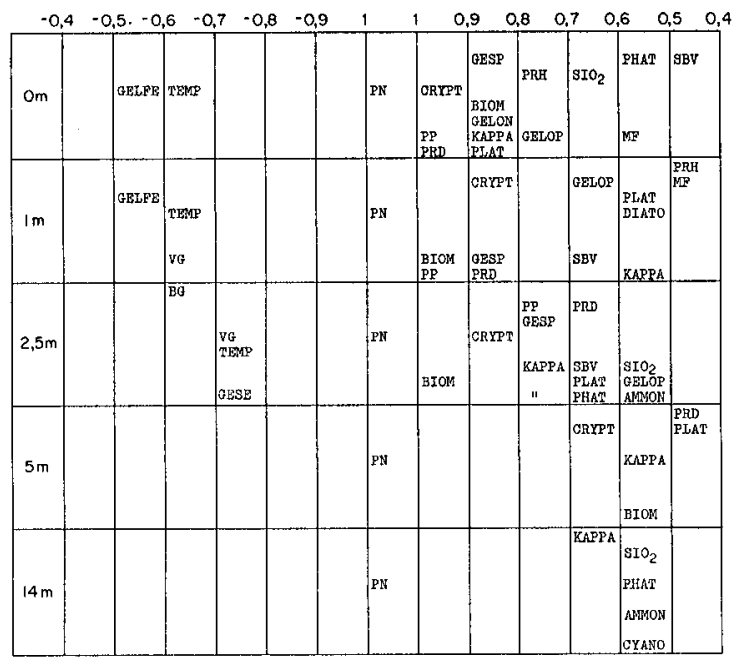

Zwischen dem partikulären Eisen (Abb. 41) und den Produktionsparametern, namentlich der Biomasse, bestehen, wie die K-Analyse in Tab. 17 demonstriert, nur äusserst spärliche Beziehungen, einzig in $0 \mathrm{~m}$ ist ein $\mathrm{KK}$ zu den Chlorophyceen festzustellen.

Im Jahresverlauf stellt man ein Verarmen der trophogenen Schicht an partikulärem Eisen fest. 


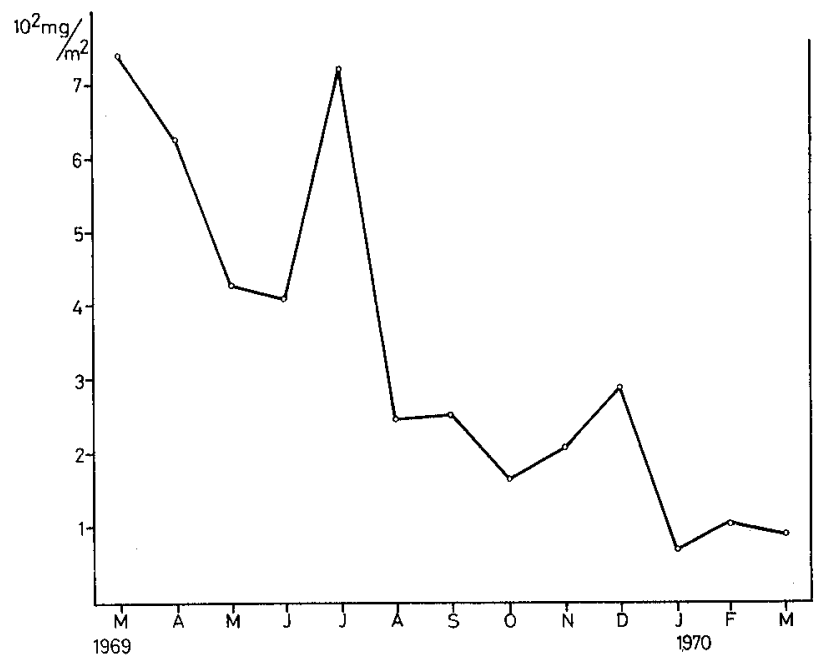

Abb, 41. Quadratmeterwerte $(0-5 \mathrm{~m})$ des partikulären Eisens (mg-Fe/m²), Rotsee.

Tab. 17. K-Analyse zum Bezugsparameter partikuläres Eisen, Rotsee.

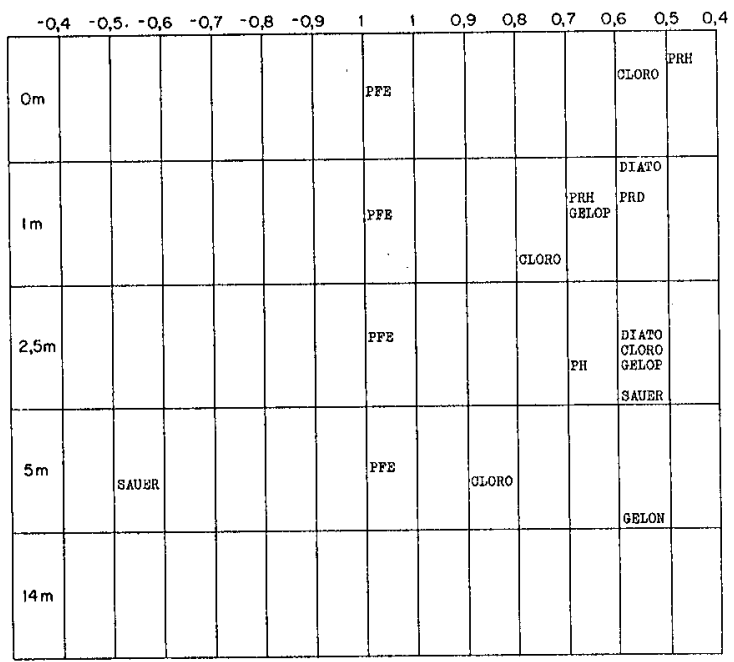

\section{Schlussfolgerungen}

Im Rotseeplankton sind die Cryptophyceen vorherrschend. Aus der Feststellung, dass im Hypolimnion praktisch keine intakten Zellen gefunden wurden, lässt sich schliessen, dass ein grosser Teil der Zellen schon im Epilimnion mineralisiert wurde.

Die Aneinanderreihung der KK bezüglich Biomasse ergibt eine ökologisch «sinnvolle» Rangordnung. 


\subsection{Phytoplankton im Vierwaldstättersee}

Gestützt auf die im letzten Kapitel gemachten Feststellungen der Aussagekraft der Bestimmung von partikulärem Stickstoff und die Tatsache, dass das Phytoplankton im Vierwaldstättersee durch STADELMANN [73] und Bloksch [8] bearbeitet wurde, sei in diesem Zusammenhang auf eine eingehendere Darstellung verzichtet.

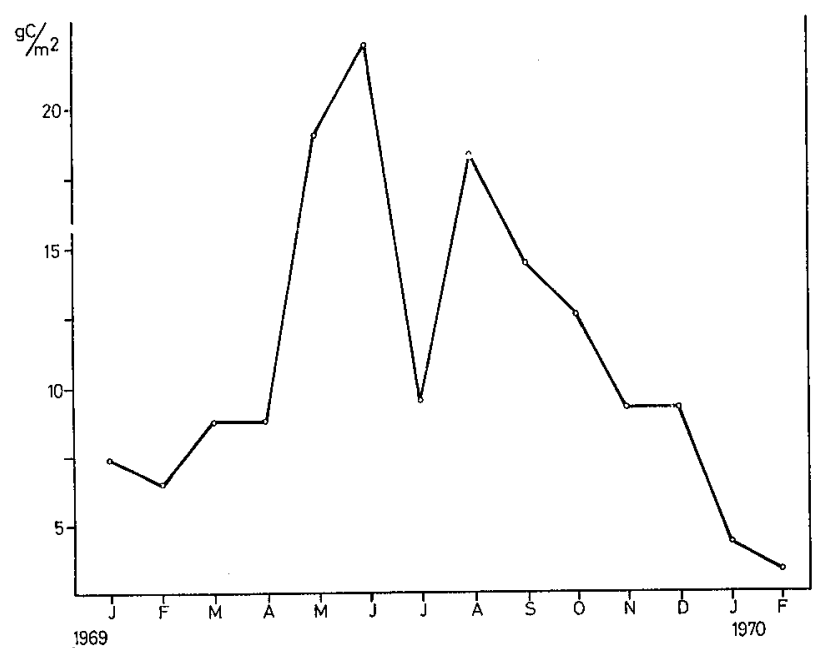

Abb. 42. Quadratmeterwerte der Phytoplanktonbiomasse nach Stadelmann (1971), gC/m², 0-15 m, Vierwaldstättersee.

Zur Orientierung über die Verhältnisse bezüglich Biomasse im Vierwaldstättersee ist in Abb. 42 die von Stadelmann [73] aus den C:N-Werten berechnete Biomassekurve in Form von $\mathrm{gC} / \mathrm{m}^{2}$ aufgezeichnet. Im Plankton vorherrschend waren die Blaualgen, und zwar beinahe über das ganze Jahr Oscillatoria rubescens und im Herbsit Pseudanabaena catenata. Unter den Diatomeen waren vor allem Flagilaria crotonensis, Tabellaria fenestrata, Cyclotella spp. und Diatoma elongatum vertreten. Fast über das ganze Jahr waren bei den Flagellaten Rhodomonas lacustris und Rhodomonas lens, Cryptomonas ovata und Cryptomonas erosa vorhanden.

\section{$K$-Analyse}

Da die Biomassewerte der Kurve, unter Berücksichtigung eines Faktors, denjenigen des partikulären Stickstoffs entsprechen, kann für die K-Analyse direkt der partikuläre Stickstoffwert (Tab, 18) verwendet werden.

Über die ganze trophogene Schicht bestehen zwischen partikulärem Stickstoff und den Nährstoffen Nitrat und Phosphat negative KK. Es zeigt sich hier deutlich die produktionsbestimmende Rolle der beiden Nährstoffe. Ein enger Zusammenhang besteht zwischen partikulärem Stickstoff und partikulärem Phosphor mit einem KK von 0,82 . Ebenso bestehen signifikante Korrelationen zwischen Primärproduktion und partikulärem Stickstoff. Auf den Zusammenhang zwischen der Biomasse und den Bakterien wird auf Seite 497 eingetreten. 
Tab. 18. K-Analyse zum Bezugsparameter partikulärer Stickstoff, Vierwaldstättersee.

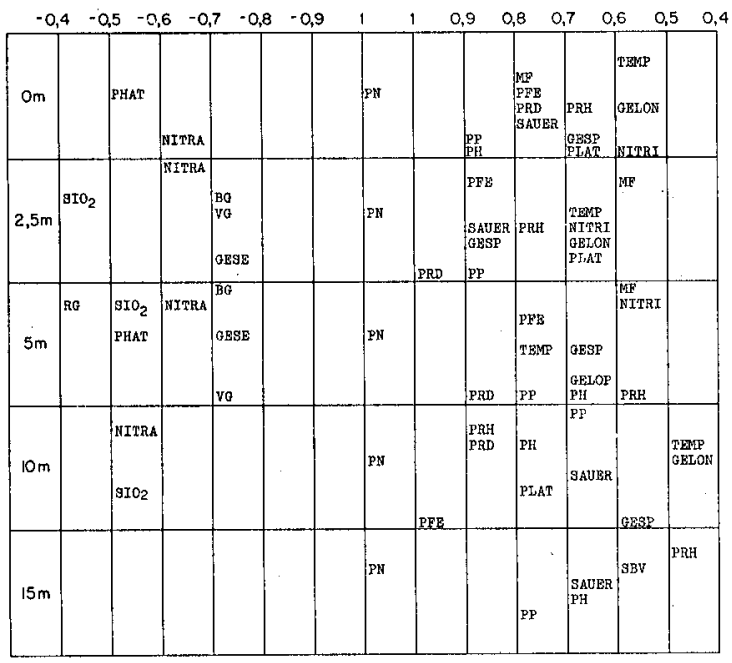

\subsection{Tagesrhythmik}

\subsection{Primärproduktionsmessung}

Jeder Berechnung einer Primärproduktion für einen bestimmten Zeitabschnitt, z.B. für die Jahresproduktion, liegt eine Umrechnung, basierend auf der stündlichen Produktion, zugrunde. Eine wesentliche Voraussetzung dafür ist die Kenntnis des Tagesverlaufs der Primärproduktion. Die beiden nachfolgend beschriebenen Untersuchungen haben nur Stichprobencharakter, dienen aber trotzdem für die untersuchten Seen der Absicherung der Berechnungen der Tages- und Jahresproduktion sowie der Beurteilung der angewandten Expositionsmethodik.

Im Rotsee (12. August 1969) und im Vierwaldstättersee (21. Mai 1969) wurden an einem Tag ohne Bewölkung Versuche «in situ et loco» zur Beantwortung folgender Fragen durchgeführt:

1. Welcher Umrechnungsfaktor ist anzuwenden, um aus einer Messung, die zwischen 10 und $14 \mathrm{Uhr}$ stattgefunden hat, auf die Tagesproduktion zu schliessen?

2. Ist die Summe der Produktion kurzzeitig aneinandergestaffelter Experimente mit derjenigen eines Langzeitexperimentes identisch?

3. Wie verläuft die Tagesproduktionskurve im Vergleich zur Lichtkurve?

\section{Methodik}

Die Entnahmetiefe betrug im Vierwaldstättersee 2,5 m, im Rotsee $1 \mathrm{~m} . \mathrm{Zu}$ Beginn des Experimentes wurden 20 Liter Seewasser in eine Flasche abgefüllt und diese während des Tages in der Entnahmetiefe gelagert. Damit war die Voraussetzung, dass während der Untersuchung eine gleichbleibende Phytoplanktonpopulation vorliegen muss, erfüllt.

Es wurden 2 Serien Flaschen gebildet. Die erste Serie wurde zu Beginn des Experimentes mit ${ }^{14} \mathrm{C}$ versetzt und exponiert. Stündlich wurden dann je 2 Flaschen entnommen und ausgewertet. Diese Expositionsart wird im folgenden als "long time» 
bezeichnet. Von der 2 . Serie wurden jede Stunde 2 Flaschen aus der 20-Liter-Flasche abgefüllt, mit ${ }^{14} \mathrm{C}$ versetzt und während einer Stunde exponiert. Diese Art wird als «short time» bezeichnet.

Mittels eines Solarimeters wurde die auf den Quadratmeter Seeoberfläche fallende Kalorienzahl bestimmt und mit Hilfe der relativen Lichtmessung (siehe Methodik) unter Berücksichtigung einer Rückstrahlung an der Seeoberfläche von 44\% die in der jeweiligen Expositionstiefe auf den Quadratmeter fallende Energie in kcal berechnet. Aus diesen Werten lässt sich der Quotient der Lichtausnützung ( $\mathrm{mg} \mathrm{C}_{\mathrm{Cix}}$ / $\mathrm{kcal} \cdot \mathrm{m})$ berechnen.

\section{Resultate}

\section{Vierwaldstättersee}

In Abb. 43 sind die aufsummierten Werte des «long-time»- und des "short-time»Experimentes aufgezeichnet. Die Tagessumme beträgt im «long-time»-Experiment $144,9 \mathrm{mgC} / \mathrm{m}^{3}$, im «short-time»-Experiment $139,7 \mathrm{mgC} / \mathrm{m}^{3}$, d. h. im Vierwaldstättersee ist die Tagessumme der "short-time»- mit der der «long-time»-Experimente innerhalb der Fehlerbreite der ${ }^{14} \mathrm{C}-$ Messung für die Tiefenstufe 2,5 m identisch. Die Streuung der angewandten Methodik beträgt 3-6\% (SCHEGG [62]).

Aus der Steigung der beiden Kurven lässt sich ersehen, dass der stündliche $\mathrm{Zu-}$ wachs im «long-time»-Experiment grossen Schwankungen unterworfen ist. Im Minimum betrug er nur $2 \mathrm{mgC} / \mathrm{m}^{3}$ zwischen 14 und 15 Uhr. Diese Erholungspause ist nach OHLE [47] auf die Hemmwirkung durch hauptsächlich extrazelluläre Anreicherung von Assimilaten und auf mangelnde Turbulenz zurückzuführen.

OHLE [47] hat experimentell bewiesen, dass die Wasserturbulenz, der "Wascheffekt", von ausschlaggebender Bedeutung ist. Beim "short-time»-Experiment treten diese Schwankungen nicht auf.

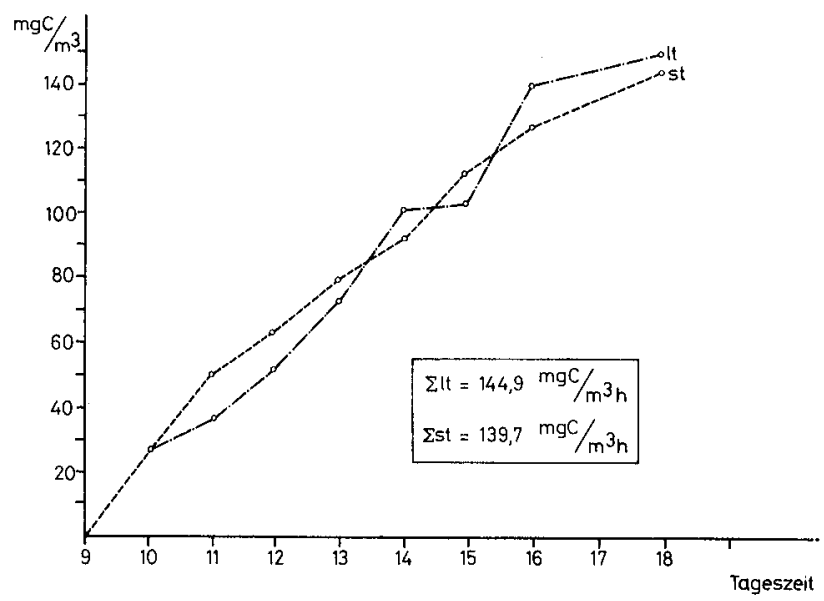

Abb. 43. Aufsummierte Produktionsraten der "short-time»-(- - ) und der "long-time»$(\ldots-\cdots-)$ Versuche im Vierwaldstättersee $\left(\mathrm{mg} \mathrm{C} / \mathrm{m}^{3}\right)$. 


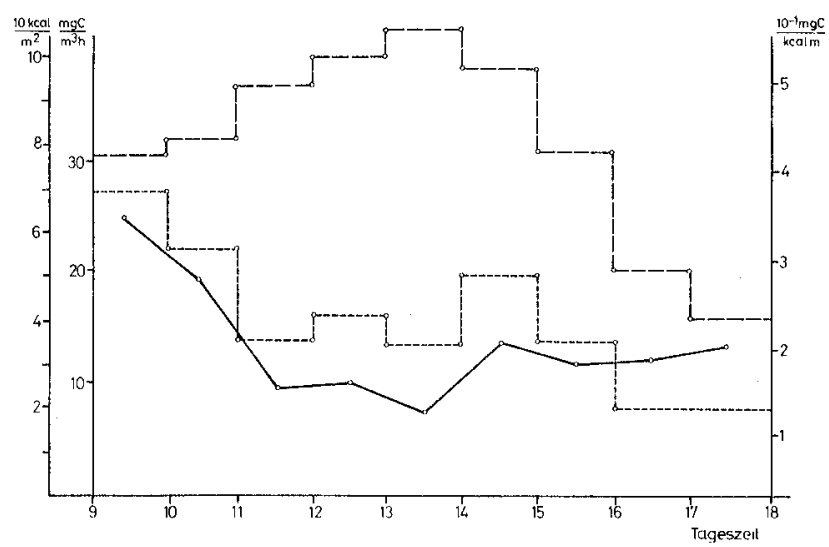

$\mathrm{Abb}$. 44. «Short-time»-Primärproduktionsmessungen (-- -), $\mathrm{mg} \mathrm{C} / \mathrm{m}^{3} \mathrm{~h}$, Einstrahlung in $2,5 \mathrm{~m}$ $(--\rightarrow)$ in $\mathrm{kcal} / \mathrm{m}^{2}$, relative Lichtausnützung $(\longrightarrow)$ in $\mathrm{mg} \mathrm{C} / \mathrm{kcal} \cdot \mathrm{m}$, Vierwaldstättersee.

In Abb. 44 sind die «short-time»-Werte der Primärproduktion gegen die vorhandene Energie aufgetragen. Ebenfalls ist der Quotient der Lichtausnützung in Kurvenform eingetragen.

Bei relativ kleiner Lichtintensität am Morgen zwischen 9 und 10 Uhr stellt sich eine überraschend hohe Primärproduktion ein mit entsprechend hohen Werten der Lichtausnützung. Bei maximaler Belichtung zwischen 13 und 14 Uhr findet sich ein Minimum der stündlichen Primärproduktion und das Minimum der Lichtausnützung. Diese Erscheinung kann mit einer Lichthemmung erklärt werden. Sie kann aber auch die Folge der physiologischen Erschöpfung des Photosyntheseapparates (OHLE [47]) sein.

$\mathrm{Zu}$ einem zweiten Maximum der Primärproduktion kommt es zwischen 14 und 15 Uhr bei abnehmender Lichtintensität in der Expositionsschicht. Gegen Abend fällt die Primärproduktion entsprechend der Erniedrigung der Lichtintensität wieder $a b$.

\section{Rotsee}

Am 12. August 1969 wurde im Rotsee die Sequenz der Probenahmen noch weiter eingeengt, indem die "short-time»-Experimente über eine halbe Stunde überlappend durchgeführt wurden. (Die Proben wurden sofort nach der Entnahme auf dem Schiff filtriert.)

Die Resultate sind in Abb. 45 zusammengestellt. Zwischen 7 und 10 Uhr erfolgt ein sehr rascher Anstieg der stündlichen Primärproduktionswerte, der zwischen 10 und $13 \mathrm{Uhr}$ in ein Plateau ausmündet.

Bei höchsten Lichtintensitäten zwischen 12 und 14 Uhr ergibt sich der schon im Vierwaldstättersee bemerkte Hemmeffekt mit einer Verringerung der stündlichen Primärproduktion um fast die Hälfte. Ebenfalls konnte wieder der Anstieg der Primärproduktion bei fallenden Lichtintensitäten am Nachmittag beobachtet werden.

Die Differenzen bei den um eine halbe Stunde verschobenen "short-time»-Experimenten zeigten, dass die Produktion innerhalb kurzer Intervalle grossen Schwankungen unterliegen kann. 


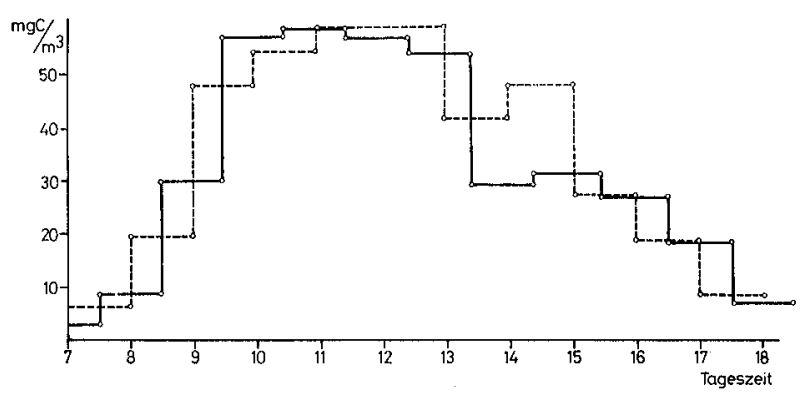

Abb. 45. Überlappende "short-time»-Experimente, $\mathrm{mg} \mathrm{C} / \mathrm{m}^{3}$, ganzstündliche Expositionen $(\rightarrow-\rightarrow)$, halbstündliche Expositionen ( - , Rotsee.

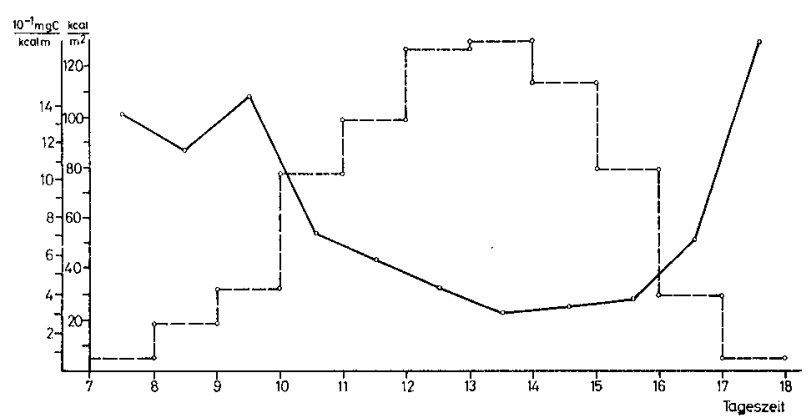

Abb. 46. Lichteinstrahlung in $1 \mathrm{~m}$ in $\mathrm{kcal} / \mathrm{m}^{2}(-\ldots-)$, Lichtausntitzung in $\mathrm{mg} \mathrm{C} / \mathrm{kcal} \cdot \mathrm{m}(--)$, Rotsee.

Vergleich der Tagessummen:

"short time»: Summe mit ganzstündlichem Beginn "short time»: Summe mit halbstündlichem Beginn «long time»: über den ganzen Tag

$388,1 \mathrm{mgC} / \mathrm{m}^{3}$

$374,6 \mathrm{mgC} / \mathrm{m}^{3}$ $384,9 \mathrm{mgC} / \mathrm{m}^{3}$

Die «short-time»-Werte (je 12) liegen unter Berücksichtigung der vielen Einzelexperimente erstaunlich nahe beieinander. Wie im Vierwaldstättersee weichen die «long-time»-Werte im stündlichen Zuwachs wesentlich von demjenigen der «shorttime »-Werte ab, die Tagessumme beider Expositionsarten ist jedoch wieder identisch.

In Abb. 46 sind die Werte der eingestrahlten Energie der Expositionstiefe aufgezeichnet. Die maximale Einstrahlung fällt zeitlich wieder mit der beobachteten Hemmung der Primärproduktion zusammen. Daraus ergibt sich die schlechteste Ausnützung des eingestrahlten Lichtes.

\section{Schlussfolgerungen}

Die eingangs gestellten Fragen können folgendermassen beantwortet werden:

1. Die Tagessumme von stündlichen Experimenten entspricht den Werten von Tagesmessungen, d.h. die Produktivität ist für dieselbe Planktonpopulation konstant. DOTY et al. [13] geben für Lang- und Kurzzeitversuche ebenfalls gleiche Tagessummen an. 
2. Es treten beträchtliche Tagesschwankungen auf, die sehr kurzfristig, d.h. in der Grösse von Minuten sein können.

3. Die Tageskurve der Primärproduktion der Kurzzeitexperimente zeigt eine Affinität zur Lichtkurve in zwei Richtungen:

a) die Abhängigkeit von der Lichtintensität bei suboptimaler Belichtung,

b) die Hemmung der Primärproduktion durch Überbelichtung. Offenbar ist die physiologisch-optimale Belichtung im Tagesverlauf nur ganz kurze Zeit vorhanden.

4. Unter Voraussetzung einer Exposition zwischen 10 und 14 Uhr liegt der Umrechnungsfaktor der stündlichen Produktion für den Vierwaldstättersee über 9. Bei Interpolation auf die Tagesproduktion der Werte zwischen 7 und 9 Uhr ergibt sich ein Wert von etwa 10 für die 2,5-m-Schicht. Dieser Faktor wurde von STADELMANN [73] zur Berechnung der Tagesproduktion für die Werte pro $\mathrm{m}^{2}$ Seeoberfläche, d.h. für das ganze Profil, verwendet.

Für den Rotsee dürfte dieser Faktor tiefer liegen; bei einer mittleren Produktion zwischen 10 und $14 \mathrm{Uhr}$ von $52,8 \mathrm{mgC} / \mathrm{m}^{3} \mathrm{~h}$ liegt er für die 1 - $\mathrm{m}$-Schicht bei 7,5-8.

Diese Werte gelten für die maximalproduktive Schicht.

5. Die in dieser Arbeit angewandte Expositionszeit von 4 Stunden stellt nicht die optimale Lösung dar, da sie am Ende der Untersuchungszeit in die Periode der Lichthemmung fällt. Nach OHLE [47] werden in diesen Perioden auch verstärkt Assimilate wieder abgegeben. Bessere Umrechnungsgrundlagen auf die Tagesproduktion liessen sich mit einer 2-3stündigen Exposition in der optimalen Zeit zwischen 10 und 12-13 Uhr unter Berücksichtigung der Lichtkurve erhalten oder durch eine Exposition über den ganzen Tag von einer Stunde nach Sonnenaufgang bis eine Stunde vor Sonnenuntergang.

\subsection{Die Primärproduktion im Rotsee}

In Abb. 47 sind die Werte der Primärproduktion in räumlicher und zeitlicher Abfolge dargestellt. Auf eine eigentliche Isopletendarstellung wurde in Berücksichtigung des Stichprobencharakters der Einzelmessung verzichtet. Die in der Tabelle eingetragenen Zahlen sind die in der Hellflasche gemessenen Werte. Bewusst wurde auf eine Differenzbildung zu den Dunkelwerten verzichtet, weil jeder Einbau von C-Atomen in organische Substanz zu einer Erhöhung derselben beiträgt.

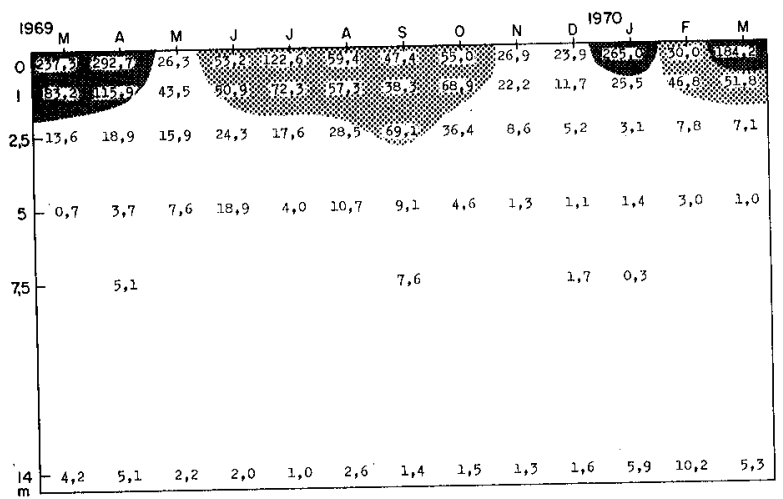

Abb. 47. Primärproduktionsraten (Hellwerte), $\mathrm{mg} \mathrm{C}_{\mathrm{ass}} / \mathrm{m}^{3} \mathrm{~h}$ im Rotsee. 
Die oberste Schicht von 0 bis $2,5 \mathrm{~m}$ ist Träger der physiologisch «hochaktiven» Planktonpopulation. In ihr wird der grössteTeil der Phytoplanktonbiomasse aufgebaut. Die Hauptvegetationszeiten fallen in den frühen Frühling und in kleinerem Masse auf die Sommermonate. Im Januar 1970 finden sich extreme Maxima unter dem Eis. Sie weisen aber eine sehr kleine Tiefenausdehnung auf.

Die Korrelationsanalyse (Tab. 19) zeigt hohe KK zur Biomasse, zu den Dunkelwerten (siehe Appendix), zu den PP- und PN-Werten. Auf die Beziehung zu den Bakterien wird auf Seite 492 eingetreten. Eine negative K zu Phosphat und Nitrat besteht nur in der Schicht 2,5 m, wo auch eine negative $\mathrm{K}$ zu Ammonium beobachtet wird. Daneben lässt sich ein KK von 0,52 zu gelöstem Eisen feststellen.

Tab. 19. K-Analyse zum Bezugsparameter Primärproduktion (Hellwerte), Rotsee.
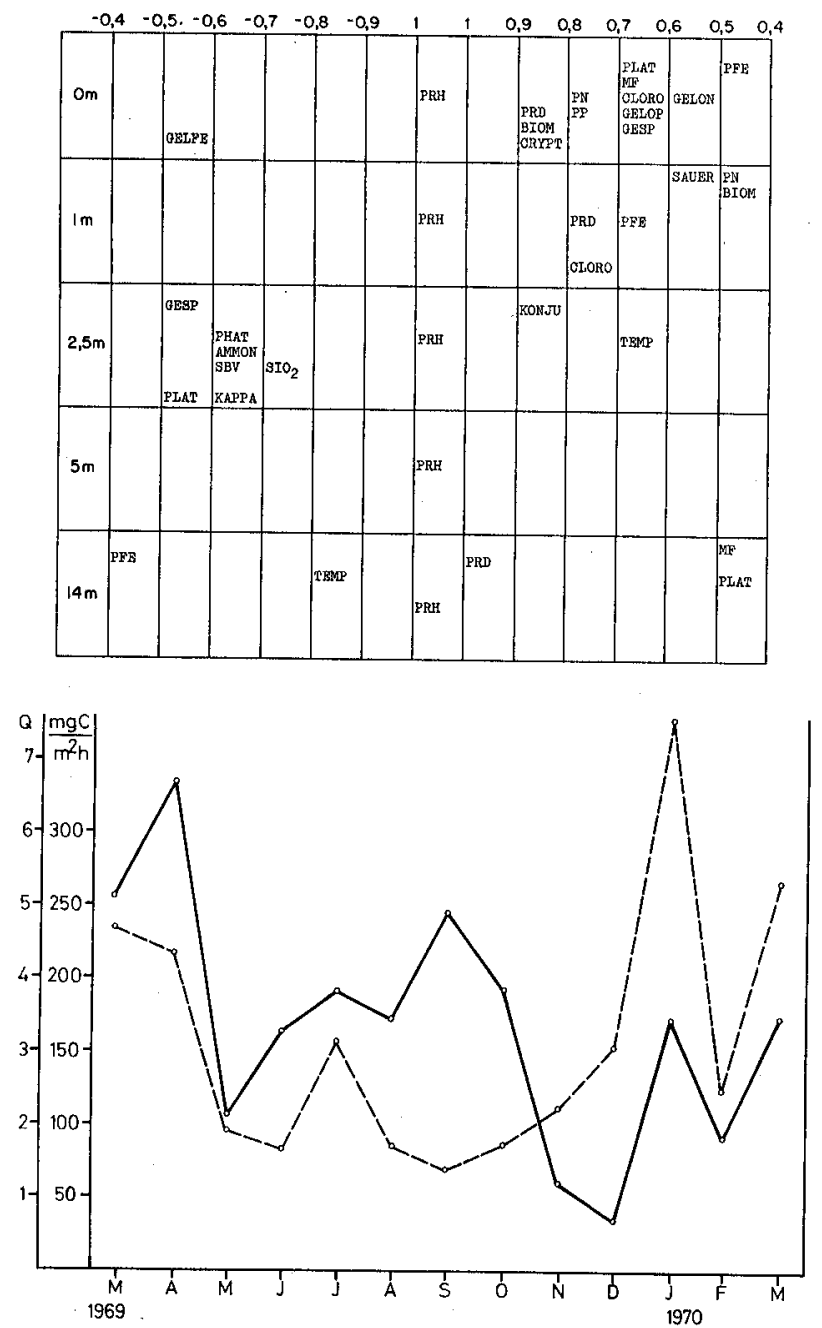

Abb. 48. Quadratmeterwerte der Primärproduktion $(0-5 \mathrm{~m}) \mathrm{mg} \mathrm{C}_{\text {ass }} / \mathrm{m}^{2} \mathrm{~h}$ ( - - , Quotient Maximalwert durch Mittelwert (- - -), Rotsee. 
In Abb. 48 sind die Assimilationsleistungen unter $1 \mathrm{~m}^{2}$ Seeoberfläche aufgezeichnet (Berechnung mit Programm «Profil»). Sie zeigen eine ausgeprägte Spitze im Frühjahr 1969, eine kleinere Sommerspitze 1969 und eine weitere Spitze im Januar 1970. Der Quotient von Maximalwert zu Mittelwert, der ein Mass für den Verlauf der Kurve darstellt, erreicht im Januar 1970 einen Wert von 7,6, d.h. dass die hauptproduktive Schicht eine geringe Mächtigkeit aufweist. Dieser Quotient eignet sich bei eingipfligen Kurven gut zu der von FindENEGG [16] vorgeschlagenen Seencharakterisierung mit der vertikalen Verteilung der Primärproduktion.

\subsection{Die Primärproduktion im Vierwaldstättersee}

Abb. 49 zeigt das Raum-Zeit-Diagramm der Primärproduktionshellwerte im Vierwaldstättersee. Auf ein ausgeprägtes Frühjahrsmaximum folgen ein Minimum im Juni und Juli 1969 und ein weiteres Spätsommermaximum. Die Schicht höchster Produktion liegt meistens bei 2,5 m Tiefe. Ein einzelner hoher Wert im August 1969 in $10 \mathrm{~m}$ Tiefe von $34,8 \mathrm{mgC} / \mathrm{m}^{3} \mathrm{~h}$ konnte auf die Anwesenheit einer Einschichtung von Oscillatoria rubescens zurückgeführt werden.

Die Primärproduktionswerte liegen höher als die von GÄCHTER [19] mitgeteilten. Die Meßstelle der vorliegenden Untersuchung ist allerdings um einige hundert Meter in die Bucht hinein verschoben. Es ist auch möglich, dass diese Erhöhung nicht ausschliesslich auf eine erhöhte Abwasserbelastung, sondern auf eine tiefergreifendere Zirkulation zurückzuführen ist. Dass diese Durchmischungstiefen im Vierwaldstättersee grossen Schwankungen unterliegen, hat АмвüHL [4] gezeigt.

GERLETTI [20] hat festgestellt, dass im tiefen Lago Maggiore die jeweilige Vollzirkulationstiefe eine wichtige Rolle für die Produktion im nächsten Jahr spielt.

Für direkte Schlüsse auf die trophische Entwicklung müsste eine längere Zeitperiode berücksichtigt werden.

Die $K$-Analyse (Tab. 20) zeigt eine sehr enge Verknüpfung mit den Produktionsparametern, namentlich einen hohen KK zur Temperatur, der anzeigt, dass im Vierwaldstättersee die Temperatur eine wesentliche Rolle bei der Primärproduktion spielt. Negative KK liegen zu Nitrat in $0 \mathrm{~m}$ und zu Phosphat in allen Tiefen bis $5 \mathrm{~m}$ vor. Die Primärproduktion (Hellwerte) ist immer mit der Primärproduktion Dunkel korreliert bis zu $10 \mathrm{~m}$ Tiefe.

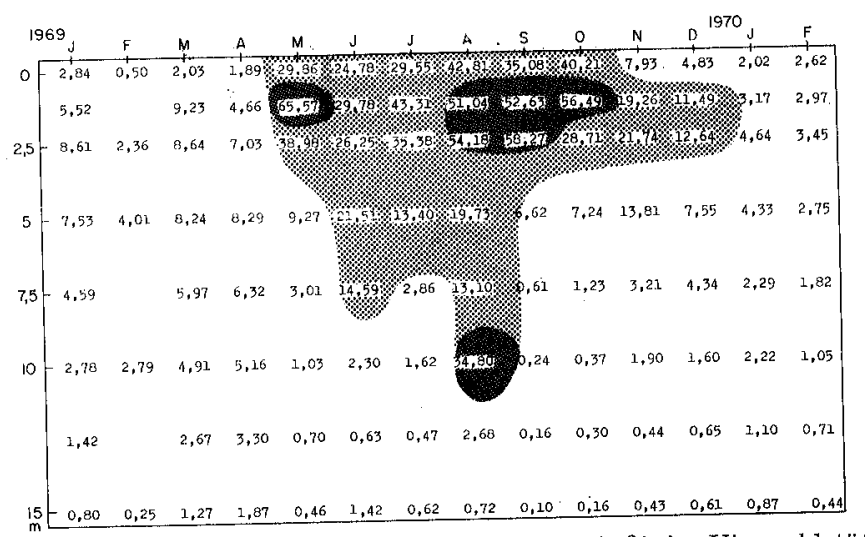

Abb. 49. Primärproduktionsraten (Hellwerte) $\mathrm{mg} \mathrm{C}_{\text {ass }} / \mathrm{m}^{3} \mathrm{~h}$ im Vierwaldstättersee. 


\section{Produktion in Beziehung zur Destruktion}

Unter Mineralisation versteht man den Abbau energiereicher chemischer Verbindungen in energieärmere. Dieser Abbau kann rein chemisch oder mit Hilfe von Organismen (Destruktion) erfolgen. Bei der Destruktion wird ein Teil wieder im Baustoffwechsel zu sekundärer Biomasse heterotropher Organismen aufgebaut. Die sekundäre Biomasse ist in der Regel kleiner als die autotroph gebildete Biomasse. Dies lässt sich in wenig belasteten Seen deutlich erkennen (PAvoni [54]).

Die heterotrophe Biomasseproduktion kann erst dann die autotrophe überwiegen, wenn grössere Mengen assimilierbaren Substrates allochthonen Ursprungs oder aus Rückführungen vom Bodensediment vorhanden sind. Ein solches Beispiel beschrieben Kuznezov und Romanenko [37] für den Rybinsk-Stausee.

In der Produktionsbiologie von Seen kann man nur dann Zusammenhänge erkennen und Wertungen setzen, wenn der Energiefluss nicht nur bis zum aufgebauten Organismus (mit energiereichen chemischen Verbindungen), sondern bis zur Remineralisation und zum Aufbau von sekundärer heterotropher Biomasse verfolgt wird. Es genügt daher nicht, nur die Folgeerscheinungen dieser Vorgänge wie Sauerstoffdefizite, $\mathrm{CO}_{2}$-Akkumulierung usw. festzustellen.

Die energetische Grundlage (Substrat) für heterotrophes Wachstum sind organische energiereiche Verbindungen. Diese können in einem See in partikulärer Form als «standing crop» und Detritus, oder in gelöster Form als Exkretions- oder Autolyseprodukte vorliegen. Gelöste Substrate stehen für die planktische Bakterienflora als Substrate im Vordergrund.

\subsection{Exkretion und Autolyse des Phytoplanktons}

Der Herkunft organisch gelöster Komponenten und ihrer ökologischen Bedeutung sind schon viele Untersuchungen gewidmet worden (FogG et al. [18], Provasoli [57], Hellebust [25], Nalewajko [43] und Hoon [29]). Nach FogG et al. [18] exkretie-

Tab. 20. K-Analyse zum Bezugsparameter Primärproduktionshellwerte, Vierwaldstättersee.

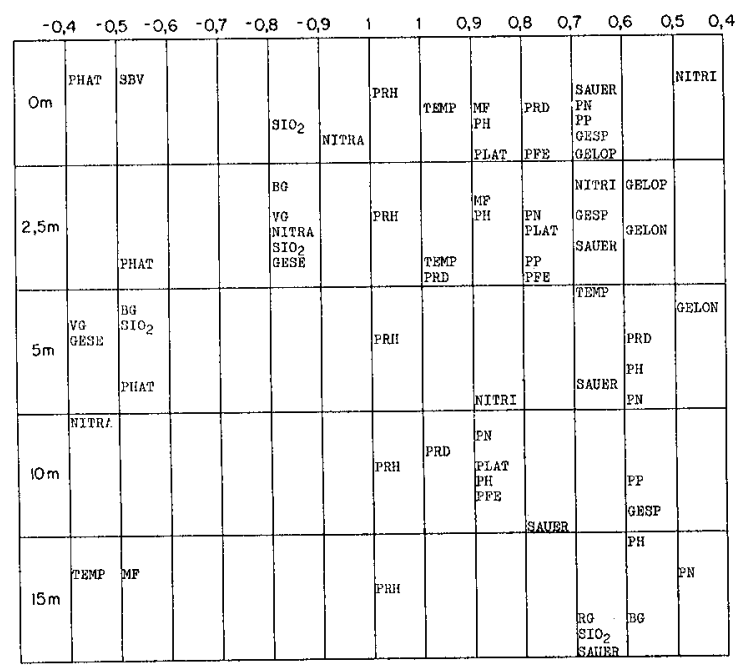


ren Plankter organische Säuren, die für Bakterien leicht assimilierbar sind. Für Exkretionsprodukte wie Glukose und Acetat wurde von HoBBIE und WRIGHT [27] nachgewiesen, dass die Aufnahmegeschwindigkeiten sehr gross sind. Tatsächlich können in einem Gewässer, wie Allan [1] und Weinmann · [82] feststellten, nur äusserst geringe Zuckermengen, z.B. Glukose, nachgewiesen werden. Für Aminosäuren hat GockE [21] an bakterienhaltigen und bakterienfreien Kulturen von Scenedesmus quadricauda experimentell nachgewiesen, dass in der bakterienhaltigen Kultur bedeutend kleinere Mengen an freien Aminosäuren akkumuliert werden, so dass auch diese in relativ kleinen Konzentrationen auftreten. Daneben gibt es aber auch schwerer angreifbare Verbindungen, hauptsächlich Huminsäuren.

Im Zusammenhang mit den Phosphor- und Stickstoffpartikuläranalysen (STADELMANN [73]) wurden auch deren gelöste organische Komponenten bestimmt.

Die Bestimmung gelöster organischer Stoffe im Seewasser bietet in methodischer Hinsicht einige Schwierigkeiten. Es ist möglich, dass die relativ hohen Werte zum Teil durch Platzen von Zellen bei der Filtration entstanden sind. Dieser Verdacht liegt insbesondere nahe bei der Untersuchung im Januar 1970 im Rotsee, wo etwa 1700 $\mu \mathrm{g} / \mathrm{l}$ gefunden wurden. Die Planktonpopulation bestand zu dieser Zeit vor allem aus Flagellaten, Rhodomonas und Cryptomonas, die für druckempfindliche Zellwände bekannt sind (VoLLENwEIDER [80]). Ein direkter Nachweis von Verlusten wurde mit

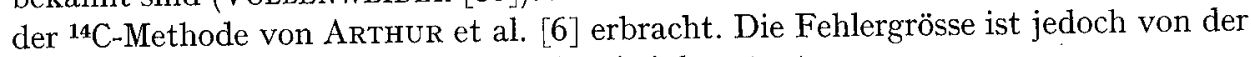
Art der Plankter abhängig, dadurch ist sie inkonstant.

In Abb. 50 und 51 sind die gelösten organischen Stickstoffverbindungen im RaumZeit-Diagramm für die beiden Seen dargestellt.

Nach STADELMANN [73] überwiegt in der Horwer Bucht der partikuläre organische Stickstoff mit Ausnahme in den Wintermonaten den gelösten organischen Stickstoff pro $1 \mathrm{~m}^{2}$ Seeoberfläche. Im Rotsee überwiegt entsprechend der Produktionszahlen im Januar bis im April 1969 und 1970 der partikuläre Stickstoff und in den uibrigen Monaten der organisch gelöste Stickstoff. In beiden Seen ist aber der Wert der besprochenen Komponenten in derselben Grössenordnung.

\section{Diskussion}

Bei Absenz von Mineralisation und Wiederaufbau müsste die gelöste organische Substanz die Aufsummierung aller Exkretions- und Autolyseprodukte während der Stagnation darstellen. Nach OHLE [48] und Messungen von BLOESCH (mündliche Mitteilung) kann von der vorhandenen Primärproduktion nur ein kleinerer Teil im Sediment aufgefangen werden. Wenn in einem See eine grosse Biomasse mit entsprechend grosser Exkretions- und Autolyseleistung vorhanden ist und nur kleine Sedimentationsraten und relativ kleine Werte organisch gelöster Substanz festgestellt werden, können diese Verhältnisse nur in der Weise verstanden werden, dass organische Substanz, die frei wird, ausserordentlich rasch mineralisiert und rezirkuliert wird (NALEWAJKo [43]).

Wenn man die teilweise hohen Exkretionsleistungen der Algen in der Schicht höchster Produktion berücksichtigt, so müssten auch die gelösten organischen Komponenten (gelöst organisch N und $\mathrm{P}$ ) wesentlich höhere Unterschiede in der Vertikalverteilung zeigen. Dies ist nicht der Fall und stellt daher einen weiteren Hinweis für die Leistungsfähigkeit der Bakterienpopulation in der trophogenen Schicht dar. 


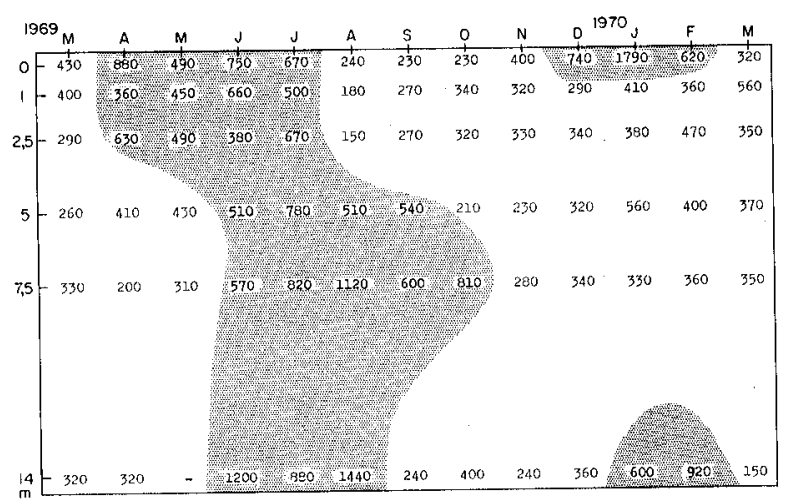

Abb. 50. Gelöster organischer Stickstoff, $\mu \mathrm{g} \mathrm{N} / \mathrm{l}$ im Rotsee.

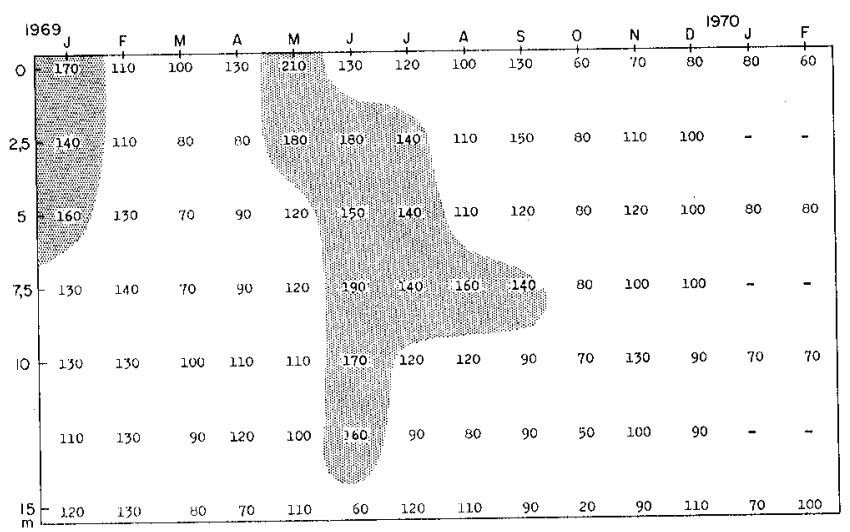

Abb. 51. Gelöster organischer Stickstoff, $\mu \mathrm{g}$ N/1 im Vierwaldstättersee.

Auf den ersten Blick ist es enttäuschend, dass vergleichsweise zu den Bakterienzahlen, insbesondere den Membranfilterzahlen, in beiden Seen keine KK im Jahreszyklus bestehen. Bezüglich Plattenzahlen besteht im Rotsee ein relativ niedriger $\mathrm{KK}$ von $0,58 \mathrm{zu}$ gelöstem organischem Stickstoff. Es gibt allerdings einige Ausnahmen, so z. B. im Oktober 1969, als bei hohen Membranfilterzahlen minimale Zahlen gelösten organischen Stickstoffs vorhanden waren.

Eine ähnliche Diskrepanz zwischen gelöstem organischem Stickstoff und dessen Verwertung durch Bakterien findet sich im marinen Bereich, wo im Durchschnitt $1 \mathrm{mgC} / 1$ gelöst vorliegen (KALLE [33]). Für das Epilimnion im Süsswasser können diese relativ hohen gelösten organischen Substratwerte folgendermassen erklärt werden:

Nach Weinmann [82] liegt der grösste Anteil der gelösten organischen Substanz höher molekular, vornehmlich als Huminsäuren vor, die nicht direkt von Bakterien angreifbar sind. Es besteht im See ein gewisses Niveau der organischen Substanz, das für die bakterielle Mineralisation schwer verwertbar ist. Die relativ hohen Werte 
gelöster organischer Substanz sind demnach die «aufsummierten» schwerer angreifbaren organischen Verbindungen.

Die Bakterienpopulation bezieht ihr Substrat vornehmlich aus frischer organischer Substanz, d.h. aus Substanz, die unmittelbar durch Autolyse und Exkretion frei wird. Erst wenn diese nur noch in kleineren Mengen anfällt, wird auf das vorhandene organisch gelöste Niveau zurückgegriffen.

\subsection{Morphologie der Bakterien des freien Wassers}

Es hiesse Ursache und Wirkung vertauschen, wollte man die mikrobiologischen Vorgänge in einem See nur auf Grund chemischer Messungen interpretieren. Voraussetzung zum Verständnis dynamischer Zusammenhänge ist die Kenntnis der Organismen, die Veränderungen des Chemismus des Biotops weitgehend mitbestimmen. Neben der Bakterienbiomasse ist auch das morphologische Erscheinungsbild eine «Antwort» der Bakterienflora auf die Substratverhältnisse.

\subsection{Planktische Bakterien}

Das Wasser ist als natürlicher Standort der Mikroorganismen für deren Nährstoffbedürfnisse unteroptimal. Die charakteristische Form der allochthonen heterotrophen Mikroflora liegt physiologisch in "Wartestellung» oder wie Waksman (aus JANNASCH [32]) definierte, als "waiting cells» vor. Diese latent vorhandenen, sozusagen auf "Sparflamme" metabolisierenden Bakterien werden nach Winogradsky (aus JANNASCH [32]) auch als "zymogen» bezeichnet.

Die Gesamtheit der Population weist eine ungeheuer grosse ökologische Valenz auf, d.h. aus einer Vielzahl von physiologischen Gruppen wird diejenige mobilisiert, die die dem Nährstoffangebot entsprechende enzymatische Ausrüstung besitzt. Es handelt sich dabei um eine von WuHRMANN [83] als «soziologische Adaptation» bezeichnete Erscheinung. Der Begriff «Adaptation» ist dabei bezüglich der Biozönose als Gesamtheit zu verstehen.

Der grösste Teil der aquatischen Bakterien kommt freischwimmend vor. Das Erscheinungsbild kann je nach Nährstoffangebot stark variieren.

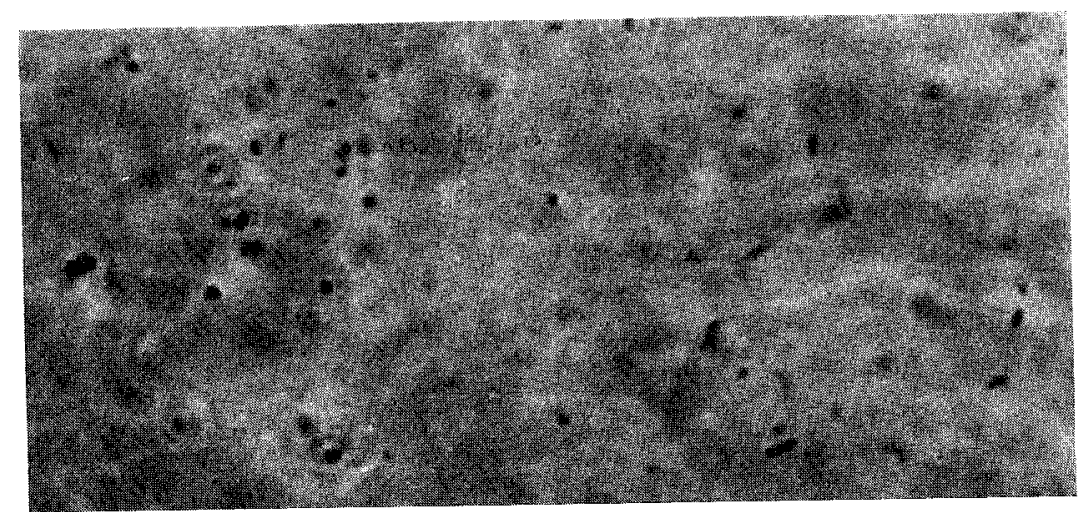

Abb. 52. Kokken und kurze Stäbchenformen auf Membranfilterpräparat (2,5 m Tiefe) aus dem Vierwaldstättersee (Vergrösserung etwa $1800 \times$, Phasenkontrast). 
Die zymogenen Keime sind durchwegs klein, in der Grössenordnung von 0,3 bis $1 \mu$. Besondere Schwierigkeiten bereitet die Erkennbarkeit der «zymogenen» Keime in nährstoffarmen Gewässern. In Abb. 52 ist ein Membranfilterpräparat mit zymogenen Bakterien aus dem Vierwaldstättersee dargestellt.

Zur Verifizierung dieser sehr kleinen Formen wurde eine Probe aus dem Vierwaldstättersee vom April 1967 unter dem Elektronenmikroskop untersucht. Das Seewasser wurde dabei mit 5 prozentigem Formol fixiert, mit membranfiltriertem $(0,1 \mu)$ Wasser 10fach verdünnt und $0,02 \mathrm{ml}$ auf einem Formvardfilm im Wasserstrahlvakuum eingedampft. Das Übersichtsbild aus dem Elektronenmikroskop (Abb. 53) lässt erkennen, dass die vorliegenden Partikeln gleich gross wie die auf den Membranfiltern ausgezählten Partikeln sind. Bei 18000facher Vergrösserung (Abb. 54) erkennt man Bakterien mit einer scharf abgegrenzten Zellwand und einem leicht geschrumpften Plasmakörper. Die Grösse der Partikeln liegt bei $0,3-0,4 \mu$.

Elektronenmikroskopische Untersuchungen sollten Bestandteil einer ausgedehnten morphologischen Abklärung der Veränderlichkeit allochthoner Bakterienflora im Vorfluter sein. Solche Untersuchungen über gestielte Bakterien wurden von HIRSCH [26] durchgeführt.

Ein wesentlich anderes Bild fanden wir im Rotsee, wo eine viel höhere Bakteriendichte aufgefunden wurde als im Vierwaldstättersee (siehe Seite 491). Die Einzelzellen sind entsprechend der höheren Substratkonzentration grösser und daher auch leichter erkennbar.

Als Beispiel wird in Abb. 55 eine Lebendaufnahme der Population vom 17. Januar 1970 aus $0 \mathrm{~m}$ angeführt. Im Vergleich zur Planktondichte ist die Bakterienzahl ausserordentlich hoch. Wir sehen hier, wie schwierig die Formen zu erkennen sind, weil nur der kleinste Teil der Bakterien in einer Bildebene liegt.

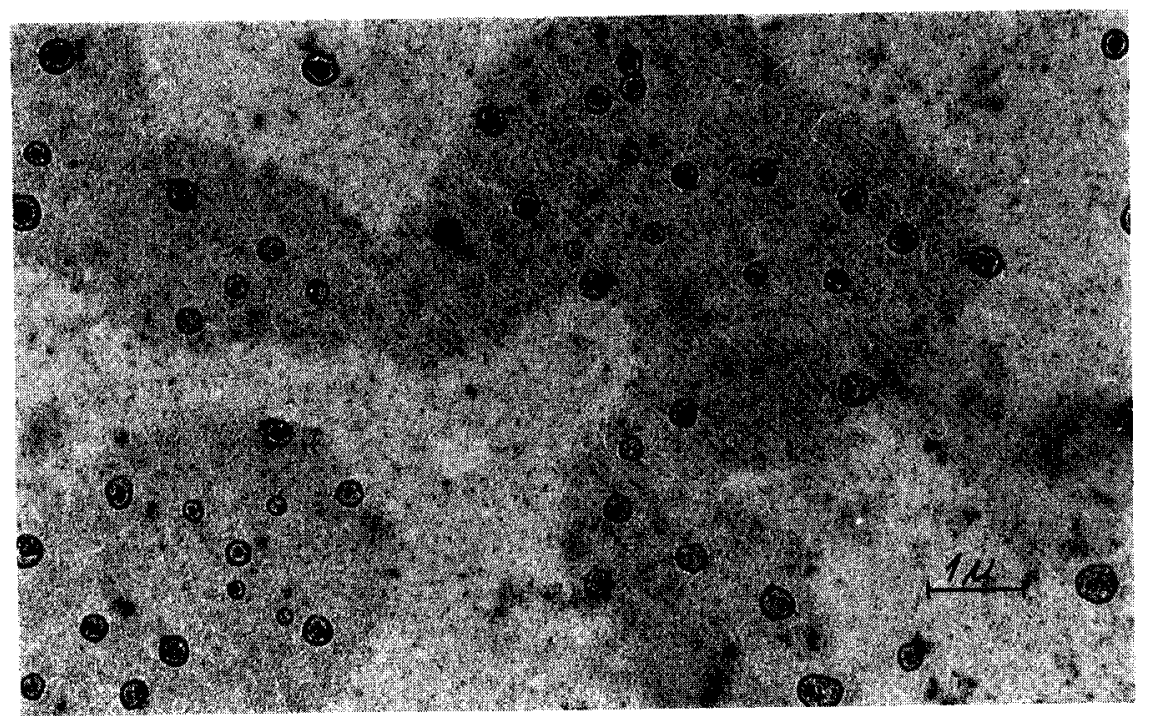

Abb. 53. Zymogene Keime (elektronenmikroskopische Aufnahme, Ubersichtsbild), Vierwaldstättersee, $0 \mathrm{~m}$ Tiefe (Vergrösserung etwa $3000 \times$ ). 


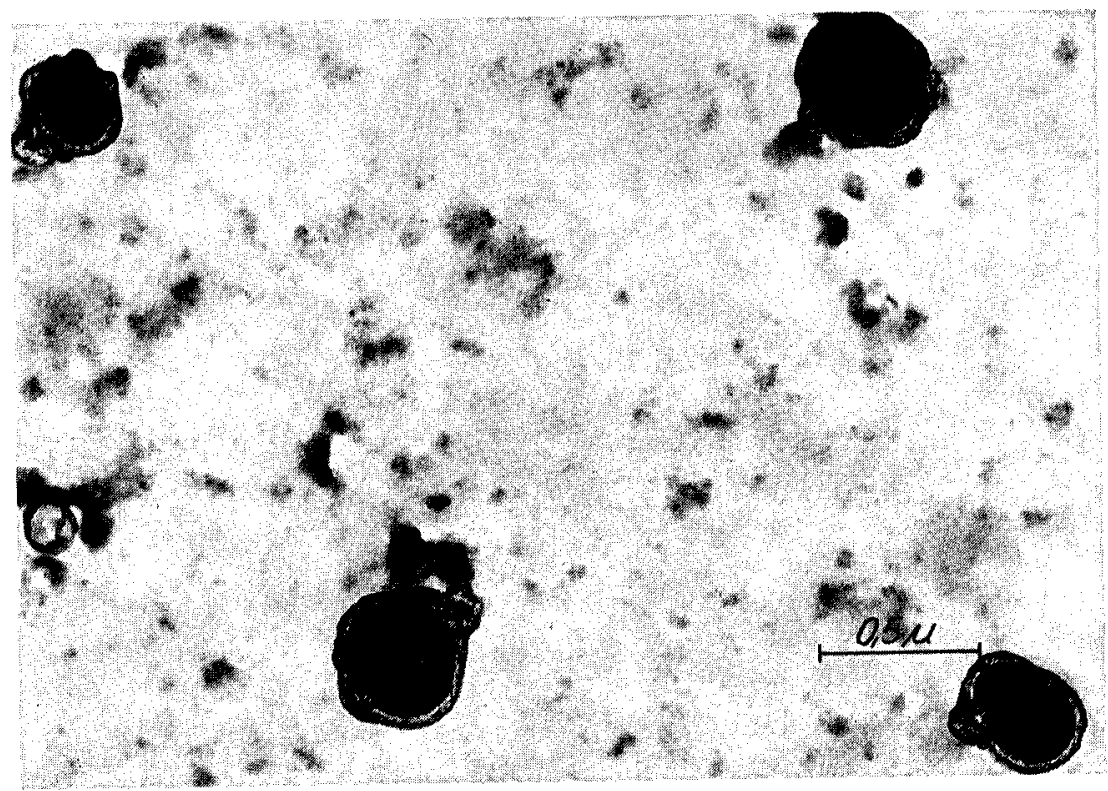

Abb. 54. Zymogene Keime: Kokkenformen $(0,3 \mu)$, Vierwaldstättersee, $0 \mathrm{~m}$ Tiefe (elektronenmikroskopische Aufnahme, Vergrösserung etwa $18000 \times$ ).

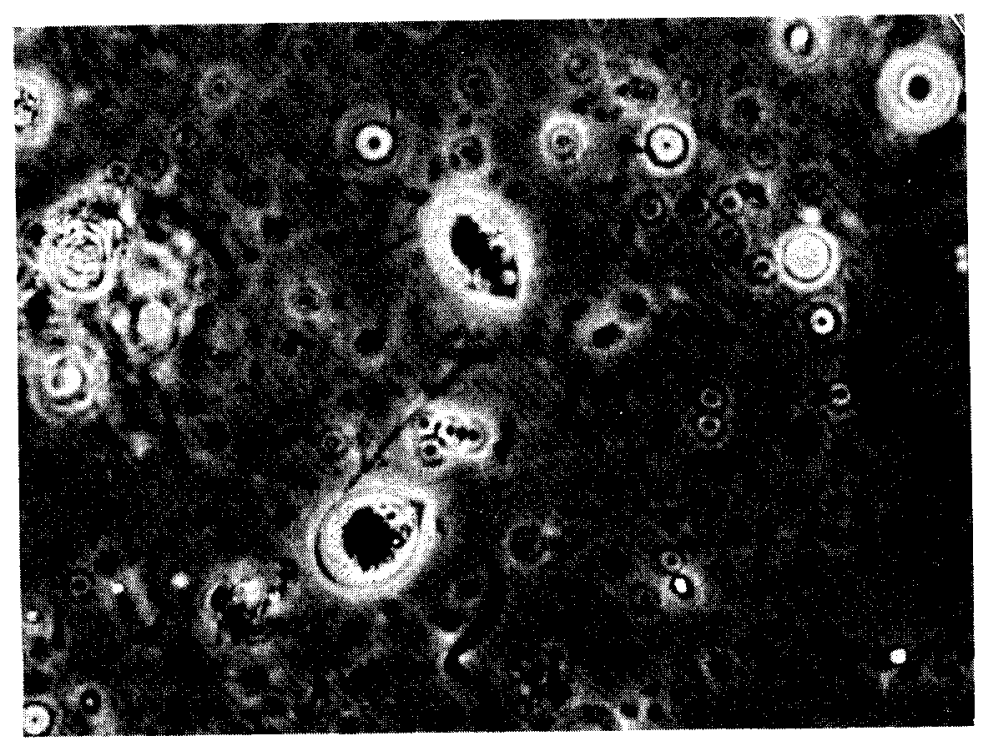

Abb. 55. Lebendaufnahme (normale Wasserprobe): Die beiden planktischen Flagellaten sind Chlamydomonas sp. (20 $\mu$ Länge). Grösse der Bakterien 1-2 $\mu$. 17. 1. 70, $0 \mathrm{~m}$ Tiefe, Rotsee (Vergrösserung etwa $800 \times$, Phasenkontrast). 
Im Rotsee traten sehr oft fädige, ausserordentlich dünne Bakterien (Durchmesser $0,1-0,2 \mu$ ) auf; gleichzeitig fanden sich kleine Anhäufungen von Spirillen (Abb. 56). Im Epilimnion des Rotsees können aber auch grössere Spirillen vorkommen (Abb. 57). Die sehr langen dünnen Formen sind auch im Hypolimnion vertreten, wo die bakterielle Besiedelung ausserordentlich hohe Werte erreicht (Abb. 58).

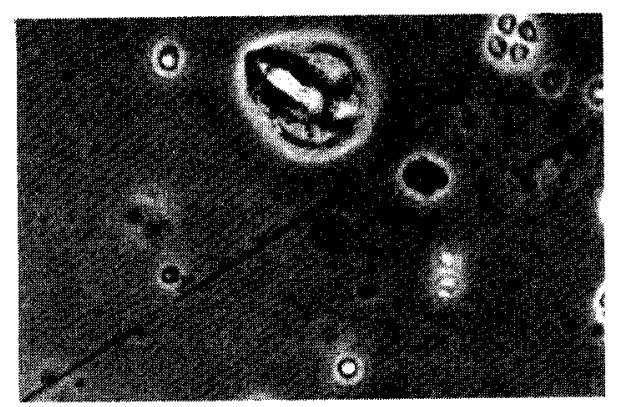

Abb.56: Lebendaufnahme: Fädiges Bakterium (1). (Länge bis über $50 \mu$, Durchmesser $0,1-0,2 \mu$ ). Rechts davon sind Spirillenformen (2) von sehr grosser Schraubenbreite zu erkennen. April1969, 2,5 m Tiefe, Rotsee (Vergrösserung etwa $800 \times$, Phasenkontrast).

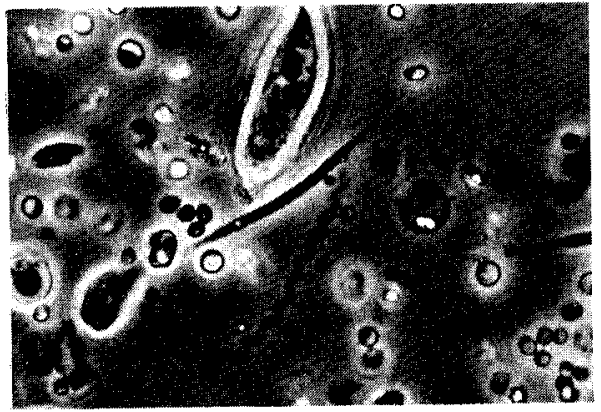

Abb. 57. Lebendaufnahme: Spirillenformen (1) aus dem Epilimnion. April 1969, $0 \mathrm{~m}$ Tiefe, Rotsee (Vergrösserung etwa 1250x, Phasenkontrast).

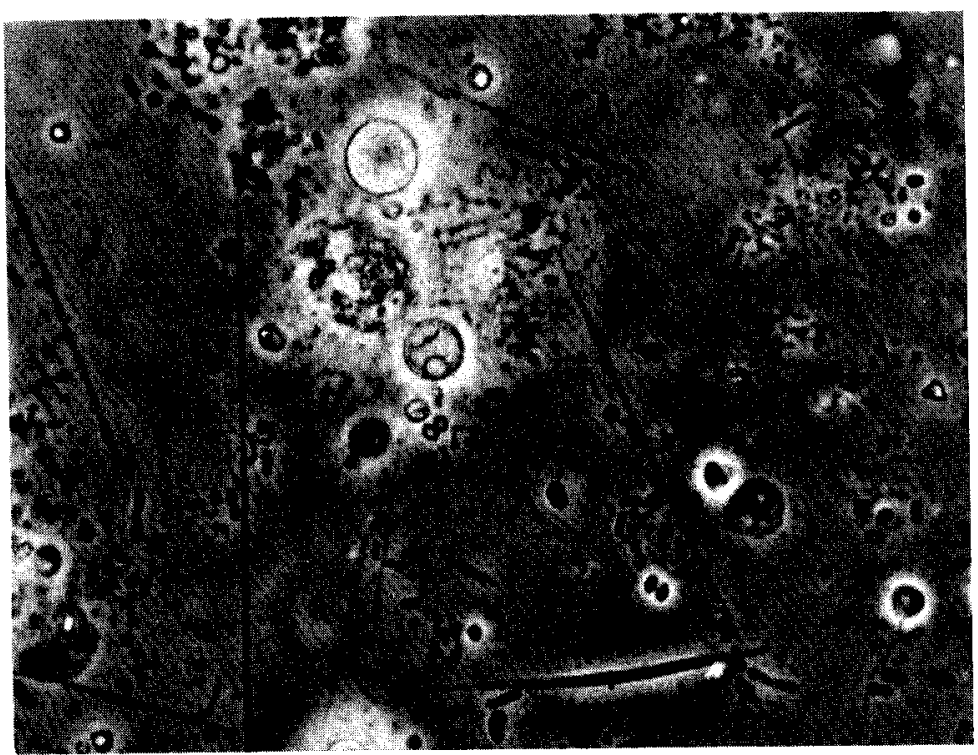

Abb. 58. Lebendaufnahme: Bakterien aus dem Hypolimnion (14 m Tiefe). April 1969, $14 \mathrm{~m}$ Tiefe, Rotsee (Vergrösserung etwa $1000 \times$, Phasenkontrast). 


\subsection{Aufwuchsformen}

Unter Aufwuchsformen werden Verbände verstanden, die im Innern grössere organische oder anorganische Partikel erkennen lassen. Ihr Vorkommen kann standortbedingt sein. In Seen mit kleineren Substratkonzentrationen entstehen Aufwuchspartikel aus Mangelerscheinungen. Die Aufnahme aus dem Vierwaldstättersee vom Februar 1969 (Abb. 59) ist ein Beispiel dafür. Andererseits finden sich Aufwuchskörper auch in stark belasteten Gewässern, wo Bakterien sich auf eingeschwemmten organischen Partikeln ansiedeln.

Bakterienaufwuchs auf Phytoplankton ist bei intakten Populationen kaum zu beobachten, hingegen tritt bakterielle Zersetzung von Phytoplankton nach Wasserblüten und unterhalb der maximalproduktiven Schicht auf. Abb. 60 stammt aus dem Rotsee aus $5 \mathrm{~m}$ Tiefe vom März 1970. Es handelt sich dabei um eine Flagellatenzelle, die stark mit Bakterien besetzt ist.

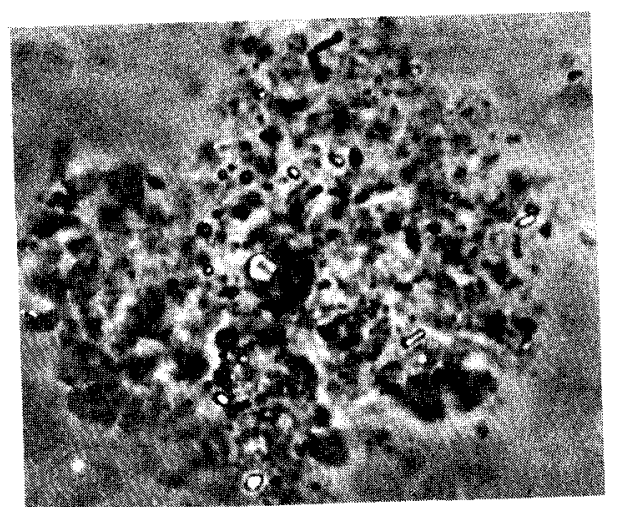

Abb. 59: Aufwuchspartikel auf Membranfilter präparat. Februar 1969, $0 \mathrm{~m}$ Tiefe, Vierwaldstättersee (Vergrösserung etwa $800 \times$, Phasenkontrast).

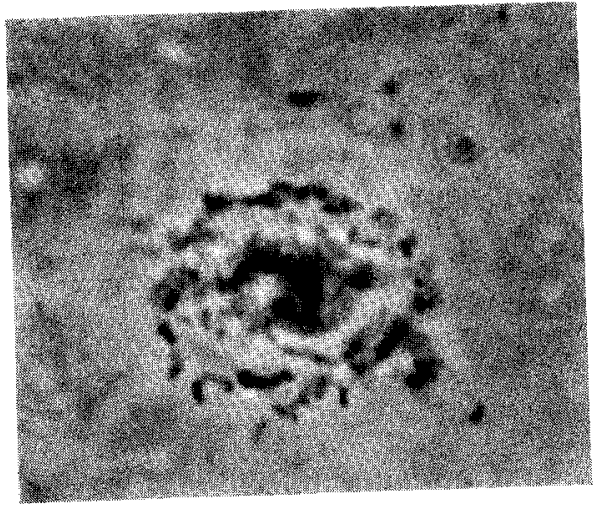

Abb. 60. Bakterielle Destruktion eines Plankters im Metalimnion. März 1970, 5 m Tiefe, Rotsee (Vergrösserung etwa $1250 \times$, Membranfilterpräparat, Phasenkontrast).

\subsection{Zoogloen}

Zoogloen sind Zellansammlungen ohne Aufwuchskern. Meistens sind sie artbestimmt. Typisch ist das Auftreten von Zoogloen in Gewässern mit hoher Substratkonzentration und im speziellen Milieu, wie die Beispiele aus dem Rotsee demonstrieren.

Eine spezielle Zoogloenform aus dem Rotsee ist in Abb. 61 neben fädigen Bakterienformen zu beobachten.

Auf weitere Zoogloen aus dem Rotsee, wie Thiopedia rosea, Leptothrix psendovacuolata und Lamprocystis roseopersicina soll später (siehe Seiten 483, 485, 488) noch eingegangen werden.

Auch im Vierwaldstättersee traten zeitweise Zoogloen spezieller Art auf. Abb. 62 zeigt die auch in Pavoni [53] beschriebene Form Planktomyces bekefii Gimesi, ein gestieltes Bakterium, das im Vierwaldstättersee relativ oft beobachtet werden kann. Solche sternbildende gestielte Bakterien werden in meeresbakteriologischen Arbeiten (KRIss [34]) verschiedentlich und in grosser Formenmannigfaltigkeit angeführt. 


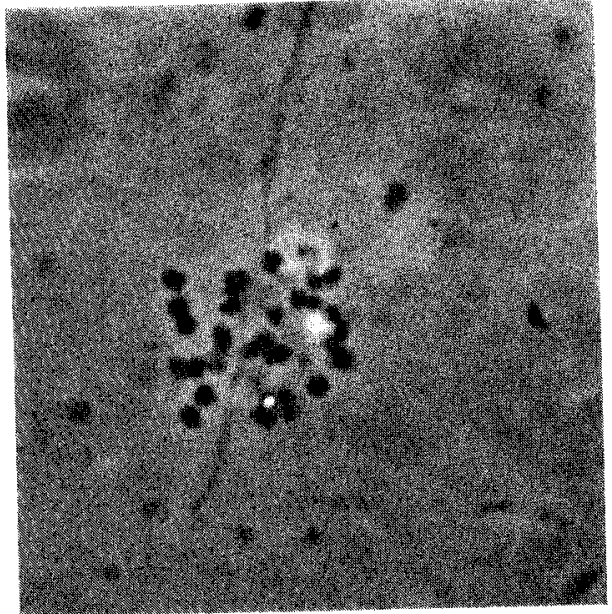

Abb. 61: Zoogloenform, Membranfilterpräparat. Februar 1970, $5 \mathrm{~m}$ Tiefe, Rotsee (Vergrösserung etwa $1000 \times$, Phasenkontrast).

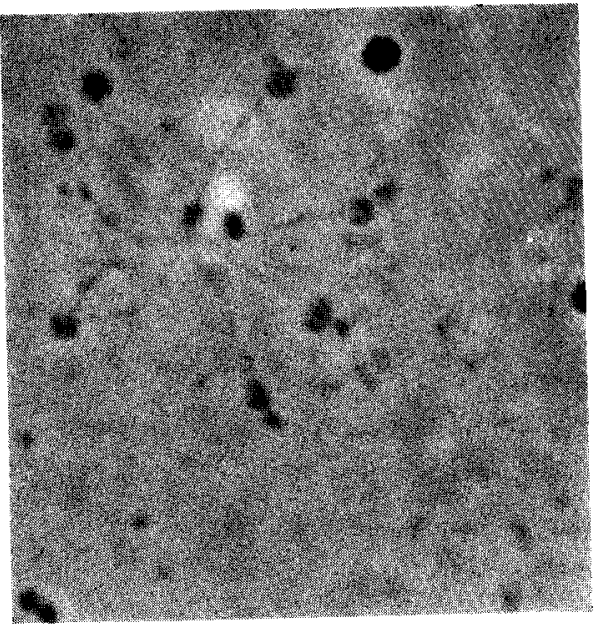

Abb. 62. Planktomyces bekefii Gimesi, gestieltes, sternbildendes Bakterium, Zelldurchmesser 0,8-1 $\mu$. September 1969, 7,5 m Tiefe, Vierwaldstättersee (Vergrösserung etwa $1500 \times$, Phasenkontrast, Membranfilterpräparat).

\subsection{Spezielle Formen aus dem Rotsee}

Thiopedia rosea Winogradsky

Die auffälligste Form der hypolimnischen Bakterien im Rotsee ist Thiopedia rosea Winogradsky (Huber-Pestalozzi [30]) (Abb. 63). Thiopedia gehört zu den Thiorhodaceen. Dies sind photosynthetisierende Bakterien, die Kohlenstoff fixieren unter Ausnützung von Schwefelwasserstoff, Thiosulfat oder molekularem Wasserstoff als Wasserstoffdonatoren. Die $\mathrm{CO}_{2}$-Fixierung kann über den Calvin-Zyklus oder andere Carboxylierungsmechanismen (ScHLEGEL [66]) erfolgen. Neben der $\mathrm{CO}_{2}$-Fixierung kann aber auch Kohlenstoff in Form von stark reduzierten organischen Verbindungen (Fettsäuren) assimiliert werden (SCHLEGEL [67]).

Zur Jahreskurve von Thiopedia rosea:

Nach Utermöhl (aus Huber-Pestalozzi [30]) ist Thiopedia in hohem Masse mikroaerophil. Das in Abb. 64 angegebene Raum-Zeit-Diagramm ist eine Bestätigung dieser Eigenschaft. Scheinbare Ausnahmen (April 1969, Februar und März 1970), wo Thiopedia in Schichten mit höheren Sauerstoffgehalten vorkamen, sind durch die Zirkulation der Wassermassen entstanden.

Die Maximalwerte "tasten" sozusagen die Grenze Sauerstoff-Schwefelwasserstoff über das ganze Jahr ab (eingezeichnet in Abb. 64). Aus den Bedürfnissen des Stoffwechsels, dass Schwefelwasserstoff als H-Donator vorhanden sein muss, kann das maximale Auftreten im März 1969 in 14 m Tiefe und im Juni 1969 in 7,5 m Tiefe erklärt werden. Vom Juli bis zum September 1969 traten praktisch keine Thiopediazellen im Hypolimnion auf. Im November begann die Herbstzirkulation, die eine Sauerstoffverfrachtung in die Tiefe brachte und damit das Auftreten von Thiopedia hervorrief. Eine besonders interessante Situation zeigte sich im Dezember 1969, als eine Zirkulation fast über die ganze Wassersäule stattfand. Aus dem Schlamm aus- 


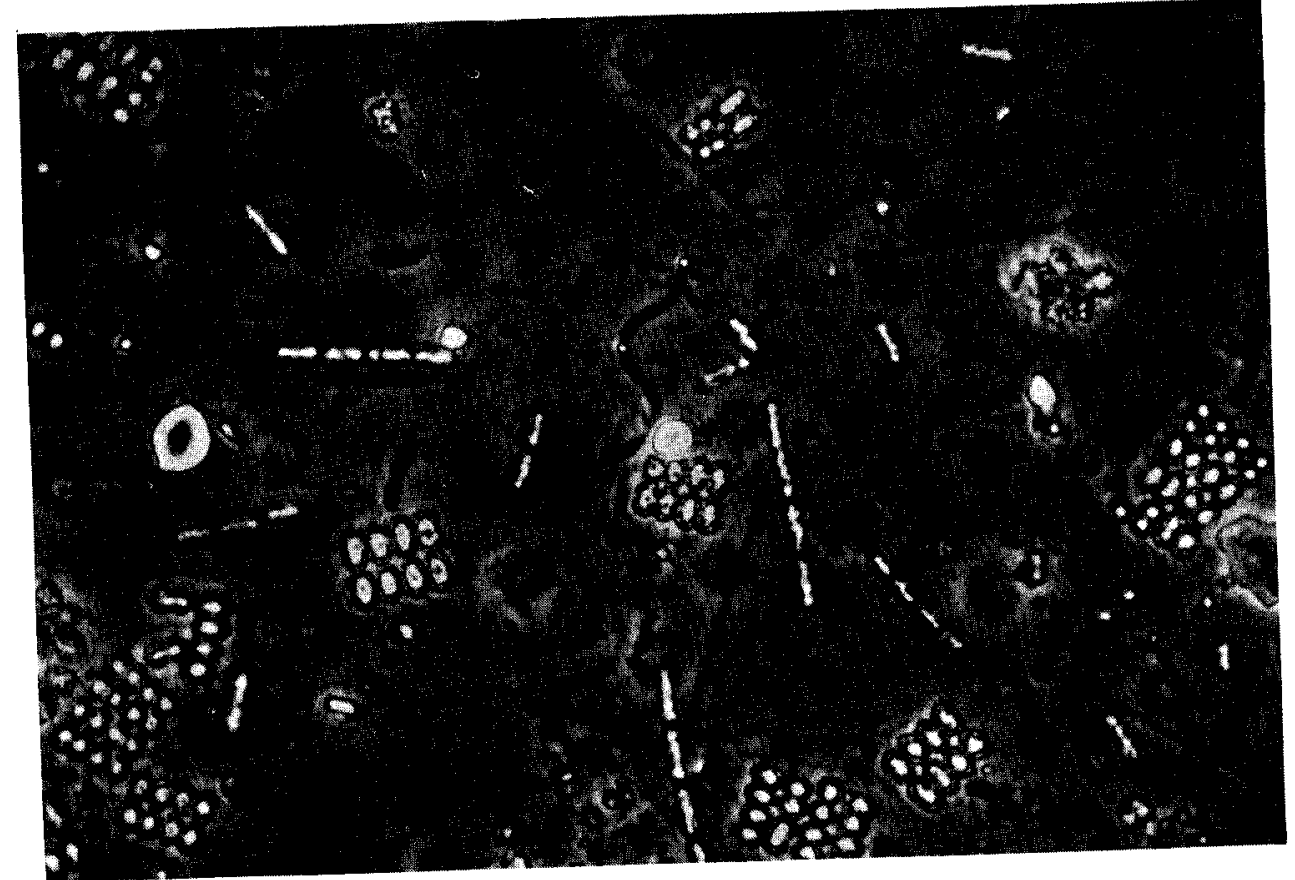

Abb. 63. Thiopedia rosea: Ansammlung von tafelförmig angeordneten Zellen (1). Die Färbung ist relativ schwach, nur an der Zellperipherie verstärkt. Die Zellen sind leicht elipsoid, mit einem (nönen in den Polarkappen Schwefelkörner beDurchmesser von 1,5-2 $\mu$. In einzelnen Zobachtet werden.

In der Mitte findet sich eine ausserordentlich grosse Spirillenform, mit 2 Schwefelkörnern (2). Lebendpräparat aus dem Hypolimnion. Januar 1970, $14 \mathrm{~m}$ Tiefe, Rotsee (Vergrösserung etwa $1000 \times$, Phasenkontrast).

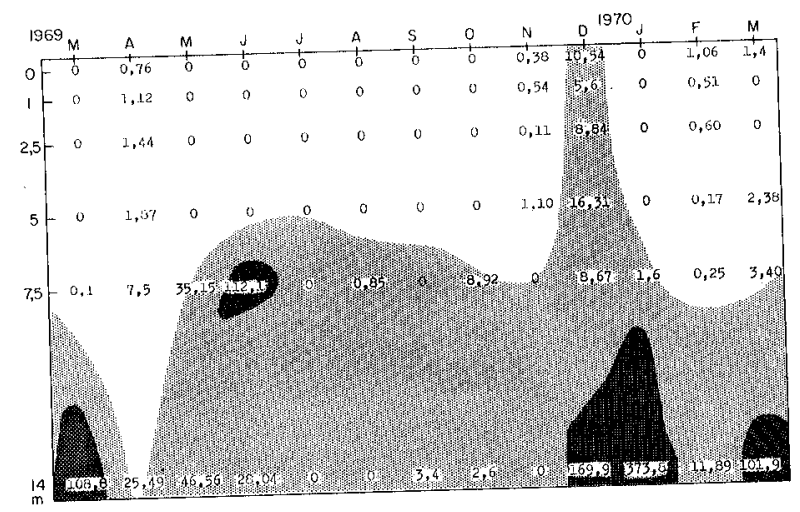

Abb. 64. Thiopedia rosea, $10^{3}$ Zellen/ml, Rotsee. Hellgrauer Raster: Sauerstoffgehalt kleiner als $1 \mathrm{mg} / 1$. Dunkelgrauer Raster: Thiopediaanhäufungen. 
tretend (nach Utermöhl aus Huber-Pestalozzi [30] kommt Thiopedia in grossen Mengen auch in anaerobem Schlamm vor), wurden Thiopediazellen in grosser Zahl ins Epilimnion bis auf $0 \mathrm{~m}$ hochgetragen. Die zu erwartende homogene Verteilung trat aber nicht ein, indem in $5 \mathrm{~m}$ Tiefe ein relatives Maximum auftrat, was die wahrscheinlich optimalen Lichtverhältnisse in dieser Tiefe widerspiegelt. Die Sauerstoffwerte betrugen im Dezember über die ganze Wassersäule weniger als $1 \mathrm{mg} / 1$. Dadurch wurde die Massenentfaltung von Thiopedia ausgelöst. Im Januar 1970 trat bei dem sehr hohen Schwefelwasserstoffwert von $13,1 \mathrm{mg} / \mathrm{l}$ das absolute Maximum der Thiopediaentwicklung mit 373000 Zellen/ml auf. Diese Probe war dadurch makroskopisch intensiv blaurot gefärbt. Einen Monat später, im Februar, war der Schwefelwasserstoffgehalt von $13,1 \mathrm{mg} / \mathrm{l}$ auf $1 \mathrm{mg} / \mathrm{l}$ abgesunken, was auf eine intensive Ausnützung des Schwefelwasserstoffs als Wasserstoffdonator schliessen liess.

\section{Diskussion}

Die Produktionswerte der ${ }^{14} \mathrm{C}$-Messung in $14 \mathrm{~m}$ Tiefe widerspiegeln das Auftreten der photomixotrophen Bakterien, wie Thiopedia und Lamprocystis (siehe Seite 486). So traten im März und April 1969 Werte von 4 bis $5 \mathrm{mgC} / \mathrm{m}^{3} \mathrm{~h}$ und im Januar, Februar und März 19705 bis $10 \mathrm{mgC} / \mathrm{m}^{3} \mathrm{~h}$ auf. Im Januar wurde eine Probe aus $14 \mathrm{~m}$ Tiefe in $5 \mathrm{~m}$ Tiefe exponiert, d.h. sie wurde einer erhöhten Lichtintensität ausgesetzt. Dabei wurde festgestellt, dass in dieser Probe $34,2 \mathrm{mgC} / \mathrm{m}^{3} \mathrm{~h}$ eingebaut wurden; dies ist der 6fache Wert der Produktion in $14 \mathrm{~m}$. Daraus lässt sich schliessen, dass im natürlichen Vorkommen, in der äusserst schwach belichteten Tiefe von $14 \mathrm{~m}$, die Produktion weit unterhalb der Produktivität der Organismen liegt.

Erstaunlich ist die Tatsache, dass Thiopedia rosea ihre maximale Entwicklung in $14 \mathrm{~m}$ Tiefe aufwies, wo mit den angewandten Mitteln kein Licht mehr gemessen werden konnte. Offenbar ist Thiopedia auf äusserst geringe Lichtmengen sensibilisiert. Nach Schlegel [67] können die Thiorhodaceen neben Infrarot mit Hilfe von Karotinoiden Licht im sichtbaren Bereich zwischen 400 und $600 \mathrm{~nm}$ absorbieren und dadurch die photosynthetische Leistung erbringen, d.h. in jenem Wellenlängenbereich, aus dem das schwache Licht in tieferen Schichten besteht. Das grüne Licht $(1 \%$ VG $9[=525 \mathrm{~nm}])$ drang im allgemeinen in den Monaten am tiefsten ein, in denen hypolimnische Thiopediamaxima zu beobachten waren.

Es ist nicht anzunehmen, dass diese Thiopediamaxima ausschliesslich auf die Verwertung reduzierter organischer Verbindungen, also auf heterotrophes Wachstum, zurückzuführen sind. Eine entsprechende sensible In-situ-Lichtmessung würde über diesen Punkt weitere Klarheit schaffen.

Wollte man eine Priorität der begrenzenden Faktoren über das Auftreten von Thiopedia aufstellen, müsste man den Schwefelwasserstoffgehalt an erste Stelle setzen. Bezüglich Produktivität ist aber Licht im grünen Bereich ausschlaggebend.

\section{Lamprocystis roseopersicina}

In Abb. 66 ist das Auftreten von Lamprocystis aufgetragen. Auch dieses Bakterium gehört zu den Thiorhodaceen. Zusammen mit den Thiopedia-rosea-Zellen wurden auch Massenentfaltungen von Lamprocystis roseopersicina beobachtet (Abb. 65). Parallel zur Massenentfaltung in 7,5 m Tiefe von über 100000 Thiopediazellen im Juni 1969 traten 19000 Lamprocystiszellen/ml auf. Eine zweite kleinere Entwicklung fand sich 


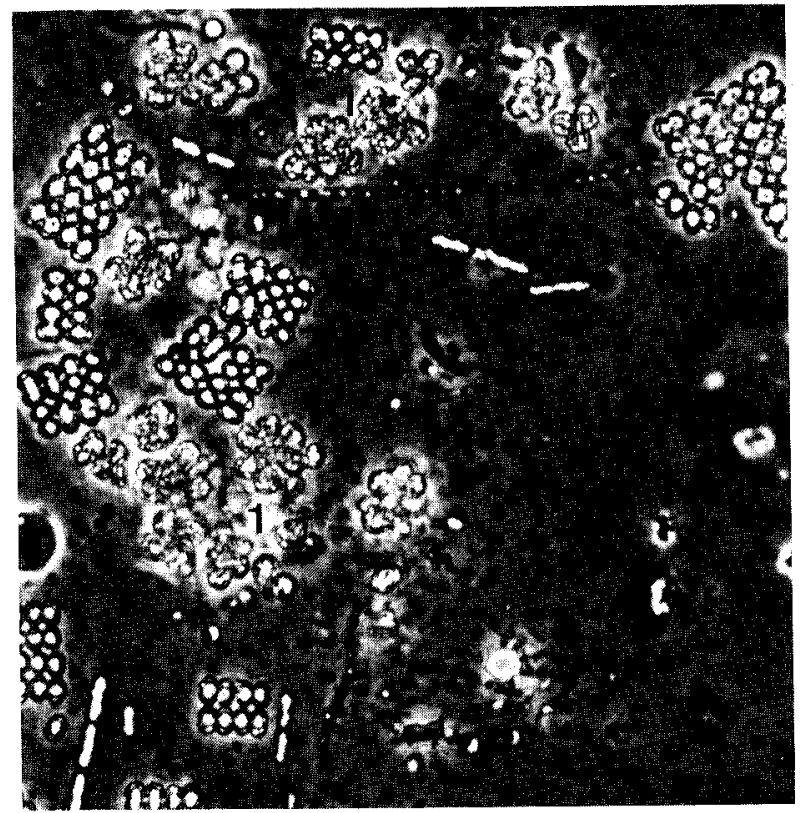

Abb. 65. Lamprocystis roseopersicina: Ungeordnete Zellhaufen (1) neben tafelförmigen Ansammlungen von Thiopediazellen (2). Januar 1970, $14 \mathrm{~m}$ Tiefe, Rotsee (Vergrösserung etwa $1250 \times$, Lebendpräparat, Phasenkontrast).

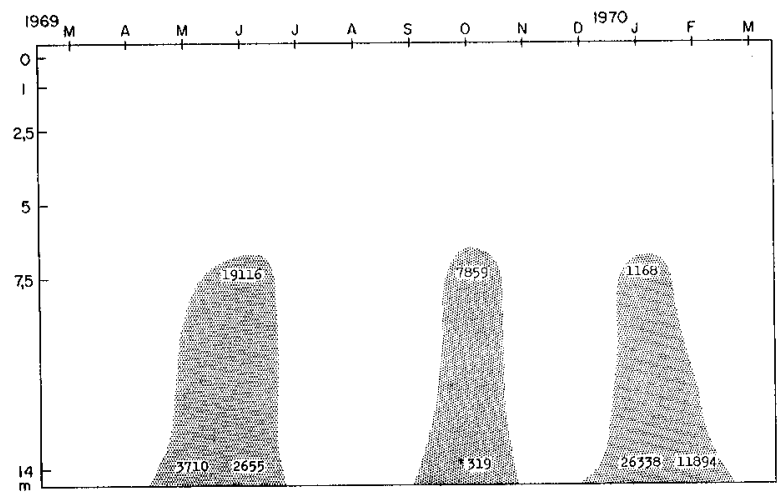

Abb. 66. Lamprocystis roseopersicina, Rotsee.

im Oktober 1969 mit 7800 Zellen/ml Lamprocystis in 7,5 m Tiefe. Gleichzeitig mit der Massenentfaltung von Thiopedia rosea im Januar 1970 in $14 \mathrm{~m}$ Tiefe fanden sich 26300 Lamprocystiszellen/ml. Diese Population hatte eine grosse Stoffwechselaktivität. Dies zeigte sich in einem sehr hohen Primärproduktionswert von $10 \mathrm{mgC} / \mathrm{m}^{3} \mathrm{~h}$.

Chromatium densegranulatum Skuja (Chromatium Linsbaueri Gickhorn)

In Abb. 67 ist diese von SkuJA [71] beschriebene Chromatiumart ersichtlich. Nach ihm sind die beiden oben erwähnten Arten ausserordentlich schwierig auseinanderzu- 


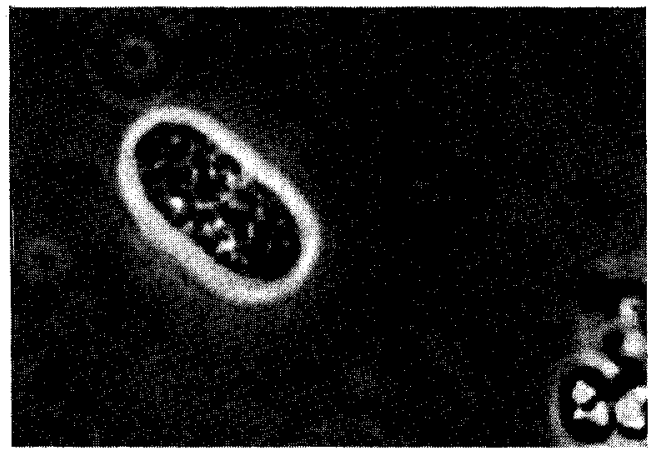

Abb. 67. Chromatium densegranulatum Skuja. Länge etwa $12 \mu$, Breite etwa $6 \mu$. April 1969, $5 \mathrm{~m}$ Tiefe, Rotsee (Lebendaufnahme, Vergrösserung etwa $1250 \times$, Phasenkontrast).

halten, sie sind wahrscheinlich sogar identisch. Die beobachteten Zellen waren 12-1.5 $\mu$ lang und 6-8 $\mu$ breit. In den Granula entsprachen sie den von Skuja angegebenen Chromatium densegranulatum. Die Farbe war schwach ausgeprägt, so dass die Konturen erst im Phasenkontrastbild hervortraten.

Die beobachteten Zellen wiesen einen ziemlich ausgeprägten kleinen Hof auf. Die von HubER-Pestalozzi [30] beschriebenen lichtbrechenden amorphen Kügelchen $\left(\mathrm{CaCO}_{3}\right)$ konnten auch festgestellt werden.

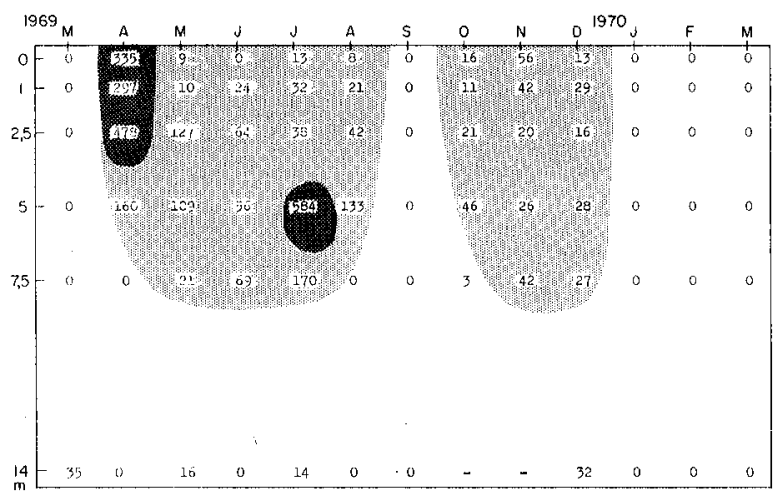

Abb. 68. Chromatium densegranulatum, Zellen/ml, Rotsee.

In Abb. 68 ist das Raum-Zeit-Diagramm des Chromatiums dargestellt. Es fanden sich 2 maximale Anhäufungen im April 1969 in 2,5 m Tiefe und im Juli 1969 in 5 m Tiefe.

Vergleicht man das Auftreten des Chromatiums mit der von Stadelmann [73] angegebenen Nitritkonzentrationen (Abb. 69), stellt man fest, dass beide Zellmaxima mit den epilimnischen Nitritmaxima zusammenfallen. Das Nitritmaximum war auf Nitrifikation zurückzuführen, da gleichzeitig hohe Konzentrationen von Ammonium vorlagen. Diese räumlich-zeitliche Übereinstimmung lässt vermuten, dass Chromatium densegranulatum an der Nitrifikation beteiligt ist. 


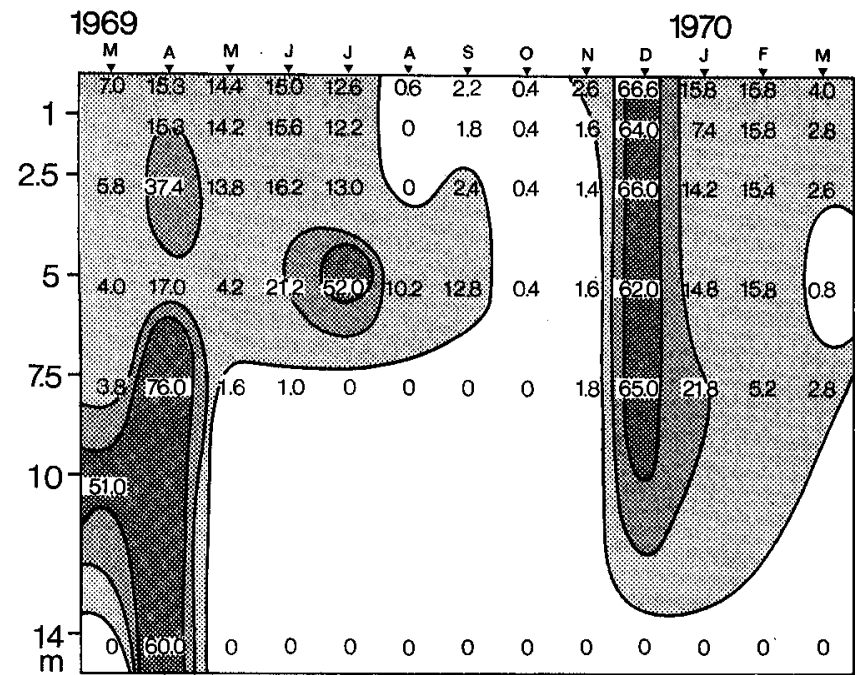

Abb. 69. Nitritkonzentration ( $\mu \mathrm{g} \mathrm{NO}_{2}-\mathrm{N} / 1$ ) des Rotsees (nach StadeLmann 1971).

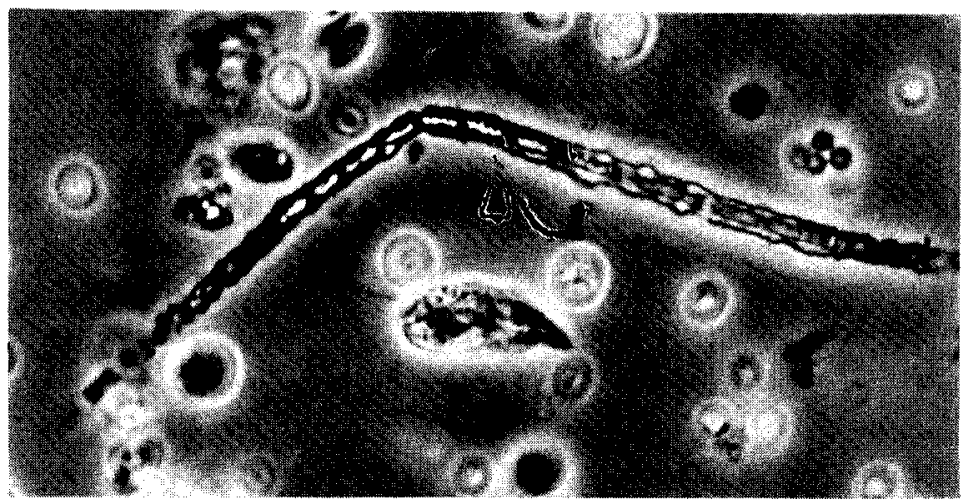

Abb. 70. Leptothrix pseudovacuolata. Es lässt sich die Scheidenbildung erkennen sowie das Austreten der Einzelzellen aus den Scheiden. Februar 1970, 2,5 m Tiefe, Rotsee (Vergrösserung etwa $2000 \times$, Phasenkontrast).

\section{Leptothrix sp. (cf. psendovacuolata [Berfiliev] Dorff)}

Im Rotsee trat diese Leptothrixform recht häufig auf. In Abb. 70 ist ein Leptothrixfaden dargestellt. Die Fadenlängen variierten im Laufe des Jahres ziemlich stark, so waren sie im April 1969 sehr kurz, während sie mit inkrustierter Scheide (September und Oktober 1969) grössere Längen erreichten. Nach Skuja [71] gibt es zwei verschiedene Arten, eine in Spiralform auftretende und eine leicht gebogene. Die im Rotsee beobachteten Leptothrix-pseudovacuolata-Fäden waren durchwegs gerade. Die Zellgrösse und die Anzahl der Pseudovakuolen kann stark variieren. Die Trichome ohne inkrustierte Scheide sind zwischen 1,5 und $1,8 \mu$ breit. In Trichomen mit inkrustierter Scheide fanden sich weniger Vakuolen als in unbescheideten. Die Vakuolen sind 
immer axillär angeordnet. Die Ausbildung der Scheiden war im Vergleich zu der bei SkUjA beschriebenen Leptothrix pseudovacuolata auffallend klein, sie erreichte meist nur die doppelte Trichombreite. Die bei Huber-Pestalozzi [30] beschriebenen Riesenzellen wurden nicht gefunden. Die Inkrustierung mit Eisenverbindungen liess sich nur an Hand der rötlichbraunen Färbung der Scheiden erkennen.

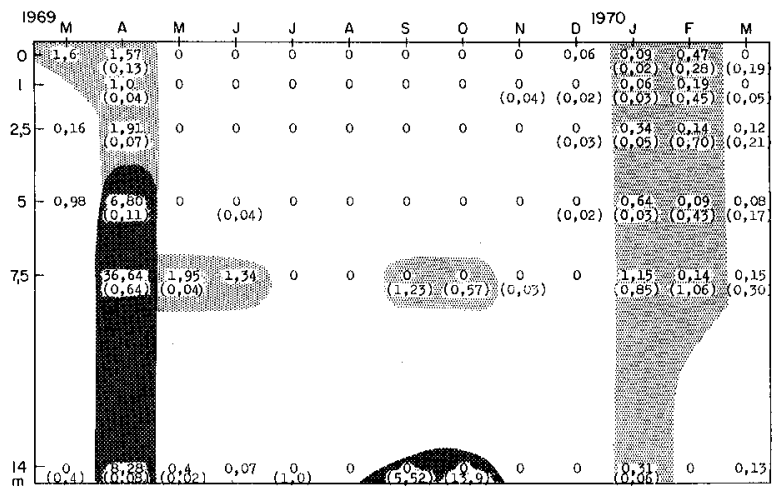

Abb. 71. Leptothrix pseudovacuolata, $10^{4} \mu$ Fadenlänge/ml, Rotsee. Zahlen ohne Klammern: Filamente ohne inkrustierte Scheide, Zahlen in Klammern: Filamente mit inkrustierter Scheide.

In Abb. 71 ist das Raum-Zeit-Diagramm der Leptothrix pseudovacuolata im Rotsee aufgetragen. Im April fand sich eine Massenentfaltung im Hypolimnion, mit einem Maximum von $36 \cdot 10^{4} \mu$ Fadenlänge/ $\mathrm{ml}$ in $7,5 \mathrm{~m}$ Tiefe. Im Frühjahr herrschten die wenig inkrustierten Trichome vor. Die Massenentfaltung im Frühling fiel mit derjenigen von Thiopedia rosea zusammen. Durch die Frühjahrszirkulation wurde eine Verteilung durch die Wassersäule hervorgerufen. Das Maximum lag bei einer sehr kleinen Sauerstoffspannung von $1 \mathrm{mg} / \mathrm{l}$ vor. Dies stimmt mit den Angaben von HubERPestalozzi [30] überein, der ein Auftreten von Leptothrix im Schlamm bei geringer Sauerstoffspannung beschrieben hat.

Eine zweite hypolimnische Blüte lag im September und Oktober 1969 in 14 und 7,5 m Tiefe vor. Diese Entfaltung wurde ausschliesslich von Formen mit inkrustierter Scheide gebildet. Das Auftreten ist an niedere Temperaturen unterhalb $10^{\circ} \mathrm{C}$ gebunden, optimale Entwicklungen finden sich bei etwa $7^{\circ} \mathrm{C}$. PAvoni [53] beschrieb ebenfalls das Auftreten von Leptothrix pseudovacuolata im Winter und im Frühjahr. Leptothrix kann sowohl in sauerstoffangereicherten wie in sauerstoffarmen Zonen auftreten. So wurden im April 1969 in $0 \mathrm{~m}$ bei einem Sauerstoffgehalt von $12 \mathrm{mg} / 1$ noch $1,5 \cdot 10^{4} \mu$ Fadenlängen $/ \mathrm{ml}$ gefunden. Interessant ist das Auftreten von inkrustierten Scheiden bei geringen Sauerstoffgehalten.

In die Scheiden sind nach Huber-Pestalozzi [30] Eisen- und Manganverbindungen eingelagert. Zwischen partikulär vorhandenem Eisen und dem Auftreten von Leptothrix konnten keine eindeutigen Beziehungen festgestellt werden. Ein einziger Hinweis darauf könnte die Untersuchung vom April 1969 geben, als das partikuläre Eisen über $100 \mathrm{mg} / \mathrm{l}$ bei gleichzeitigem Aufbruch des gelösten Eisens betrug. 


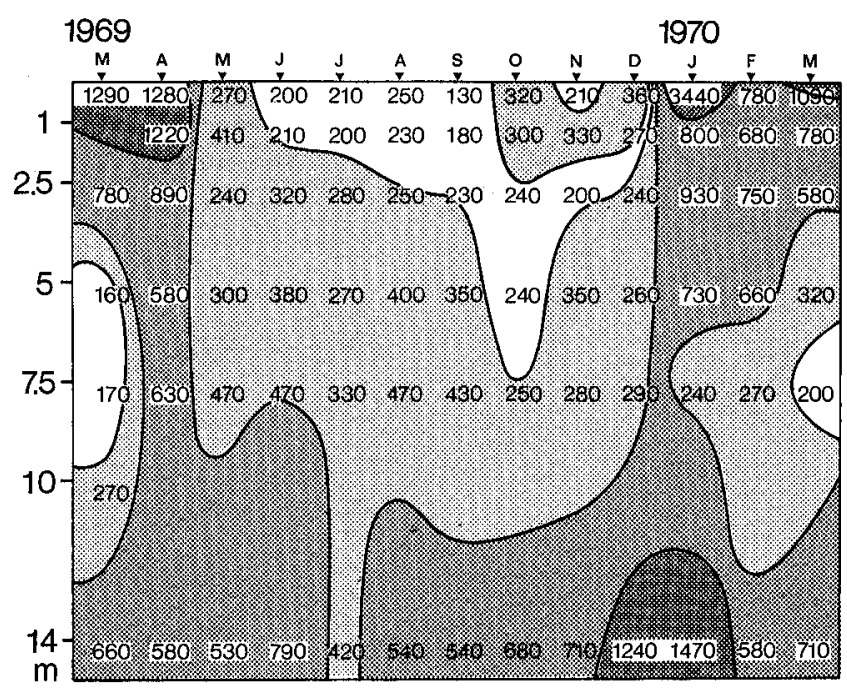

Abb. 72. Partikulärer Kjeldahl-N ( $\mu$ g N/l) des Rotsees (nach Stadelmann 1971).

\section{Diskussion}

Abb. 724) zeigt die Verteilung des partikulären Stickstoffs in Isopletendarstellung. Im Hypolimnion waren ausserordentlich grosse Mengen an partikulärem Stickstoff vorhanden, dessen Vorkommen weitgehend auf die vorhandene hypolimnische Bakterienflora zurückzuführen war. Diese Hypothese erhärtet sich durch die Tatsache, dass parallel zum Auftreten von Thiopedia rosea in 14 m Tiefe im Dezember 1969 und Januar 1970 ein starker Anstieg der partikulären Stickstoffzahlen von $710 \mu \mathrm{g} / \mathrm{l} \mathrm{im}$ November 1969 auf $1200 \mu \mathrm{g} / \mathrm{l} \mathrm{im}$ Dezember 1969 und auf $1400 \mu \mathrm{g} / \mathrm{l}$ im Januar 1970 gefunden wurde.

Es muss mit allem Nachdruck festgestellt werden, dass dieser partikuläre Stickstoff organismisch fixiert ist und nur zu einem kleineren Teil als Detritus vorliegt. Auf diesen Sachverhalt soll in der zusammenfassenden Diskussion (siehe Seite 516) noch eingetreten werden.

\subsection{Vertikale und jahreszeitliche Verteilung der Bakterien}

OverBeck [51] hat auf Methoden zur deskriptiven Interpretation von Vertikalprofilen hingewiesen und konnte damit einige wesentliche Aussagen zur Dynamik des Stoffkreislaufes im See gewinnen.

In einer früheren Arbeit (SchegG und Ruschke [65]) wurde ebenfalls versucht, aus Einzelprofilen von Seen verschiedenen Trophiegrades auf die Dynamik des Stoffkreislaufes zu schliessen. Da es sich bei Einzelprofilen immer um Momentaufnahmen handelt, die sich sehr rasch wieder ändern können, wird eine Aneinanderreihung der Einzelprofile, auch unter Vorbehalt grosser Streubreiten, aussagekräftiger für den Handlungsablauf.

4) Die Isopletendarstellung ist der Arbeit von Stadelmann [73] entnommen. 
Zur mathematischen Erfassung der Kombinationen verschiedener Isopletendarstellungen wurde die Korrelationsanalyse über das ganze Jahr in jeder Tiefenstufe durchgeführt. Trotz den Vorteilen des Raum-Zcit-Diagramms ist es aber angebracht, verschiedene Parameter am Vertikalprofil durchzutesten (Overbeck [51]).

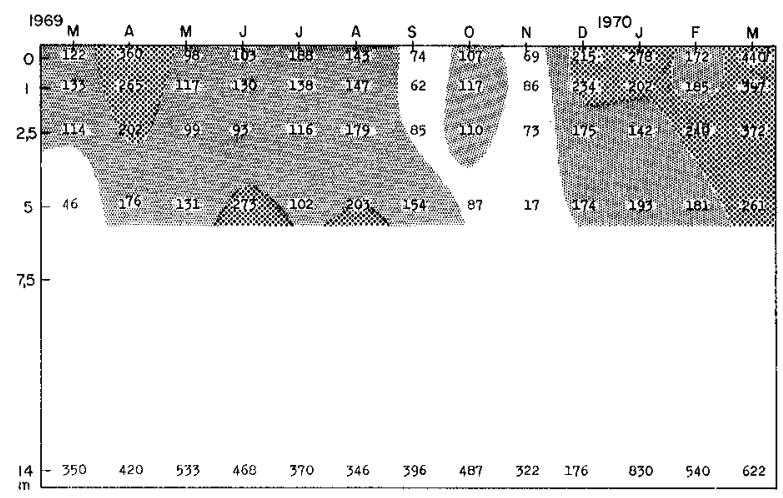

Abb. 73. Membranfilterbakterien, $10^{4}$ Zellen/ml, Rotsee.

\subsection{Rotsee}

In Abb. 73 ist das Raum-Zeit-Diagramm der Membranfilterbakterien im Epilimnion von 0 bis $5 \mathrm{~m}$ dargestellt. Die Zahlen lagen zwischen 600000 und 4000000 Bakterienzellen $/ \mathrm{ml}$ Probewasser. Die Bakterienzahlen in $14 \mathrm{~m}$ Tiefe lagen zwischen 1,7 und 8,3 Mio Zellen/ml. Diese Angabe ist für das Hypolimnion repräsentativ.

Maximale Bakterienzahlen fielen mit grosser Primärproduktion zusammen, was sowohl im Frühling 1969 als auch im Winter und Frühling 1970 ersichtlich ist.

Nach Wuhrmann [83] besteht in der Geschwindigkeit der physiologischen Reaktionen bei psychrophilen und mesophilen Mikroorganismen ein Temperaturfaktor pro $10^{\circ}$ von 1,5 bis 2,5. Dieser Wert gilt für Reinkulturen. In einer Biozönose (biologische Klärschlammanlagen) ist der Temperaturfaktor bedeutend kleiner (etwa 1,2 pro $10^{\circ} \Delta \mathrm{t}$ ). Dies wird mit der "soziologischen Adaptation» erklärt, indem für die jeweils selektierte Population relativ optimale Bedingungen vorliegen. Die Grösse, die Zahl und die Umsatzgeschwindigkeit ist aber ausschliesslich vom vorhandenen, leicht assimilierbaren Substrat abhängig. Es ist anzunehmen, dass eine ähnliche Planktonpopulation auch bei höheren Temperaturen keine wesentliche Erhöhung der Umsatzgeschwindigkeit und der Zahl bei gleichbleibendem Substratangebot aufweisen würde.

Auf Grund dieser Überlegungen sind die im Rotsee beobachteten hohen Keimzahlen bei so tiefer Temperatur zu verstehen. In der Vertikalverteilung zeigt sich, dass die maximale Entwicklung meistens in $0 \mathrm{~m}$ oder $1 \mathrm{~m}$ Tiefe anzutreffen ist. Es ist dies die Zone hoher photosynthetischer Aktivität des Phytoplanktons. Diese Verteilung im Vertikalprofil stellt eine Bestätigung der Befunde von 1967 dar (ScHEGG [63]).

\section{$K$-Analyse}

Die K-Analyse (Tab. 21) zeigt in $0 \mathrm{~m}$ einen $\mathrm{KK}$ von 0,87 mit den Plattenzahlen, d.h. man kann von einer Konstanz des Verhältnisses von Membranfilterzahlen zu den 
Tab. 21. K-Analyse zum Bezugsparameter Membranfilterbakterien, Rotsee.

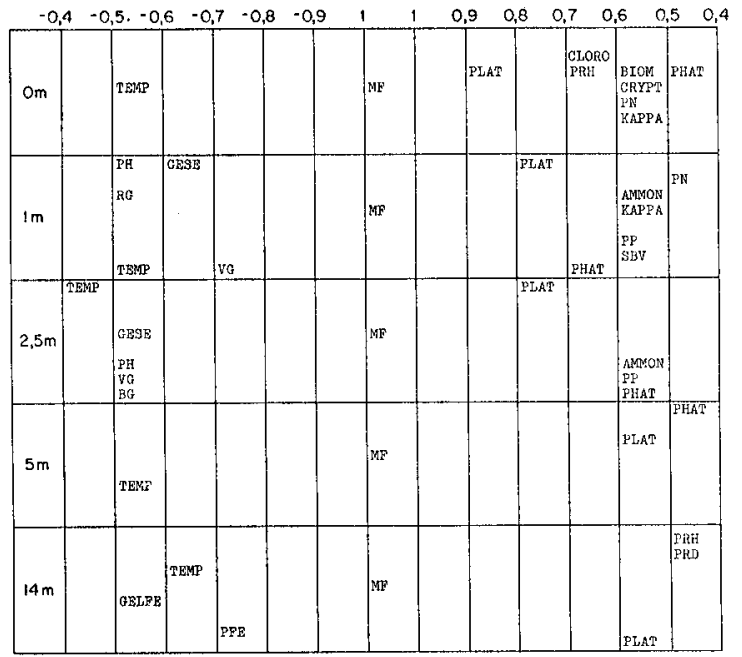

Plattenzahlen sprechen. In einem eutrophen Gewässer ist die K der Membranfilterzahlen zu den Plattenzahlen eng, da ein grösserer Teil der zymogenen Keime an das höhere Substratangebot des Gussplatten adaptiert ist.

In $0 \mathrm{~m}$ bestehen weitere KK der Membranfilterzahlen zur Primärproduktion und ein etwas kleinerer KK zu Biomasse, Cryptomonas und partikulärem Stickstoff. In $1 \mathrm{~m}$ Tiefe ist nur noch eine Korrelation zu PN und PP zu beobachten. Schon in 2,5 m Tiefe bestehen diese Zusammenhänge zu den Produktionsparametern nicht mehr. Die von Overbeck [49] mitgeteilte feste Korrelation zwischen Phytoplankton und Primärproduktion muss dahingehend modifiziert werden, dass diese Beziehung hauptsächlich für die Schicht maximaler Produktion gilt.

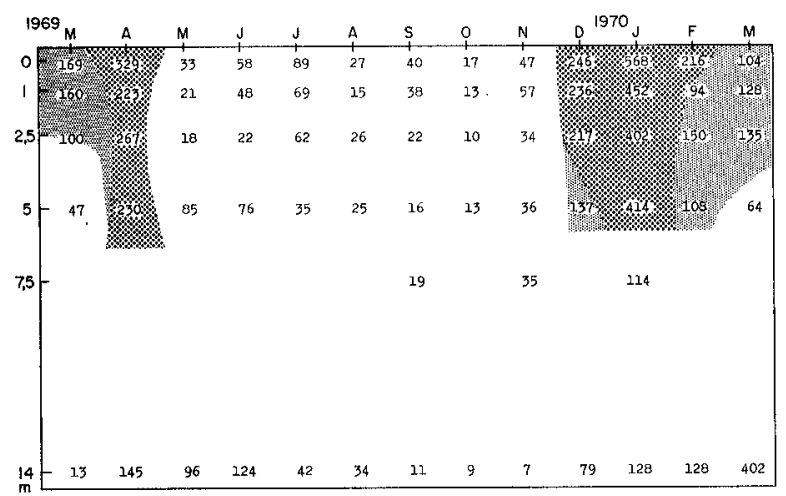

Abb. 74. Plattenzahlen, $10^{2}$ Zellen/ml, Rotsee.

In Abb. 74 sind die Plattenzahlen im Raum-Zeit-Diagramm aufgezeichnet. In den hauptproduktiven Perioden je im Frühjahr 1969 und 1970 fanden'sich Anhäufungen 
der heterotrophen, auf Tryptonglukoseagar wachsenden Bakterien. Mit dieser Methode wurden nur aerobe heterotrophe Keime bestimmt. Die Messungen in $14 \mathrm{~m}$, im Hypolimnion, ergaben daher nur grössere Werte, wenn noch eine minimale Sauerstoffspannung vorhanden war. Eine solche minimale Sauerstoffspannung war in den Zirkulationen im Frühjahr 1969 und im Dezember 1969 vorhanden. Die epilimnischen Werte deckten sich im wesentlichen mit der Verbreitung der Membranfilterzahlen $(\mathrm{KK}+0,87)$. Die absoluten Zahlen lagen zwischen 1500 und $56800 \mathrm{Zellen} / \mathrm{ml}$.

Die Grössenordnung der auf Platten bestimmten heterotrophen Bakterien wich nicht stark von derjenigen von DüGGELI [14] auf Heyden-Agar bestimmten Zahlen ab. Die Werte können aber nicht direkt mit denjenigen von DüGGELI [14] verglichen werden, da die Methodik und die Substratzusammensetzung voneinander abwichen.

Tab. 22. K-Analyse zum Bezugsparameter Plattenzahlen, Rotsee.

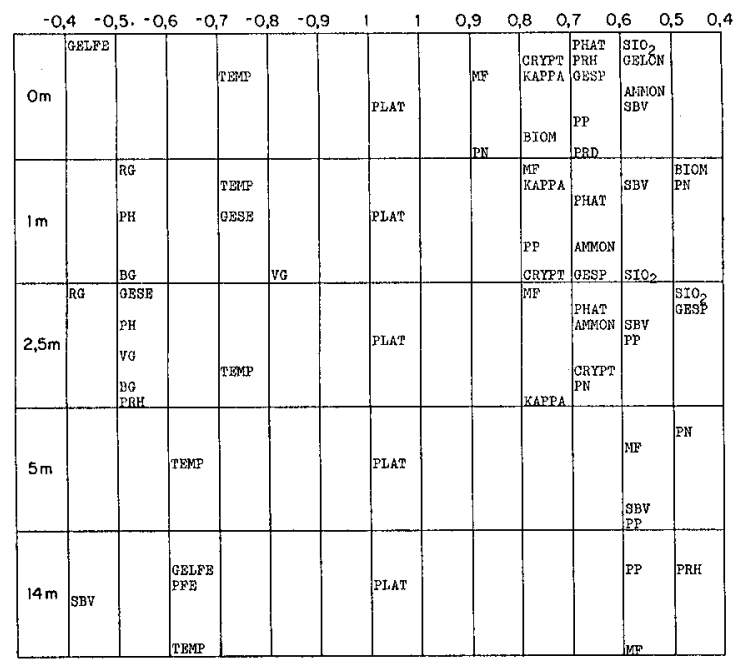

\section{K-Analyse (Tab. 22)}

Es bestehen mehr Korrelationen zwischen den Plattenzahlen und den Produktionsparametern als bei den Membranfilterzahlen, da im Rotsee ein höherer Prozentsatz heterotropher Keime an das angereicherte Nährstoffmedium adaptiert ist als in einem weniger belasteten Gewässer. Insbesondere finden sich $\mathrm{KK}$ zwischen den Plattenzahlen und partikulärem Stickstoff, der Biomasse, den Cryptomonaden, der Primärproduktion, dem partikulären Phosphor und den Nährstoffen Phosphat und Ammonium. In $1 \mathrm{~m}$ Tiefe ergibt sich dieses Muster, indem die $\mathrm{K} \mathrm{zu}$ den Cryptomonaden und partikulärem Phosphor höher ausfallen. Dies deutet auf die Abbauvorgänge in der hauptproduktiven Schicht hin.

\section{Ciliaten (Abb. 75)}

Die Ciliaten sind neben dem Zooplankton (das in dieser Untersuchung leider unberïcksichtigt bleiben musste) Konsumenten von bakteriellem Plankton (RUTTNER $[60]$ ). Sie werden als ganze Gruppe zusammengefasst. (Die häufigsten Formen waren 
Strombidium sp. und Coleps sp.). Ihr Auftreten fiel räumlich und zeitlich mit den Bakterienmaxima zusammen, insbesondere fanden sich Anhäufungen im April 1969 in $1 \mathrm{~m}$ Tiefe und im Januar 1970 von 0 bis 2,5 m Tiefe. Das erste grosse Auftreten erreichte im Mai 1969 ein Maximum, während die Bakterien- und Planktonpopulation stark zurückgegangen waren. Die Verteilung über das ganze Jahr zeigte die enge Verknüpfung der Ciliaten mit der als Nahrung dienenden primären und sekundären Biomasse.

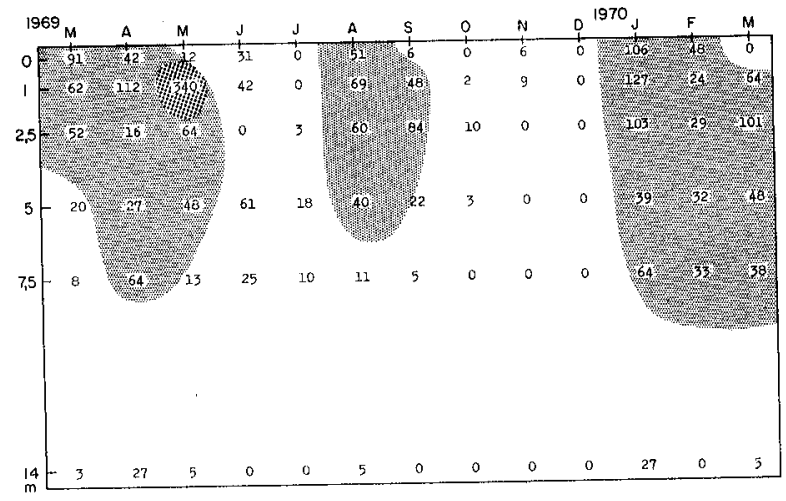

Abb. 75. Ciliaten, Zellen/ml, Rotsee.

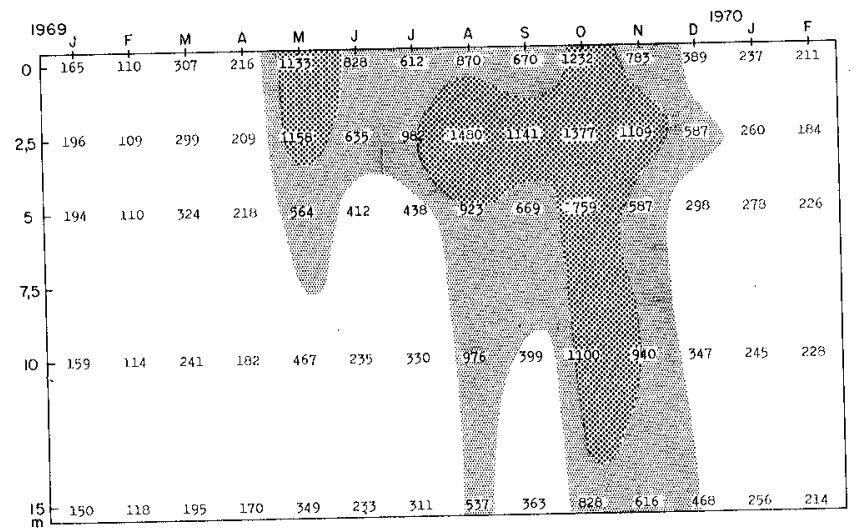

Abb. 76. Membranfilterbakterien, $10^{3}$ Zellen $/ \mathrm{ml}$, Vierwaldstättersee.

\subsection{Vierwaldstättersee}

In Abb. 76 ist das Raum-Zeit-Diagramm der Membranfilterbakterienzahlen aus dem Vierwaldstättersee aufgetragen. Die Zahlen bewegten sich zwischen 110000 Zellen $/ \mathrm{ml}$ und 1,8 Mio. Zellen $/ \mathrm{ml}$. Sie sind ein «Spiegelbild» der Planktonentwicklung mit beginnender Vegetation im März 1969, einem ersten Maximum im Mai 1969 und einem zweiten Maximum im Oktober 1969. Die Anreicherung im Oktober 1969 griff in tiefere Schichten, bis unterhalb $15 \mathrm{~m}$, über. Diese Anreicherung im Metalimnion fiel mit der auf Seite 503 beschriebenen metalimnischen Sauerstoffzehrung zusammen. 
Dynamisch betrachtet zeigt es sich, dass aus der Verteilung der Bakterien auf den Abbau der anfallenden organischen Substanz in der trophogenen Schicht geschlossen werden kann.

Ein relatives Maximum in $10 \mathrm{~m}$ Tiefe im August 1969 wurde durch eine Einschichtung von Oscillatoria rubescens hervorgerufen.

Tab. 23. K-Analyse zum Bezugsparameter Membranfilterbakterien, Vierwaldstättersee.

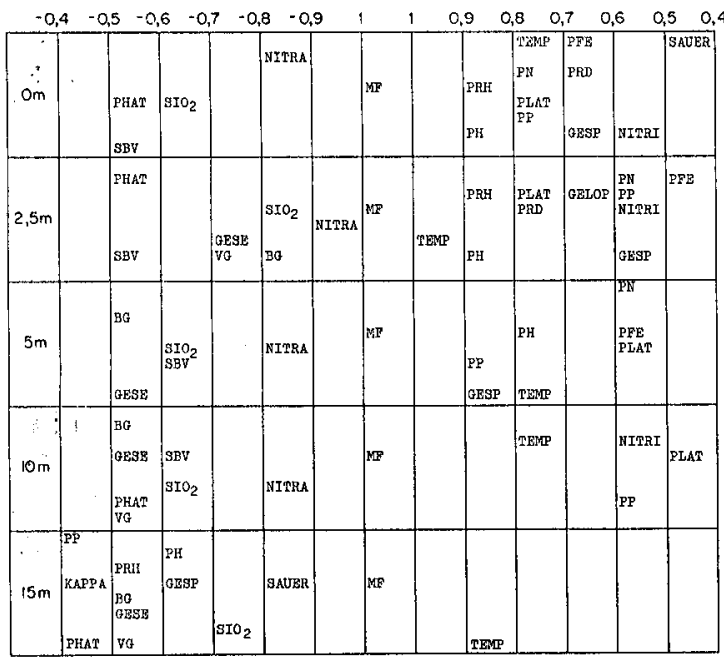

Die $K$-Analyse zeigt bei den Membranfilterbakterien (Tab. 23) eine enge Beziehung zu den Produktionsparametern, insbesondere einen KK von 0,86 zwischen Primärproduktion und Membranfilterbakterien. In 2,5 m Tiefe ist der KK zur Primärproduktion mit 0,87 am höchsten. Die für die Biomasse repräsentativen Parameter PP und PN sind ebenfalls mit den Membranfilterbakterien signifikant korreliert. Interessant ist der über das ganze Epilimnion bestehende hohe negative KK zwischen Membranfilterbakterien und Nitrat; in der maximal trophogenen Schicht, in 2,5 m Tiefe, beträgt er -0,94. Eine direkte Folge der Anwesenheit der Bakterien ist die Sauerstoffzehrung in der betreffenden Schicht. In $15 \mathrm{~m}$ Tiefe, wo die Assimilationsbilanz negativ ist, besteht ein hoher negativer KK zwischen Membranfilterbakterien und Sauerstoff von $-0,85$.

Wie im Rotsee stellt man auch einen KK zwischen den Plattenzahlen und den Membranfilterbakterien fest, er ist aber geringer.

Die Verteilung der Plattenzahlen (Abb. 77) widerspiegelt, wie diejenige der Membranfilterzahlen, die beiden sommerlichen Anhäufungen organischer Substanz durch das Phytoplankton sowie ein Zurückweichen in der Herbstzirkulation und in der Winterstagnation.

Die K-Analyse zwischen den Plattenzahlen (Tab. 24) und den untersuchten Werten ergibt, wie bei den Membranfilterbakterien, einen engen Zusammenhang der Bakterienflora zu den Produktionsparametern. Besonders auffällig ist ein KK von 0,82 zur Primärproduktion in $0 \mathrm{~m}$ und von 0,73 in $2,5 \mathrm{~m}$ Tiefe. 


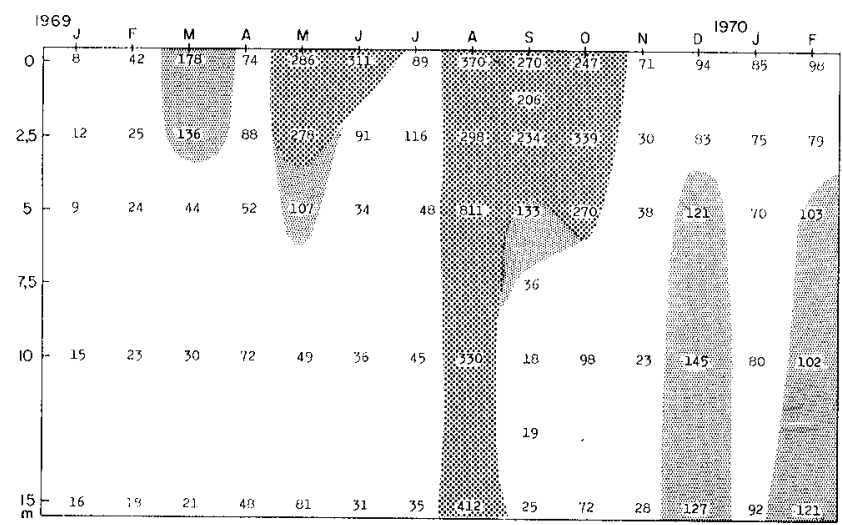

Abb. 77. Plattenzahlen, 10 Zellen/ml, Vierwaldstättersee.

Tab. 24. K-Analyse zum Bezugsparameter Plattenzahlen, Vierwaldstättersee.

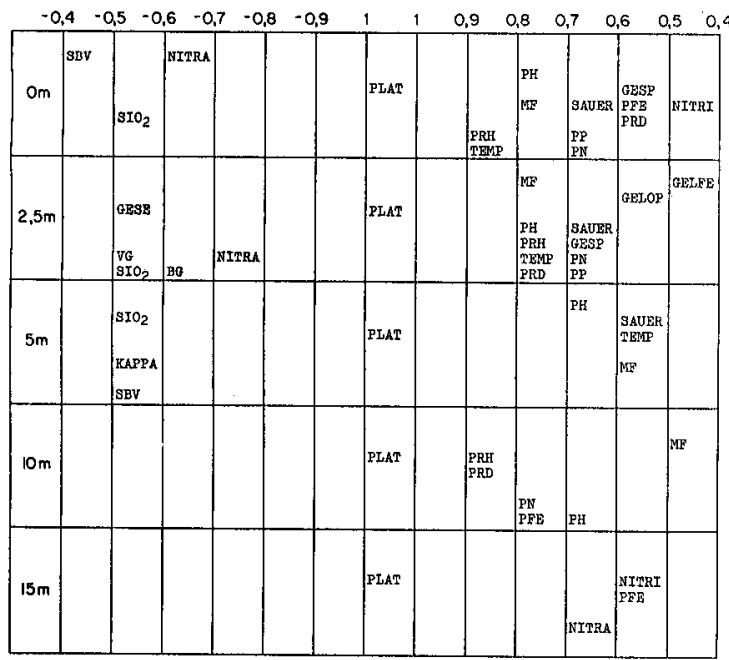

\section{Schlussfolgerungen}

1. Die räumlich-zeitliche Verteilung der Bakterien und des Phytoplanktons ist weitgehend übereinstimmend, d.h. das anfallende organische Material bewirkt am Ort seines Aufbaus höhere Bakterienzahlen.

Deduktiv ergibt sich der Schluss, dass in natürlichen Verhältnissen das durch Exkretion und Autolyse freiwerdende Material sofort abgebaut wird. Diese Befunde decken sich mit denjenigen von OvERBECK $[49,50]$.

2. Bildet man eine Rangfolge der KK, ergibt sich für die Bakterien folgendes Bild in der hauptproduktiven Schicht: 


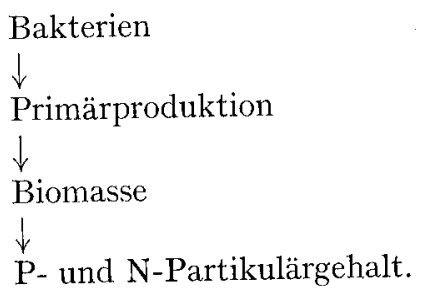

\subsection{Bakterienzahlen und Primärproduktion}

In einer früheren Arbeit (SCHEGG [63]) wurden für die beiden untersuchten Seen Resultate zu den Beziehungen zwischen Primärproduktion und Bakterienzahlen mitgeteilt. Die nachfolgenden Kurven sind einerseits als Ergänzung und Vervollständigung, andererseits als Verdeutlichung der mit den KK beschriebenen Beziehungen zu verstehen.

In beiden Seen wurden für diejenige Tiefenstufe, die bezüglich der Primärproduktion Maximalwerte aufwies (im Rotsee $0 \mathrm{~m}$ und im Vierwaldstättersee 2,5 m), die Membranfilterbakterien gegen die Biomasse und die Primärproduktion aufgetragen.

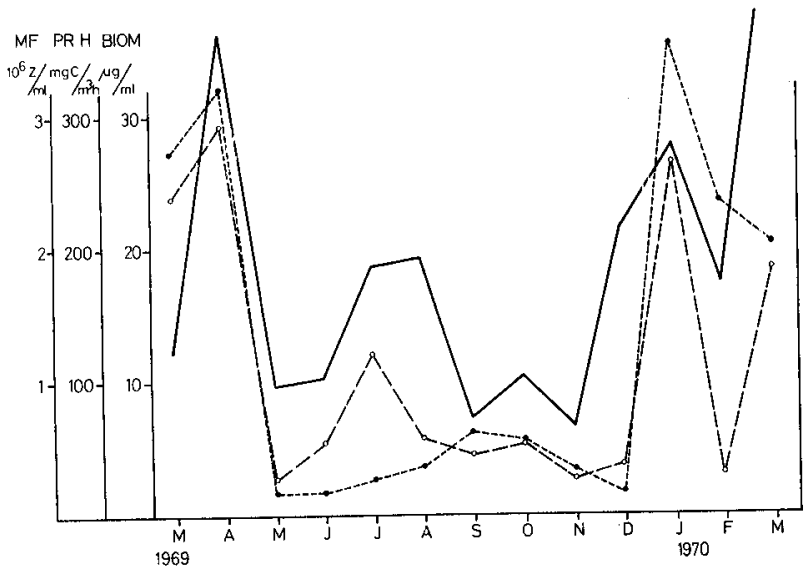

Abb. 78 .

Membranfilterzahlen, $10^{6}$ Zellen $/ \mathrm{ml}$, ( - - ) Primärproduktion Hell, $\mathrm{mg} \mathrm{C}_{\mathrm{ass}} / \mathrm{m}^{3} \mathrm{~h}$ (-_--) Biomasse Phytoplankton, $\mu \mathrm{g} / \mathrm{ml}, 0 \mathrm{~m}$ Tiefe, Rotsee.

In Abb. 78 sind die Werte aus dem Rotsee dargestellt. Die Kurven der drei Parameter laufen weitgehend parallel. Abweichungen finden sich im Juli 1969 und im März 1970, wo die Biomasse eine andere Kurvenform aufweist.

Die analoge Zusammenstellung aus dem Vierwaldstättersee (Abb. 79) ergibt im Prinzip den gleichen gemeinsamen Kurvenverlauf. Entsprechend der Planktonkurve ergeben sich zwei Maxima, nämlich das erste im Frühjahr und das zweite im Spätsommer. Diese Beobachtung der doppelten Maxima in der Bakterienkurve wird unter anderen Autoren auch von Deufel [11], Overbeck [49] und Potaenko [55] gemacht. Auch im Vierwaldstättersee kann ein Divergieren zwischen der Biomassekurve und den beiden anderen Kurven im Mai 1969 festgestellt werden. 


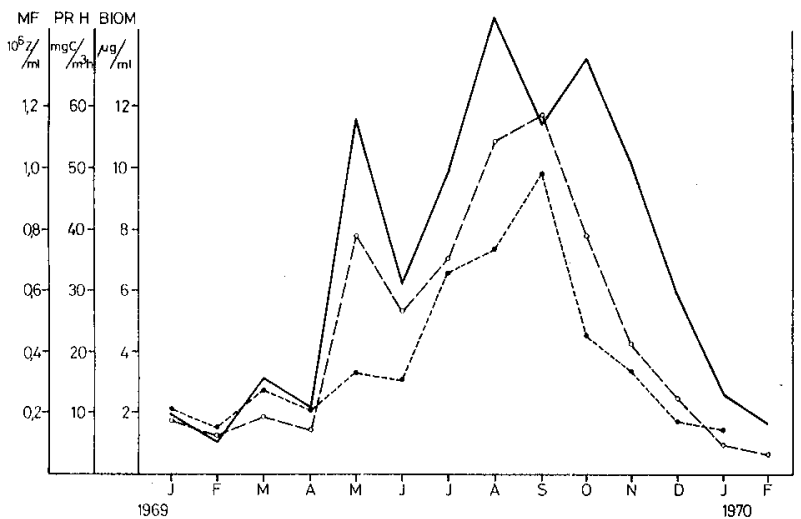

Abb. 79. Membranfilterzahlen, Primärproduktion Hell, Biomasse Phytoplankton, Vierwaldstättersee, $2,5 \mathrm{~m}$ Tiefe (Erklärungen siehe Abb. 78).

\section{Diskussion}

In der hauptproduktiven Schicht ist die Korrelation zwischen der Primärproduktion und den Bakterienzahlen enger als die Beziehung der Bakterien zur vorhandenen Biomasse. Dieses Ergebnis deutet darauf hin, dass die laufende Exkretion einer Planktonpopulation einen bedeutenden substratbildenden Einfluss hat. Diese Befunde decken sich mit den früher mitgeteilten (ScHEGG [63]).

Aus der Tatsache, dass die Bakterienpopulation sehr rasch auf die Primärproduktionsleistung in der hauptproduktiven Schicht reagiert, kann man auf relativ kurze Generationszeiten der Bakterienpopulation schliessen. Solche Generationszeitbestimmungen werden von KUZNEzov et al. [37] angegeben. Im Rybinsk-Stausee fanden Kuznezov et al. [37] Werte für die Generationszeiten zwischen 10 und 110 Stunden. Nach eigenen Untersuchungen (SchEGG [62]) ist im Vierwaldstättersee mit einer Generationszeit von 20 bis 30 Stunden im epilimnischen Bereich zu rechnen, während im Rotsee diese Zahlen etwas tiefer, zwischen 6 und 20 Stunden, liegen.

Die Generationszeiten wurden nach einer Methode durchgeführt, bei der das Wasser filtriert $(5 \mu)$ und unfiltriert während einer gewissen Zeit "in situ et loco" exponiert wurde, wobei die Bakterienpopulation beobachtet wurde (KuZNEzov [36]). Diese Untersuchungen unterliegen teilweise Streuungen, ändern sich doch für die Bakterienpopulation die Verhältnisse in einer Flasche gegenüber dem natürlichen Milieu ziemlich schnell. Theoretisch entspricht dies dem Schritt von einer «MomentFliesskultur» in eine "Batch-Kultur». Immerhin dürften die Grössenordnungen der Generationszeiten von einigen Stunden bis einige Tage der Wirklichkeit entsprechen. Diese Wachstumsgeschwindigkeit der Bakterien übertrifft diejenige anderer Organismen im See, liegt aber weit unterhalb derjenigen einer Bakterienreinkultur unter optimalen Bedingungen.

Es zeigt sich dabei eine sehr wesentliche Tatsache, nämlich dass die in einem See ablaufenden biologischen Prozesse zwar der bekannten Reinkultur-Wachstumskurve mit einer lag-, log-, stationär- und Absterbephase folgen, dass die bakteriologischen Wachstumskurven im natürlichen Gewässer fortwährend und von verschiedenen Faktoren limitiert sind und dass optimales Wachstum nie erreicht wird. Im Endeffekt 
kommt es zu Wachstumsvorgängen, die in der Bilanz nicht mehr exponentiell, sondern mehr oder weniger linear verlaufen. Die Konzentration des jeweils limitierenden Faktors ist immer unter derjenigen des halbmaximalen Wachstums, womit man die äusserst differenzierte und rasche "Antwort» der Bakterienpopulation auf Substratänderungen erklären kann.

\subsection{Bakterienzahlen und Trophiegrad}

ThIEnemann [78] hat den Sauerstoffgehalt zur Charakterisierung des Gewässers verwendet. Damit hat er die Folgen der heterotrophen Aufspaltung organischer Substanz, nämlich die Sauerstoffzehrung, als Kriterium eingeführt. Es soll nun versucht werden, auch bezüglich der Ursache der Sauerstoffzehrung, nämlich der Bakterienpopulation, eine Trophieeinteilung aufzustellen.

Im epilimnischen Bereich der trophogenen Schicht ist die Sauerstoffzehrung von der autotrophen Produktion überlagert, so dass ein direkter Zusammenhang zwischen Sauerstoffzehrung und Bakterienpopulation schwer aufzuzeichnen ist.

In Tab. 25 sind die Bakteriengesamtzahlen (mit der Membranfiltermethode bestimmt) von verschiedenen Seen aufgetragen. Es handelt sich dabai um Zahlen von verschiedenen Autoren aus vollständig verschiedenen Gewässern. Trotzdem lässt sich in weiten Grenzen eine trophische Skala aufstellen.

Da die Zahl und Zusammensetzung der bakteriellen Population eine Folge des vorhandenen Substrates ist, ist es in Seen, die nicht allzu stark mit allochthonem Material belastet sind, naheliegender, die eigentlichen Produktionsparameter zur trophischen Charakterisierung zu verwenden. Die vorliegende Zusammenstellung ist daher eher als eine Übersicht der zu erwartenden Bakteriengesamtzahlen in Gewässern verschiedener Trophieeinteilung zu verstehen.

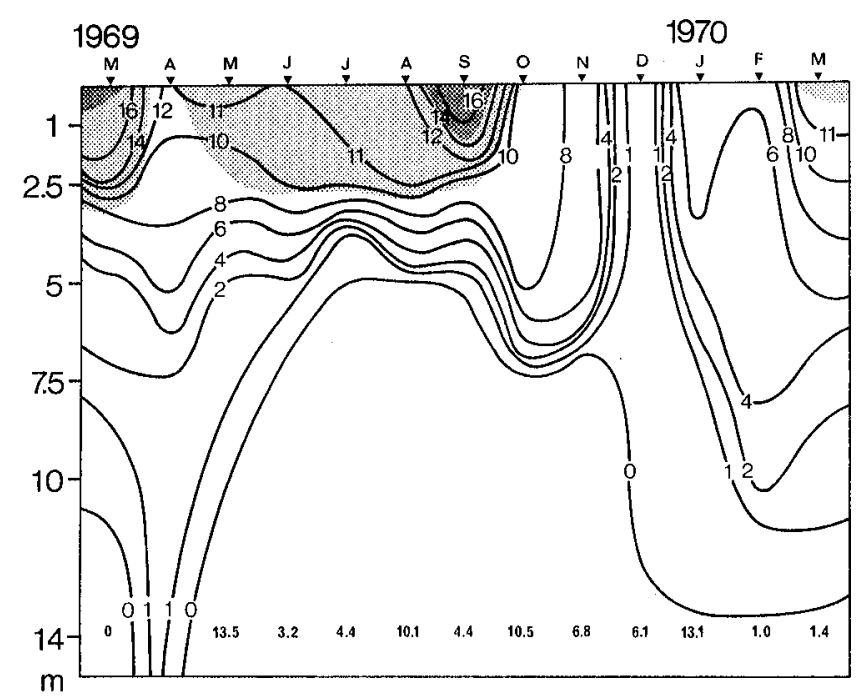

Abb. 80. Sauerstoff $\left(\mathrm{mg} \mathrm{O}_{2} / \mathrm{l}\right)$ and Schwefelwasserstoff $(\mathrm{mg} \mathrm{S} / \mathrm{l})$ im Rotsee. Schwacher Raster: $100 \%$ Sättigung, starker Raster $=150 \%$ Sättigung. Schefelwasserstoff in $14 \mathrm{~m}$ angegeben (nach StadelmanN 1971). 
500

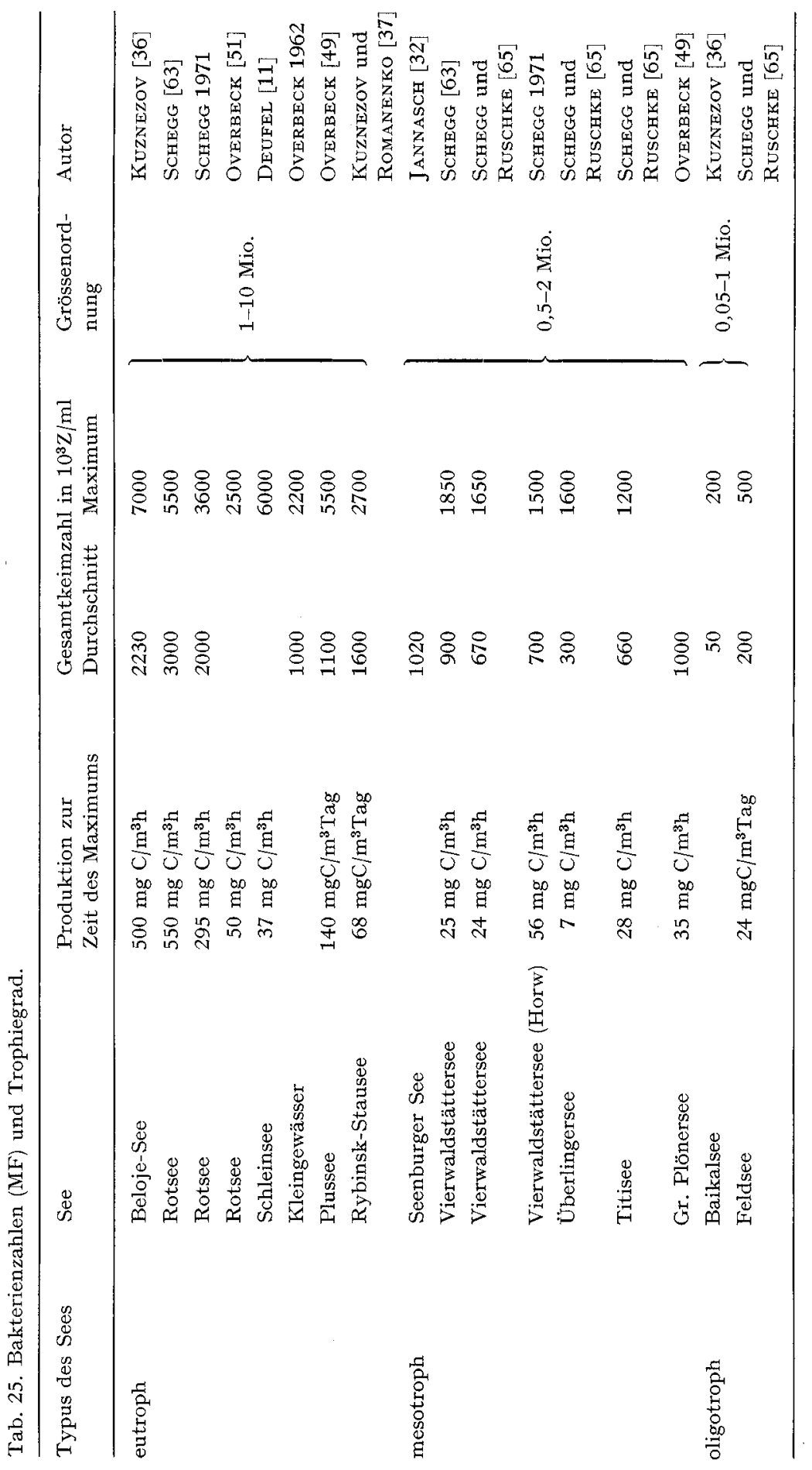




\subsection{Der «kurzgeschlossene Kreislauf»}

Der Begriff des «kurzgeschlossenen Kreislaufs» wurde von OHLE [45] geprägt. Darunter wird der intrabiozönotische Kreislauf von produktionsbeteiligten Stoffen in der trophogenen Schicht verstanden. OHLE [45] hat die Zusammenhänge experimentell, vor allem mittels Sedimentationsmessungen, nachgewiesen. Seine Untersuchungen sind Ausgangspunkt für ein besseres Verständnis der Stoffkreisläufe, insbesondere derjenigen im Epilimnion.

\subsection{Sauerstoff}

Die Sauerstoffverhältnisse im Epilimnion sind eine Folge verschiedener Vorgänge:

1. Austausch an der Kontaktschicht Wasser und Luft.

2. Photosynthetische Exkretion von Sauerstoff durch Phytoplankton.

3. Sämtliche Arten von Atmungsvorgängen und chemischen Oxidationen.

Der Sauerstoffgehalt widerspiegelt den Bilanzsaldo der mannigfaltigen Vorgänge des Gasaustausches. Nur in ganz speziellen Situationen ist es möglich, daraus direkte Schlüsse auf Vorgänge im See zu ziehen. Eine derartige Situation stellte sich im Dezember 1969 (Abb. 80) im Rotsee ein, als infolge einer Zirkulation bis ins Hypolimnion der Sauerstoffgehalt auch in der obersten Wasserschicht auf unter $1 \mathrm{mg} / \mathrm{l} \mathrm{ab}$ sank. Bald darauf kam es zur Eisbedeckung des Sees, wodurch die Diffusion zwischen Luft und Wasser aufgehoben wurde. Der Sauerstoffgehalt, der im Januar 1970 dann unter Eis ermittelt wurde, ist daher das Resultat der Assimilation und der Atmungs-

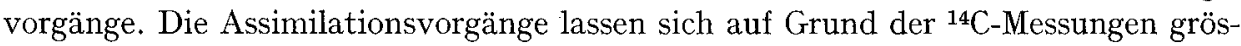
senordnungsmässig berechnen.

Dađurch können die Atmungsvorgänge abgeschätzt werden. Dabei ergeben sich folgende Werte:

Sauerstoffgehalt am 3. Dezember 1969

Sauerstoffgehalt am 15. Januar 1970

$28,7 \mathrm{mg} \mathrm{O} / \mathrm{m}^{2}$

Sauerstoffzunahme im Epilimnion $(0-5 \mathrm{~m})$

$376,7 \mathrm{mg} \mathrm{O} / \mathrm{m}^{2}$

Dieser Wert stellt die Nettozunahme des Sauerstoffs dar.

$348 \mathrm{mg} \mathrm{O} / \mathrm{m}^{2}$

Am 15. Januar 1970 betrug die Photosyntheseleistung $172,2 \mathrm{mgC} / \mathrm{m}^{2} \mathrm{~h}$. Dies entspricht einer Tagesproduktion von etwa $2400 \mathrm{mg} \mathrm{O} / \mathrm{m}^{2}$ (Umrechnungsfaktor auf Tagesproduktion nach 4.331: 8).

Die Respirationsintensität wird nach SteEMAN-Nielson [75] als etwa $10 \%$ der optimalen Photosynthese angenommen. Von den etwa $2400 \mathrm{mg} \mathrm{O}_{2} / \mathrm{m}^{2}$ müssen rund $500 \mathrm{mg}$ Sauerstoff (Tag und Nacht) als Respiration des Phytoplanktons abgezogen werden. Als Nettosauerstoffproduktion bleiben $1900 \mathrm{mg} \mathrm{O} / \mathrm{m}^{2}$ Tag. Dieser Tageswert ist das 5,5fache des durch Akkumulation während des ganzen Monates festgestellten Wertes! Es besteht hier offensichtlich ein sehr grosses Sauerstoffdefizit. Dieses kann auf zwei Arten erklärt werden:

1. durch rein chemische Oxidationsvorgänge und

2. durch bakterielle Veratmung der anfallenden organischen Substanz.

Nimmt man an, dass die rein chemischen Oxidationsvorgänge die Hälfte der Sauerstoffzehrung ausmachen, ergibt sich für den Sauerstoffverbrauch der Bakterien ein Wert von etwa $850 \mathrm{mg} \mathrm{O} / \mathrm{m}^{2}$ Tag. Bei einer Bakterienbesiedlung von 9,17 $10^{12}$ Bakterienzellen $/ \mathrm{m}^{2}$ ergibt dies eine stündliche Atmungsintensität von etwa $4 \cdot 10^{-12}$ 
mg $\mathrm{O}_{2} /$ Zelle und Stunde. Dieser Wert stimmt sehr gut mit demjenigen von KuZNEZov [36] von $6 \cdot 10^{-12} \mathrm{mg} \mathrm{O}_{2} / Z$ elle und Stunde überein.

Kuznezov [36] gibt an, dass in Seen mit kleinem Huminsäurengehalt die rein chemischen Oxidationsvorgänge einen unbedeutenden Prozentsatz ausmachen. Andererseits haben die Arbeiten von BREHM [9] und Gocke [21] ergeben, dass ein grösserer Anteil durch rein chemische Dekomposition freigesetzt wird. Der in diesem Zusammenhang angenommene Wert von $50 \%$ rein chemischer Vorgänge dürfte eine obere Grenze bedeuten.

Vom Sauerstoffverbrauch kann auch mit Hilfe der Atmungsgleichung auf den Substratverbrauch geschlossen werden. Dabei erhalten wir einen Substratverbrauch von etwa $7,5 \cdot 10^{-12} \mathrm{mg}$ Glukose/Zelle und Stunde.

Tab. 26. K-Analyse zum Bezugsparameter Sauerstoff, Rotsee.

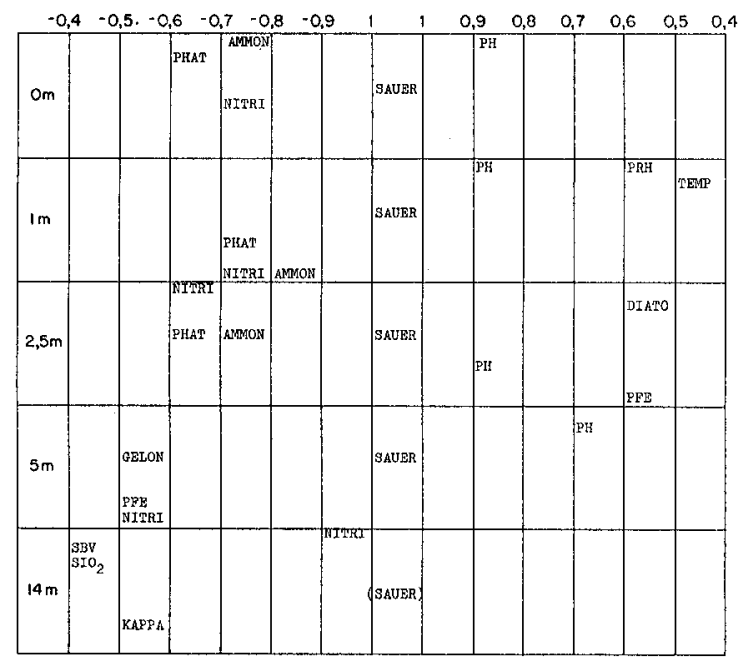

Sucht man die Korrelationen zum Sauerstoffgehalt im Rotsee auf (Tab. 26), stellt man fest, dass nur wenige Parameter in direkter Abhängigkeit vom Sauerstoff sind. Durch eine Teilzirkulation wurde im Dezember 1969 eine Veränderung im Sauerstoffgehalt bewirkt, die mit der Produktion nichts zu tun hatte. Der Sauerstoffgehalt wurde dadurch auch in den folgenden Monaten beeinflusst. Dies kommt auch durch die negativen KK zu Phosphat und Ammonium zum Ausdruck, die ihren Jahresverlauf ebenfalls hauptsächlich der hydrologischen Situation verdankten. Dadurch wird eine K-Betrachtung über das ganze Jahr verfälscht.

Dieses Beispiel weist auf die begrenzte Aussagekraft der Korrelationsbetrachtungen hin.

Die epilimnischen Sauerstoffgehalte im Vierwaldstättersee (Abb. 81) fielen zeitlich mit den hauptproduktiven Perioden zusammen. Ein Maximum von $14 \mathrm{mg} \mathrm{O}_{2} / 1 \mathrm{im}$ August 1969 in der Tiefe von $10 \mathrm{~m}$ war auf eine Einschichtung von Oscillatoria rubescens zurückzuführen.

Obwohl im Vertikalprofil eine geringe Erhöhung der Bakterienzahlen festgestellt werden konnte, fiel diese relativ klein aus. Es ist möglich, dass durch Oscillatoria 
$33 / 2,1971$

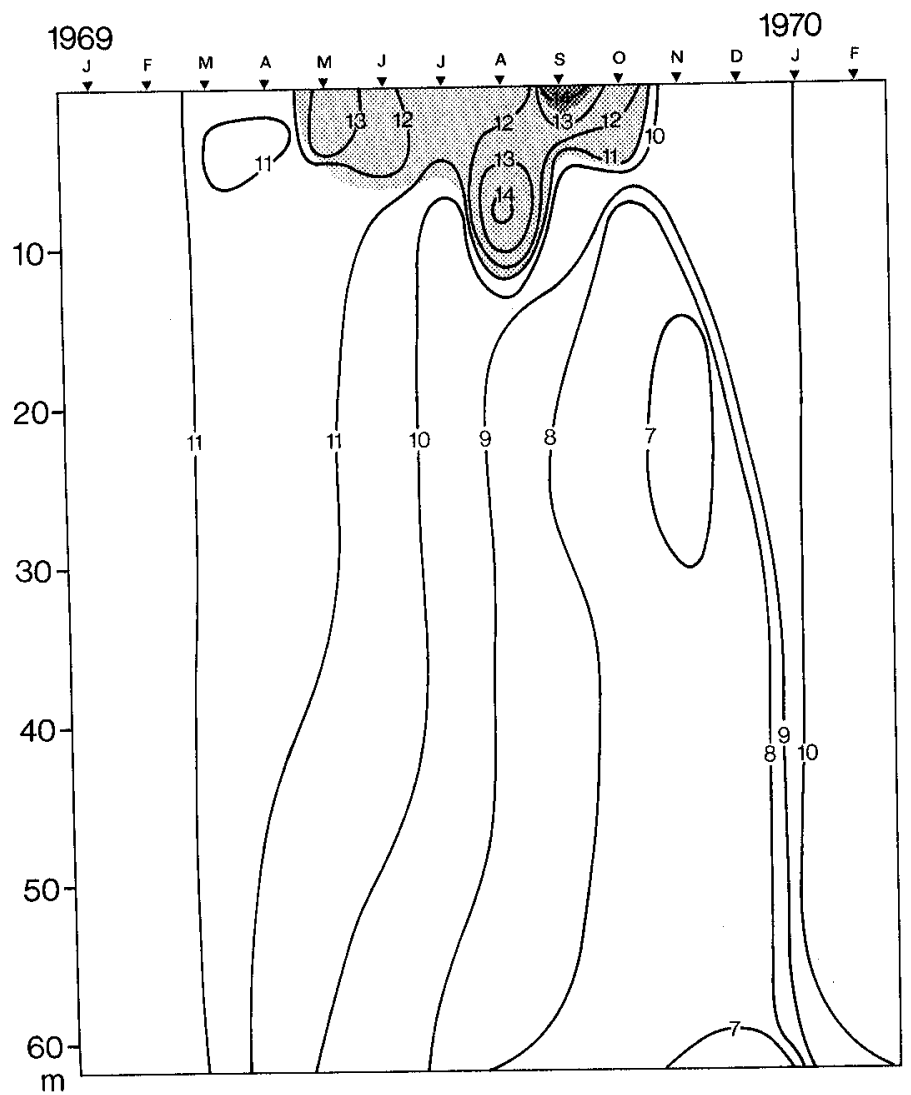

Abb. 81. Sauerstoff der Horwer Bucht $\left(\mathrm{mg} \mathrm{O}_{2} / 1\right)$. Schwacher Raster $=100 \%$ Sättigung, starker Raster $=150 \%$ Sättigung (nach STADELMANN 1971).

Tab. 27. K-Analyse zum Bezugsparameter Sauerstoff, Vierwaldstättersee.

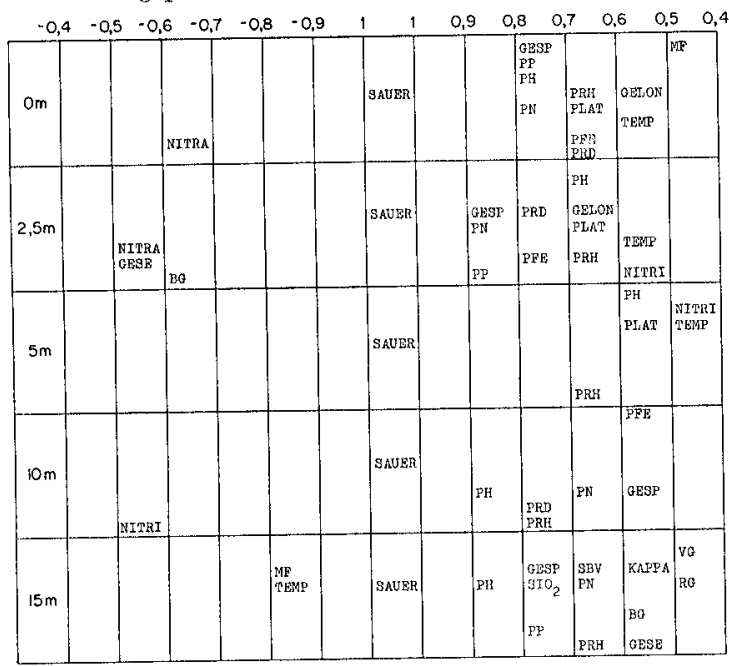


rubescens eine temporäre Hemmung der bakteriellen Entwicklung auftritt. Im Oktober 1969 zeigte sich eine ausgesprochene Sauerstoffzehrung von 7,5 m Tiefe an abwärts; diese Veränderung kam auch im Vertikalprofil der Bakterien zum Ausdruck, indem im Oktober 1969 die grössten Werte der Bakterienentwicklung gefunden wurden, wobei ebenfalls grosse Zahlen bis auf $15 \mathrm{~m}$ Tiefe vorkamen.

Die $K$-Analyse des Sauerstoffs für den Vierwaldstättersee (Tab. 27) ergibt ein prinzipiell anderes Bild als diejenige im Rotsee. Im Vierwaldstättersee ist der Sauerstoffgehalt ausschliesslich produktionsbedingt. Diese Beziehung ist allerdings nicht ganz so eng, wie man sie erwarten würde; die Produktionsparameter korrelieren zwischen 0,6 und 0,8. Dies kann dadurch erklärt werden, dass die Veränderungen im Sauerstoffgehalt durch eine Änderung in der Umsatzgeschwindigkeit des Sauerstoffs bewirkt werden.

\section{Diskussion}

Wie in den vorhergehenden Betrachtungen gezeigt wurde, ist der aktuelle Sauerstoffgehalt eigentlich nur der Bilanzsaldo einer quantitativ sehr viel grösseren Umsetzung. Im berechneten Beispiel wird ein Sauerstoffatom im «kurzgeschlossenen Kreislauf» bis zu 10mal täglich umgesetzt. Jede Veränderung im Sauerstoffgehalt ist so zu verstehen, dass das Ökosystem auf der Produktions- oder auf der Destruktionsseite temporär mehr leistet als auf der anderen. Ein wesentlicher Einwand, den man diesen Überlegungen entgegenhalten kann, ist die Tatsache, dass wir trotz relativ hohen Bakterienzahlen im Hypolimnion oligo-mesotropher Seen keine grössere Sauerstoffzehrung vorfinden. Dies lässt sich aber so erklären, dass die Bakterienpopulation in jeder Schicht die dem Substratangebot entsprechende Aktivität, Umsatzgeschwindigkeit, zeigt, dass also in tieferen Schichten die Umsatzgeschwindigkeit in der bakteriellen Tätigkeit sinkt. Es lässt sich demnach schon aus der Sauerstoffkurve und der Bildung metalimnischer Sauerstoffminima (z.B. Vierwaldstättersee im November 1969, Abb. 81) der Sedimentationsweg angeben, den die organische, assimilierbare Substanz zurücklegt, bis sie abgebaut ist.

Auf derselben Basis liessen sich die $\mathrm{CO}_{2}$-Werte im Wasser berechnen. Wie OHLE [48] gezeigt hat, ist es möglich, aus hypolimnischer $\mathrm{CO}_{2}$-Anreicherung unter Berücksichtigung der Sedimentationsraten auf die Produktion und deren Abbau zu schliessen.

\section{Schlussfolgerungen}

Der aktuelle Sauerstoffgehalt sagt über die Vorgänge, die ständig ablaufen, wenig aus, insbesondere ist er für die einzelnen Vorgänge quantitativ vernachlässigbar klein. Er ist aber, da er die Bilanz der Vorgänge zieht, ein äusserst sensibler Index für qualitative Veränderungen im Stoffhaushalt. Quantitative Umsatzraten können nur auf Grund von produktionsbiologischen Zahlen errechnet werden.

\subsection{Stickstoff und Phosphor}

Stadelmann [73] kommt auf Grund von detaillierten Messungen zur Stickstoffbilanz in den beiden untersuchten Seen (unter Berücksichtigung der natürlichen $\mathrm{Zu}$ fuhr, der Zufuhr durch Abwasser, der Zufuhr aus der Luft, der Zehrung an gelösten Stickstoffverbindungen während der Stagnation, der Verluste durch Sedimentation und auf Grund der Produktionsmessungen) zu folgenden Ergebnissen: 
Vierwaldstättersee:

Primärproduktion

Externe Zufuhr und Zehrung

$58,7 \mathrm{gN} / \mathrm{m}^{2}$

Durch kurzgeschlossenen Kreislauf geliefert

Rotsee:

Primärproduktion

$66,9 \mathrm{gN} / \mathrm{m}^{2}$

Externe Zufuhr und Zehrung

Durch kurzgeschlossenen Kreislauf geliefert

Nach diesen Werten, die für den Durchschnitt der Stagnationsperiode gelten, wurden in beiden Seen etwa 60\% des Stickstoffs durch den «intrabiozönotischen Kreislauf» geliefert.

Wie effektiv der «kurzgeschlossene Kreislauf» in Extremsituationen wirken kann, zeigt sich bei Berechnungen aus Untersuchungen vom August, September und Oktober 1969 im Rotsee (Tab. 28).

Tab. 28. Berechnung des «kurzgeschlossenen Kreislaufs» bezüglich Stickstoff im Rotsee. Die Werte gelten für die trophogene Schicht $(0-5 \mathrm{~m}) . \mathrm{E}=$ Erneuerungskoeffizient (nach STadeLmann [73].) $\mathrm{E}=\frac{\text { "standing crop» }}{\text { Tagesprimärproduktion }}$.

\begin{tabular}{llll}
\hline & 14. Aug. 1969 & 11. Sept. 1969 & 10. Okt. 1969 \\
\hline Vorhandener partikulärer $\mathrm{N}$ & $1,43 \mathrm{~g} / \mathrm{m}^{2}$ & $1,19 \mathrm{~g} / \mathrm{m}^{2}$ & $1,34 \mathrm{~g} / \mathrm{m}^{2}$ \\
$\mathrm{E}$ & 0,22 & 0,37 & 0,28 \\
Tageszuwachs & $0,31 \mathrm{~g} / \mathrm{m}^{2}$ & $0,440 \mathrm{~g} / \mathrm{m}^{2}$ & $0,375 \mathrm{~g} / \mathrm{m}^{2}$ \\
Vorh. Ammon-, Nitrit-, Nitrat-N & $0,810 \mathrm{~g} / \mathrm{m}^{2}$ & $0,55 \mathrm{~g} / \mathrm{m}^{2}$ & $0,090 \mathrm{~g} / \mathrm{m}^{2}$ \\
\hline
\end{tabular}

Am 10. Oktober 1969 wurde mehr als die vierfache Menge des vorhandenen gelösten anorganischen Stickstoffs als partikulärer Stickstoff aufgebraucht.

Berechnung der stündlichen Stickstoffumsatzrate: Teilt man den Tageszuwachs (10. Oktober 1969) durch den experimentell bestimmten Faktor 8,0 (Tagesproduktion zur stündlichen Produktion), so erhält man den pro Stunde umgesetzten Stickstoff. Er betrug $47 \mathrm{mgN} / \mathrm{m}^{2}$. Bei einer bakteriellen Besiedlung von 5,29 $10^{12}$ Zellen $/ \mathrm{m}^{2}$ ergibt dies einen Stickstoffumsatz von $8,9 \cdot 10^{-12} \mathrm{mgN} /$ Bakterium und Stunde.

\section{Schlussfolgerungen}

An diesen drei Tagen in der Sommerstagnation wurde der tägliche N-Bedarf praktisch vollständig vom «kurzgeschlossenen Kreislauf» gedeckt. Dies zeigte sich auch darin, dass die Abnahme des gelösten organischen Stickstoffs von 0,8 auf $0,09 \mathrm{gN} / \mathrm{m}^{2}$ in den zwei Monaten einer täglichen Abnahme von $0,012 \mathrm{gN} / \mathrm{m}^{2}$ entsprach. Dies waren 2-3\% des täglichen Bedarfs. Demnach wurden in den Sommermonaten, in denen die Nährstoffe grösstenteils aufgebraucht waren, 90-95\% der Nährstoffe, die zur Erhaltung und Vermehrung der Phytoplanktonpopulation dienten, aus dem «kurzgeschlossenen Kreislauf» regeneriert.

Ähnliche Werte konnten im Vierwaldstättersee erhoben werden. Dort wurde innert 2-3 Tagen der vorhandene gelöste anorganische Stickstoff aufgebraucht. 
Phosphate:

Auf Grund von Untersuchungen in der Horwer Bucht gibt Gächter [19] an, dass der Phosphatbedarf der trophogenen Schicht bis zu zwei Dritteln aus dem «kurzgeschlossenen Kreislauf» gedeckt wird.

In den beiden untersuchten Seen zeigte sich eine ausgeprägte Phosphatzehrung im Sommer, indem während dreier Monate die Phosphatgehalte äusserst gering waren. In diesen Monaten ist für den Phosphor mit einer ähnlichen Umsatzgeschwindigkeit zu rechnen, wie dies für den Stickstoff berechnet wurde.

Tab. 29. Berechnung des "kurzgeschlossenen Kreislaufs" bezüglich Phosphat im Rotsee.

\begin{tabular}{lccc}
\hline & 14. Aug. 1969 & 11. Sept. 1969 & 10. Okt. 1969 \\
\hline Partikulärer Phosphor & $151 \mathrm{mg} / \mathrm{m}^{2}$ & $174 \mathrm{mg} / \mathrm{m}^{2}$ & $175 \mathrm{mg} / \mathrm{m}^{2}$ \\
E (nach STADELMANN [73]) & 0,22 & 0,37 & 0,28 \\
Eingebautes P/Tag & $33 \mathrm{mg} / \mathrm{m}^{2}$ & $64 \mathrm{mg} / \mathrm{m}^{2}$ & $49 \mathrm{mg} / \mathrm{m}^{2}$ \\
Vorh. PO 4 -P & $43 \mathrm{mg} / \mathrm{m}^{2}$ & $12 \mathrm{mg} / \mathrm{m}^{2}$ & $28 \mathrm{mg} / \mathrm{m}^{2}$ \\
\hline
\end{tabular}

In Tab. 29 ist der Phosphorbedarf pro Tag für die Untersuchungstage, an denen der Phosphatgehalt im Rotsee klein war, ausgerechnet. Am 14. August 1969 wurde etwas weniger als der vorhandene gelöste Phosphor als partikulärer Phosphor eingebaut, während am 11. September 1969 die fünffache und am 10. Oktober 1969 die doppelte Menge zur Bildung von Biomasse benötigt wurde.

Bei einem stündlichen Zuwachs von $8 \mathrm{mg} \mathrm{P} / \mathrm{m}^{2}$ ergibt sich für die anwesende Bakterienpopulation am 11. September 1969 von $3,52 \cdot 10^{12}$ Zellen eine Umsatzrate von $2,3 \cdot 10^{-12} \mathrm{mgP} /$ Bakterium und Stunde. Diese Umsatzraten pro Bakterienzelle sind als Grössenordnungswerte anzusehen und gelten für den speziellen Fall.

\section{Zusammenfassung}

Sowohl der vorhandene gelöste anorganische Stickstoff als auch das gelöste Phosphat sind zur Aufrechterhaltung der Primärproduktion in der Sommerstagnation absolut ungenügend. Die vorhandene Menge wäre in den Sommermonaten innerhalb weniger als eines Tages aufgebraucht. Die Tatsache, dass trotzdem eine relativ grosse Phytoplanktonpopulation vorhanden war, kann nur durch die grosse Umsatzgeschwindigkeit des «kurzgeschlossenen Kreislaufs» erklärt werden. Es ist möglich, dass für die beiden Komponenten Stickstoff und Phosphor auch allochthone Einflüsse eine Rolle spielen. Diese Vorgänge sind aber im Vergleich zur räumlichen Verzahnung, die der "kurzgeschlossene Kreislauf» aufweist, ausserordentlich langsam, so dass für eine Tagesproduktion dieser allochthone Einfluss vernachlässigt werden kann. Für den See werden sie erst voll wirksam, wenn die Nährstoffe dieser meist punktförmigen Quellen homogen über den See verteilt sind. Die Bilanzrechnungen von GÄCHTER [19] für den Phosphor einerseits und von StadelmanN [73] für den Stickstoff andererseits ergeben in der Horwer Bucht übereinstimmend etwa zwei Drittel der Nachlieferung von benötigtem gelöstem Stickstoff und Phosphor aus dem «kurzgeschlossenen Kreislauf». 


\subsection{Sedimentation, Destruktion und Primärproduktion}

Nach Berechnungen von Stadelmann [73] aus Sedimentationsmessungen von BLOESCH [8] wurde im Vierwaldstättersee nur $8 \%$, im Rotsee etwa $30 \%$ der Primärproduktion im Sediment unter der trophogenen Schicht aufgefangen. Diese Zahlen beziehen sich auf die Stickstoffkomponenten und die trophogene Schicht. In eingehenden Sedimentationsmessungen hat OHLE [48] in norddeutschen Seen nachgewiesen, dass nur ein kleiner Prozentsatz der im Epilimnion gebildeten Biomasse bis zum Grund aussedimentiert. Daraus ersieht man, dass auch aus Sedimentationsuntersuchungen die Existenz und Leistungsfähigkeit des «intrabiozönotischen Kreislaufs» experimentell nachgewiesen werden kann. Dabei handelt es sich aber auch wieder nur um eine Bilanzbetrachtung, die die umgesetzten Mengen innerhalb des Kreislaufs nicht berücksichtigt. Diese dürften, wie dies für den Sauerstoff, den Phosphor und. den Stickstoff gezeigt wurde, beträchtlich höher liegen als die Mengen, die in der Bilanz auftreten.

Eine weitere Arbeit zum Phosphorkreislauf, der Primärproduktion und Sedimentationsraten wird aus derselben Untersuchungsserie von BLOESCH [8] erscheinen.

\section{Experimentelle Untersuchungen}

Der Zusammenhang von Bakterien und Phytoplankton im See kann nur deduktiv und deskriptiv erfasst werden. Will man das komplexe System eines Sees in seinen Wechselwirkungen und vor allem die Geschwindigkeit derselben untersuchen, so drängen sich Experimente mit standardisierten Bedingungen und Organismen auf. Im folgenden werden zwei Experimentalserien geschildert, wobei im Verlaufe der ersten, in Abweichung von den Seeverhältnissen, eine Reinkultur von Algen neben einer Mischpopulation von Begleitbakterien benützt wurde. Dabei standen sich Produzent und Destruent in derselben räumlichen Verteilung gegenüber.

Die Idee, die der zweiten Versuchsserie zugrunde lag, war eine Trennung der beiden Organismengruppen, und zwar derart, dass sie nicht in unmittelbarem Kontakt zueinander standen, deren extrazelluläre Tätigkeit in der Wechselwirkung hingegen erhalten blieb.

\subsection{Experiment I}

Im Zusammenhang mit Untersuchungen über die Nährstoffaufnahmekinetik von KrUMmenacher [35] an einer nicht bakterienfreien Kultur von Microcystis sp. (Algothek EAWAG, Nr. 167, Ml) wurde neben dem Algenwachstum die Entwicklung der Begleitbakterienmischkultur verfolgt. Eine Voraussetzung dabei bestand darin, dass die Bakterien in der vorliegenden anorganischen Nährlösung an und für sich kein Substrat zur Verfügung hatten. Um die Geschwindigkeit der Nährstoffaufnahme und das Wachstum bei verschiedenen Nährstoffkonzentrationen zu untersuchen, wurden wechselnde Mengenverhältnisse von $P: N$ (als Phosphat und Nitrat) zugegeben. Dabei wurde versucht, folgende Fragestellungen zu beantworten:

1. Stehen die Begleitbakterien in einem Verhältnis zur Algenkultur?

2. Besteht ein Zusammenhang zwischen Bakterien- und Algenwachstum und wie verlaufen diese beiden Wachstumskurven? 


\subsection{Methodik}

Sämtliche Arbeiten wurden steril ausgeführt. Die Microcystiskultur wurde in eine autoklavierte P- und N-freie Stammlösung eingeimpft und in einem 2-Liter-G-20Glaskolben unter Dauerlicht (Fluoreszenzröhren) und Belüftung kultiviert (Lichtintensität $6000 \mathrm{Lux}$ ). Die Temperatur lag bei $24^{\circ} \mathrm{C}$. In diese Stammlösung wurde Nitrat und Phosphat in den angegebenen konstanten Verhältnissen eingebracht und täglich auf die Ausgangskonzentration ersetzt im Sinne einer semikontinuierlichen Nährstoffzufuhr.

Die jeweiligen Algenzellzahlen wurden durch Auszählung der mit Erythrosin gefärbten Membranfilter bestimmt. Die Präparation erfolgte analog derjenigen der Membranfilter für Bakterienzählungen gemäss Angaben auf Seite 432. Diese Präparation hat gegenüber dem normalen Auszählverfahren nach Utermöhl bedeutende Vorteile, indem die Membranfilter in unbeschränkter Menge laufend hergestellt, bis zur Zählung verwahrt werden können und die entsprechenden Präparate auch später als Belege noch vorhanden sind. Die Zählung auf dem Membranfilter ist zudem bei uniformen Algenkulturen äusserst einfach. Die Keimzahlen wurden nach dem früher angegebenen Gussplattenverfahren (siehe Seite 431) ermittelt.

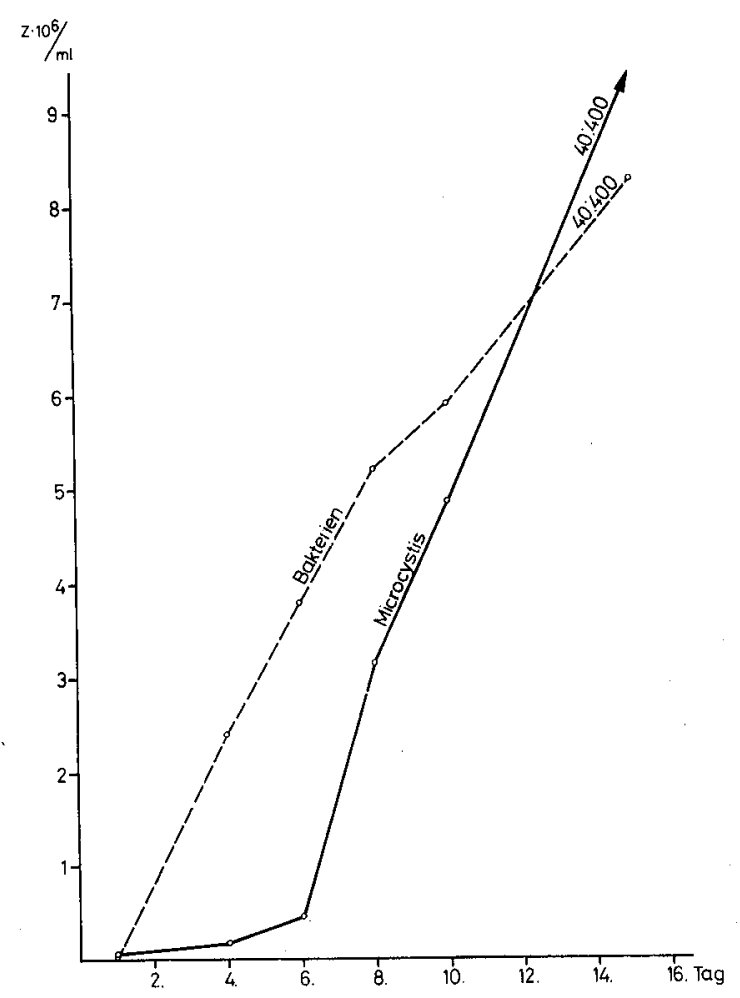

Abb. 82. Wachstumskurve Microcystis sp. $\left(10^{6}\right.$ Zellen $\left./ \mathrm{ml}\right)(-)$, Wachstumskurve Bakterien (Plattenzahlen) $\left(10^{6}\right.$ Zellen $\left./ \mathrm{ml}\right)(--\cdots)$. 


\subsection{Resultate und Interpretation}

In $\mathrm{Abb} .82$ sind die maximalen Wachstumskurven aufgetragen. Interessant ist

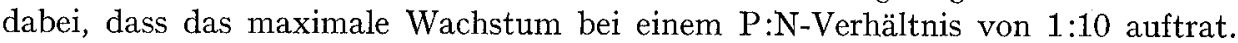
Dieses Verhältnis lag am nächsten bei dem Verhältnis 1:7,2 (Sтuмm [77]).

Die Kulturen wurden bis zum 16. Tage nach dem Beimpfen verfolgt. Dabei wies die Bakterienkultur anfänglich ein rascheres Wachstum als die Algenkultur auf. Dies änderte sich zu Beginn der log-Phase der Algenkultur.

In Abb. 83 sind die Wachstumskurven bei verschiedenen Nitratgehalten und konstantem P-Gehalt von $80 \mu \mathrm{g} / \mathrm{l}$ aufgetragen. Prinzipiell verliefen die Algenwachstumskurven in der lag-Phase bis zum 6 . Tage ungeachtet des $\mathrm{P}: \mathrm{N}$-Verhältnisses immer ungefähr gleich, während in der anschliessenden log-Phase die Unterschiede in den Konzentrationen des Nährmediums starke Differenzen in der Wachstumsgeschwindigkeit bewirkten.

Auf der rechten Seite in Abb. 86 sind die Bakterienwachstumskurven aufgetragen. Starkes Wachstum setzte in der Bakterienkultur bereits in der lag-Phase der Algen ein. Zwischen dem 8. und 10. Tag, als die Algenkulturen die grösste Zunahme der Zellzahlen erfuhren, trat eine Hemmung des Bakterienwachstums auf und zwar um so stärker, je kleiner die Konzentration an verfügbarem Nitrat war. Beim Abflachen der Algenwachstumskurven verstärkte sich das Wachstum der Bakterien neuerdings.

In der lag-Phase der Algen ist die Nährstoffzusammensetzung für das Algenwachstum nicht limitierend. Die Exkretionsvorgänge sind daher im Verhältnis zur Algenbiomasse relativ gross. Die Bestätigung dieser Aussage fanden wir darin, dass die
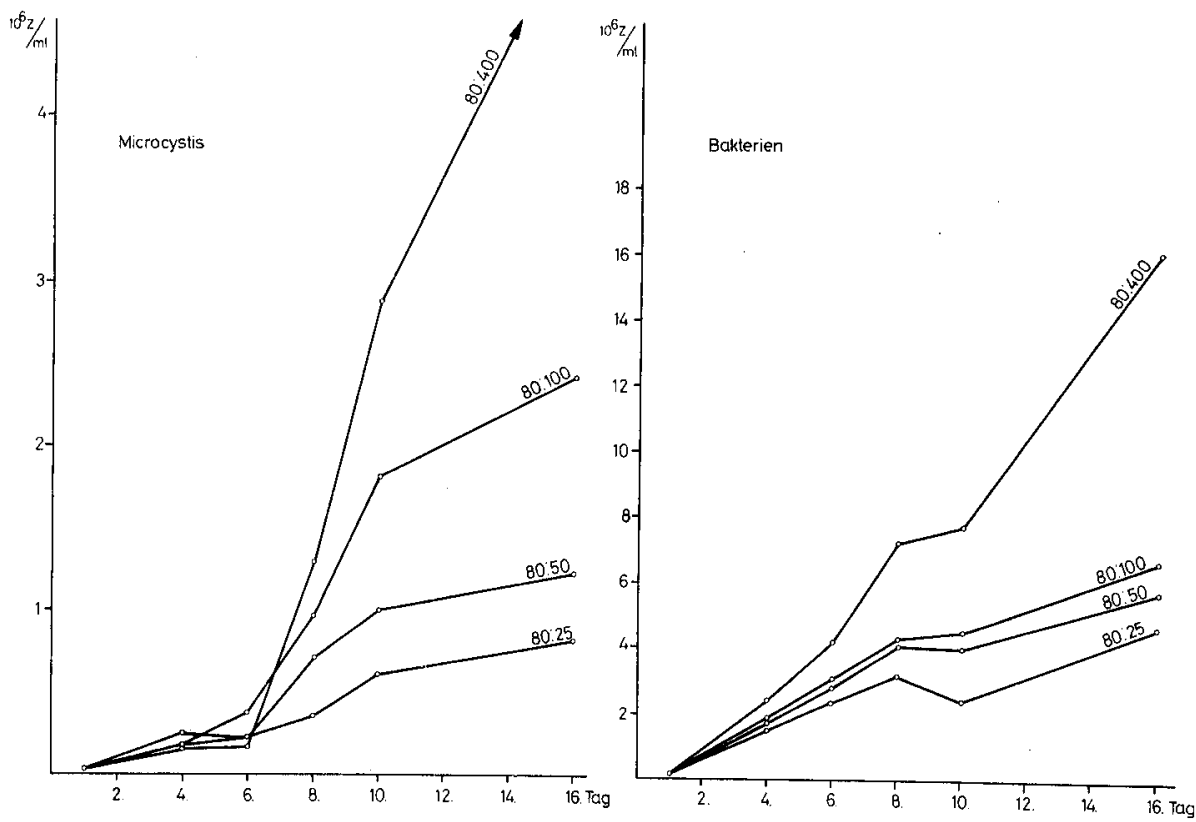

Abb. 83. Wachstumskurven von Microcystis sp. und Begleitbakterien-Mischpopulation bei verschiedenen P: N-Verhältnissen als Phosphat und Nitrat $(\mu \mathrm{g})$ in der Nährlösung. 
Bakterienzahlen schneller zunahmen als die Algenpopulation. In der Mitte der logPhase der Algenkultur (zwischen dem 8. und 10. Tage) wurde offenbar ein grosser Teil der Stoffe intrazellulär umgesetzt, das Wachstum wurde bezüglich Nährstoffkonzentration optimal und dadurch wurde das Wachstum durch die Nährstoffkonzentration limitiert. Die Exkretion wurde dabei trotz erhöhter Algenzahlen kleiner. Die deutliche Verlangsamung bis zur Stagnation des Bakterienzuwachses zwischen dem 8. und dem 10. Tage bestätigte diese Interpretation.

Beim Abflachen der Wachstumskurven von Microcystis zwischen dem 10. und 16. Tage traten wieder grössere Exkretionsmengen auf, die teilweise bereits auf autolytische Vorgänge zurückzuführen waren. Diese Substratanreicherung bewirkte ein erneutes Anwachsen der Bakterienzahlen.
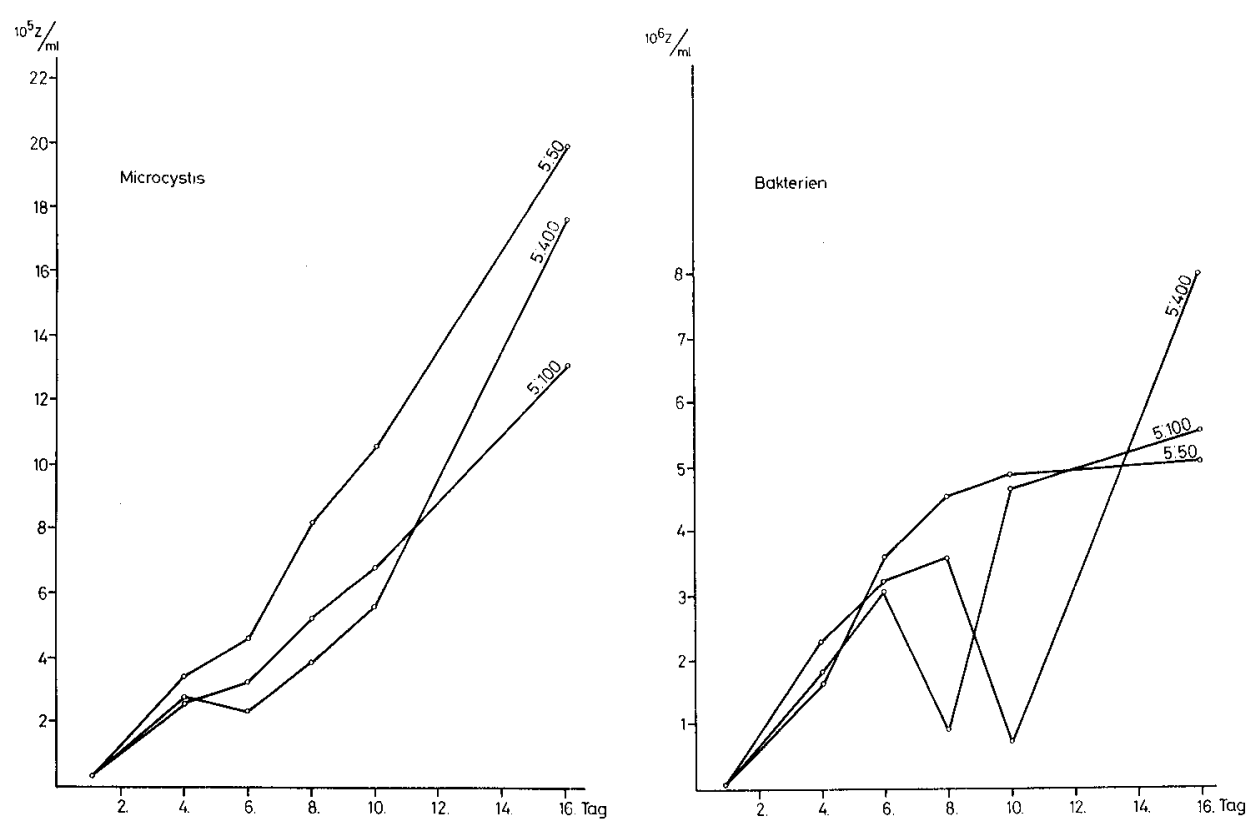

Abb. 84.

Ein wesentlich differenzierteres Bild ergab sich bei einer konstanten Phosphorkonzentration von nur $5 \mu \mathrm{g} / \mathrm{l}$ (Abb. 84). Die maximale Wachstumskurve wurde bei einem P:N-Verhältnis von 5:50 erreicht. Dabei wirkte eine Steigerung der Nitratzugabe weder in der lag- noch in der log-Phase wachstumsfördernd auf die Algenpopulation. Dies zeigte sich auch bei den Bakterien. Es fehlte beim P:N-Verhältnis

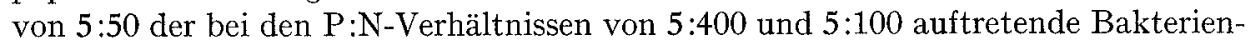
hemmeffekt zwischen dem 8. und 10. Tag. Man kann bei diesen Wachstumsbedingungen von einem ausgewogenen System sprechen. Die Bakterienwachstumskurve erfuhr hingegen eine Begrenzung vom 10. Tag an durch das vollständige Aufbrauchen des Phosphates (Krummenacher [35]). Auf dieselbe Ursache können die beiden 
Minima in den Bakterienkurven bis P:N-Verhältnissen von 5:400 und 5:100 zwischen dem 8. und 10. Tage zurückgeführt werden.

\subsection{Schlussfolgerungen}

1. Die Befunde bejahen die erste eingangs gestellte Frage eindeutig, indem ein direkter Zusammenhang zwischen dem Algenwachstum und der Bakterienpopulation festgestellt werden konnte. Jedes Bakterienwachstum war eine Folge der Anreicherung des Substrates durch die Algenpopulation, da kein anderes organisches Material als energetische Grundlage für heterotrophes Wachstum zur Verfügung stand. Eine nährstoffbedingte Erhöhung des Algenwachstums ergab eine substratbedingte Erhöhung des Bakterienwachstums.

Optimale Nährstoffverhältnisse wirkten somit direkt und indirekt auf das Bakterienwachstum. Die Substratabgabe der Algenpopulation war von dessen physiologischem Zustand abhängig. Bei gleichem physiologischem Zustand war die Substratabgabe annähernd eine lineare Funktion der vorhandenen Biomasse.

2. Die Bakterienpopulation «antwortet» mit einem verstärkten Wachstum auf eine Erhöhung und Produktion der Algenpopulation. Die "Antwort» der Bakterienpopulation erfolgt sofort; dies ist durch die kurzen Generationszeiten der Bakterien erklärlich.

3. Das Wachstum der Bakterien in einem Mischsystem ist grundsätzlich verschieden von demjenigen in einem definierten Substratsystem.

\subsection{Experiment $I I$}

Im folgenden physiologischen Experiment in vitro wurde versucht, im See gefundene Erkenntnisse zu verifizieren. Ein taugliches Mittel dafür stellte die gemeinsame Aufzucht von Bakterien und Algen dar, und zwar derart, dass Algen- und Bakterienzellen räumlich getrennt wurden, deren extrazelluläre gegenseitige Beeinflussung aber erhalten blieb. Im Gegensatz zum vorangehenden Experiment wurde hier mit einer bakterienfreien Kultur von Chlamydomonas sp. (Sammlung der Universität Göttingen) und einer Bakterienmischkultur aus dem Rotsee gearbeitet. Das Ziel der Untersuchung war die Beantwortung folgender Frage:

Eine Algenkultur gibt durch exkretorische Vorgänge organische Verbindungen ins Milieu ab. Wie lange hat nun ein C-Atom, das in der Alge inkorporiert war, bis es in parallel laufenden Bakterienanreicherungskulturen auftritt?

\subsection{Methodik}

Wie aus Abb. 85 und $86 \mathrm{zu}$ ersehen ist, wurde mit einem "Spinner-flask» der Fa. Belcot als Doppelkulturgefäss gearbeitet. Die Chlamydomonaskultur wurde nach steriler Abimpfung während dreier Tage angezogen, wobei die Kultur im Dauerlicht auf einer Schüttelmaschine 10 Minuten/Stunde geschüttelt wurde. Die Lichtintensität lag bei etwa 2000 Lux und die Temperatur im thermostatierten Raum bei $20-21^{\circ} \mathrm{C}$. Am 3. Tage wurde den Kulturen $20 \mu \mathrm{C} \mathrm{NaH}{ }^{14} \mathrm{CO}_{3}$ in steriler Lösung zugegeben und die Kulturen während weiterer drei Tage unter den vorgängig geschilderten Bedingungen angezogen. Als Nährlösung wurde die modifizierte Z8-Lösung von Zehnder (nach Staub [74]) verwendet. Am 6. Tage wurde die Algenkultur mittels eines Steril- 


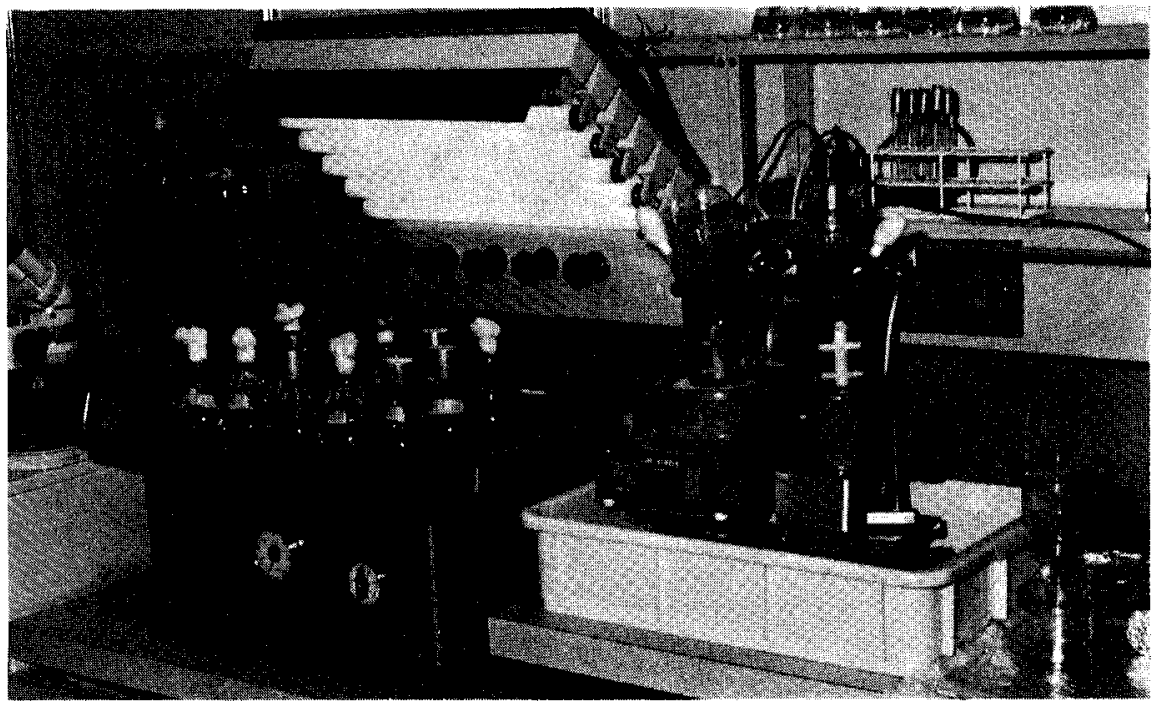

Abb. 85. Versuchsanordnung Experiment II.

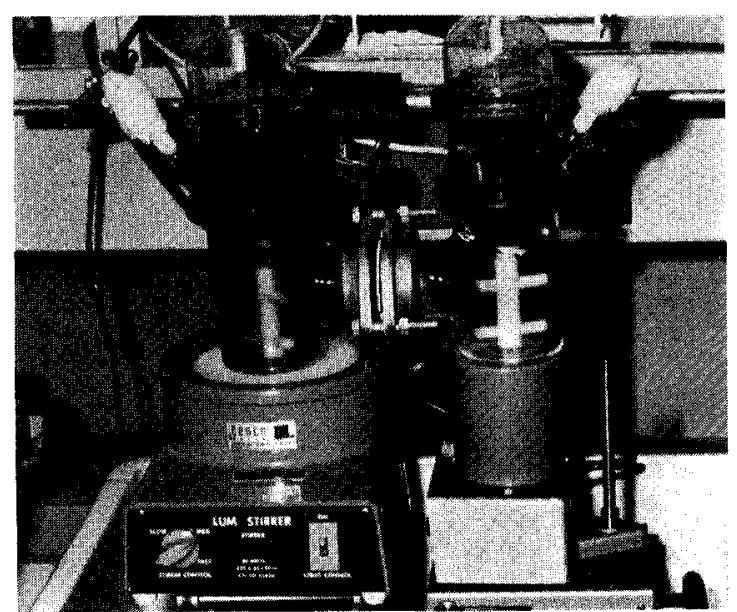

Abb. 86. "Spinner-flask» (Doppelkulturgefäss): Rechts: Bakteriensuspension, links: von unten belichtete Algenkultur.

filtrationsgeräts abfiltriert und zweimal mit steriler Z8-Lösung nachgewaschen (Sterilfiltrationsgerät, Membranfiltergesellschaft, Göttingen SM 165 C).

Die Bakteriensuspension wurde folgendermassen gewonnen: Wasser aus $1 \mathrm{~m}$ Tiefe aus dem Rotsee wurde auf Trypton-Glukoseextraktagar (Difco) ausgeplattet. Nach einer Bebrütungszeit von 5 Tagen wurden 30 Kolonien in eine Trypton-Glukoseextrakt-Flüssigkeit überimpft. Die Suspension wurde jeweils mittels Zentrifugation aufgetrennt (bei 2000 Umdrehungen/min 10 Minuten lang), das Bakteriensediment mit steriler Z-Lösung nachgewaschen, in Z-Lösung aufgenommen und eine Kultur- 
kammer der «Spinner-flask» damit beimpft. Die andere Kulturkammer der «Spinnerflask» wurde mit der gewaschenen Chlamydomonaskultur beschickt. Als Trennmembran wurde ein rein anorganischer «Selas-Silver-Membranfilter», Porenweite 0,45 $\mu$, benützt.

Die Zellzahl des Chlamydomonas wurde im Umkehrmikroskop nach Utermöhl, die Bakterienzahlen auf Trypton-Glukoseextrakt-Agar bei Verdünnungen von $10^{-5}$ bis $10^{-8}$ bestimmt. Dabei wurden immer drei Parallelausplattungen durchgeführt.

Messung der radioaktiven Proben auf Membranfiltern gemäss Angaba unter Methodik (siehe Seite 430).

\subsection{Resultate und Interpretationen}

Die Kulturen wurden täglich mikroskopisch geprüft, die Algenkultur auf Verunreinigung durch Bakterien, die Bakterienkultur auf Algenzellen. Es konnten nie Infektionen festgestellt werden. Ebenso wurden Proben aus der Algenkultur ausgeplattet auf denselben Glukose-Agar wie die Bakterien. Auch in diesen Kontrollen konnten keine Bakterien festgestellt werden.

Versuch I (Abb. 87) wurde während 20 Tagen durchgeführt. Aus den vorliegenden Kurven lässt sich folgende Dynamik herauslesen:

In diesem Versuch I wurden die Algen nach der Markierung gewaschen und während einer Woche in unmarkierter Z-Lösung weiter angezogen; nach einer Woche wurden sie eingeimpft. Die Zellzahl der Algen erfuhr in den ersten drei Tagen eine Verdoppelung und zeigte zwischen dem 5. und 10. Tage «exponentielles» Wachstum. Nach einer stationären Phase von vier Tagen kam es, nach insgesamt 14 Tagen, zum Absterben der Population mit starker Verminderung der Zellzahlen, d.h. dass starke Autolysevorgänge einsetzten. Warum es zu diesem Zusammenbruch der Population kam, konnte nicht geklärt werden. Da nie neue Kulturlösung zugegeben wurde, ist es möglich, dass das Absterben auf die vollständige Zehrung eines Mikronährstoffes zurückzuführen war.

Verfolgte man die Markierung der Algen über diese Zeitperiode, stellte man eine relativ starke Exkretion bis zum 3. Tage fest, obwohl die Zellzahl anstieg. Dies hatte seine Auswirkungen auf die Bakterienpopulation, indem die Bakterien sowohl in bezug auf Zellzahl als auch in der ${ }^{14} \mathrm{C}$-Markierung einen Anstieg aufwiesen. Die Markierung der Algen blieb anschliessend, zwischen dem 5. und 9. Tage, fast konstant, die Algenzellen hingegen befanden sich im "logarithmischen" Wachstum. Daraus lässt sich schliessen, dass in dieser Wachstumsphase der Algenpopulation die Exkretionsvorgänge klein waren, eine Beobachtung, die derjenigen im Experiment I entspricht. Die "Antwort» der Bakterienpopulation war eine Verminderung der Zellzahl durch Aufbrauchen des Substrates und eine stagnierende Markierung. Beim Übergang in die stationäre Phase der Algenpopulation begann der Anstieg der Bakterienpopulation, und dieser verstärkte sich ganz besonders beim Einsetzen der Autolysevorgänge der Algen. Parallel zur Erhöhung der Bakterienzellzahl verlief die Markierung in der Bakterienkultur. Dies ist als Beweis dafür anzusehen, dass die Bakterien ihr Substrat zur höheren Wachstumsrate aus der Autolyseproduktion bezogen.

Um die interessante Phase zwischen dem 1. und 3. Tage, in der das Bakterienwachstum ausschliesslich auf Exkretionsvorgänge zurückzuführen war, genauer abzuklären, wurde ein zweiter Kurzzeitversuch durchgeführt. Die Algenzellen wurden 


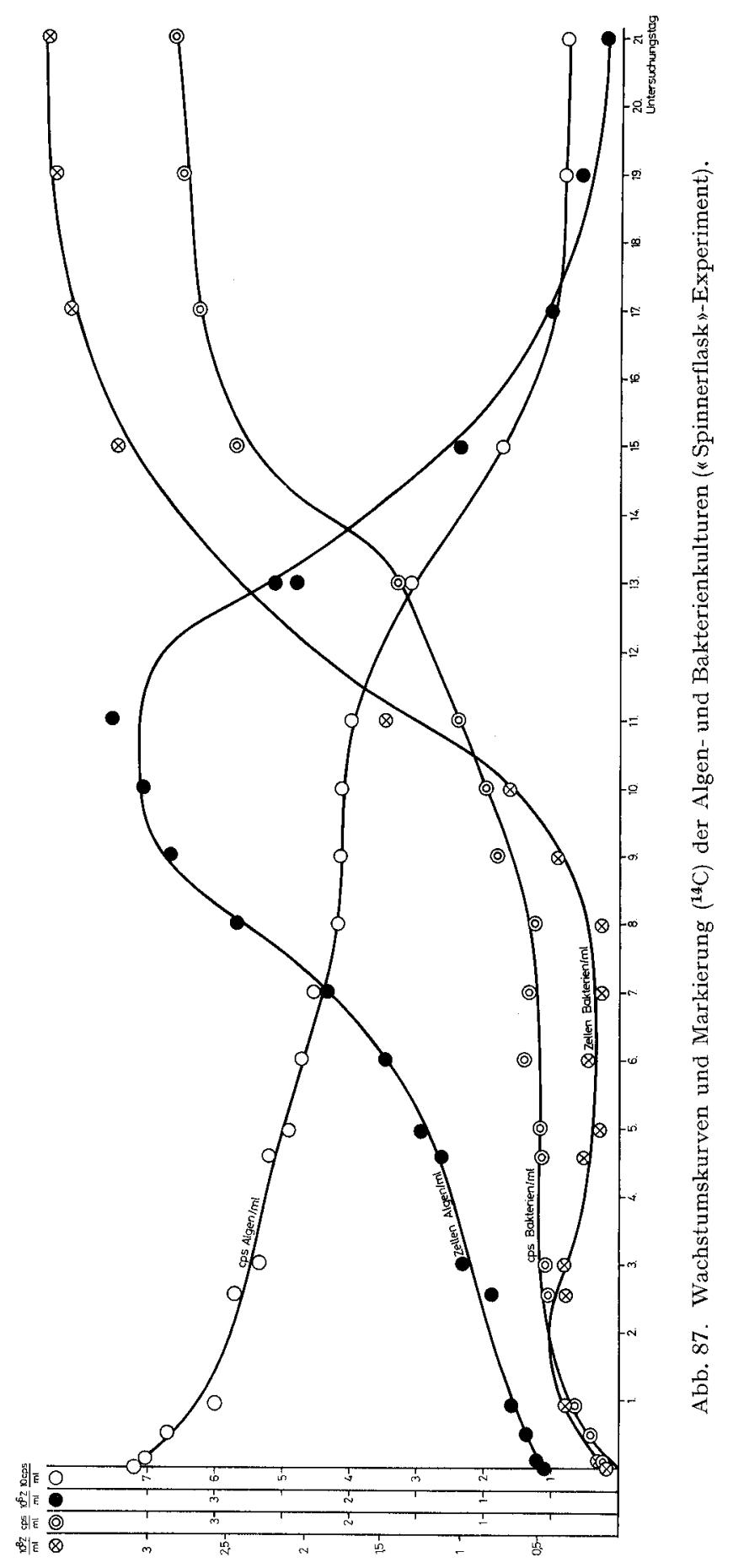




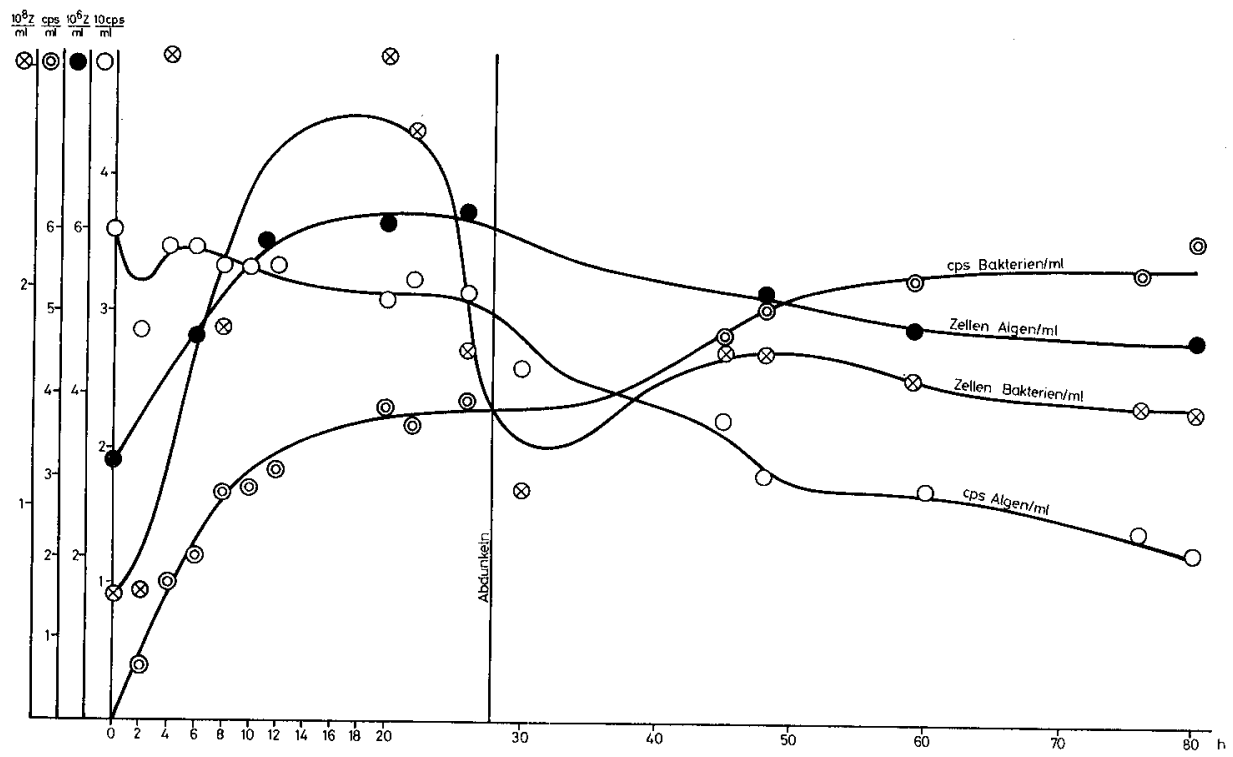

Abb. 88. Wachstumskurven und Markierung $\left({ }^{14} \mathrm{C}\right.$ ) der Algen- und Bakterienkulturen ("Spinnerflask»-Experiment).

nach dem Auswaschen der ${ }^{14} \mathrm{C}$-bikarbonathaltigen Lösung direkt in das Kulturgefäss eingeimpft. Aus Abb. 88 ist ersichtlich, dass die Exkretionsvorgänge dabei sehr rasch einsetzten. Insbesondere gab die Algenkultur innerhalb der ersten zwei Stunden sehr viel ihrer markierten C-Atome ins Milieu ab. Es ist möglich, dass diese Abgabe eine Folge der Präparation war und damit auch die Wiederaufnahme in die Algen (nach 4 Stunden) zu erklären ist. Absolut gesehen wurden innerhalb der ersten 10 Stunden $30 \mathrm{cps} / \mathrm{ml}$ Algensuspension ausgeschieden. In diesem Zeitraum trat ebenfalls eine starke Vermehrung der Bakterienpopulation auf sowohl in Hinsicht auf die Aufnahme von markiertem organischem Material als auch bezüglich der Zellzahl. Nach der 12. Stunde begann sich das System zu stabilisieren, die Exkretion der Algen nahm ab, ebenso die Aufnahmegeschwindigkeit in der Bakterienpopulation. Es zeigte sich, dass die Zahl der Bakterien, d.h. deren Wachstumsgeschwindigkeit, sehr empfindlich und rasch auf die Veränderungen in der Algenpopulation reagierte. In diesem Sinne war auch der Abfall der Bakterienzahlen um die 20. Stunde zu verstehen. Nach der 26. Stunde wurde der Einfluss der Photosynthese durch Abdunkelung des Algenkulturgefässes aufgehoben. Bis zur 80. Stunde des Versuches nahmen die Algenzellen leicht ab, bedingt durch die gestoppte Nachlieferung von organischem Material, d.h. die Vermehrungsgeschwindigkeit der Algen wurde gedrosselt. Gleichzeitig wurde durch Autolyse und Exkretion durch die Algenpopulation vermehrt markiertes Material ins Medium abgegeben. Die Bakterienpopulation erfuhr dadurch sowohl im Einbau als auch in der Zellzahl einen entsprechenden Anstieg.

\subsection{Schlussfolgerungen}

1. Die Chlamydomonaszellen exkretieren laufend. Die Exkretion ist vom physiologischen Zustand der Zellen abhängig. 
2. Die Aufnahmegeschwindigkeit von exkretiertem Material durch eine Bakterienpopulation ist ausserordentlich gross.

3. Die gegenseitige Beeinflussung verschiedener Organismen bewirkt ein von Reinkulturverhältnissen vollständig abweichendes Verhalten der Einzelorganismen. In der Bilanz, über einen längeren Zeitraum betrachtet, laufen solche Vorgänge im linearen Bereich ab.

\section{Zusammenfassende Diskussion}

\subsection{Die trophogene Schicht}

Unter Berücksichtigung der bedeutenden Destruktionsintensität in der trophogenen Schicht muss von der strengen Aufteilung eines Sees in trophogene und tropholytische Schicht Abstand genommen werden. Wie aus Abb. 89 ersichtlich ist, erstrecken sich die tropholytischen Vorgänge über das ganze Profil. Wertet man diese Vorgänge in der Bilanz, so kann grössenorđnungsgemäss die in der trophogenen Schicht destruierte organische Substanz mit etwa 60\% angenommen werden (siehe Seite 506). Im weiteren Sedimentationsweg werden noch einmal 20-30\% mineralisiert und die restlichen 5-10\% dem Dauersediment einverleibt.
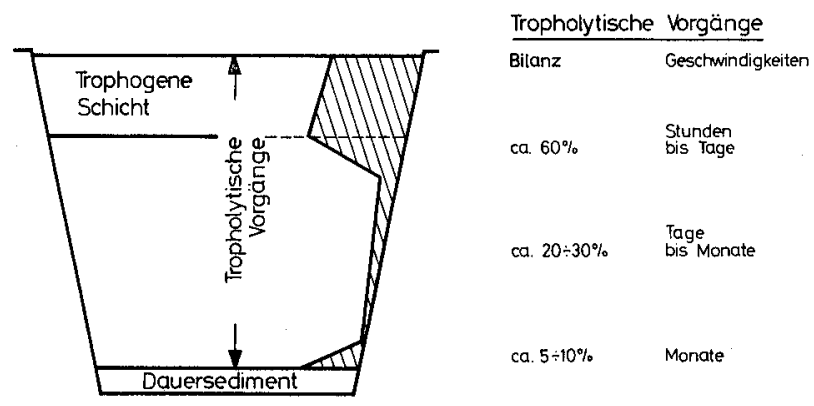

Abb. 89. «Modell» eines Sees bezüglich Tropholyse. Schraffierte Fläche stellt die tropholytischen Vorgänge in relativen Werten im Vertikalprofil dar.

Für das Verständnis ist es aber wichtig, diese Vorgänge nicht nur in der Bilanz, sondern auch in ihren Geschwindigkeiten zu werten. Die Umsatzgeschwindigkeiten in der trophogenen Schicht liegen in der Grössenordnung von Stunden bis Tagen (siehe Seite 505), während diejenigen unterhalb des Kompensationspunktes bedeutend langsamer verlaufen. Dies findet seine Bestätigung darin, dass die Sauerstoffzehrung im Metalimnion nie die für die trophogene Schicht errechneten Werte erreicht (metalimnische Sauerstoffzehrung während der Sommerstagnation lag in der Grössenordnung von wenigen $\mathrm{mg} / \mathrm{l})$. Die Einverleibung ins Dauersediment nimmt ebenfalls längere Zeit in Anspruch (OHLE [48]).

Es ist auch möglich, dass, wie Messungen aus dem polytrophen Rotsee ergaben, das Hypolimnion zu einer trophogenen Schicht wird. Der vorhandene partikuläre Stickstoff ergab im Rotsee über das ganze Jahr im Hypolimnion höhere Werte als im Epilimnion (Abb. 75). Wie Spezialuntersuchungen (5.25) ergaben, lag ein grosser Teil 
dieses partikulären Stickstoffs als bakterielle Biomasse vor. Im weiteren wird diese Feststellung durch Messung der ${ }^{14} \mathrm{CO}_{2}$-Aufnahme pro $\mathrm{m}^{2}$ unterhalb der trophogenen Schicht erhärtet. Die durchschnittliche ${ }^{14} \mathrm{C}$-Fixierung durch verschiedene Carboxylierungsmechanismen (BAchoren [7], SCHLEGEL [66], Sorokrn [72]) ergab einen Wert von $600 \mathrm{mg} \mathrm{C} / \mathrm{m}^{2}$ pro Tag, was einer jährlichen Produktion von $220 \mathrm{gC} / \mathrm{m}^{2}$ entspricht. Die neben diesen Vorgängen verlaufende chemosynthetische und heterotrophe C-Fixierung übertrifft diesen Wert um ein Vielfaches. Nach KuzNEzov [37] macht diese direkte $\mathrm{CO}_{2}$-Fixierung im Mittel nur etwa $6 \%$ des gesamten Aufbaus heterotropher Biomasse aus. Dieser generelle Wert kann nicht ohne weiteres auf unsere Verhältnisse übertragen werden. Aber auch bei vorsichtiger Schätzung dürfte die Gesamtproduktion im Hypolimnion $\left({ }^{14} \mathrm{C}\right.$-Messung $220 \mathrm{gC} / \mathrm{m}^{2}$ pro $\mathrm{Jahr}$ ) diejenige in der trophogenen Schicht (381 $\mathrm{g} \mathrm{C}_{\text {ass }} / \mathrm{m}^{2}$ und 182 Tage, nach StadelmanN [73]) stark übertreffen.

Für den praktischen Gewässerschutz ergibt sich daraus folgende Schlussfolgerung:

Ein See kann dann als irreversibel geschädigt betrachtet werden, wenn das Hypolimnion zu einer "trophogenen Schicht» wird. Eine Sanierung wäre dann nur denkbar, wenn neben der bekannten rigorosen Unterbindung der allochthonen Zufuhren gleichzeitig die Produktivität der hypolimnischen "trophogenen Schicht», z.B. durch massives Ableiten des Tiefenwassers, eingeschränkt werden könnte.

\subsection{Modell kausaler Verknüpfung im "kurzgeschlossenen Kreislauf"}

Auf Grund der quantitativ-qualitativen Zusammenhänge, die diese Untersuchung ergaben, drängt sich eine Revision der kausalen Verknüpfungen im «kurzgeschlossenen Kreislauf» auf. Im Schema (Abb. 90) ist diese kausale Verknüpfung folgendermassen dargestellt:

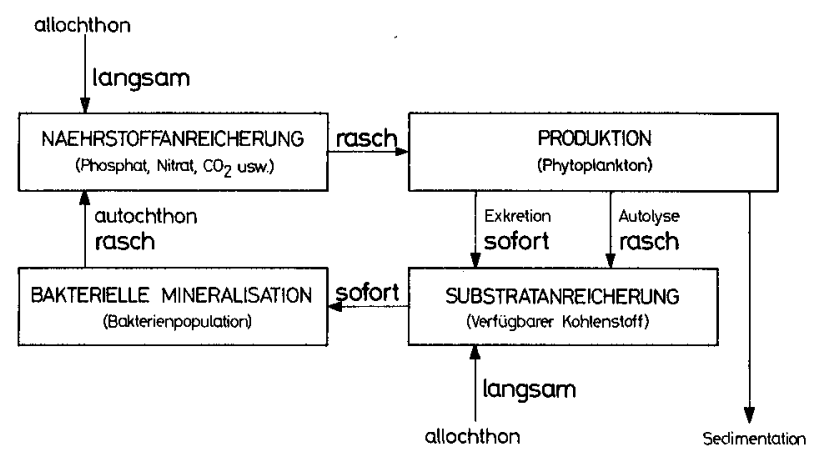

Abb. 90. "Modell» kausaler Verknüpfung im «kurzgeschlossenen Kreislauf».

Das autotrophe Phytoplankton baut eine bestimmte Biomasse auf. Diese Primärproduktion ist, abgesehen von Faktoren wie Temperatur, hauptsächlich vom Nährstoffangebot abhängig. VolLENWEIDER [80] schreibt im Bericht der OECD zum Eutrophierungsproblem folgendes: «Es muss aber mit allem Nachdruck festgestellt werden, dass der Schlüssel des Eutrophierungsproblems nicht bei den Nährstoffkonzentrationen, sondern bei der Nährstoffnachlieferung liegt." 
Gächter [19] hat für den Phosphor als Nährstoff experimentell nachgewiesen, dass eine dauernde Zugabe von kleineren Mengen Phosphat eine höhere Produktion auslöst als die einmalige Gabe einer grösseren Phosphatmenge.

Wie bei einer kommerziellen Untersuchung der Geschäftsverlauf nicht nur mit einer Bilanz ausgedrückt werden kann, sondern auch eine Gewinn- und Verlustrechnung erstellt werden muss, die für den betreffenden Zeitraum unvergleichlich aussagekräftiger ist, sind bei der Berücksichtigung der Wirkungsweise von Nährstoffen die Umsatzgeschwindigkeiten, die Verfügbarkeit dieser Nährstoffe, von ausserordentlicher Bedeutung.

Das Phytoplankton baut im wesentlichen den organischen Kohlenstoff in einem Gewässer auf. Davon ist ein bestimmter Teil, sei es durch Autolyse oder durch Exkretion, der bakteriellen heterotrophen Assimilation zugänglich.

Nach OHLE (mündliche Mitteilung) kann die Degradation organischer Zellkomponenten auch auf rein chemischem Wege vor sich gehen. Dadurch wird es möglich, dass auch schwerer angreifbare Verbindungen für Bakterien eröffnet werden.

Die Leistungsfähigkeit der bakteriellen Population ist vom Substratangebot abhängig (HoBbIE und WRIGHT [28]). In Abb. 90 wird das Substratangebot für Bakterien als "verfügbarer Kohlenstoff" bezeichnet. Dieser verfügbare Kohlenstoff kann einerseits allochthonen Ursprungs, andererseits durch die Phytoplanktonproduktion gebildet worden sein. Aus den vorhandenen organischen Kohlenstoffverbindungen werden durch die Bakterienpopulation Nährstoffe durch Mineralisation freigesetzt. Diese Nährstoffe stehen wieder dem Phytoplankton bei der Produktion zur Verfügung. Dies geschieht derart rasch, dass analytisch in den Sommermonaten die Phosphate kaum mehr nachgewiesen werden können, während die Phytoplanktonpopulation sowohl in Biomasse als auch in Produktion relativ hohe Werte aufwiesen. Das konnte nicht ausschliesslich mit dem Einfluss allochthoner Nährstoffzufuhren erklärt werden, da gerade in der stabilen Sommerschichtung die homogene Verteilung allochthoner, meist punktförmiger Zuflüsse äusserst lange Zeit erfordert und wahrscheinlich nicht vor der folgenden Vollzirkulation zustande kommt.

Die geschilderten Beziehungen sind im Prinzip bekannt. Wesentlich ist jedoch, diesen Kreislauf in den Geschwindigkeiten und der Verfügbarkeit der Komponenten zu werten, einen wieder in kommerziellen Sinn ausgedrückten Liquiditätsausweis zu erbringen.

Man kann den Vorgang der Nährstoffzugabe durch allochthone Einflüsse als langsam bezeichnen. Der autochthone Anfall von Nährstoffen stammt aus der Mineralisation, evtl. auch aus der Tätigkeit freier Enzyme, wie dies von REICHHARDT et al. [58] im speziellen für die Phosphatase nachgewiesen wurde. Dieser Vorgang ist räumlich, wie die vorliegende Arbeit zeigt, ausserordentlich eng mit der Zone, in der das Phytoplankton aufgebaut wird, verbunden. Nährstoffe, die auf diese Weise mobilisiert werden, stehen viel rascher als diejenigen bei allochthonen Einflüssen zur Verfügung.

Durch die bakterielle Mineralisation werden nicht nur Nährstoffe rasch wieder frei, sondern auch $\mathrm{CO}_{2}$. Es ist möglich, dass in Mikroschichtungen in Phytoplanktonpopulationen bei hoher Photosynthese $\mathrm{CO}_{2}$ limitierend wird (KUEnTZEL [38, 39]). Wäre die Population nur von Duffisionsvorgängen, dem Eintrag von $\mathrm{CO}_{2}$ aus der Luft usw., abhängig, dann müssten diese $\mathrm{CO}_{2}$-Minima in der unmittelbaren Zellumge- 
bung ungleich viel grösser ausfallen. Durch bakterielle Tätigkeit wird $\mathrm{CO}_{2}$ frei, das sofort für das Phytoplankton zur Verfügung steht. Verschiedene experimentelle Untersuchungen lassen solche Überlegungen als sehr naheliegend erscheinen (LANGE [40]). Ein weiterer Hinweis ist der von OHLE [47] beschriebene Wascheffekt.

Da es sich aber bei diesen Vorgängen um Mikroaustausche handelt, die quantitativ schwer nachweisbar sein werden, müssen die Aussagen über $\mathrm{CO}_{2}$-Limitierung in einem Gewässer vorläufig mit einigen Vorbehalten beurteilt werden.

Die geschilderten kausalen Beziehungen gelten für alle am Stoffkreislauf beteiligten, insbesondere für den jeweils limitierenden Faktor.

Dem Phosphor kommt in verschiedenen Seen diese Rolle zu (Vollenweider [80]). Für eine Phosphorbelastung in einem See ergeben sich die in Abb. 91 und 92 dargestellten qualitativen Beziehungen. Ein allochthoner Phosphatzufluss bewirkt über eine Erhöhung der Produktion eine Vergrösserung des verfügbaren Kohlenstoffs. Dadurch wird aber die Umsatzgeschwindigkeit im «kurzgeschlossenen Kreislauf» erhöht und das Niveau des ganzen Kreislaufs im Sinne einer Zinseszinsrechnung erhöht (Abb. 91). Die Phosphatzugabe wirkt dadurch als Initialfaktor und "Katalysator» für eine viel grössere Erhöhung der Produktion.
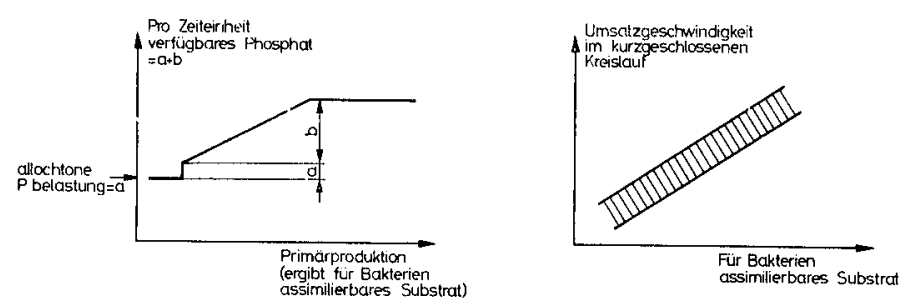

Abb. 91/92. "Modell» der Wirkungsweise einer Phosphatbelastung in der trophogenen Schicht.

In Abb. 92 ist die hypothetische Kurve der Umsatzgeschwindigkeit im «kurzgeschlossenen Kreislauf" gegenüber dem assimilierbaren Kohlenstoff dargestellt. In natürlichen Verhältnissen dürfte diese annähernd linear verlaufen, weil eine Bakterienmischkultur auf ein bestimmtes Substratangebot eine annähernd lineare «Antwortsfunktion" gibt (siehe Seite 511). Die Umsatzgeschwindigkeit spricht wegen der "polyvalenten» Bakterienpopulation sehr rasch auf eine Änderung des assimilierbaren Kohlenstoffs an, auch wenn dieser qualitativ variiert.

Prinzipiell gelten die für Phosphat angegebenen Überlegungen für jeden wachstumsbegrenzenden Faktor, sofern er am Stoffwechsel der Bakterien beteiligt ist.

Die Erhöhung des Niveaus des verfügbaren Kohlenstoffs kann aber auch direkt durch eine Zugabe von assimilierbaren Kohlenstoffverbindungen erfolgen; damit kann, ohne dass der limitierende Faktor erhöht wurde, die Produktion bedeutend gesteigert werden.

Für den praktischen Gewässerschutz ergibt sich aus den angeführten Kausalbeziehungen, dass neben den "produktionslimitierenden» Faktoren dem assimilierbaren Kohlenstoff im Gewässer zentrale Bedeutung zukommt. 


\section{RÉSUMÉ}

1. Un cycle d'un an (1969 à 1970) du Rotsee, un lac très eutrophe, et du lac des Quatre-Cantons (la baie de Horw), qui est mésotrophe, a été examiné du point de vue physique, chimique et biologique. L'accent a été mis sur la détérmination quantitative et - de façon plus restreinte - qualitative de la flore bactérienne et son influence écologique.

2. Plus de 30 constituants séparés ont été déterminés dans chaque échantillon. Des relations mathématiques (coefficient de correlation linéaire) et écologiques dans les diverses profondeurs ont été examinées au cours de l'année. Deux programmes d'ordinateur adaptés à la limnologie ont été mis au point à cette effet (voir l'appendice).

Grâce à ce programme, une série de relations causales a pu être calculée mathématiquement. Quant à la biomasse du Rotsee (tableau 14), il est important de constater que les paramètres suivants se sont révélés comme étant l'enchaînement écologique la plus évident dans la série des corrélations: biomasse - forme spécifique (dominante) du plancton - teneur en $\mathrm{P}$ et en $\mathrm{N}$ - population en bactéries.

3. La population du phytoplanction du Rotsee a été minutieusement examinée. Les valeurs très élevées (basées sur le poids de la matière fraîche) de plus de $30 \mathrm{mg} / \mathrm{l}$ ont été prélevées en avril 1969 et en janvier 1970 (voir fig. 37). Lescryptomanades ont été prédominants, montrant des poussées de croissance en hiver (voir fig. 33).

4. Des expériences intensives et se recoupant ont été effectuées in situ, afin d'étudier le rythme quotidien de la production primaire. Le résultat de la somme des diverses expériences de courte durée est en accord avec ceux d'une expérience d'une journée entière (voir fig. 43 et 45). En été les valeurs maximales de la production primaire dans le lac des Quatre-Cantons se situaient autour de $60 \mathrm{mg} \mathrm{C} / \mathrm{m}^{3} \mathrm{~h}$, dans le Rotsee en hiver à environ $250 \mathrm{mg} \mathrm{C} / \mathrm{m}^{3} \mathrm{~h}$.

5. La plupart des bactéries dans l'eau sont en suspension. Elles se trouvent sous forme rachitique appelée "bactérie zymogènes». Les caractéristiques qualitatives de la concentration du substrat et de l'état trophique peuvent être déduit de la morphologie. Des colonies de "Aufwuchs" (microorganismes qui poussent sur le substrat solide) et des zoogloea ont également été observées.

Les formes suivantes, caractéristiques du hypolimnion, ont été trouvées dans le Rotsee: Thiopedia rosea (fig. 63), Lamprocystis roseopersicina (fig. 65), Chromatium densegranulatum (fig. 67), Leptothrix sp. (fig. 70).

6 . Une densité de bactéries très élevée a été relevée dans les couches de production primaire maximale (fig. 47 et 73). Le comptage de bactéries dans l'épilimnion du Rotsee et du lac des QuatreCantons (filtre millipore) donnait de $5 \cdot 10^{5}$ à $4,4 \cdot 10^{6}$ bactéries $/ \mathrm{ml}$ et $10^{5}$ à $1,7 \cdot 10^{6}$ bactéries $/ \mathrm{ml}$ respectivement.

7. Une série ascendante de comptes de bactéries (filtre millipore) peut être mise au point pour calculer le degré d'eutrophisation (tableau 25). Mais comme la population des bactéries dépend directement de la disponibilité de substrat il est évident que les paramètres de production soient utilisés pour caractériser l'état trophique.

8. Des bilans de situations particulières (p. ex. disparition quasi-totale de la matière nutritive) ont servi de base de calcul pour évaluer la vitesse de renouvellement dans un cycle intrabiocénotiques par jour (tableaux 28 et 29).

9. Il est inutile de vouloir faire une distinction entre une couche trophogène et une tropholytique, car des processus tropholytiques intenses de déroulent aussi dans la couche trophogène (fig. 89).

Ainsi l'hyoplimnion peut devenir une couche trophogène homogène si, comme dans le Rotsee, les bactéries photoautotrophes prédominent (voir fig. 63 et 72).

10. Pour étudier les influences réciproques des phytoplanctons et des bactéries deux séries d'expériences ont été effectuées in vitro. D'une part une culture mixte des deux groupes d'organismes, d'autre part des cultures séparées ont été préparées. Dans le second cas les cultures ont été séparées par un filtre millipore; les interactions extracellulaires sont cepandant restées intactes (fig. 85 et 86).

Les observations suivantes ont été faites:

a) Une augmentation de la croissance d'algues, influencée par la matière nutritive, a produit une augmentation dépendante du substrat et du taux croissance des bactéries (fig. 83).

b) Les bactéries ont réagi très rapidement au comportement physiologique des algues (fig. 88). 
c) L'accroissement des bactéries dans un système mixte est fondamentalement différent de celui d'un système de substrat défini.

11. Les conclusions suivantes ont pu être tirées grace à la synthèse des résultats et leur traitement par ordinateur (fig. 90):

a) La production primaire n'est pas le résultat direct de la concentration du facteur limitant à un moment donné, mais bien de son volume et du taux de son renouvellement.

b) La vitesse de renouvellement dans un cycle intrabiocénotique dépend du rendement de la popu* lation des bactéries qui, de son côté, dépend de la disponibilité en substrat assimilable.

c) A part son influence sur la vitesse de renouvellement dans un cycle intrabiocénotique, une augmentation du carbone assimilable dans la couche trophique peut mener à une utilisation plus efficace de la matière nutritive, et à une production plus poussée (effet de catalyse).

12. Dans le but de protéger les eaux on peut déduire des relations de causalité mentionnées plus haut, que non seulement les facteurs limitant la production, mais aussi la quantité de carbone assimilable par la population bactérienne mixte sont d'une importance primordiale.

\section{SUMMARY}

1. Physical, chemical and biological aspects of a one-year cycle (1969-70) in the high eutrophic Rotsee and the mesotrophic Lake of Lucerne (Horwer Bay) in Switzerland were examined. Attention was focused on the quantitative and, to a more limited extent, qualitative determination of the bacterial flora and its ecological influence.

2. More than thirty individual components were determined in each sample (see p. 528). Mathematical (linear correlation coefficients) and ecological correlations were sought during the course of the year and at various dephts. Two computer programs, adapted to limnological data; were developed to this end (see appendix).

A series of causative relations could be determined mathematically thanks to this program. It is important to note that with regard to the biomass in the Rotsee (Table 14) the following parameters in the lake appear to be the most meaningful causative concatination, ecologically speaking, in this order of correlations: biomass - single plankton form (predominant) $-\mathrm{P}$ and $\mathrm{N}$ particular content - bacteria population.

3. A detailed examination was made of the phytoplankton population in the Rotsee. Very high values (fresh weight) of over $30 \mathrm{mg} / \mathrm{l}$ were noted in April 1969 and January 1970 (see picture 37). The prevailing algal group was the cryptomanades, with peaks in the vegetation development in the winter months (see picture 33).

4. The maximum primary production values $\left({ }^{14} \mathrm{C}\right.$-technique) for the Lake of Lucerne in the summer lay around $60 \mathrm{mg} \mathrm{C} / \mathrm{m}^{3} \mathrm{~h}$ and for the Rotsee in the winter around $250 \mathrm{mg} \mathrm{C} / \mathrm{m}^{3} \mathrm{~h}$. Concentrated, overlapping experiments were carried out in situ to study the daily rhythm of primary production. It was found that the total of the many short experiments corresponded to the results of a full-day experiment (see pictures 43 and 45).

5. Most of the bacteria found in a water body appear in a suspended state. They consit mainly of small starved forms called 'zymogenic germs'. The qualitative characteristics of the substrate concentration and the trophic situation can be deduced from morphology. 'Aufwuchs' colonies and zoogloae were also noted. The following specifically hypolimnic forms were found in the Rotsee: Thiopedia rosea (picture 63), Lamprocystis roseopersicina (picture 65), Chromatium densegranulatum (picture 67), Leptothrix sp. (picture 70).

6 . High bacterial counts were determined in the levels with maximum primary production (pictures 47 and 73). In the Rotsee the epilimnic bacterial count (membrane-Filter count) was $5 \cdot 10^{5}$ to $4.4 \cdot 10^{6}$ germs $/ \mathrm{ml}$, in the Lake of Lucerne $10^{5}$ to $1.7 \cdot 10^{6}$ germs $/ \mathrm{ml}$.

7. An ascending series of bacterial counts (MF) can be made with regard to the trophic level (Table 25). But since the bacteria population depends directly on the substrate supply, it seems to be more meaningful to use production parameters for trophic characterization.

8. Tabulations of special situations (for example, almost complete nutrient reduction) were used as a basis to estimate turnover capacity in the intrabiocenotic cycle. It was shown that individual nutrients revealed 4 to 5 intrabiocenotic cycles per day (Tables 28 and 29).

9. Making a distinction between a trophogenic and tropholytic layer is senseless because intense tropholytic processes occur in the trophogenic layer (picture 89). 
The hypolimnion as well can become one 'trophogenic layer' if photoautotrophic bacteria are predominant as in the Rotsee (see pictures 63 and 72)

10. In order to clarify the mutual influence of phytoplankton and bacteria on each other, two test series were carried out in vitro. A mixed culture of both organism groups on the one hand and separate cultures, on the other hand, were set up. In the latter case both cultures were separated by means of a membrane filter; however, extracellular influencing remained intact (pictures 85 and 86 ).

The following observations were made:

a) A nutrient-induced increase in algal growth brought about a substrate-induced increase in bacterial growth (picture 83).

b) The bacteria population responded very rapidly to the physiological behavior of the algae (picture 88).

c) Bacterial growth in a mixed system is basically different from that in a defined substrate system.

11. The following conclusions could be drawn on the basis of a synthesis of the results and their evaluation through data processing (picture 90):

a) Primary production is not the direct result of a concentration at a particular time but of the turnover volume and velocity of the 'limiting factor'.

b) The turnover velocity in an intrabiocenotic cycle depends on the performance capacity of the bacterial population, which, in turn, depends on the available quantity of substrate that can be assimilated.

c) Besides having a bearing on the turnover velocity in an intrabiocenotic cycle, an increase of assimilable carbon in the trophic layer leads to more effective utilization. of nutrients and greater production (catalytic effect).

12. For practical water pollution control it can be concluded, on the basis of the causative relations mentioned, that not only the production limiting factors but also the amount of assimilable carbon for mixed bacterial population is of pivotal importance.

\section{LITERATURVERZEICHNIS}

[1] Allan, H. J., Chemo-Organotrophic Utilization of Dissolved Organic Compounds by Planktic Algae and Bacteria in a Pond, Intern. Rev. gesamt. Hydrobiol. Hydrogr. 54, 1, 1-33 (1969).

[2] Alsterberg, G., Die Winklersche Bestimmungsmethode fïr in Wasser gelösten, elementaren Sanerstoff sowie ihre Anwendung bei Anwesenheit oxydierbarev Substanzen, Biochem. Z. 170 (1926).

[3] АмвÜнL, H., Die praktische Anwendung der elektro-chemischen Sauerstoffbedingungen im Wasser, Schweiz. Z. Hydrol. 22, 23-39 (1960).

[4] AmвÜHL, H., Die neueste Entwericklung des Vierwaldstättersees (Lake of Lucerne), Verh. Intern. Verein. Limnol. 77, 219-230 (1969).

[5] АмвӥнL, H., und SснміD, M., Bestimmung geringster Mengen von Phosphation im Wassev von Binnenseen, Schweiz. Z. Hydrol. 27, 172-183 (1965).

[6] Arthur, G. R., und Rigler, F. H., A Possible Source of Error in the ${ }^{14}$ C-Method of Measuring Primary Productivity, Limnol. Oceanogr. 12, 1, 121-124 (1967).

[7] Bachofen, R., Ferrodoxin und die $\mathrm{CO}_{2}$-Fixierung bei Bakterien, Vischr. Naturf. Ges. in Zürich 111, 2, 225-246 (1966).

[8] BLoEsch, J., Sedimentation und Phosphorkreislauf im Vierwaldstättersee (Horwer Bucht) und im Rotsee, Diss. ETH (in Vorbereitung).

[9] BRenM, J., Untersuchungen über den Aminosäuvenhaushalt holsteinischer Gewässer, insbesondere des Pluss-Sees, Arch. Hydrobiol, Suppl. XXXII, 3, 313-435 (1967).

[10] DEUFEL, J., Zählung von Wasserbakterien auf Membranfiltern mittels Fluoreszenzmikroskopie, Die Naturwissenschaften 23, 654-655 (1959).

[11] Deufe, J., Hydrobakteriologische Untersuchungen im Bodensee, I. Über die Vertikalverteilung der Bahterien im Pelagial. Int. Revue ges. Hydrobiol. 52, 4, 617-626 (1967).

[12] Dokumenta-Geigy, 7. Auflage, Geigy, Basel (1968).

[13] Doty, M. S., Newhouse, J., und Isuda, R. T., Daily Phytoplankton Primary Productivity Relative to Hourly Rates, Arch. Oceanogr. Limnol. 15, 1-9 (1967). 
[14] DüGgelt, M., Bakteriologische Studien am Wasser des Rotsees, Schweiz. Z. Hydrol. 6, 3/4, 216 (1943).

[15] Einheitsverfahren, deutsche, Verlag Chemie, Weinheim, 3. Auflage (1960).

[16] Findenegg, I., Bestimmung des Trophiegrades von Seen nach der Radiobikarbonmethode, Die Naturwissenschaften 15, 368 (1964).

[17] Findenegg, I., Das Phytoplankton des Piburger Sees im Jahve 1966, Ber. nat.-med. Ver. Innsbruck 56, 163-176 (1968).

[18] FogG, G. E., und Westlake, D. F., The Importance of Extracellular Products of Algae in Fresh Water, Verh. Internat. Ver, Limnol 12, 219-232 (1955).

[19] Gächter, R., Phosphorhaushalt und planktische Primärproduktion im Vievwaldstattersee (Horwer Bucht), Schweiz. Z. Hydrol. 30, 1 (1968).

[20] Gerlettr, M., Primary Productivity Along the Axis of Lake Maggiore, Mem. Ist. Ital. Idrobiol. 23, 29-47 (1968).

[21] Gocke, K., Untersuchungen über Abgabe und Aufnahme von Aminosauren und Polypeptiden durch Planktonorganismen, Arch. Hydrobiol. 67, 3, 285-367 (1970).

[22] Gadman, C. R., Mason, D. T., und Wood, B. J. B., Light Injury and Inhibition in Antarctic Freshwater Phytoplancton, Limnol. Oceanogr. 8, 313-322 (1963).

[23] Goldmann, C. R., Gerletti, M., Javornicky, P., Melchiorri-Santolini und de Amezaga, E., Primary Productivity, Bacteria, Phyto-andZooplankton in Lake Maggiove: Correlations and Relationships with Ecological Factors, Mem. Ist. Ital. Idrobiol. 23, 49-127 (1968).

[24] Harvey, H. E., und Rodie, W., The Chemistry and Fertility of Sea Waters, Cambridge University Press London (1958).

[25] Hellebust, I. A., Excretion of Some Organic Compounds by Marine Phytoplankton, Limnol. Oceanogr. 10, 192-206 (1965).

[26] HIrsch, P., Gestielte und knospende Bakterien: Spezialisten für C-1-Stoffwechsel an nährstoffarmen Standorten, Mitt. Internat. Ver. Limnol. 14, 52-63 (1968).

[27] НоввIE, J. E., und Wrighr, R.T., Bioassay with Bacterial Uptake Kinetics: Glucose in Freshreater, Limnol. Oceanogr. 10, 471-474 (1965a).

[28] Hовbie, J. E., und WRIGHT, R. T., Competition between Planktonic Bacteria and Algae for Organic Solutes. Mem. Ist. Ital. Idrobiol. 18, 175-187 (1965 b).

[29] Hood, D. W., Symposium on Organic Matter in Natural Waters, University of Alaska (1970).

[30] Huber-Pestalozzi, G., Das Phytoplankton des Sïsswassers, Teil 1-5 in "Die Binnengewässer", Bd. 16 (E. Schweizerbartsche Verlagshandlung 1938-1961).

[31] Jannasch, H. W., Kurze Mitteilung zur Anwendung der Fluoreszenzmikroskopie bei bakteriologischen Wasseruntersuchungen, Ber. limn. Flußstation Freudental VI (1954).

[32] JaNNASCH, H. W., Zur Ökologie der zymogenen planktischen Bakterienflora natürlicher Gewässer, Arch. Mikrobiol 23, 146 (1955).

[33] Kalle, K., Das Problem der gelösten organischen Substanz, erläutert an den Verhältnissen im Meeveasser, Mitt. Internat. Ver. Limnol. 14, 72-82 (1968).

[34] KRISS, A. E., Meeresbiologie, Tiefseeforschungen, Fischer, Jena (1961).

[35] Krummenacher, T., Untersuchungen ïber das Wachstum und die Nährstoffaufnahme von Microcystis sp. in Abhängigkeit der Nährstoffkonzentrationen, Diplomarbeit ETH (1970).

[36] Kuznezov, S. I., Die Rolle der Mikroorganismen im Stoffkreislauf der Seen, VEB Deutscher Verlag d. Wiss., Berlin (1959).

[37] Kuznezov, S. I., und Romanenko, W. I,, Produktion der Biomasse heterotropher Bakterien und die Geschwindigkeit ihrer Vermehrung im Rybinsk-Stausee, Ver. Int. Ver. Limnol. 16, 1493-1500 (1966).

[38] Kuentzel, L. E., Bacteria, Carbin Dioxide and Algal Blooms, J. W. P. C. F. 41 (10), 1737-1747 (1969).

[39] Kuentzel, L. E., Bacteria-algae-symbiosis - A Cause of Algal Blooms, American water Resources Association Proceedings Series, Urbana, Illinois, 8, 321 (1970).

[40] Lange, W., Cyanophyta-bacteria-systems: Effects of Added Carbon Compounds or Phosphate on Algal Growth at Low Nutrient Concentrations, J. Phycol. 6, 230-234 (1970).

[41] Lebensmittelbuch, schweizerisches, 3. Auflage.

[42] Müller, R., und WIDEMANn, O., Die Bestimmung des Nitrat-Ions im Wasser, Vom Wasser, Jahrbuch für Wasserchem. und Wasserreinigungstechnik (Verlag Chemie) 12, 247-271 (1955). 
[43] Nalewajko, C., Photosynthesis and Excretion in Various Planktonic Algae, Limnol. Oceanogr. $11,1,1-10(1966)$.

[44] NaUWERck, A., Die Beziehungen zwischen Zooplankton und Phytoplankton im See Erken, Symb. Bot. Ups. 17, 1-163 (1963).

[45] OHLE, W., Die hypolimnische Kohlendioxyd-Akkumulation als produktionsbiologischer Indikator. Arch. Hydrobiol. 46, 153-285 (1952).

[46] OHLE, W., Typologische Kennzeichnung der Gewässer anf Grund ihrer Bioaktivität, Verh. Int. Ver. Limnol. 13, 196 (1958).

[47] OHLе, W., Tagesvhythmen der Photosynthese von Planktonbiozönosen, Verh. Int. Ver. Limnol. 14, 113-119 (1961).

[48] OHLE, W., Der Stoffhaushalt der Seen als Grundlage einer allgemeinen Stoffwechseldynamik der Gewässer, Kieler Meeresforschung 18/3, 107-120 (1962).

[49] OvERBeck, J., Primärproduktion und Gewässerbakterien, Naturwissenschaften 57, 145 (1965).

[50] Overbeck, J., Zur Bakteriologie des Sïsswassers. Ergebnisse und Probleme, GWF 108, 12581260 (1967).

[51] Overbeck, J., Prinzipielles zum Vorkommen der Bakterien im See, Mitt. Internat. Ver. Limnol. 14, 134-144 (1968).

[52] Overbeck, J., und Babenzien, H. D., Bahterien wnd Phytoplankton eines Kleingewässers im Jahreszyklus, Z. f. allgem. Mikrobiol. 4, 59-76 (1964).

[53] Pavoni, M., Die Bedeutung des Nannoplanktons im Vevgleich zum Netzplankton, Schweiz. $Z$. Hydrol. 25, 219 (1963).

[54] Pavoni, M., Beziehungen zwischen Biomasse und Stichstoffgehalt des Phytoplanktons und die daraus ableitbare Anwendung der Bestimmungsmethoden für die Praxis, Schweiz. Z. Hydrol. 37, 110-127 (1969).

[55] Potaenko, S., Season Dynamics of Bacterial Total Number and Biomass in Water of Narochan Lakes, Microbiologia Tom XXXVII, 3, 540-547 (1968).

[56] Potter, L. F., The Effect of $p H$ on the Development of Bacteria in Water Stored in Glass Containers, Canad. J. Microbiol. 6, 257 (1960).

[57] Provasol., L., Organic Regulation of Phytoplankton Fertility, M. N.Hill (ed.), The sea, V. 2. Interscience, New York, 165-219 (1963).

[58] Reichhardt, W., Overbeck, J., und Steubing, L., Free Dissolved Enzymes in Lake Waters, Nature 276/5122, 1345-1347 (1967).

[59] Rodнe, W., Standavd Corvelations Between Pelagic Photosynthesis and Light, Mem. Ist. Ital. Idrobiol., Suppl. 18, 365-381 (1965).

[60] Ruttner, F., Grundriss dev Limnologie, 3. Auflage, Walter de Gruyter u. Co., Berlin (1962).

[61] Sauberer, F., Empfehlungen für die Durchführung von Strahlungsmessungen an und in Gewässern, Mitt. Intern. Ver. Limnol. 11 (1962).

[62] Schegg, E., Die limnische Produktion unter besonderer Beriucksichtigung des Bakterienanteils während der Frïhjahrsentwicklung in Seen mit verschiedenem Trophiegrad, Diplomarbeit ETH (1967).

[63] SCHEGG, E., Beziehungen zwischen Planktonentwicklung und Bakterien im Vievwaldstättersee und Rotsee, Schweiz. Z. Hydrol. 30/2, 298-296 (1968).

[64] SchegG, E., A New Bacteriological Sampling Bottle, Limnol. Oceanogr. 75, 821 (1970).

[65] SchegG, E., und Ruschke, R., Beitrag zur Bakterienökologie einiger Seen des Schwarzwaldes und der Schweiz, Schweiz. Z. Hydrol. 32/1, 192 (1970).

[66] Schlegel, H. G., Die Rolle des Kohlendioxydes im Stoffwechsel der Mikroorganismen, Zbl. Bakt. I. Abt. Org. 191, 177-190 (1963).

[67] Schlegel, H. G., Allgemeine Mikrobiologie, Verlag Georg Thieme, Stuttgart (1969).

[68] Scнмг, M., Die Bestimmung kleiner Mengen von organischem Stickstoff im Wasser von Binnenseen, Schweiz. Z. Hydrol. 30, 244-266 (1968).

[69] SснміD, M., und АмвÜнL, H., Bestimmung gevingster Mengen von Gesamtphosphor im Wasser von Binnenseen, Schweiz. Z. Hydrol. 27, 183-192 (1965).

[70] Schwörbel, J., Methoden der Hydrobiologie, Verlag Kosmos, Stuttgart (1966).

[71] Skuja, H., Toxonomie des Phytoplanktons einigev Seen in Uppland, Schweden, Symbolae bot. Upsaliensis 9 (3) (1948), $399 \mathrm{~S}$. 
[72] Sorokin, Ju. I., On the Trophic Role of Chemosynthesis and Bacterial Biosynthesis in Water Bodies, Mem. Ist. Ital. Idrobiol. 18, 187-205 (1965).

[73] Stadelmann, P., Stichstoffkreislauf und Primärproduktion im mesotrophen Vierwaldstättersee (Horwer Bucht) und im eutrophen Rotsee, mit besonderer Beriücksichtigung des Nitrats als limitierender Faktor, Schweiz. Z. Hydrol. 33, 1 (1971).

[74] StauB, R., Ernährungsphysiologische autokologische Untersuchungen an der planktischen Blaualge Oscillatoria rubescens D. C., Schweiz. Z. Hydrol. 23, 1, 83 (1961).

[75] Steemann-Nielson, E., The Use of Radioactive Carbon $\left({ }^{14} C\right)$ for Measuring of Organic Production in the Sea, J. du Cons. 78, 117 (1952).

[76] Strickland, J. H. D., und Parsons, T. R., A Pratical Handbook of Seareater Analysis, Bull. Fish. Res. Board. Can. 167, $41-44$ (1968).

[77] Sтимм, W., Diskussionsbeitrag zum Vovtrag von G. A. Rohlich, Advanc. Water. Poll. Research (London) 2, 216-230 (1964).

[78] Thienemann, A., Die Binnengewässer, Stuttgart (1925). Der Sauerstoff in eutrophen und oligotrophen Seen (1928).

[79] UTERMöHL, H., Zur Vervollhommnung der quantitativen Phytoplanktonmethodik, Int. Ver. Theor. und angew. Limnol. Mitt. 9, 38 (1958).

[80] Vollenweider, R. A., Die wissenschaftlichen Grundlagen der Seen- und Fliessgewässereutrophierung, unter besonderer Berücksichtigung des Phosphors und des Stickstoffs als Eutrophierungsfaktoren, OECD-Report, Paris, DAS/CSI/68, 28 (1968).

[81] Vollenweider, R. A., Primary Production in Aquatic Environments, IBP Handbook 12, Blackwell, Oxford and Edinburgh (1969).

[82] Weinmann, G., Gelöste Kohlehydrate und andeve organische Stoffe in natiurlichen Gewässern und in Kulturen von Scenedesmus quadricauda, Diss. Universität Kiel (1968).

[83] Wuhrmann, K., Adaptationen bei Gesellschaften von Mikroorganismen im Wasser, Bibl. Microbiol. Fasc. 4, 52-64 (1964). 
1. In der Arbeit verwendete Abkürzungen

Dimension der eingegebenen Daten

\begin{tabular}{|c|c|c|}
\hline TEMP & Temperatur & Grad Celsius \\
\hline KAPPA & Leitfähigkeit & Mikrosiemens/cm \\
\hline MF & Membranfilterbakterien & Tausend Zellen/ml \\
\hline PLAT & Plattenzahlen & Zellen $/ \mathrm{ml}$ \\
\hline SAUER & Sauerstoff & $\mathrm{mg} / \mathrm{l}$ \\
\hline PR H & Primärproduktion Hell & $\mathrm{mg} \mathrm{C}_{\mathrm{ass}} / \mathrm{m}^{3} \mathrm{~h}$ \\
\hline PR D & Primärproduktion Dunkel & $\mathrm{mg} \mathrm{C}_{\mathrm{ass}} / \mathrm{m}^{3} \mathrm{~h}$ \\
\hline GELOP & Gelöster organischer Phosphor & $\mu g \mathrm{P} / 1$ \\
\hline GELON & Gelöster organischer Stickstoff & $\mu g \mathrm{~N} / 1$ \\
\hline $\mathrm{PN}$ & Partikulärer Stickstoff & $\mu g N / 1$ \\
\hline PP & Partikulärer Phosphor & $\mu \mathrm{g} P / 1$ \\
\hline PH & $\mathrm{pH}$-Wert & \\
\hline SBV & Alkalinität & mval $/ 1$ \\
\hline NITRA & Nitrat & $\mu g \mathrm{NO}_{3}-\mathrm{N} / 1$ \\
\hline NITRI & Nitrit & $\mu g \mathrm{NO}_{2}-\mathrm{N} / 1$ \\
\hline AMMON & Ammonium & $\mu \mathrm{g} \mathrm{NH}_{4}-\mathrm{N} / 1$ \\
\hline PHAT & Phosphat & $\mu \mathrm{g} \mathrm{PO}_{4}-\mathrm{P} / 1$ \\
\hline GES $P$ & Gesamtphosphor & $\mu g \mathrm{P} / \mathrm{l}$ \\
\hline GEL FE & Gelöstes Eisen & $\mu \mathrm{g} \mathrm{Fe} / 1$ \\
\hline P FE & Partikuläres Eisen & $\mu \mathrm{g} \mathrm{Fe} / 1$ \\
\hline SI OO & Silikat & $\mu \mathrm{g} \mathrm{SiO}_{2} / 1$ \\
\hline GES E & Gesamtenergie & Prozent der Oberflächenintensität $(=100 \%)$ \\
\hline VG & Grünlicht (533 nm) & Prozent der Oberflächenintensität $(=100 \%)$ \\
\hline $\mathrm{RG}$ & Rotlicht & Prozent der Oberflächenintensität $(=100 \%)$ \\
\hline BG & Blaulicht $(423 \mathrm{~nm})$ & Prozent der Oberflächenintensität $(=100 \%)$ \\
\hline BIOM & Biomasse, Phytoplankton & $\mu \mathrm{g} / \mathrm{ml}$ \\
\hline CYANO & Biomasse Cyanophyceae & $\mu \mathrm{g} / \mathrm{ml}$ \\
\hline CLORO & Biomasse Chlorophyceae & $\mu \mathrm{g} / \mathrm{ml}$ \\
\hline $\mathrm{KONJU}$ & Biomasse & $\mu \mathrm{g} / \mathrm{ml}$ \\
\hline CRYSO & Biomasse Chrysophyceae & $\mu \mathrm{g} / \mathrm{ml}$ \\
\hline DIATO & Biomasse Diatomeae & $\mu \mathrm{g} / \mathrm{ml}$ \\
\hline CRYPT & Biomasse Cryptophyceae & $\mu \mathrm{g} / \mathrm{ml}$ \\
\hline$K$ & Korrelation & \\
\hline KK & Korrelationskoeffizient & \\
\hline
\end{tabular}




\section{Programme}

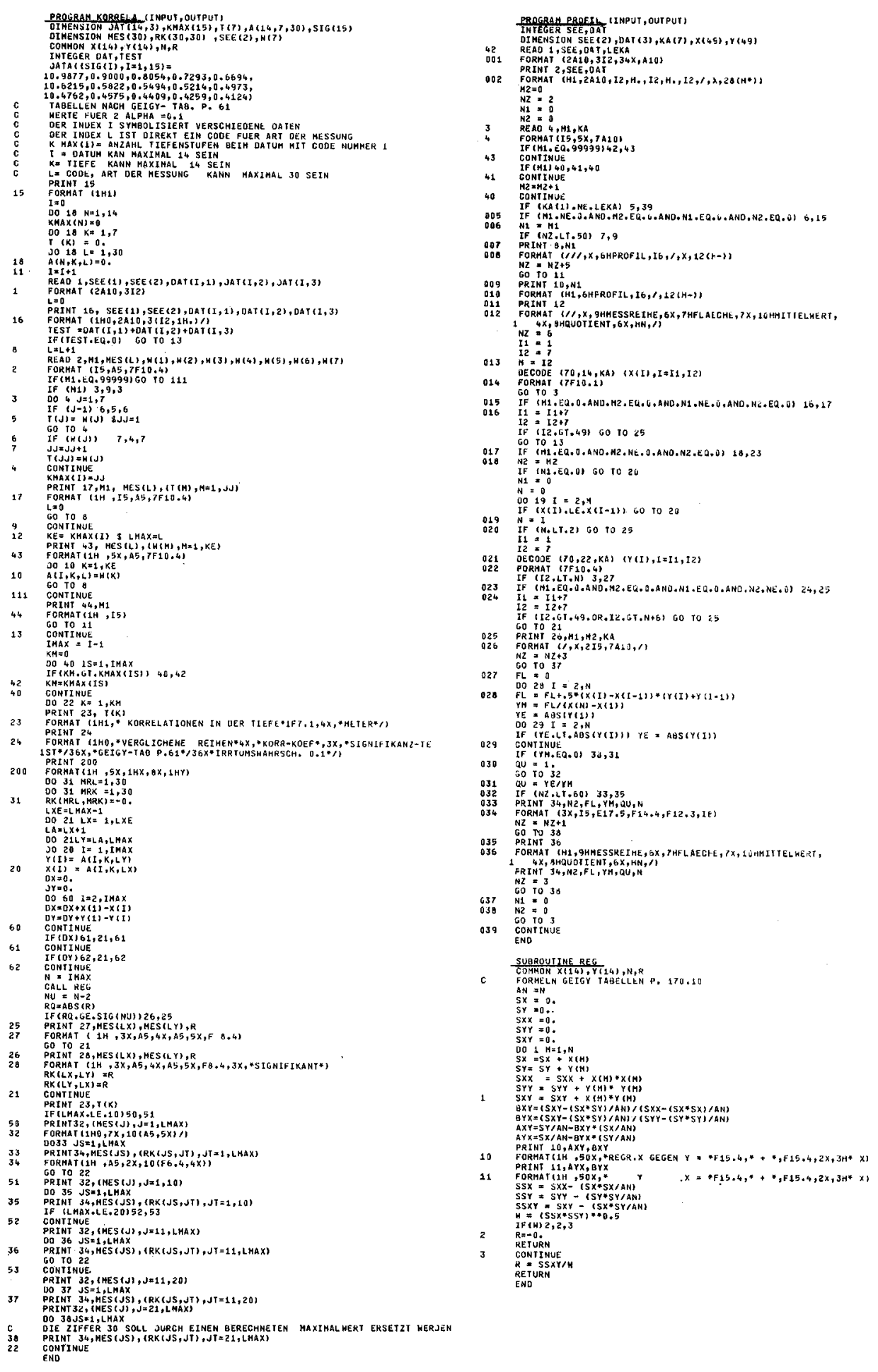




\section{Eingabedaten}
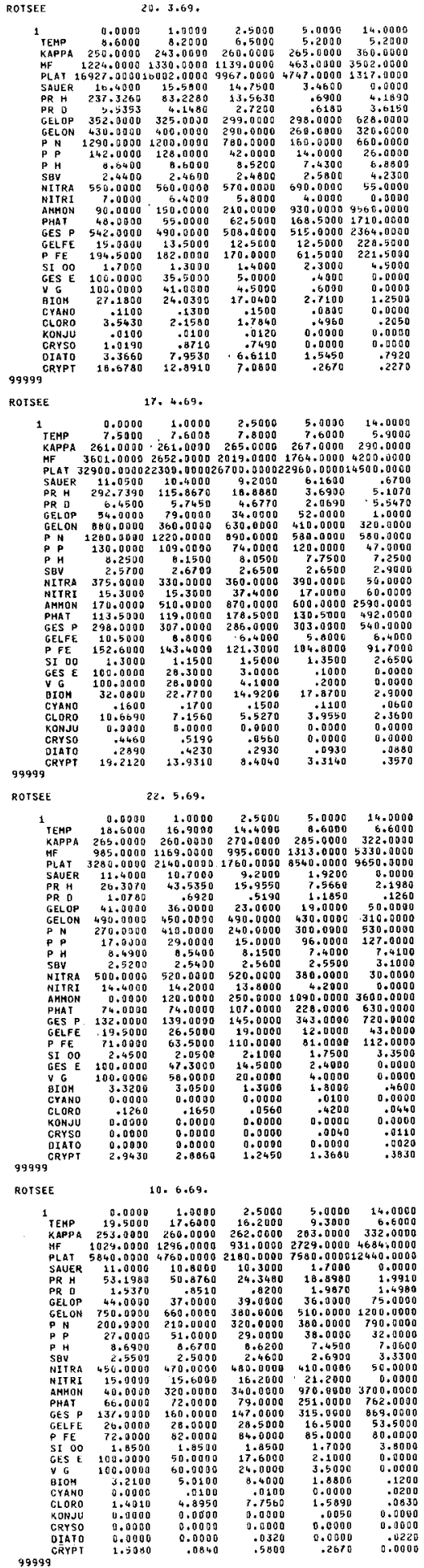
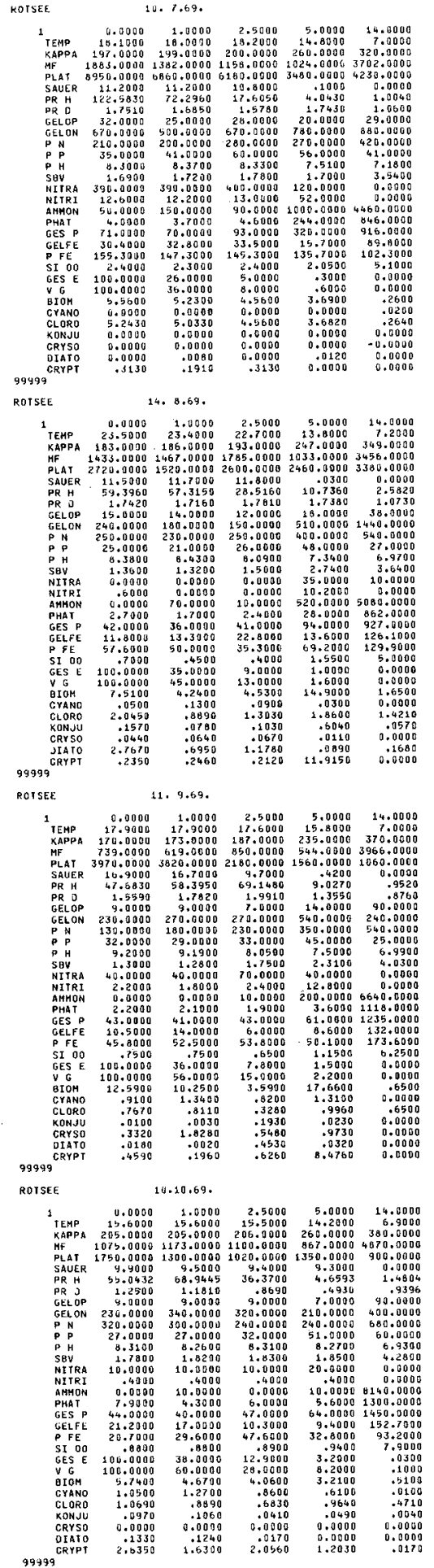



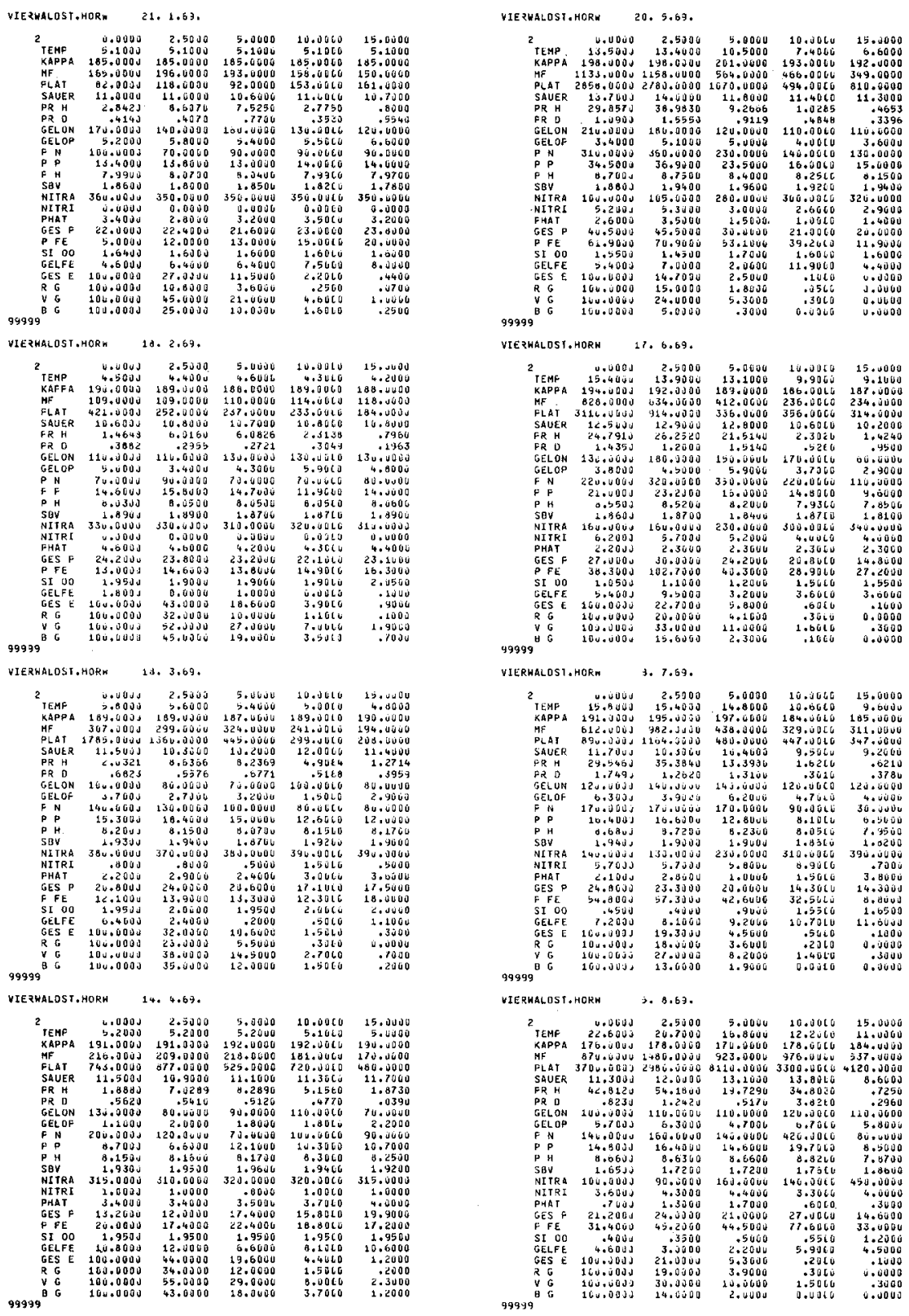

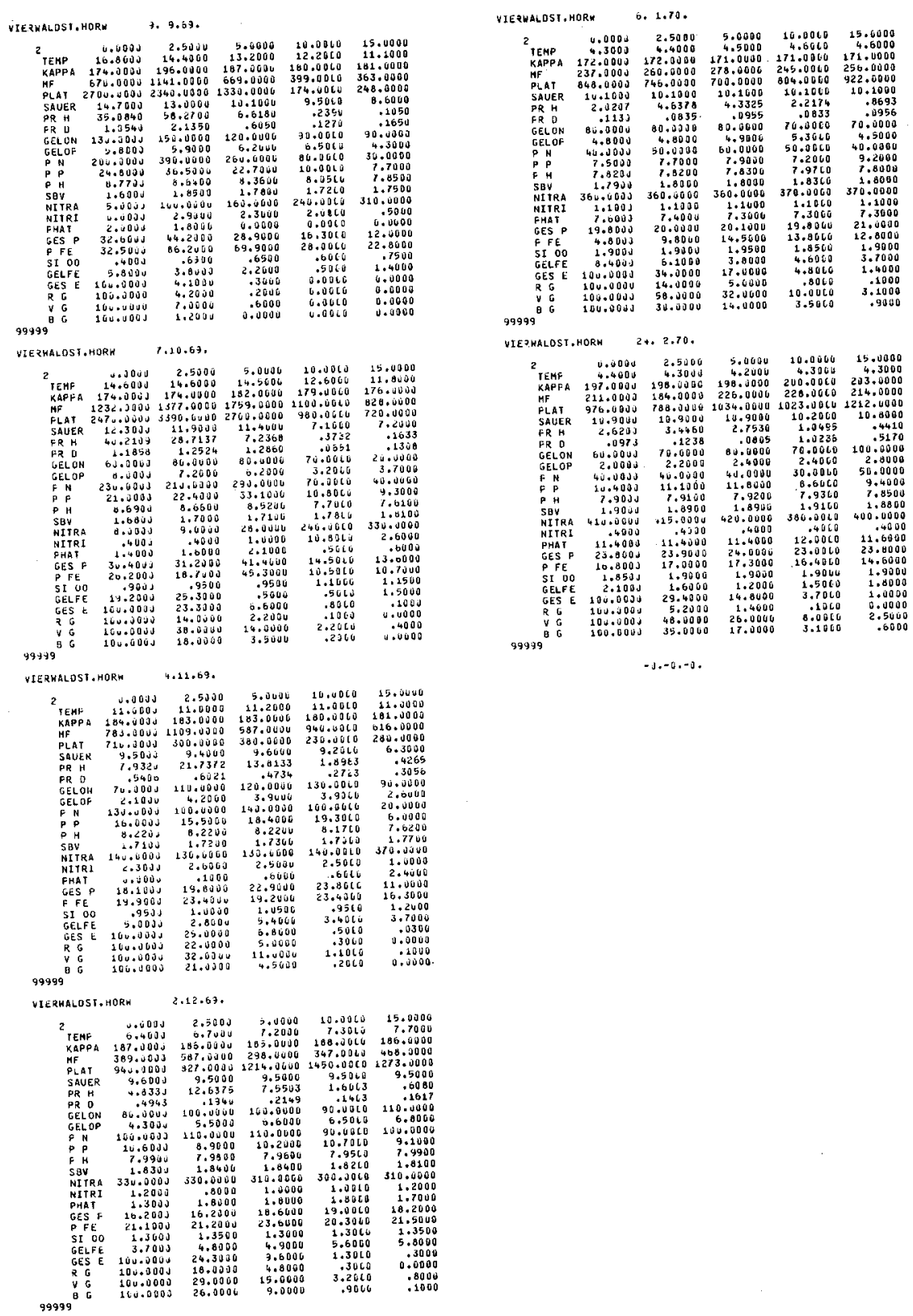


\section{VERDANKUNGEN}

Herrn Prof. Dr. O. Jaag, alt Direktor der EAWAG, möchte ich herzlich danken für die Stellung des Arbeitsthemas und die Möglichkeit, an einem grosszügig ausgerüsteten Institut arbeiten zu dürfen.

Herrn Prof. Dr. W. Stumm, Direktor der EAWAG, bin ich speziell für seine Hilfe und Unterstützung bei der vorliegenden Arbeit zu Dank verpflichtet.

Herrn Dr. H. Ambühl, Leiter der limnologischen Abteilung, danke ich für die Einführung in die Limnologie und die freundliche Unterstützung dieser Arbeit sowie deren kritische Durchsicht.

Die vorliegende Fülle von Daten konnte nur im Teamwork erarbeitet werden. Separate Arbeiten werden andere spezielle Aspekte behandeln und erscheinen. Es untersuchten: J. Bloesch: Phosphorkomponenten und Sedimentationsmessungen, H. Bührer: Sauerstoff und physiologische Gruppen der Schlammflora, P. Stadelmann: Stickstoffkomponenten, Dr. R. Gächter: Phosphorkomponenten im Vierwaldstättersee.

Viele Bestimmungen, insbesondere aber die Seearbeit, wurden in gemeinsamer Anstrengung durchgeführt. Ich möchte an dieser Stelle meinen Kollegen für die loyale Zusammenarbeit und die Überlassung verschiedener Analysenwerte danken.

Für meine Ausbildung als Limnobakteriologe war ein Aufenthalt im Max-Planck-Institut für Limnologie in Plön, Deutschland, von grosser Bedeutung. Herrn Direktor Prof. Dr. J. Overbeck sei für sein Entgegenkommen herzlich gedankt.

Danken möchte ich Herrn Dr. Deufel, staatliches Institut Langenargen, der mich in die Direktzählmethode der Bakterien einführte, ebenso Herrn Prof. Dr. Würgler, Zoologisches Institut der ETH, für seine Hilfe bei der computergerechten Verarbeitung der Daten.

Im weiteren bin ich Frau Dr. Bosli-Pavoni und Frau Weber für die Hilfe bei der Auszählung von Planktonproben und Herrn Szabo für wertvolle Diskussionen zu besonderem Dank verpflichtet.

Nicht zuletzt danke ich meiner Frau, Dr. med. M. Schegg, für Geduld und Hilfe.

Die Arbeit wurde mit der Unterstützung der "Stiftung der Wirtschaft zur Förderung des Gewässerschutzes in der Schweiz» durchgeführt.

Adresse des Autors: Dr. Ernst Schegg, Schloss Greifenstein, CH-9422 Staad SG. 